\title{
INTRODUCTION TO FIELD METHODS FOR HYDROLOGIC AND ENVIRONMENTAL STUDIES
}

By Robert R. Holmes, Jr., Paul J. Terrio, Mitchell A. Harris, and Patrick C. Mills

\section{U.S. GEOLOGICAL SURVEY}

Open-File Report 01-50

Urbana, Illinois 


\section{PREFACE}

This manual presents an introduction to the methods used for the collection of field data for hydrologic and environmental studies. It is divided into four chapters-surface water, ground water, water quality, and biology. The manual was compiled from a series of notes initially written for an upper-level undergraduate or graduate-level course at the University of Illinois, but could well serve as a primer for field operations for the professional or technician. The authors worked with UI civil engineering professors Albert Valocchi and Marcelo Garcia to design the semester-long course, which includes a weekly, 3-hour field laboratory.

The authors have borrowed liberally from various sources of information in compiling this manual, in some cases utilizing verbatim the text of other reports-most of which were authored by U.S. Geological Survey personnel. Very little attempt is made to reference those sources and reports within the body of the manual, but all pertinent references as well as supplementary materials are listed at the end of each chapter.

This manual is a work-in-progress and will evolve with time as the authors refine the course offered at the University of Illinois. The authors, along with University faculty, are planning the development of a site to be used as a field laboratory that will integrate all four components of the course. This may change the structure of the course and the order of material in the manual as the integrated field laboratory will create new opportunities for laboratory assignments. It is anticipated that sample homework problems and laboratory exercises will be included in future editions of this manual.

Robert R. Holmes, Jr.

Paul J. Terrio

Mitchell A. Harris

Patrick C. Mills 


\title{
U.S. DEPARTMENT OF THE INTERIOR \\ GALE NORTON, Secretary
}

\author{
U.S. GEOLOGICAL SURVEY \\ Charles G. Groat, Director
}

For additional information write to:

District Chief

U.S. Geological Survey

221 N. Broadway

Urbana, Illinois 61801
Copies of this report can be purchased from:

U.S. Geological Survey Books and Open-File Reports Box 25286, Federal Center

Denver, Colorado 80225 


\section{CONTENTS}

Chapter 1-Surface Water Data Collection

Introduction

Overview of streamflow gaging stations

Measurement of stage

Procedures for inspecting gages

Measurement of velocity

Determination of mean velocity

Continuity principle

Measurement of discharge

Stage-discharge relations (rating curves)

Computation of discharge

Sediment transport

Sampling theory

Sediment samplers

Suspended-sediment sampling methods

Bed material sampling methods

Bedload sampling methods

Sediment records computation

Bibliography

Chapter 2-Water Quality Data Collection

Introduction

Preparations for water sampling

Equipment for water-quality sampling

Cleaning of equipment for water sampling

Field analyses

Quality assurance and quality control

Bibliography

Chapter 3-Biological Data Collection

Ecology and biological monitoring

Fish

Invertebrates

Algae

Habitat assessment and physicochemical parameters

Bibliography

Chapter 4-Ground-Water-Data Collection

Introduction

Basic elements in planning and conducting studies

Site reconnaissance and hydrogeologic framework

Drilling and well construction

Borehole geophysics

Measuring and mapping ground-water levels in wells

Collecting water-quality and quality-control samples

Aquifer testing

Bibliography 


\title{
Field Methods For Hydrologic and Environmental Studies
}

\author{
Chapter 1
}

\section{Surface Water Data Collection}

Robert R. Holmes, Jr.. 


\section{Introduction}

Surface water hydrologic data collection involves sensing (or making measurements), recording, transmitting, and post-processing/analyzing the data. Each of these steps is quite involved and often there are many variations on a theme of how each step can be achieved. The exact variation is usually dependent on the circumstances present at the field site, both hydrologic and otherwise. The steps of collection of surface water data are detailed in the following pages.

\section{Some Reasons For Collect Surface Water Hydrologic Data}

- Flood Forecasting/Flood Warning

-Water Allocation (Lake Michigan Diversion, Western States Water Rights)

- Flood Studies (Flood Insurance, etc)

- Flood Control Design

- Water/Wastewater Plant Siting

- Watershed Best Management Practices

- Environmental Assessment/Abatement

- Hydraulic Structure Design

- Drinking Water Monitoring/Other Public Safety Issues

- Lake Management

\section{Types of Surface Water Data}

- Water Level or Stage (both continuous time series and partial record) of Rivers, Streams and Lakes

- Water Velocities/Depth $\rightarrow$ Volumetric Water Discharge

- Channel Bathometry

- Rainfall

- Temperature

- Physiographic Characteristics of the Watershed

-Water-Quality Parameters---suspended-sediment concentration, Dissolved Oxygen (DO), Pesticides, Nutrients, Metals, etc.

- Biological Indicators

\section{Some Agencies That Collect Surface Water Data}

- U.S. Geological Survey (USGS)_Primary data collector in Federal Government

- U.S. Army Corps of Engineers

- U.S. EPA (mainly water quality)

- Natural Resouces Conservation Service (formerly SCS)

- Illinois Department of Natural Resources, Office of Water Resources

- Illinois Department of Natural Resources, State Water Survey

- Illinois Department of Natural Resources, Natural History Survey (biology) 


\section{- Illinois EPA}

The USGS collects hydrologic data across the United States and its territories as well as providing assistance to various foreign countries with their data collection activities. The USGS, Water Resources Division is divided into Districts, which usually are bounded by state lines. The Illinois District is comprised of the State of Illinois, however the Hawaii District is comprised of the State of Hawaii plus the Islands of Guam and American Somoa.

Nationwide, the USGS operates over 6000 streamflow monitoring stations that collect such surface water data as: stage, discharge, water quality constituents, and sediment transport.

In Illinois, the USGS currently collects continuous streamflow data at 157 gaging stations. Data collected at streamflow stations, as well as water quality and groundwater data, are digitally stored in the USGS data base.

Check out the Web site at $\rightarrow$ http://www-il.usgs.gov/

\section{Surface Water Stage (water level)}

The stage (elevation) of a river can either be determined continuously (as a time series) by sensors interfaced with data loggers or intermittently by manual means. Stage data is used for many purposes such as: flood studies, assistance in the operation of a river control structure for navigation, reservoir operation, water intake structure operation, etc.. The location where stage data is collected is called a streamflow gaging station. Under the current technology, continuous time series stage data is easier than continuous volumetric discharge (discharge) data to collect. In most methods that will be discussed in this class, continuous time series discharge data is a dependent variable in relation to the independent variable of stage. This relation is determined by first making several direct measurements of discharge and the corresponding stage followed by deriving a relation between stage and discharge. This relation is known as a stage-discharge rating curve.

\section{Surface Water Discharge Data}

Surface water discharge data is needed for a variety of surface water studies. For example, in studies to assess the expected impacts of a waste-water treatment plant on the health of a river system, water samples are collected for laboratory analysis of various constituents. These analyses are reported as concentrations (milligram per liter, microgram per liter, etc.). However, the total flux of the contaminant is usually necessary to complete the study. Computation of the flux requires knowledge of the quantity of water flowing past a point, which when multiplied by the concentration, yields the flux of the constituent. 


\section{Surface Water Sediment Data}

Sediment data collection is also covered in this portion of the course. Sediment is transported downstream either suspended in the water column (suspended-sediment transport) or moving along bottom of the channel in contact with the bed (bedload transport). Suspended-sediment transport is determined by collecting representative samples to determine the average concentration of the sediment in suspension. This is then multiplied by the water discharge to yield the suspended-sediment load. Bedload transport is measured by various methods, both sampling and by remote sensing. The typical method in gravel bed streams is to place a sampler on the bed at several locations and collect the bedload that moves past that location in the river over a measured time interval. The bedload trasnport is then the total weight of bedload collected in the sampler divided by the time that the sampler was on the bed. 


\section{Overview of Streamflow Gaging Stations}

\section{Introduction}

When gaging stations are discussed, one usually means streamflow discharge gaging station where a continuous time series of both stage and discharge data are collected. Sometimes peak stage and discharge are only needed. In this case a Crest-Stage Gage is operated and as the name entails, only the crest stage (peak stage) and possibly the discharge are determined. Other data parameters of the stream are sometimes collected at the same site such as:

- Suspended-sediment

- Water Quality Parameters

- Temperature

- Dissolved Oxygen

- Nutrients

- Etc.

The concentration (milligram per liter, part per million, microgram per liter, etc) of these parameters can be determined irrespective of the water discharge, but in order to compute the total load or flux of these constituents, the water discharge is necessary. With this in mind, one needs to understand how water discharge data is obtained and determined.

\section{Objectives Of Streamflow Gaging Station}

- Obtain continuous record of stage and discharge (stage being the water surface elevation above some datum). Gage height and stage mean the same thing.

- Location is chosen in order to obtain the best stage/discharge rating (relationship) (see figure 1). In some sites, a unique relationship between stage and discharge is not possible because of variable backwater. In special locations like this we either install an additional gage very close so as to determine a $2^{\text {nd }}$ variable in the relationship--slope, or a reference velocity meter is installed to determine the average velocity in the stream cross section for computation of the final water discharge. (more later when we discuss Acoustic Velocity Meters

- Install instuments that sense and record the water-surface elevation

- Discharge measurements are made at periodic intervals to verify the stage-discharge relation

- At some sites, discharge is not a unique function of stage---therefore variables other than stage must be determined to obtain discharge

- Slope

- Rate of change of stage

- Velocity

- Low head weirs are sometimes constructed at some stations to stabilize the stage/discharge relation at low flows (more on this when controls are discussed). 

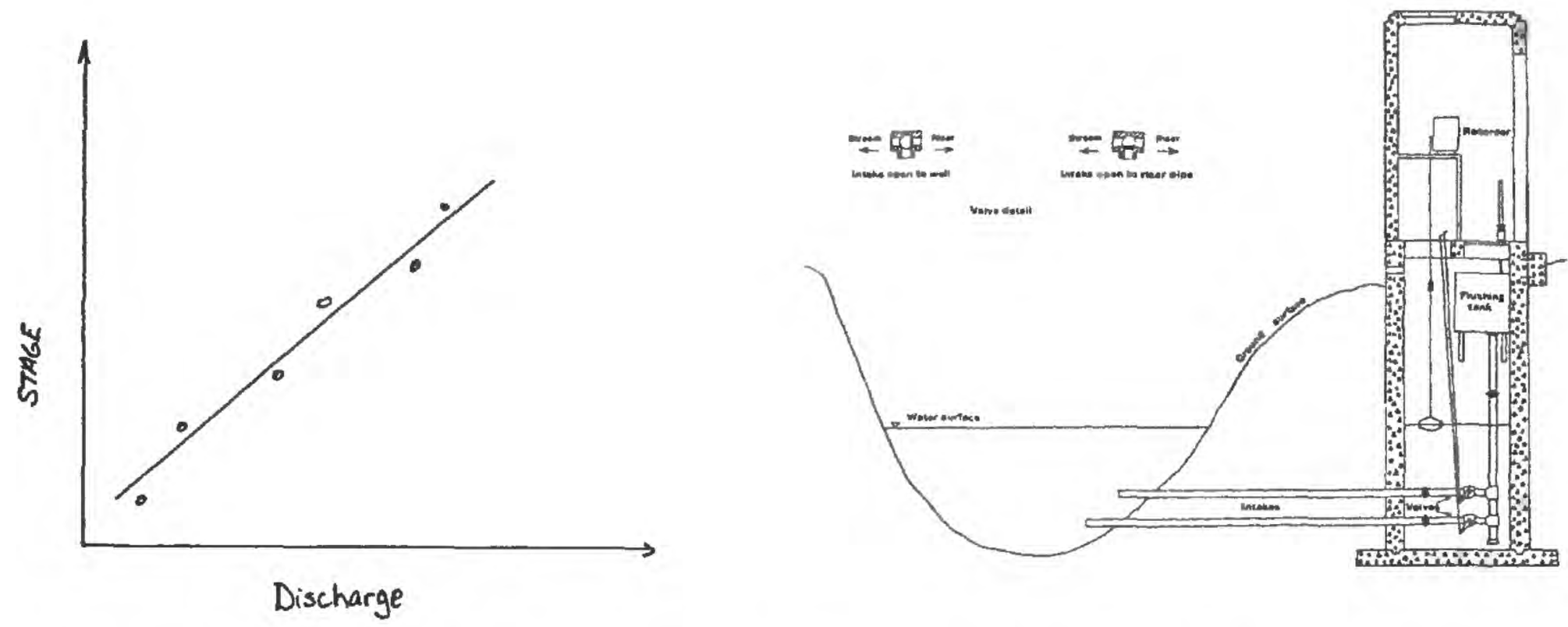

Figure 1.-Example of streamgage and associated stage-discharge rating relation.

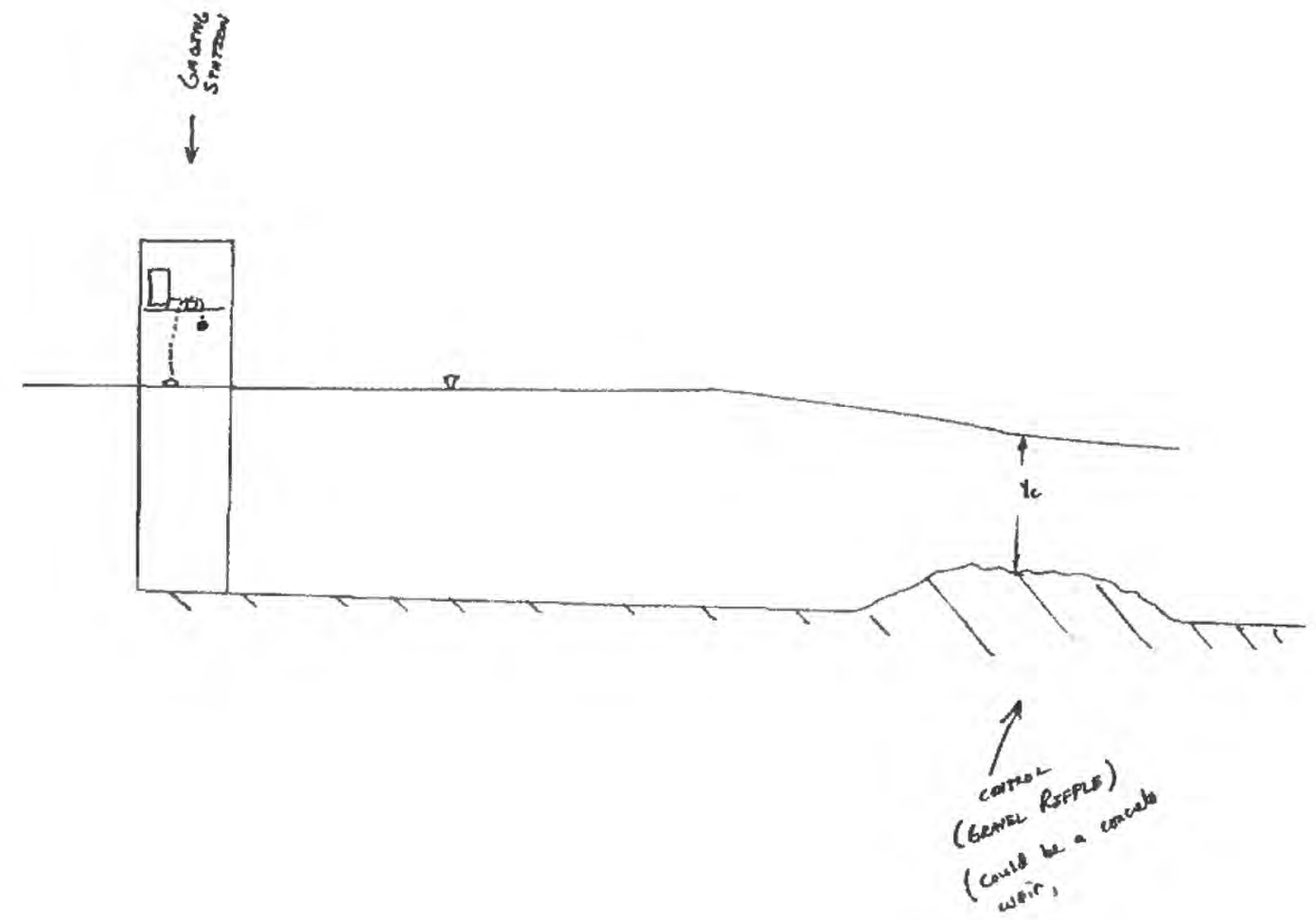

Figure 2.-Schematic of a gravel riffle 


\section{Station Components}

\section{Control}

The control is a feature in the stream downstream of the gaging station in subcritical flow, that "controls" what the relation between stage and discharge is. For most streams, multiple controls usually occur and which one dominates depends on the stage of the stream. For example, at low flow a gravel riffle may be the control, at medium to high flow a culvert restriction may be the control. Figure 2 shows a gravel riffle control downstream of a gaging station. Chow ( 1959, pp 70-74) and Henderson (1966, pp 40-43, 116-119) discuss controls on flow.

\section{Datum with Reference Marks}

The stage of river is the elevation of the water surface above some datum. The zero of this datum corresponds to some elevation above mean sea level. For example, the datum for the Boneyard Creek gaging station is 708.10 feet above sea level. This means that a stage of 0 at the Boneyard Creek gaging station corresponds to 708.10 feet above mean sea level. Therefore a stage of 2.30 feet corresponds to a mean sea level elevation of 710.40 feet. The relation between gage datum and mean sea level is determined by running surveying levels from a known bench mark to reference marks $(\mathrm{RM})$ and reference points (RP) at the gage.

In establishing the datum, Usually an arbitrary datum is assumed which will keep the reported stage in the single to double digits, ie. 3.50 feet of stage instead of 711.60 feet of stage.

\section{Stage Sensing Equipment}

- Stilling well with a float/counterweight system (figure 3)

- Gas Bubble system (figure 4)

- Submersible Pressure sensors

- Acoustic sensors

- If Partial Record station, the stage might be determined manually by intermittent observations by an observer reading an outside staff gage or wire weight gage, or by a routine visits to check a crest stage gage which records the peak of a flood event only.

\section{Recording (data logging) equipment}

- Logs the time series of the stage parameters (or other parameters such as temperature, precip, Dissolved Oxygen, etc.)

- In addition, may have telemetry equipment to automatically send data back to the office (for flood warning, etc.)

\section{Outside (independent) non-recording stage gage}

- such as staff gage, wire weight gage, tape down reference point, etc. 


\section{Shelter for the data logger}

\section{Means to Determine the discharge}

- Development of a stage-discharge rating curve by making discharge measurements by:

- Conventional Current meter discharge measurements

- Acoustic Doppler Current Profiler (ADCP)

- Calibrated Flume

- Parshall

- V-Notch Weir

- Volumetric Measurement

- Use of reference velocity by continuously sensing the velocity by acoustic or other means (Acoustic Velocity Meter (AVM) station)

\section{Optional}

- Means to collect a time series of water quality parameters (sediment, temperature, D.O., Metals, conductance)---This can be done by placing probes in the water for some parameters, others can only be determined by laboratory analysis. These samples can be collected by installing a pumping sampler or contracting with a local observer to collect samples for later analysis.

\section{Factors In Selecting a Location for Gaging Station Sites (IDEAL)}

- The course of the stream is straight for about $300 \mathrm{ft}$ upstream and downstream from the site

- The total flow is confined to one channel at all stages, and no flow bypasses site

- The streambed is not subject to scour and fill and is free of aquatic growth

- Banks are permanent, high enough to contain floods, and free of brush

- Permanent, stable control that is effective at all stages. The control can either be a section or channel control or a combination of the two

- A pool upstream from the control at low stages to ensure good stage measurements (avoids high velocities and severe turbulence at high stages)

- Gage site is far enough upstream of a confluence to avoid variable backwater

- Satisfactory conditions for measuring discharge at all stages is available

- Free from ice conditions

- Concessions to reality...land owner permissions, accessibility, required data 


\section{Measurement of Stage}

When determining the water level of a stream, there has to be a datum to which the measurement is referenced with. For example, if the water level is reported as 493 feet above mean sea level, the reference datum is the mean level of the ocean. In streamgaging applications, we refer to water level as the stage or gage height. The datum is usually something other than mean sea level because it was simpler with data recorders of old to have your stage readings to not be required to report the $3^{\text {rd }}$ digit to the left of the decimal point. Therefore, the datum is typically somewhere just below the channel bed and the stage is in the range of 1 to 20 feet for most gaging stations. This arbitrary datum is most always surveyed in to reference it to mean sea level so that conversions can be made on the stage to mean sea level if necessary

\section{Types of Sensors (sensing the water level)}

- Manually Read---Staff Gage, Wire Weight Gage, Electric Tape Gage, Crest Stage Gage (pages 22-32, Rantz, S.E., and others, 1982; Buchanan, T.J., and Somers, W.P., 1968,)

- Automatic Sensors

- Float Driven Sensor---Stilling Well with Float (figure 3)-The stilling well is hydraulically connected to the stream by a series of pipe intakes. The water level in the stilling well is equal to that of the stream, however the normal water level surges of a natural stream due to turbulence and wave action are minimized inside the stilling well. Inside the stilling well, the float and counterweight are connected by a steel tape. The steel tape runs over a calibrated wheel that is mounted on the shaft of a device used to convert mechanical shaft rotation into a digital reading of stage change. This conversion device sits on a shelf at the top of the stilling well. As the float raises and lowers with the water level, the wheel turns the shaft and the device deciphers how far the float has raised/lowered because the wheel is calibrated. Two of the more typical devices used to convert the shaft movement to a digital stage are: (1) incremental shaft encoder and (2) potentiometer. According to Latkovich and Leavesley (1993), “An incremental encoder uses an electrical counter to monitor and count increments of shaft rotation. Each increment normally represents $0.01 \mathrm{ft}$ of stage change. The incremental changes are added to or subtracted from a base-stage preprogrammed into the data logger...... A potentiometer is a resisting device with a rotating shaft input that can be placed in an electrical circuit to convert mechanical shaft rotation to a variable voltage output. The relation between resistance, as measured by voltage output, and stage is determined by calibration. This relation is then used to compute stage." 


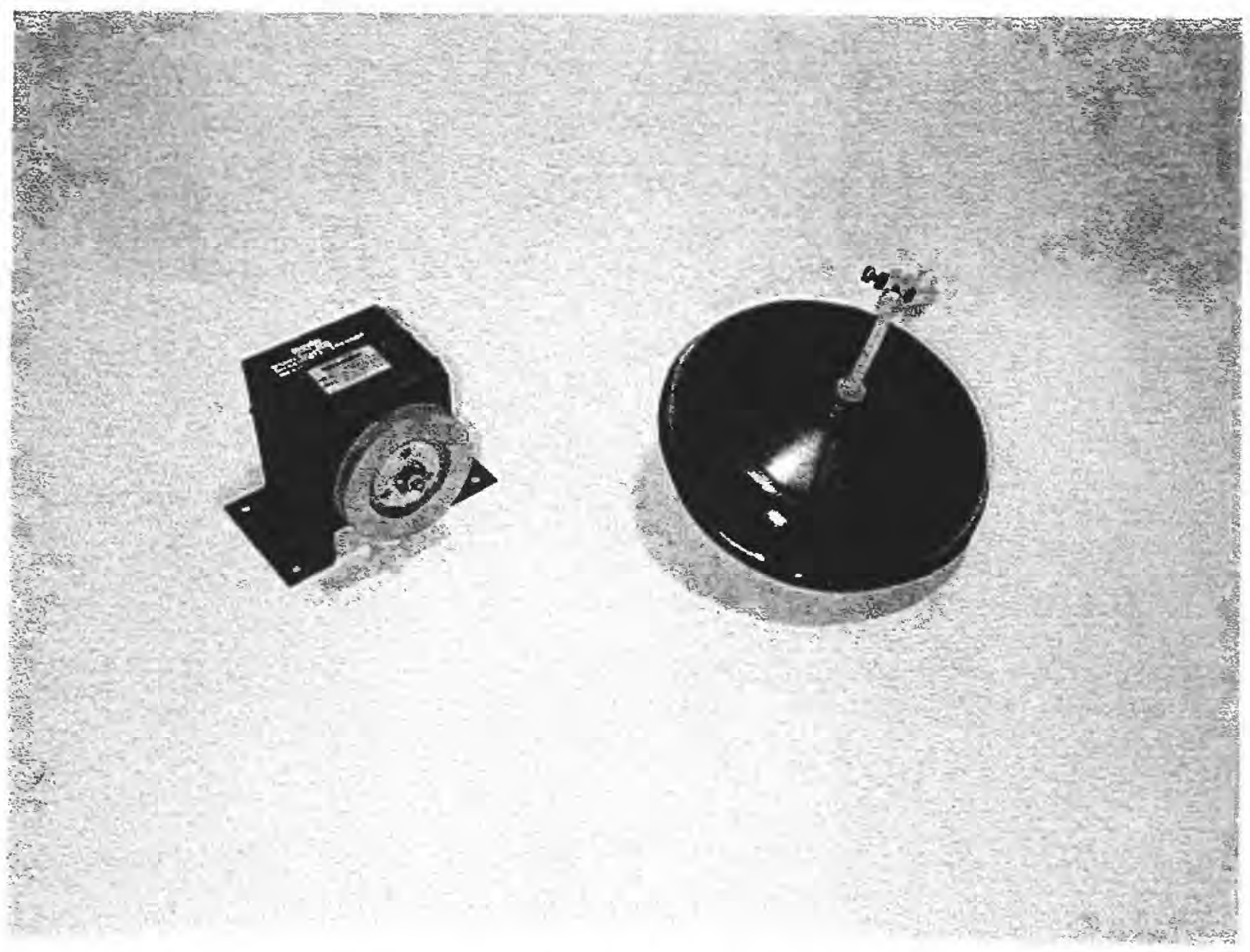

Figure 3.-Shaft encoder and float for stilling well

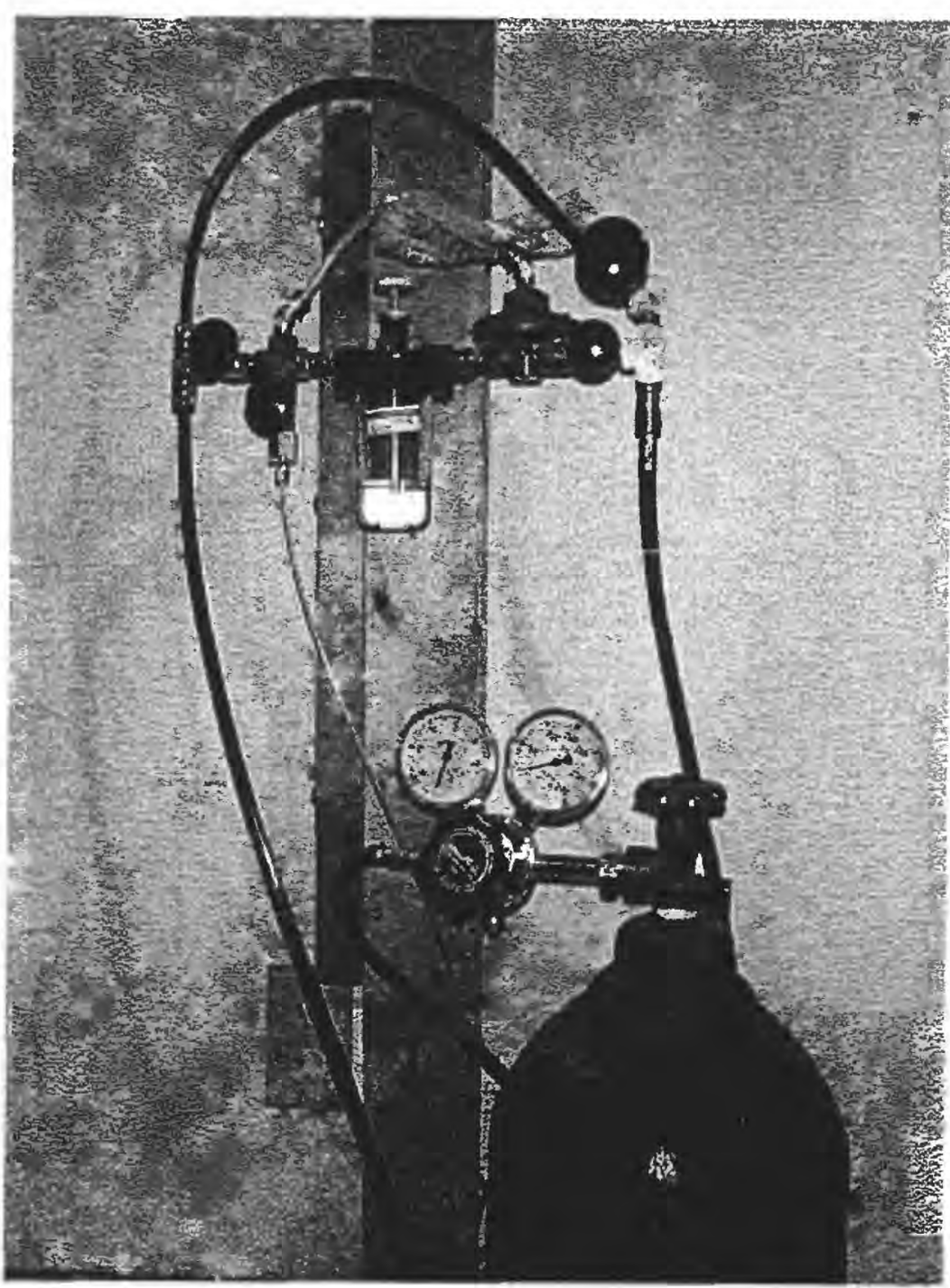

Figure 4. Gas bubble system 
- Gas-Bubble Systems (figure 4)---the gas bubble system uses a regulator to bubble gas (nitrogen or air) through an orifice near the bed of the stream at a constant rate. As the stream rises and falls, the pressure necessary to maintain the bubble rate will change proportionate to the water level over the orifice. A pressure sensor is placed in the gas line inside the gage house to sense the changes in pressure necessary to maintain the bubble rate. The following are some of the gas bubble/pressure sensor systems:

- Mercury Manometer with Nitrogen Tank (-phasing out because of mercury problem. A nitrogen tank and conoflow regulator system are used to bubble the gas into the stream. The manometer converts any pressure change to mechanical movement of a rotating shaft. The shaft rotation is transferred to the shaft of a mechanical or electromechanical data recorder, or to an encoder, by a chain and sprocket assembly (Latkovich and Leavesley, 1993).

- Pressure Transducer with Nitrogen Tank --(Sutron Accubar, Design Analysis H350, others)-Being used to replace the mercury manometers. Pressure Transducers use a pressuresensitive diaphragm which translates the pressure force exerted on the diaphragm to an electrical signal. The electrical signal can in turn be recorded by a data logger. This type of pressure transducer is nonsubmersible and just like the manometer is placed in the gas bubble line to "sense" the pressure changes due to increased pressure on the end of the orifice when water levels flucuate.

- Transducer Pressure Sensor with compressor system (Design Analysis H355, Vitel Bubbler)---This unit operates under the same principle as the Pressure Transducer with Nitrogen Tank above, however, this system has no need for a Nitrogen Tank and conoflow as the gas feed is produced by an internal compressor and pressure tank.

- Submersible Pressure Transducer---Actually submerged in the water and sense the pressure of the weight of water above the transducer directly as opposed to the non-submergible system that senses the pressure of the gas bubble system. The transducer must be vented to atmosphere to ensure that pressures measured at the transducer face are relative to atmospheric pressure. Otherwise a atmospheric pressure measurement would be required to correct the recorded data. Some manufacturers:

- Druk

- Design Analysis

- Others 
- Acoustic Sensors-Sensors that are mounted vertically and send out an acoustic (sound) pulse that bounces off the water surface to give a distance reading that is based on the speed of sound concept. The sensor can either be mounted above the water surface and look down at the water surface or can be mounted below the water surface and look up.

- Crest Stage Gages (Records the peak only of a flood event)---This stage sensor that uses powdered cork to record the peak stage on a graduated stick inside a 2-inch pipe. More on this follows later in the notes.

\section{Recorders}

Stage Data Logging Devices (these record the time series of the data)

Old Types

- Continuous Strip chart recorder (Page 9 of Buchanan, T.J., and Somers, W.P., 1968)-This is a continuous trace of gage height recorded by a pen on a rectangular graph strip chart (A-35)

- Automatic Digital Recorder (ADR) (Page6-7 of Buchanan, T.J., and Somers, W.P., 1968) - Gage height is recorded at regular intervals (from 1 minute to 1 hour) as a series of encoded holes on a 16channel paper tape.

- Observer Data-Sometimes gages are not automatic, and gage heights are read manually by an observer who then records the data Newer Types in a gage height log book and mails it into the office for processing.

- Electronic Data Loggers---Several brands and models of electronic data loggers are used in the field to collect and store unit values. Gage height must be retrieved electronically and transported or transmitted to the office for processing. A few brands/models are: Cambell Cr-10 (figure 5), Sutron 8200, Handar, Vitel 


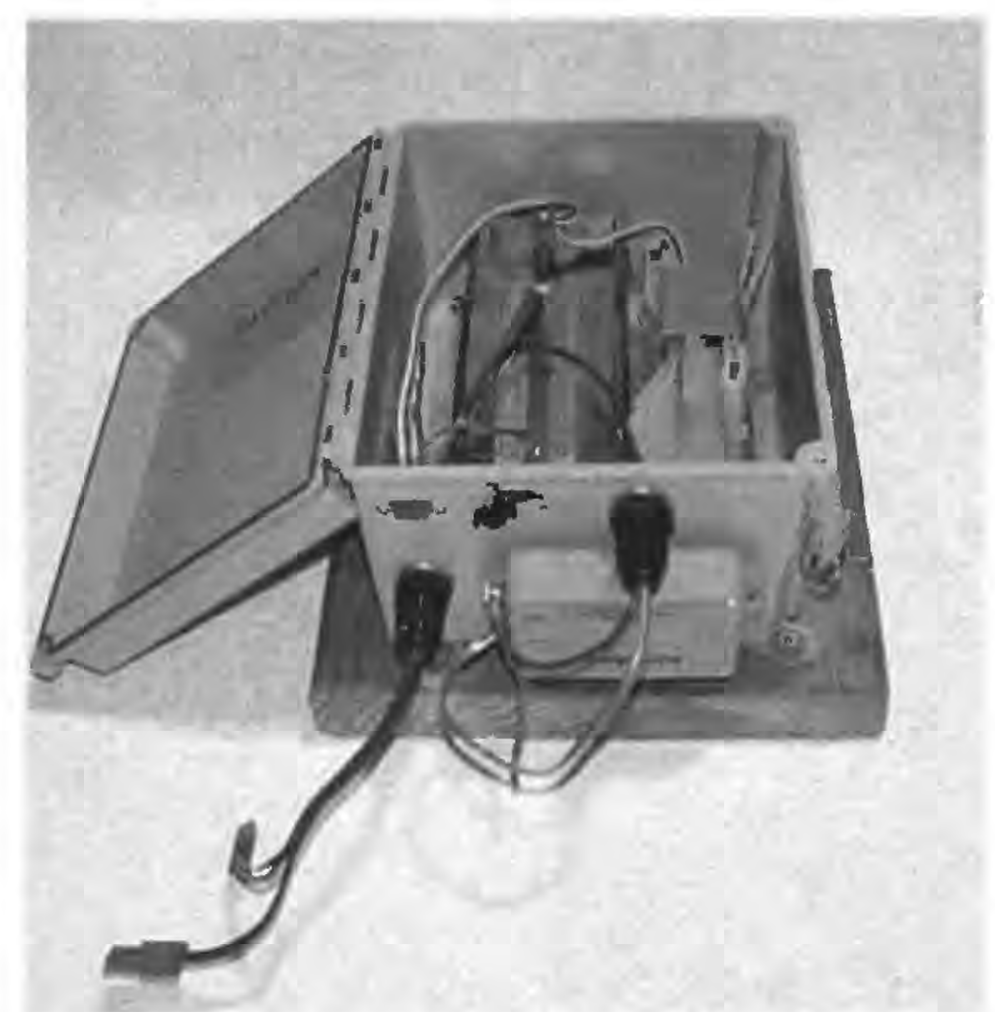

Figure 5.-CR10 Data Logger, Environmental Enclosure, and telephone modem

\section{Telemetry/Real Time Data}

- Phone/Radio Transmitted Data---The electronic data logger is equipped with a telephone modem or radio transmitter that regularly is interrogated by a computer system at the office.

- Satellite Data Collection Platform Satellite Transmission (DCP)---The electronic data logger is outfitted with a satellite transmitter that beams data back to a receiving station on regular intervals that then relays the data to an office computer.

\section{Crest-Stage Gages}

In connection with flood studies, crest-stage gages (figure 6) are operated to obtain a record of peak stages. The annual peak stage recorded is published together with the discharge, obtained either by direct or indirect methods. The gage generally consists of a 2-inch pipe with a wooden measuring stick inside and granulated cork in the bottom. Water enters holes in a cap on the bottom of the pipe and floats the cork up on the stick to the elevation of the maximum water surface. Inspecting and servicing the crest-stage gage is an exacting procedure.

The USGS places Crest-Stage Gages at some continuous discharge gaging stations to serve as a backup in case the regular gage goes down. Although the Crest-Stage Gage only provides the peak stage and discharge, this is often very useful information even if the rest of the time series data is missing. Two Crest-Stage Gages exist at the USGS Gaging Station on the University of Illinois campus. In addition, several more crest-stage gages exist along the Boneyard Creek as part of a network operated by the Illinois Department of Natural Resources, Office of Water Resources. 


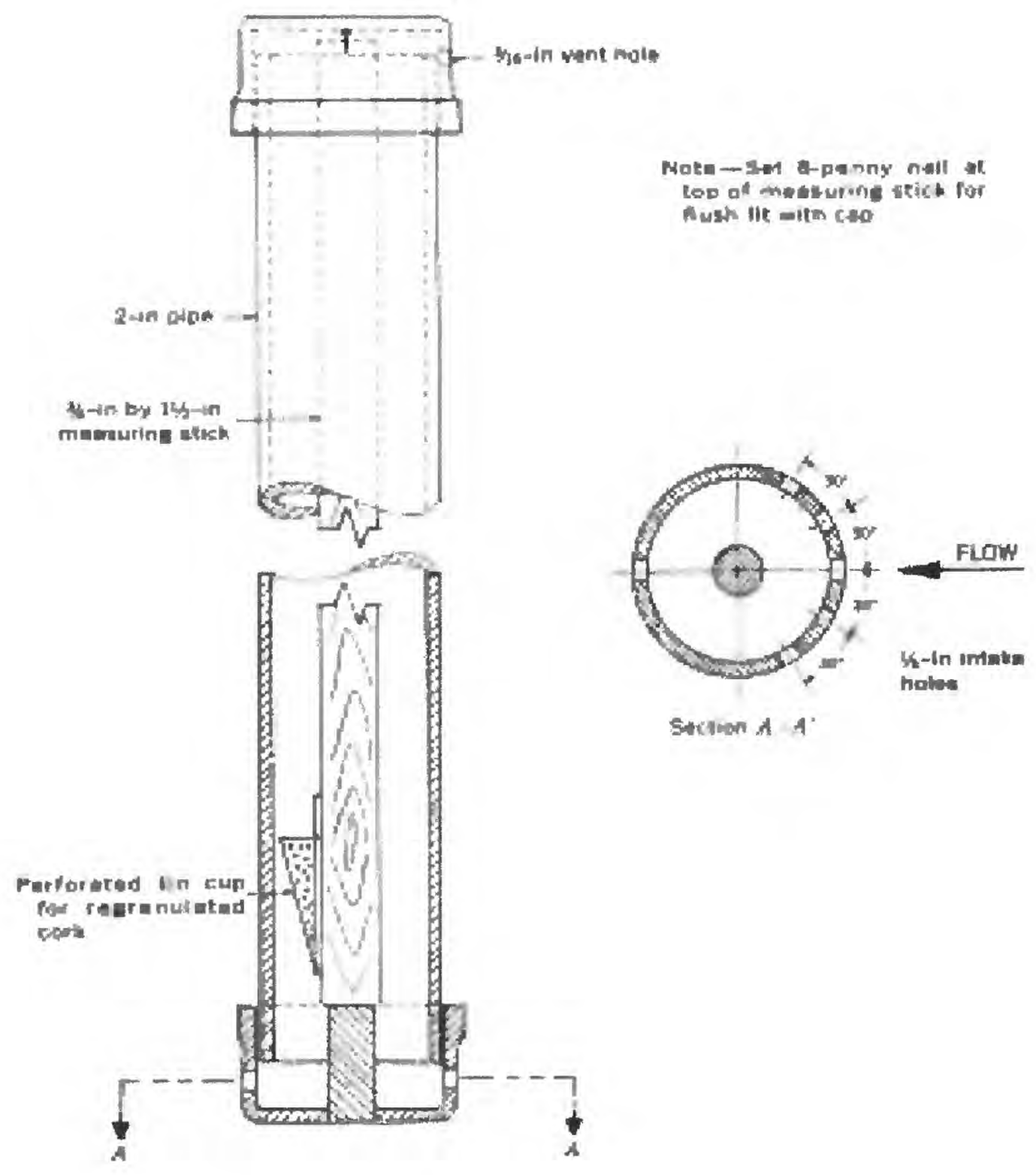

Figure 6.- Schematic of a crest stage gage 


\section{PROCEDURES FOR INSPECTING GAGES}

Fill out Measurement Note Front Sheet (figure 7) with the information as follows:

- Determine all gage readings (inside and outside)

- Record watch and data logger times

- Determine if Intakes or other types of sensors are functioning properly

- Remove electronic data (if not telemetered)

- Examine back data since last visit (use graphing package on laptop)

- Obtain High Water Marks

- Check Battery voltage

- Make Discharge Measurement

- Obtain Point of Zero Flow (PZF)

- Read and record all gage readings and times again

- Ensure equipment is operating properly before leaving station 


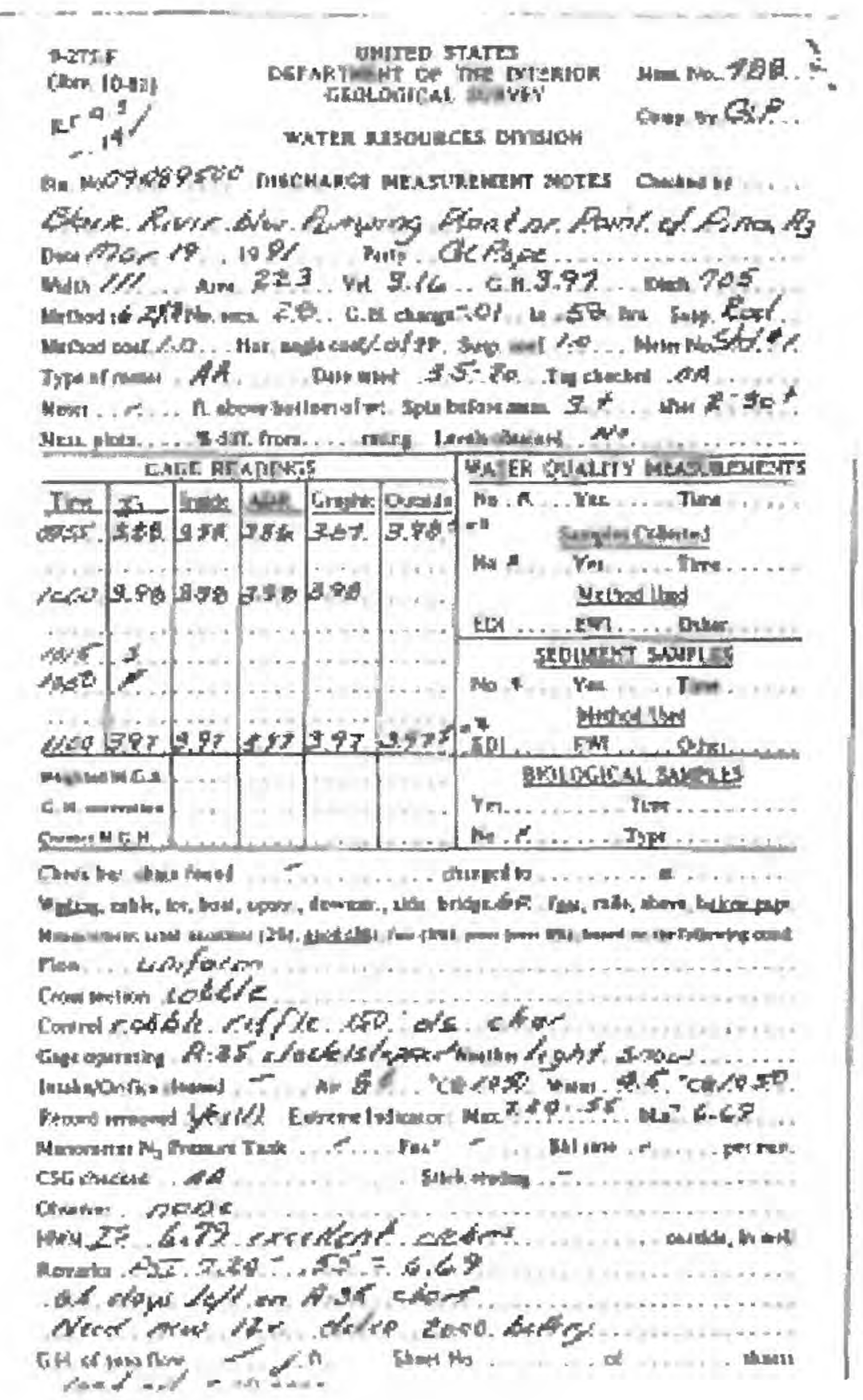

Figure 7.-U.S. Geological Survey Discharge Measurement Note Front Sheet

\section{Collection of High Water Marks}

Anytime a field visit is made, the site should be examined for high water marks to reconcile any discrepancies that may arise with the continuous record from the sensor and data logger.

- Check stage record to see if flood event occurred since last visit.

- Reasons for obtaining high-water mark (HWM)

- Intakes (for stilling well) may have plugged during the rising limb of the hydrograph

- Verification with recorded peak

- To make an indirect measurement of discharge

- Obtaining HWM's

- If a stilling well type of gage, check inside stilling well for HWM to compare with recorded peak. 
$\Rightarrow$ Install peak-stage indicator clips that fit on float-tape

$\Rightarrow$ Clean HWM from inside of well

- Obtain a HWM outside of gage well if intakes are found to be plugged. Obviously, if the gage is a gas-bubble system, HWM have to be obtained outside. Look around for mudlines, seed lines on tree, eroded leaves on banks, debris piles...NOTE. Be careful with debris piles as these are not always indicators of the highest water.

- It is especially important to get HWM if the sensing device is a gasbubble system

- If flood reached a stage such that the discharge (estimated through rating curve extrapolation) is two or more times greater than the highest discharge measurement made to date, then several high water marks along the reach of the gage should be flagged for an indirect measurement.

\section{Determination of Gage-Height of Zero Flow}

- The gage-height of zero flow (also called the point of zero flow, PZF) is the depth of water over the lowest point of control (figure 8)

- When flow conditions permit, the gage height of zero flow should be measured because it provides valuable information that can be used for interpretation of rating position and shape, as well as for rating shift interpretation (more will be explained about this later). In fact, the gage height of zero flow can actually be interpreted as another discharge measurement, where discharge equals zero for the measured gage height (gage-height of zero flow).

- The PZF can be obtained either before or after the discharge measurement

- The PZF must be obtained and recorded for each measurement because it can change with time because of:

$\varpi$ Scouring

Filling

ఐ Permanent changes

- The PZF can be used in interpreting the record during intermittent flow periods

- If there is uncertainity about the PZF, give a probable range 


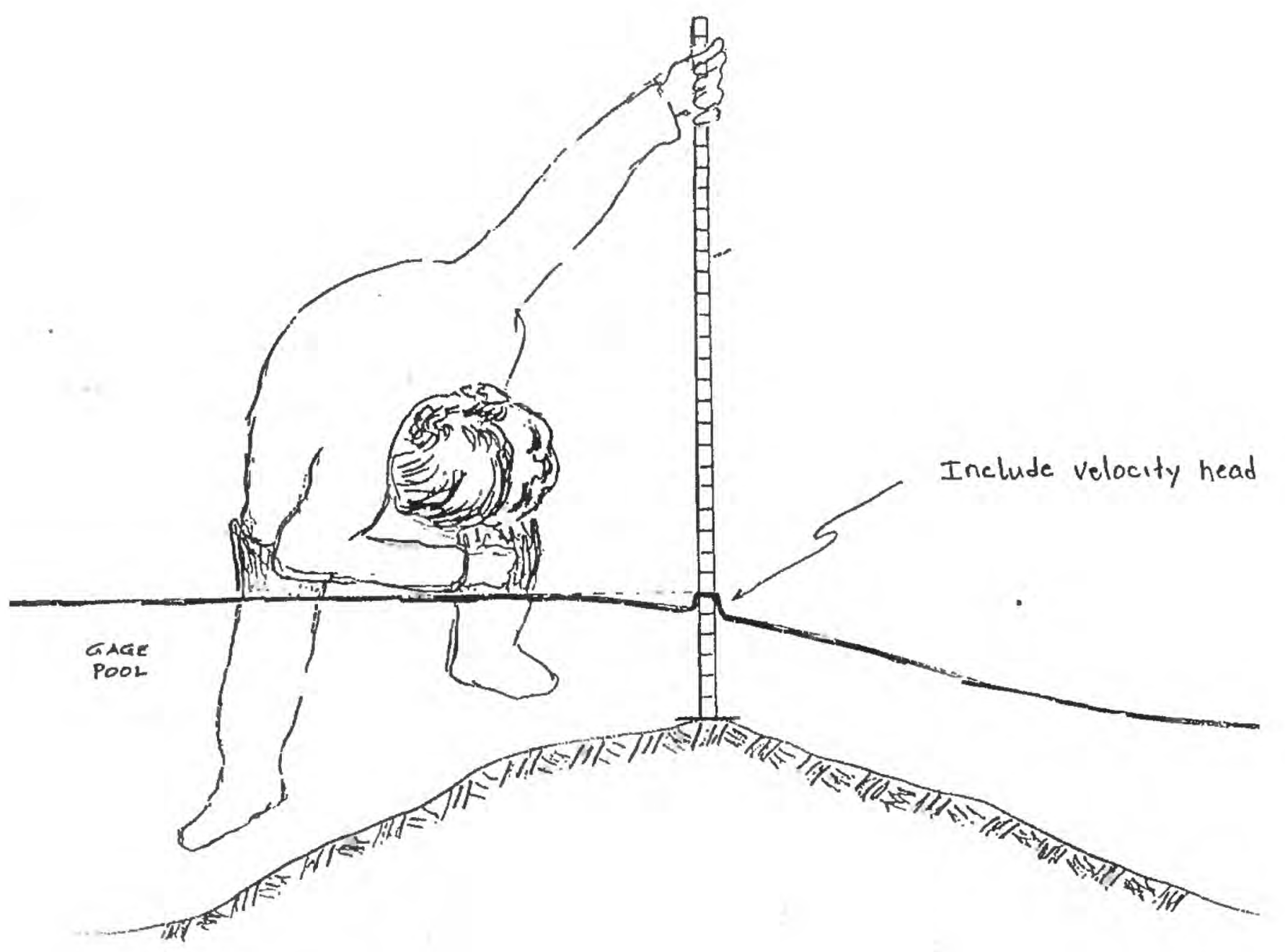

Figure 8.-Determination of Point of zero flow

\section{Measurement of Velocity}

Velocity is an important data parameter in many surface water hydrology investigations. It is absolutely essential in the determination of volumetric discharge. There are several means of measuring velocity at a point in an open channel flow.

\section{Types Of Velocity Meters}

\section{Vertical Axis Meters}

(see Buchanon and Somers, 1969, pp 4-6)

- Price AA meter (most commonly used meter in USGS)

- Meter consists of a set of cups that rotate horizontally on a sharply pointed pivot as the flowing water drags on the cups (the cups are commonly referred to as the bucket wheel. The meter looks similar to a wind speed anemometer.

- The meter is calibrated such that if the number of revolutions of the cups in a certain time is known (radial velocity), then the linear velocity of the water can be determined. Rating tables have been established by calibrating these meters in large tow tanks. This is basically done by pulling the meters through a tank of quiet water at various know speeds. 
- The meter has either a electrical contact that communicates that one rotation of the cups has occurred. This electrical signal can either be transmitted into a headset for the user to hear and mentally count the number of revolutions or into a device called a current meter digitizer (CMD) to automatically count and time the number of revolutions.

- This electrical contact head version of the meter has both a single count contact and a penta count contact gear system. If the single count is used, then an electrical signal is sent for every revolution of the bucket wheel. If the penta count is used, then an electrical signal is sent every five revolutions. When a headset is being used in faster velocities ( $>3 \mathrm{ft} / \mathrm{sec})$, the penta count is typically used as a convenience for the person trying to count the revolutions and track the time. If a CMD is used, the single count contact is used.

-Used either mounted to the top of sounding weight and lowered on a cable into the stream or mounted to a wading rod

-A tailpiece is used to align the meter parallel to flow

- For optimal meter use (as designed and calibrated), only use in water with depths greater than 1.25 feet because of boundary effects

- For optimal meter use, should not use if meter is within 0.5 feet of the water surface or bed (boundary effects)

-Meter should be raised off the pivot when not in use

- Calibrated for use in water velocities between $0.2 \mathrm{ft} / \mathrm{sec}$ and $12 \mathrm{ft} / \mathrm{sec}$

Figure 9.-Price AA Current Meter

-Price pygmy meter ( $2 / 5$ scale version of Price AA)

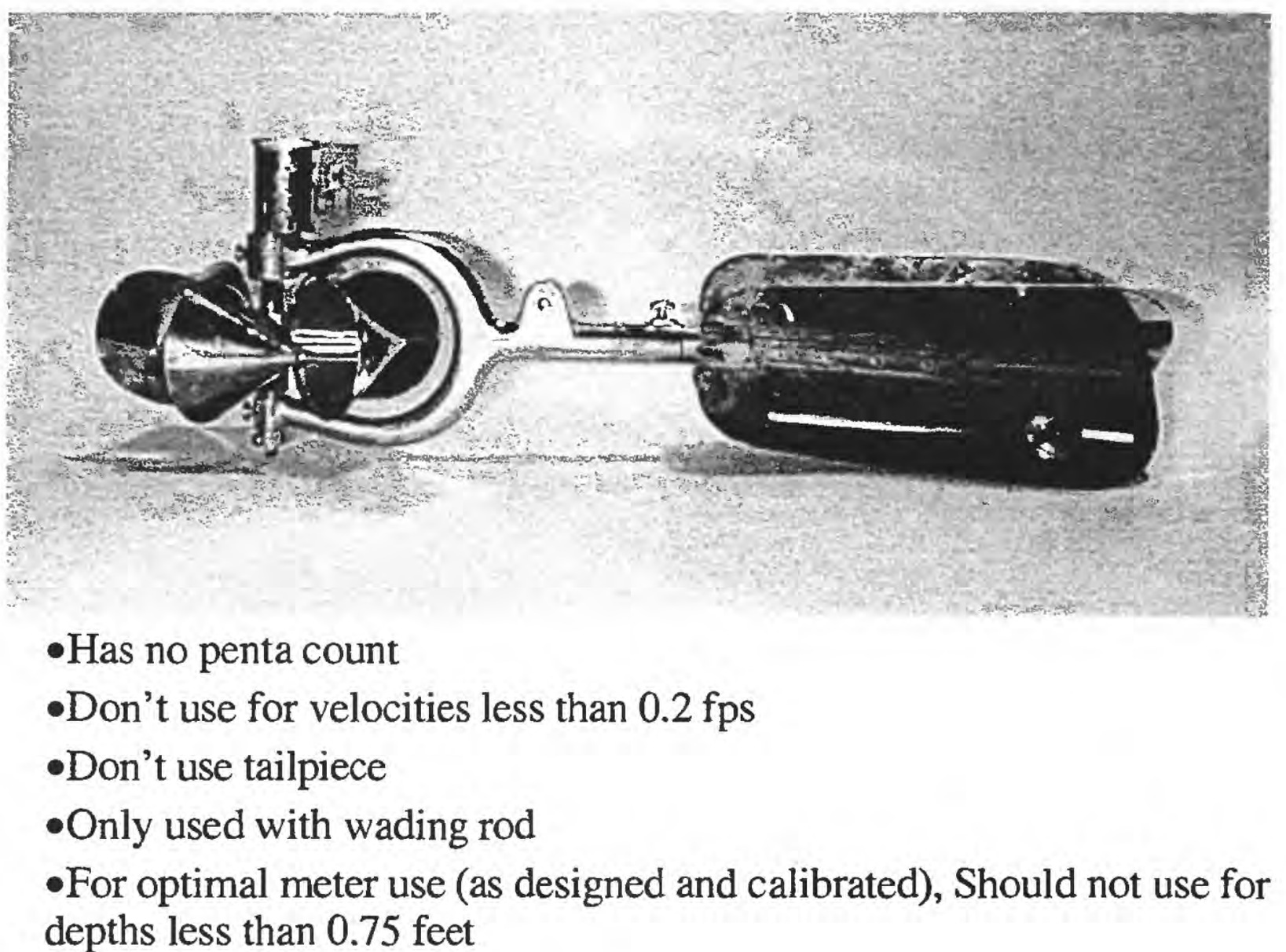


- For optimal meter use (as designed and calibrated), should not use if within 0.3 feet of water surface and bed

- Carry meter on a dummy pivot when not in use

- Calibrated for use in water velocities between $0.2 \mathrm{ft} / \mathrm{sec}$ and $2.5 \mathrm{ft} / \mathrm{sec}$

- Price OAA meter

-Exactly like the regular AA, but has a fiber-optic counting head in replacement of the electrical contact head

-Price AA Low Velocity Meter

- Similar to regular Price AA

- No penta gear present, this reduces friction

- Shaft inside of head has two eccentrics, therefore there are two counts per revolution

- Calibrated for use in water velocities from 0.08 to $3 \mathrm{ft} / \mathrm{sec}$

- Recommended when velocities are less than $1.0 \mathrm{ft} / \mathrm{sec}$

-Vane Ice meter (sheds slush ice better than AA)

- Rotors on meter do not clog with slush ice like the regular AA bucket wheel cups do

- Not the preferred meter for ice use by USGS

- USGS recommends that Price AA meter with a Water Survey of Candada Winter Style yoke be used during slush ice conditions

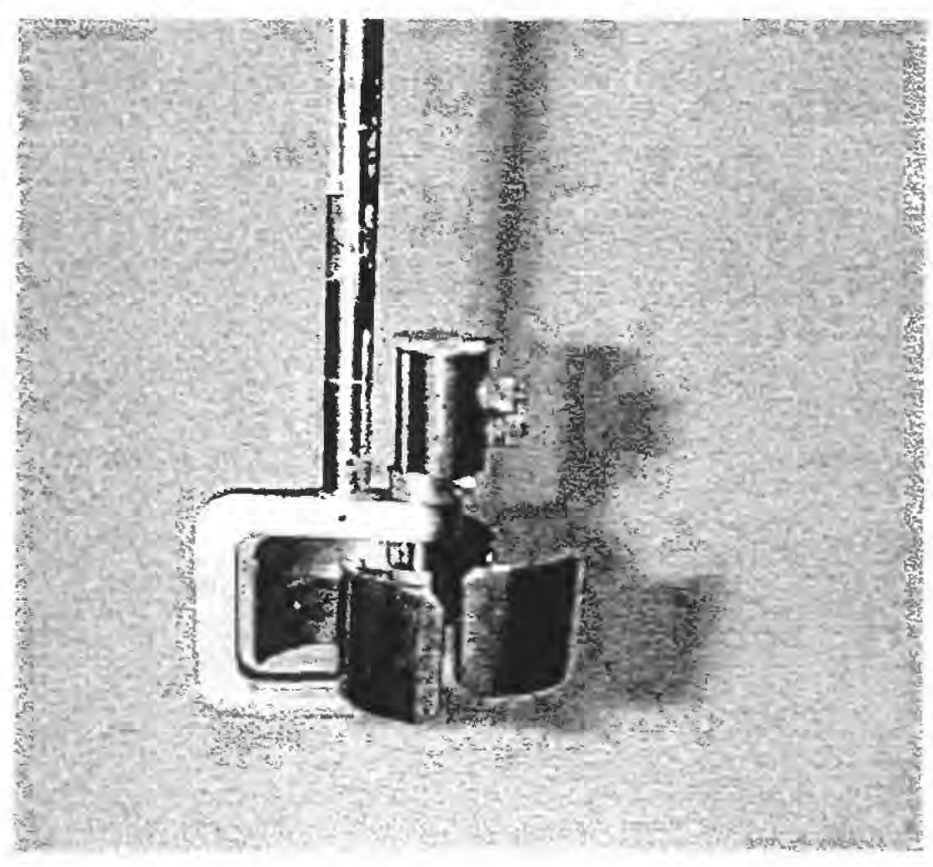

Figure 10. - Vane Ice Meter

\section{Horizontal Axis Meters}

(see Buchanon and Somers, 1969, p 7)

- Ott meter (German made, used for moving boat measurements)

- Hoff meter(Measuring velocities in pipes)

- Haskell meter(Used in deep, swift, clear streams)

- Neyrpic meter (French made) 


\section{Electromagnetic Meters}

- Marsh McBirney (both single and bi-directional probes)

\section{Acoustic meters}

Acoustic meters use sound waves in the determination of velocity. Each of the instruments mentioned below uses a slightly different approach.

- Neil Brown point velocity

-RD Instruments Acoustic Doppler Current Profiler (ADCP)_Uses sound waves reflected off of particles in the water to measure the velocity of the particles, which is also assumed to be the velocity of the water that is moving the particles. It uses the doppler shift technique to determine the velocity. Figure 11 shows one type of ADCP, the broadband ADCP. ADCP are used not only to get 3-D velocity measurements, but to make complete measurements of water discharge. A boat mounted ADCP travels across the river from one side to the other, tracking its own relative position in the horizontal by use of a technique called bottom tracking, measuring depths, and measuring velocities. The software within the ADCP computes the water discharge using all the previously mentioned data.
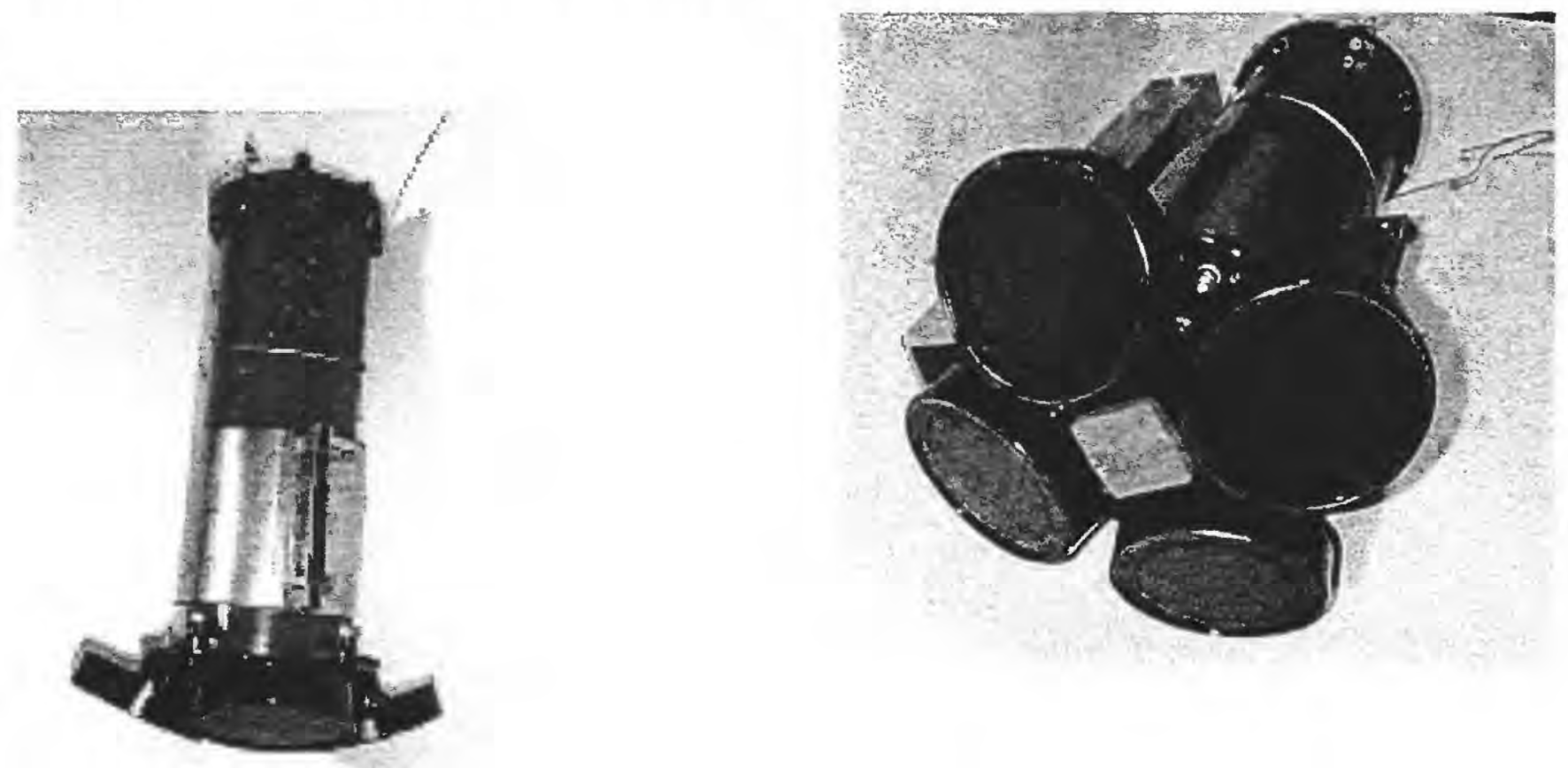

Figure 11. Acoustic Doppler Current Profiler (ADCP), Broadband Version

-Sontek Acoustic Doppler Velocimeter (ADV)—-measures a point velocity (figure 12)

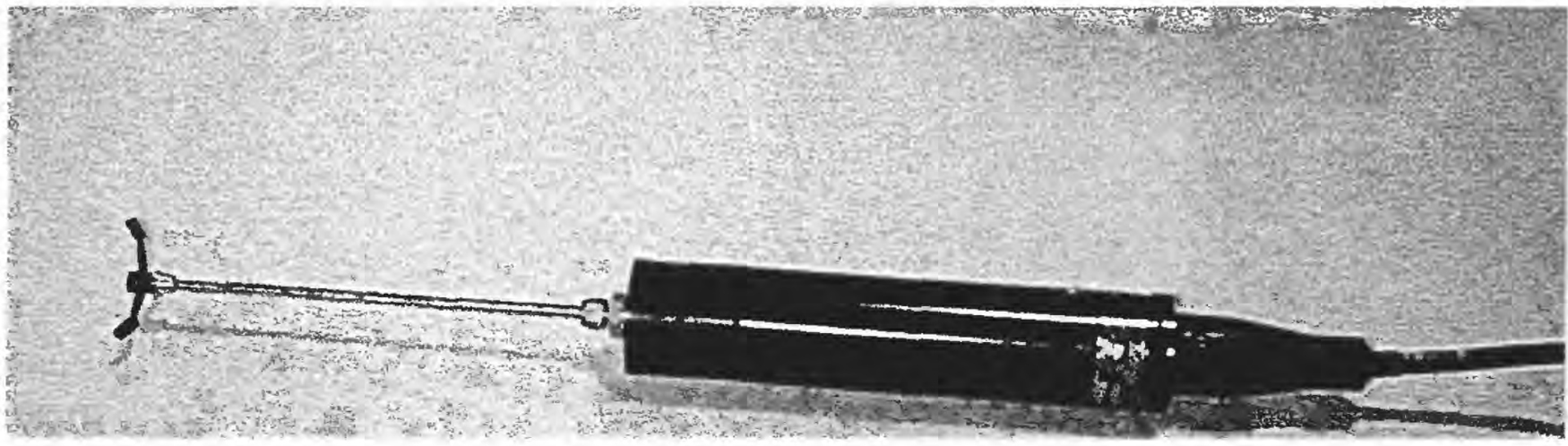




\section{Figure 12. Acoustic Doppler Velocimeter (ADV)}

-Acoustic Velocity Meter (AVM, also called UVM) path velocity meter (used to measure velocity in a horizontal plane) (Laenen, Antonius, 1985)-Determines the integrated horizontal velocity (line velocity) across the stream cross section by ultrasonically transmitting sound pulses between two transducer/receiver units. These transducers/receiver units are mounted on both sides of a stream. Sound waves emanate from one transducer and are received and sent back by the other transducer on the opposite shore. The transducer path is at an angel to the flow (figure 13). The stream velocity is the average of the amount that the speed of sound is increased (on the downstream path of the acoustic signal) and the amount the speed is decreased (on the return of the acoustic signal moving upstream).

The AVM is used to monitor continuous discharge at sites where conventional stage-discharge ratings are not possible. A relation is developed between the line velocity and the mean streamflow velocity by making several discharge measurements, calculating the mean velocity of the measurement, and relating this to the line velocity collected by the AVM during the measurement of discharge. In addition to the line velocity/mean streamflow velocity relation, a relation between stage and cross sectional area must also be developed. After these relations are developed, as the AVM collects line velocities and stage, the discharge can be determined by multiplying the mean velocity (determined from the relation between line velocity and mean velocity) and the area (determined from the relation between stage and area of the channel cross section).

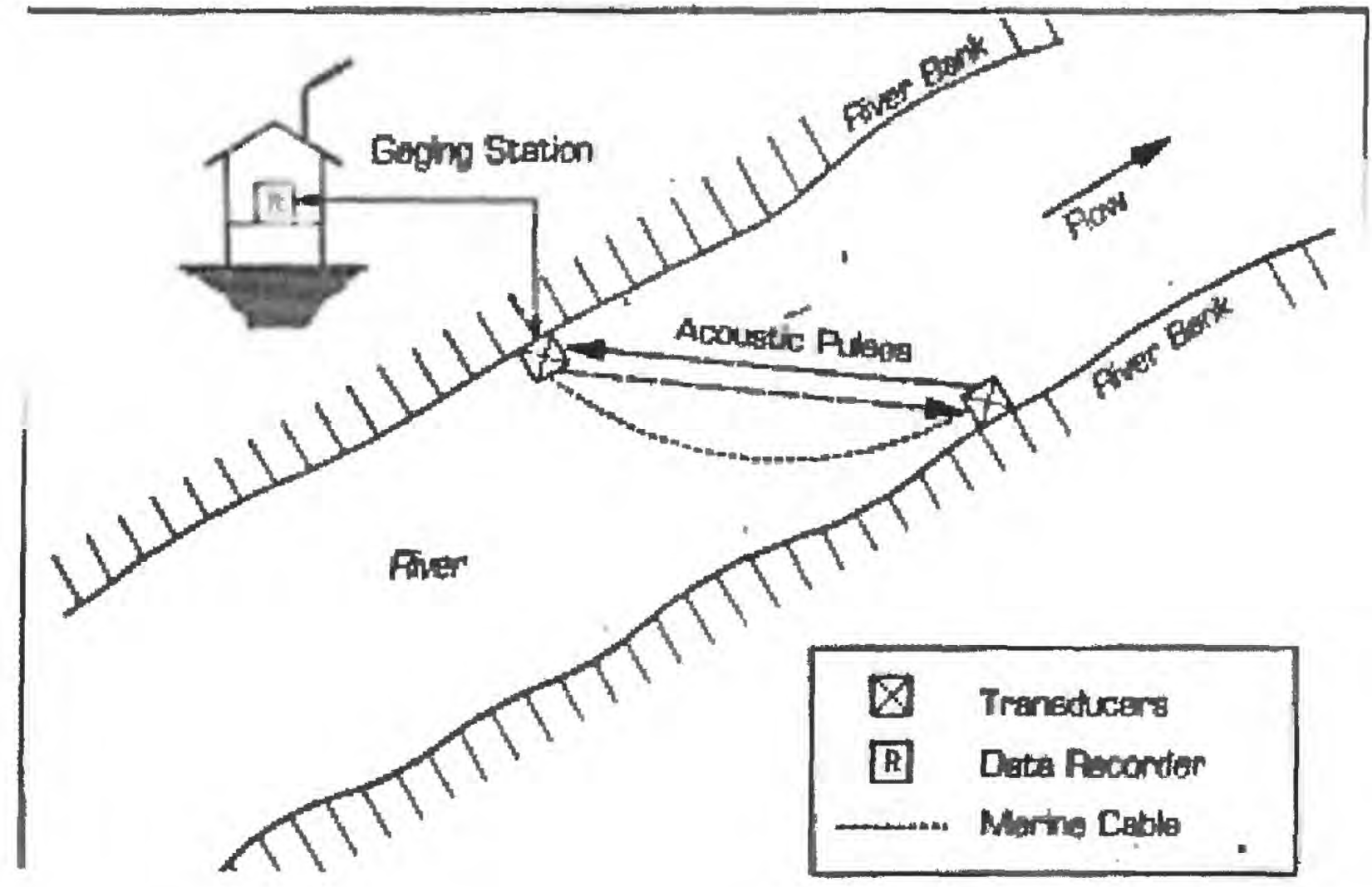


Figure 13.-Plan View of Acoustic Velocity Meter (AVM) data collection station

\section{Quality Assurance Spin Tests For Price AA and Pygmy Meters}

A spin test is conducted for each meter to ensure that the moving parts of the meter are in proper alignment and lubrication, and that the meter is functioning similar to the condition of the meter when it was manufactured and calibrated. A spin test is conducted by placing the meter on a flat surface away from any wind effects. The meter is then given a spin, simultaneously starting a stopwatch. The stopwatch is stopped when the meter cups quit rotating.

- Minimum spin test standards for meters, according to the USGS, Office of Surface Water Technical memorandum 89.07 are:

Pygmy meters-------0:45 seconds

AA Meters (all types)---2:00 Minutes

- Logs should be kept of all spin tests for each meter 


\section{Determination of Mean Velocity}

In a turbulent open channel flow, the velocity profile in the vertical is similar to that seen in figure 1.

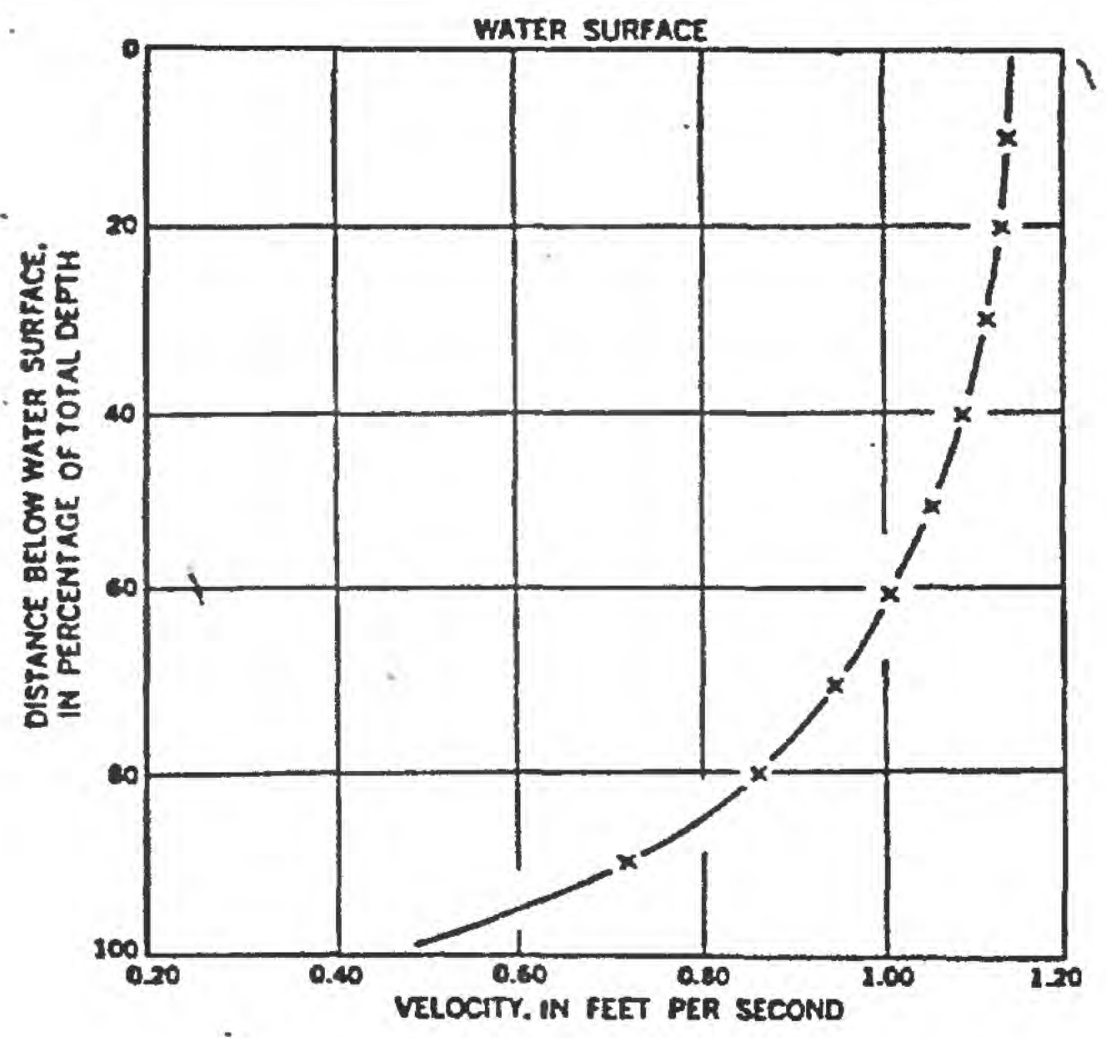

Figure 14.-Typical Velocity Profile

To determine the mean velocity in the vertical, point observations have to be made and averaged in some way as to approximate the mean velocity. The following are some of the methods that are used:

-Vertical-Velocity Method - a series of velocity observations at points well distributed between the water surface and the streambed are made at each of the verticals. The velocity values are plotted versus depth and a curve is put through the points. The area is determined between the ordinate axis and the curve, then this area is divided by the depth to get the average velocity.

- Two-Tenths Method-The velocity is determined at 0.2 -depth below the surface. A coefficient is applied to the observed velocity to determine the mean velocity.

- Six-Tenths Method-The velocity is determined at 0.6-depth below the surface. This observation location is theoretically the average of a logarithmic velocity profile. This method is recommended by the USGS in the following cases: (1) depths between 0.3 and 2.5 feet, (2) when large amounts of slush ice or debris make it impossible to observe the velocity at the 0.2-depth location, thus preventing use of the two-point method, (3) When the meter is placed a distance above the sounding weight which makes it impossible to place the meter at the 0.8-depth, thus preventing use of the two-point method, or (4) when the stage in a stream is changing rapidly and a measurement must be made quickly (Bucanon and Somers, 1969, p 33). 
- Subsurface-Velocity Method-The velocity is observed at some distance below the water surface. This distance should be at least 2 feet below the surface to avoid the effect of surface disturbances. The subsurface method is used when it is impossible to measure velocity and depth much below the surface (because of debris in river, ice flow, etc). A coefficient must be applied to this observed velocity to determine the mean velocity. The coefficients are difficult to determine and may vary with stage.

- Two-Point Method-Velocity is observed at 0.2-depth and 0.8-depth below the water surface. The mean velocity is the average of these two values, which for the theoretical logarithmic velocity distribution is the average. Much field data observations have shown that this method gives more consistent and accurate results than any of the other methods (Buchanon and Somers, 1969, p 32). As such, this method is the preferred method by the USGS. The two-point method is not used in depths less than 2.5 feet because the current meter would be too close to the water surface and to the streambed to give dependable results. In this case, the 0.6-depth method is used.

- Three-Point Method-This method combines the two-point method with the 0.6depth method. Velocity is observed at $0.2,0.6$, and 0.8 of the depth from the water surface. The average of the 0.2 - and 0.8 -depth is determined then that value is averaged with the 0.6-depth observation. This method is used when the velocity in the vertical is abnormally distributed.

Each of these methods is explained in Buchanon and Somers (1969, pp 31-37).

Typically, as has been previously stated, the two-point and six-tenths methods are used most frequently, as they can be demonstrated to represent the mean of the theoretical logarithmic velocity profile. Consider the following from Rantz (1982, p 134) that further discusses those situations where these methods need to be altered:

"The vertical-velocity curve will be distorted by overhanging vegetation that is in contact with the water or submerged objects, such as large rocks and aquatic growth, if those elements are in close proximity, either in the upstream or downstream direction, to the vertical in which velocity is being measured. Where that occurs the two-point method will not give a reliable value of the mean velocity in the vertical, and an additional velocity observation at the 0.6 depth should be made. The three observed velocities should then be used in the three-point method. A rough test of whether or not the velocities at the 0.2 and 0.8 depths are sufficient for determining the mean vertical velocity is given in the following criteria: the 0.2depth velocity should be greater than the 0.8-depth velocity but less than twice as great." 


\section{Continuity Principle}

Before we can discuss measurement of discharge, the principle of conservation of mass (continuity principle) must be discussed.

This principle says that:

$$
\mathrm{Q}=\mathrm{A}^{*} \mathrm{~V}
$$

$$
\text { Where: } \quad \begin{aligned}
& Q=\text { Discharge through the Cross Section } \\
& A=\text { Cross Section Area } \\
& V=\text { Mean Velocity of the Cross Section }
\end{aligned}
$$

Consider the following discussion and derivation of the Continuity Equation:

The application of the principle of conservation of mass (matter can neither be created nor destroyed) to a steady flow in a streamtube results in the equation of continuity, which expresses the continuity of flow from section to section of the streamtube. Consider the streamtube shown in figure 15 through which passes a steady flow of fluid. At section 1 the cross-sectional area is A1 and at section 2 the area is A2. If the mass of fluid occupying position $\mathrm{BB}^{\prime}$ moves to position $\mathrm{CC}^{\prime}$ in time $\mathrm{dt}$, the conservation of mass principle yields

$\rho \mathrm{A} 1 \mathrm{ds} 1=\rho \mathrm{A} 2 \mathrm{ds} 2$,

where ds 1 and ds 2 are the displacement lengths at sections 1 and 2, respectively. Dividing by $\rho \mathrm{dt}$ (this assumes that $\rho$ is constant) yields

$$
A_{1} \frac{d s_{1}}{d t}=A_{2} \frac{d s_{2}}{d t}
$$

however, $\mathrm{ds}_{1} / \mathrm{dt}$ and $\mathrm{ds}_{2} / \mathrm{dt}$ are the mean velocities of flow past sections 1 and 2 , respectively; therefore,

$$
A_{1} V_{1}=A_{2} V_{2}=Q
$$

which is the equation of continuity. The product $\mathrm{A} \times \mathrm{V}$ is designated as the flow rate, $\mathrm{Q}$, and has units of cubic feet per second. 


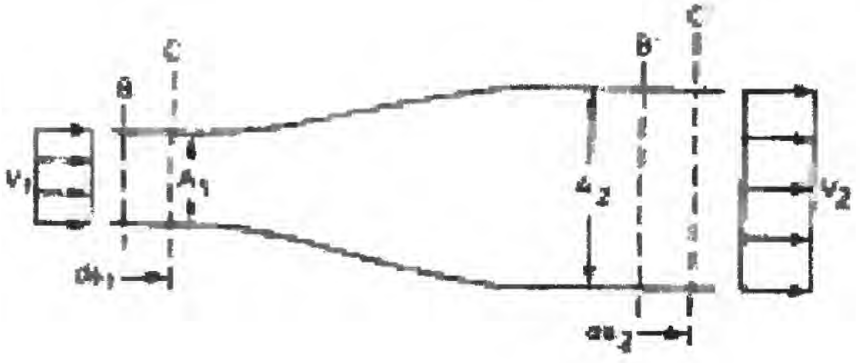

Figure 15.--Steady flow through a streamtube. 


\section{Measurement of Discharge}

A continuous streamflow gaging station produces both stage and discharge data. Stage time series data are produced directly by determining the water level through some type of sensor and data logger. Discharge time series data are typically produced by stage as the independent variable to a stage-discharge relation to determine the discharge for a particular stage. There are other ways of producing discharge time series data, such as use of AVM's to collect line velocity data, however most of these methods require discrete direct measurements of discharge at various stages and hydrologic situations.

\section{Conventional Current Meter Method For Discharge Determination}

(Buchanan, T.J., and Somers, W.P., 1969)

A conventional current meter measurement consists of:

1. Selecting a suitable measurement site. The following are things to consider

- Straight reach is most ideal

- Velocities greater than $0.5 \mathrm{ft} / \mathrm{sec}$

- Flow is relatively uniform

- Minimize affects of tributary inflow

- Exercise judgement in meeting above criteria

2. Subdividing the channel cross section, perpendicular to flow, into several subsections, to make measurements of area and mean velocity within these subsections. The accuracy of the measurement will increase proportionate to the ability of the velocity observations in each subsection to accurately reflect the true mean velocity in that subsection. Figures 16 illustrates how a typically cross section is subdivided.

3. Determine the depth and width of each subsection by using both a sounding device (wading rod, lead weight, etc) and some sort of horizontal position marker (tag line, markings on a bridge rail, etc). The initial point for width measurement is at one bank, using either a tag line or special pre-marked stationing on a bridge or cableway. The subsection area is the product of the width and average subsection depth. The mean velocity of the subsection is then determined by point velocity observations. This is typically done at the midpoint of the subsection using either the two-point method or 6-tenths method (discussed in previous sections).

- Wading Rods for sounding---marked every 0.1 feet for depth determination

- Sounding Weights

- Selection of Sounding Weights

* Weight Used $\geq\left(\mathrm{V}_{\max } * \mathrm{D}_{\max }\right)$ Where: $\mathrm{V}_{\max }=$ Maximum Velocity in Cross Section; $\mathrm{D}_{\max }=$ Maximum Depth in Cross Section

For some measurements, the maximum weight available will not be adequate to prevent errors in depth measurement when the sounding weight drifts downstream. This will 
necessitate the use of wet line/air line correction methods which are discussed in Buchanon and Somers (1969, pp 4752)

․ Sounding for depth using a sounding weight and reel

Lower meter until the meter cups are _ submerged at the water surface, then zero the depth indicator on the reel

Lower weight until the streambed is touched (for soft beds, the weight will continue to sink into the bed, therefore, when you first "feel" the weight touch, use that as the bed level), then read the depth indicator

* To get the total depth, add the appropriate length that corresponds to the distance between the centerline of the meter cups and the bottom of the sounding weight. When using a 100 pound sounding weight, this distance is 1 foot.

- Taglines

ㅁ Kevlar Taglines are marked as follows: 1 mark every 2 feet, 2 marks every 10 feet, 3 marks every 100 feet

․ Steel taglines are marked as follows: 1 mark every 2 feet for first 50 feet, every 5 feet between 50 and 150 feet, every 10 feet beyond 150 feet. Two or three marks placed at selected points.

ㅁ Distances between marks are estimated

- Each velocity observation should be a minimum of 40 seconds unless: rapid stage change, debris or ice heavy, or other special circumstances regarding safety.

- When the flow in a subsection is not perpendicular to the tag line, bridge, or cableway, an angle of flow must be determined to adjust the velocity observation. This is done by use of the angle coefficients marked on the back of the measurement note sheets (figure 17).

4. For each subsection, the pertinent notes are recorded on a discharge measurement note sheet (figure 18).

- Record the time at the beginning and end of the measurement along with gage height of all gages (inside, outside, and recorder) on the note sheet. If stage is changing rapidly, show time every 15 minutes or so. This will be used for a determination of Weighted Mean Gage Height.

- Show the side of the stream corresponding to the beginning and end of the measurement, e.g. LEW or REW for left or right edge of water.

5. An effort is made to have no more than $5 \%$ of the total discharge in any one subsection. 


\section{Measurement Sectioning}

"The verticals should be so spaced that no subsection has more than $10 \%$ of the total discharge. The ideal measurement is one in which no subsection has more than $5 \%$ of the total discharge, but that is seldom the achieved when 25 subsections are used. It is not recommended that all observation verticals be spaced equally unless the discharge is evenly distributed across the stream. The spacing between verticals should be closer in those parts of the cross section that have the greater depths and velocities" (Rantz and others, 1982, p. 140)

- If the stream has an established rating, before the measurement, estimate $\mathrm{Q}$ from the rating then shoot for $5 \%$ per subsection as you do your computations during the measurement.

- If the stream has no established rating, make an estimate of the $Q$ by visual estimation of velocity, mean depth and width (utilizing continuity $Q=A * V$, where $A=D^{*} W$ ). Shoot for no more than $5 \%$ of this value in each subsection.

- Common sense is the rule, no 50 subsection measurements just to achieve the under $5 \%$ in each subsection.

- There are times during floods that the aforementioned guidelines on the previous pages are violated.

\section{Rating of the Quality of the Discharge Measurement}

Discharge measurements should be rated to indicated the accuracy based on conditions noted at the time they are made (Excellent, Good, Fair, Poor). The USGS typically considers an Excellent measurement to be within $2 \%$ of the actual discharge ( $2 \%$ error), a Good measurement to be within $5 \%$ of the actual discharge, a Fair Measurement to be within $8 \%$ of the actual discharge, and a Poor Measurement to be greater than $8 \%$ error. Do not consider your performance in the evaluation, unless you are not following the established guidelines. Do NOT base it on "a gut feeling"---carefully note the conditions affecting the accuracy of the measurement.

Measurements should be rated down, accordingly, for the following adverse conditions:

- Significant variation in the interval between "clicks" or revolutions of the current meter cups. This would indicate turbulent flow.

- Significant variation between velocities of adjacent sections

- Abnormal velocity distributions

- Very sluggish velocities

- Poor distribution of observation sections (too much flow in some sections....failure to achieve the goal of no more than $5 \%$ in any section)

- Angular flow

- Poor measuring section:

․ Uneven bottom or other poor section shape

口 Wide overflow

口 Considerable aquatic growth/debris

Some of the potential error sources in conventional discharge measurements:

- Width measurement

- Depth measurement 
- Current meter

- Vertical velocity profile

- Horizontal velocity profile

- Oblique flow

- Computation methodology

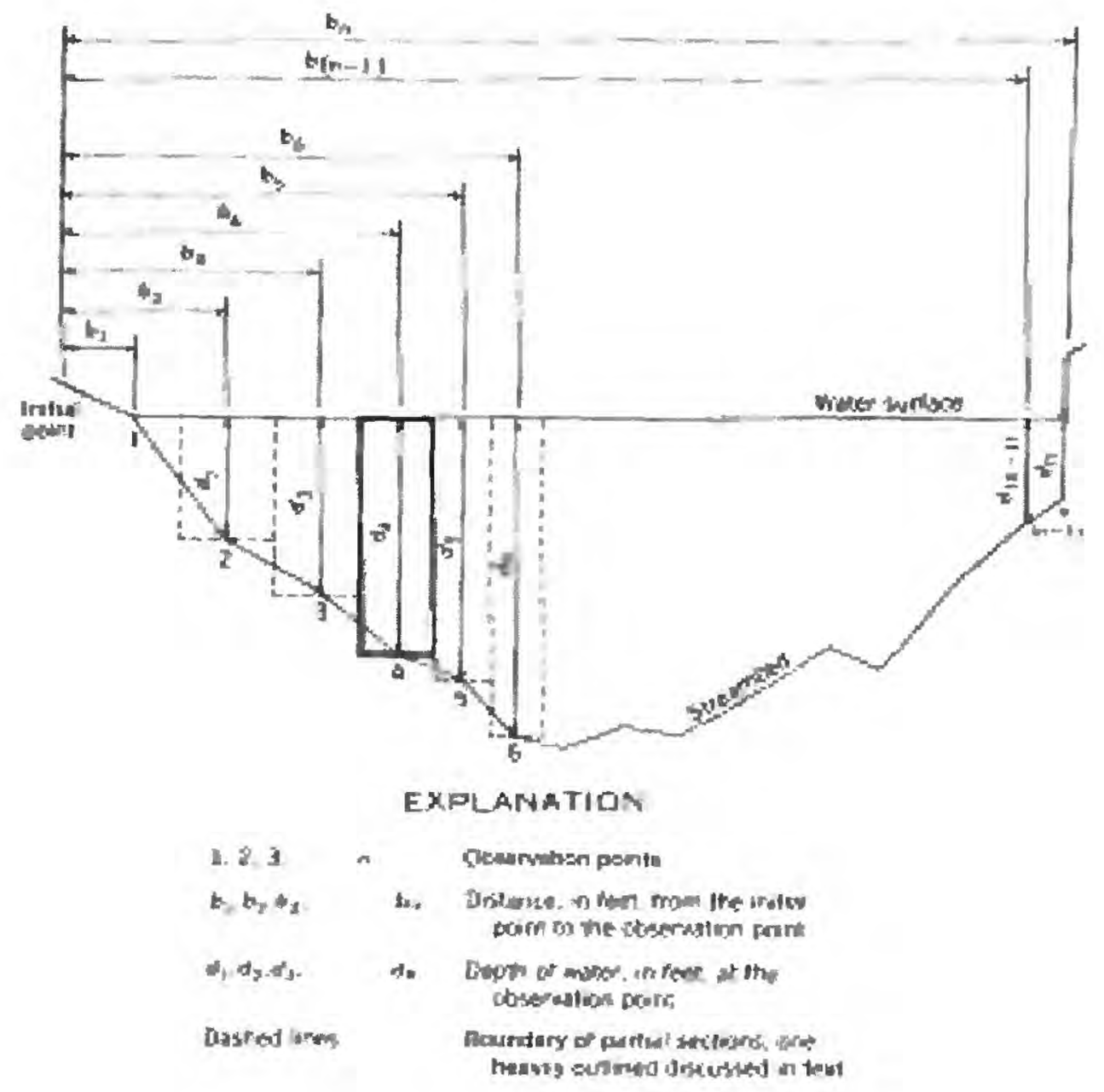

Figure 16.- Schematic showing mid-section discharge measurement method

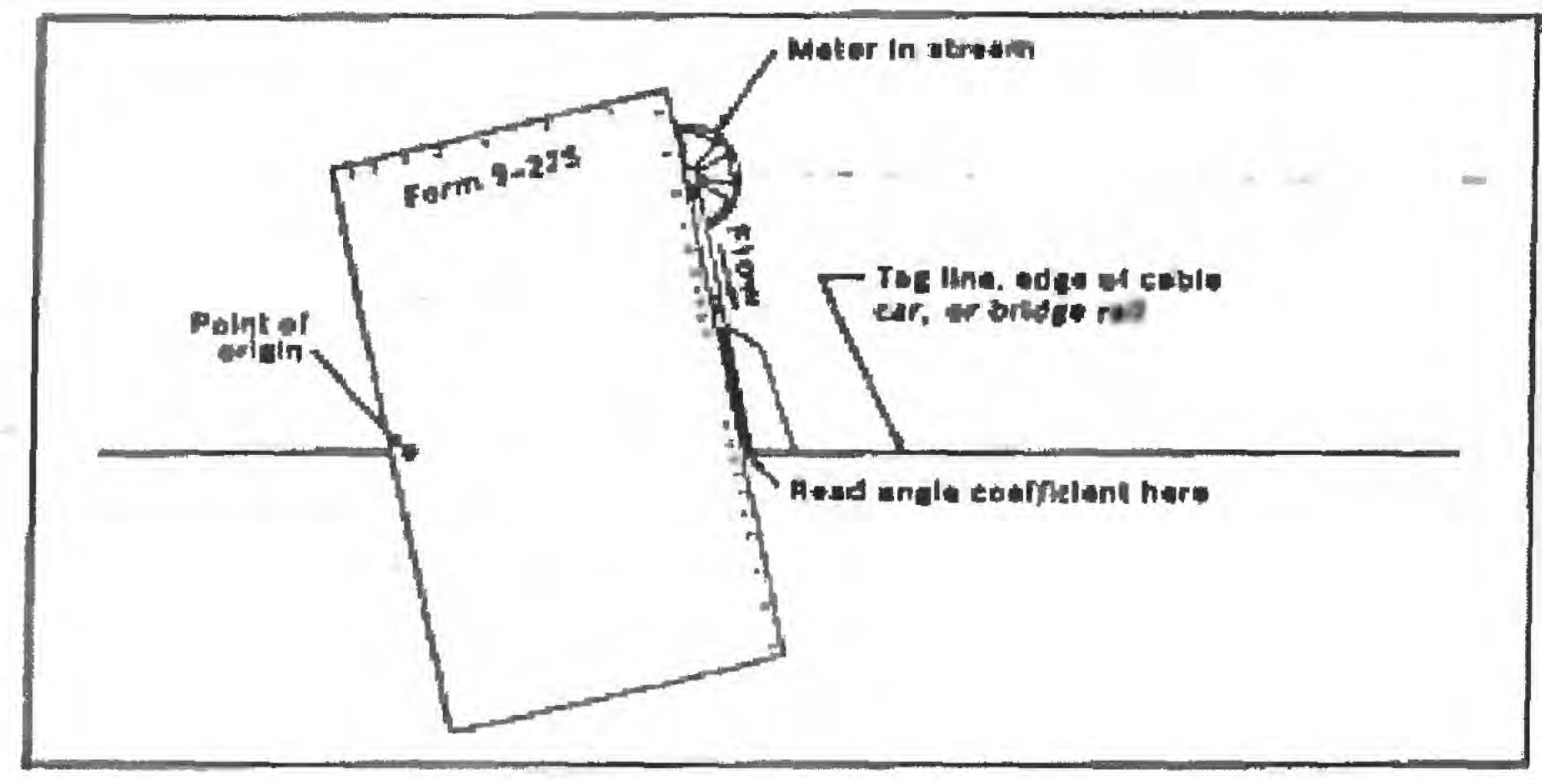

Figure 17.-Measurement of horizontal angle with measurement notes 
Figure 18.-Example of discharge measurement notes
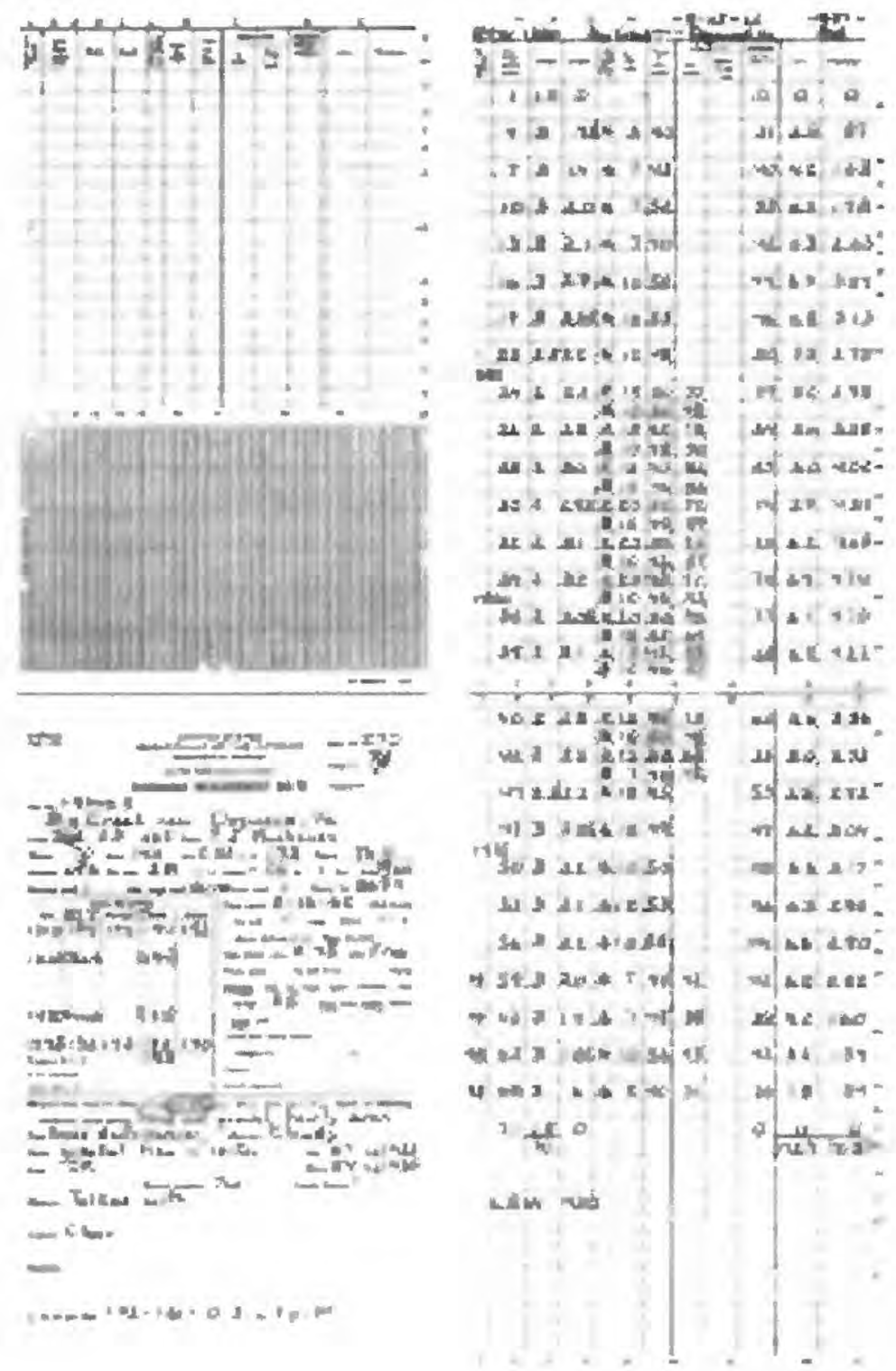

\section{Non-Conventional Discharge Methods}

- ADCP (Acoustic Doppler Current Profiler)-The ADCP is seeing continued growth in applications and utility. The ADCP has been typically used only on larger rivers because of minimum depth limitations of this unit. The new generation ADCP's are lighter and more versatile to shallower environments.

Frequencies and Models (manufactured by RD Instruments) used for data collection

Frequency
$300 \mathrm{kHz}$
$600 \mathrm{kHz}$
$1200 \mathrm{kHz}$
$2400 \mathrm{kHz}$

Frequency

$600 \mathrm{kHz}$

$2400 \mathrm{kHz}$

\section{Models}

Broadband

Workhorse

Rio Grande

- Dye Dilution (Kilpatrick, F.A., and Cobb, E.D.1985) - Injection of a solution of a known tracer concentration into the river flow. By measuring 
the dilution of the concentration of the tracer with distance and time, the discharge can be calculated. There are two methods in common use:

- Slug Injection Method-the tracer concentration is injected instantaneously

- Constant-Rate Injection Method-the tracer concentration is injected at a constant rate for a sufficient period of time to obtain steady state tracer conditions at the sampling site.

- Volumetric-Using a rigid container of known volume, determine the time it takes for the flow to fill the container. The discharge is the volume divided by the time.

-Calibrated Flume (Kilpatrick, F.A., and Schneider, V.R., 1983)

- Portable Sharp Crested Weir Plates-This usually consists of a $90^{\circ}$ $\mathrm{V}$-notch weir that has a free flowing nappe. The stage is measured upstream of the weir, out of the drawdown zone. The stage is the head above the low point of the $\mathrm{V}$-notch. The equation of flow is:

$$
Q=\operatorname{Ch}^{\frac{5}{2}} \text {. }
$$

Where: Q-discharge over the weir

C-coefficient of discharge and is about 2.47 but should be specifically determined for each weir

$\mathrm{h}$-head above the bottom of the V-notch

Any leakage around the sides or the bottom of the weir will result in errors in discharge measurement. With a large weir, flows ranging from 0.02 to 2.0 cubic feet per second are possible. 


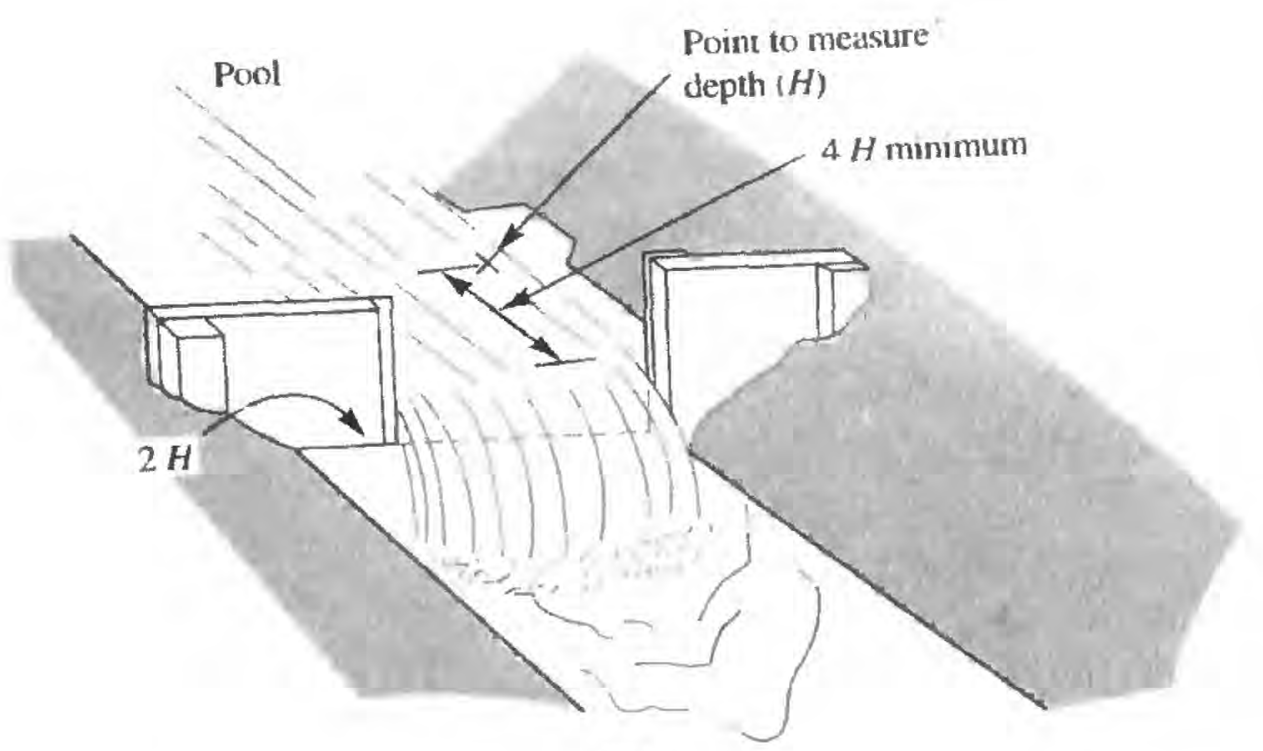

(a)

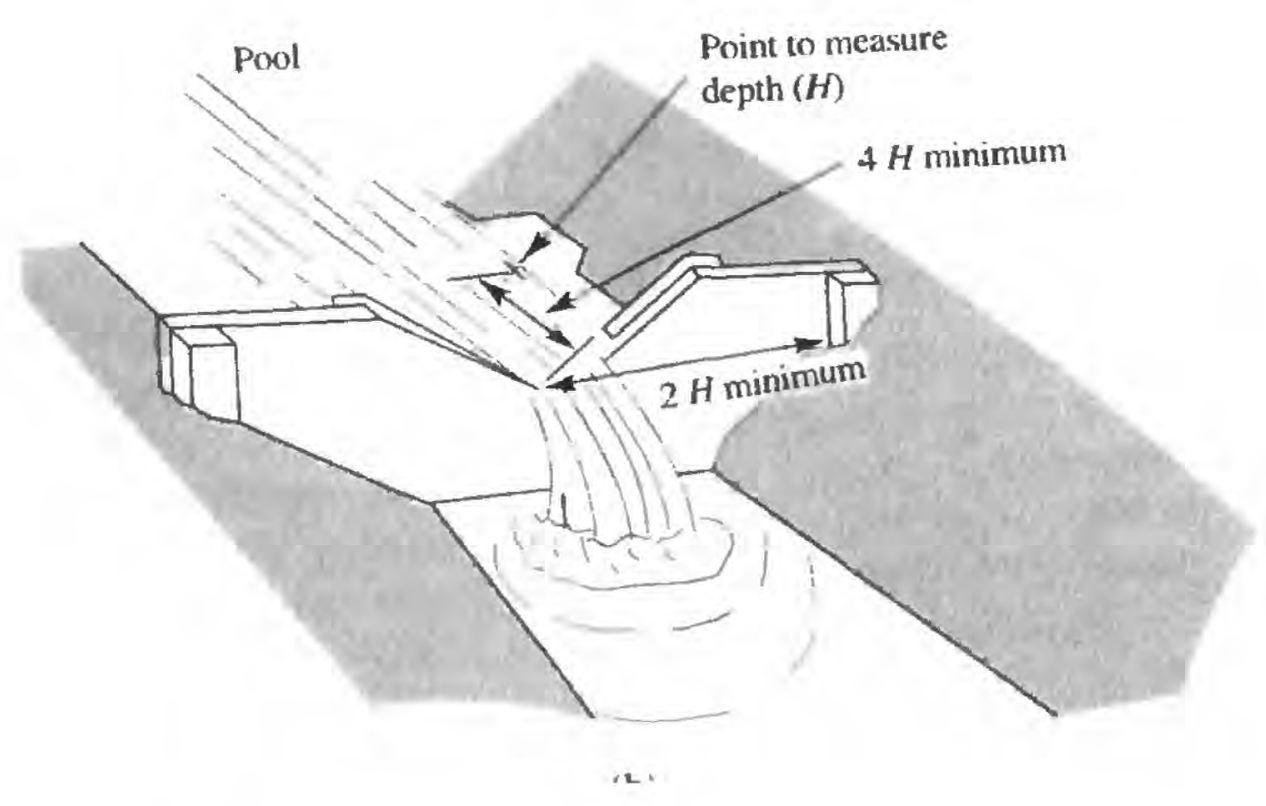

Figure 19. - Example of sharp-crested v-notch and rectangular weirs

- Portable Parshall Flume-This type of flume is good for shallow depths and low velocities. The flume converges down to a throat that has an adverse slope, thus forcing critical depth in this throat section. It is important that the flume be level. (Figure 20) 


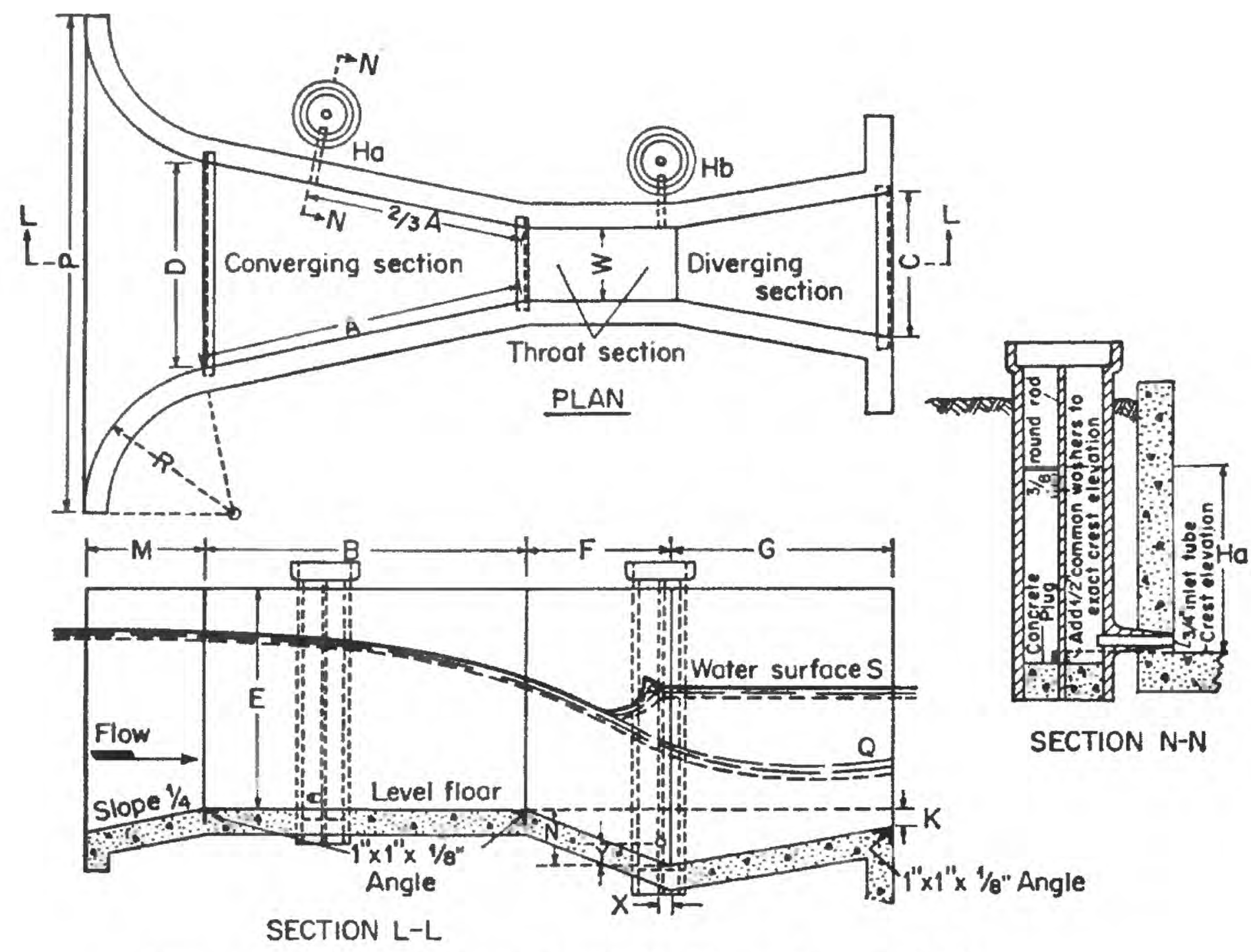

Figure 20-Parshall Flume (modified from Chow, 1959) 


\section{Stage-Discharge Relations (Rating Curves)}

A Rating Curve is used to determine the discharge from an observation of the gage height (stage) of a river or stream. The rating curve is, therefore, the fundamental tool that allows the computation of discharge from a continuous or periodic record of stage. These rating curves are typically derived from both hydraulic theory and actual field measurements of discharge taken at various gage heights.

\section{Controls}

The control is a feature in the stream downstream of the gaging station in subcritical flow, that "controls" what the relation between stage and discharge is. There are two main types of controls: Section Control and Channel Control.

Section control is a specific cross section of a stream channel, located downstream from a gage, that controls the relation between gage height and discharge at the gage. The section control could be a natural feature such as a rock ledge, a sand bar, a severe channel constriction (culvert, bridge opening, etc), or an accumulation of debris. It can also be a man-made feature such as a weir, flume or an overflow spillway. Section controls can frequently be visually identified in the field by observing a riffle, or pronounced drop in water surface, as the flow passes over the control. Section controls usually control low flows, but may sometimes control medium and even high flows. The governing equation for section control takes the form:

$$
\mathrm{Q}=\operatorname{Cbh}^{1.5}
$$

Where $\mathrm{Q}=$ discharge

$$
\begin{aligned}
& \mathrm{C}=\text { coefficient of discharge } \\
& \mathrm{b}=\text { channel width } \\
& \mathrm{h}=\text { stage }
\end{aligned}
$$

Channel control consists of a combination of features throughout a reach downstream from a gage. These features include channel size, shape, curvature, slope and roughness. The length of channel reach that controls a stage-discharge relation varies. For steep streams, the control reach may be relatively short, whereas for mild or flat sloped streams, the control reach may be very long. The precise definition of the length of channel control reach is usually not possible, or necessary. Channel controls usually control the higher magnitude flows. The governing equation for channel control takes the form of the well known Manning Equation:

$$
Q=\frac{1.4986}{n} A R^{\frac{2}{3}} S^{\frac{1}{2}}
$$

Where $\mathrm{Q}=$ discharge 
$\mathrm{n}=$ Manning's roughness coefficient

$\mathrm{A}=$ Cross Sectional Area

$\mathrm{R}=$ Hydraulic Radius $=\mathrm{A} / \mathrm{P}$

$\mathrm{P}=$ Wetted Perimeter

$\mathrm{S}=$ Bed Slope (for uniform flow)

=Friction Slope (for non-uniform flow)

On most streams, control changes from section to channel control as the stage increases. For example, at low flow a gravel riffle may be the control, at medium to high flow the channel may be the control. For a short range in stage between the two dominating controls, the rating curve is governed by a combination of section and channel control. This part of the rating is commonly referred to as the transition zone of the rating, and represents the change from section control to channel control. In other instances, a combination control may consist of two section controls, where each has partial controlling effects. Figure 21 shows a gravel riffle control downstream of a gaging station. Figure 22 shows a gage house upstream of a concrete broad-crested weir. Chow (1959, pp 70-74) and Henderson (1966, pp 40-43, 116-119) discuss controls on flow.
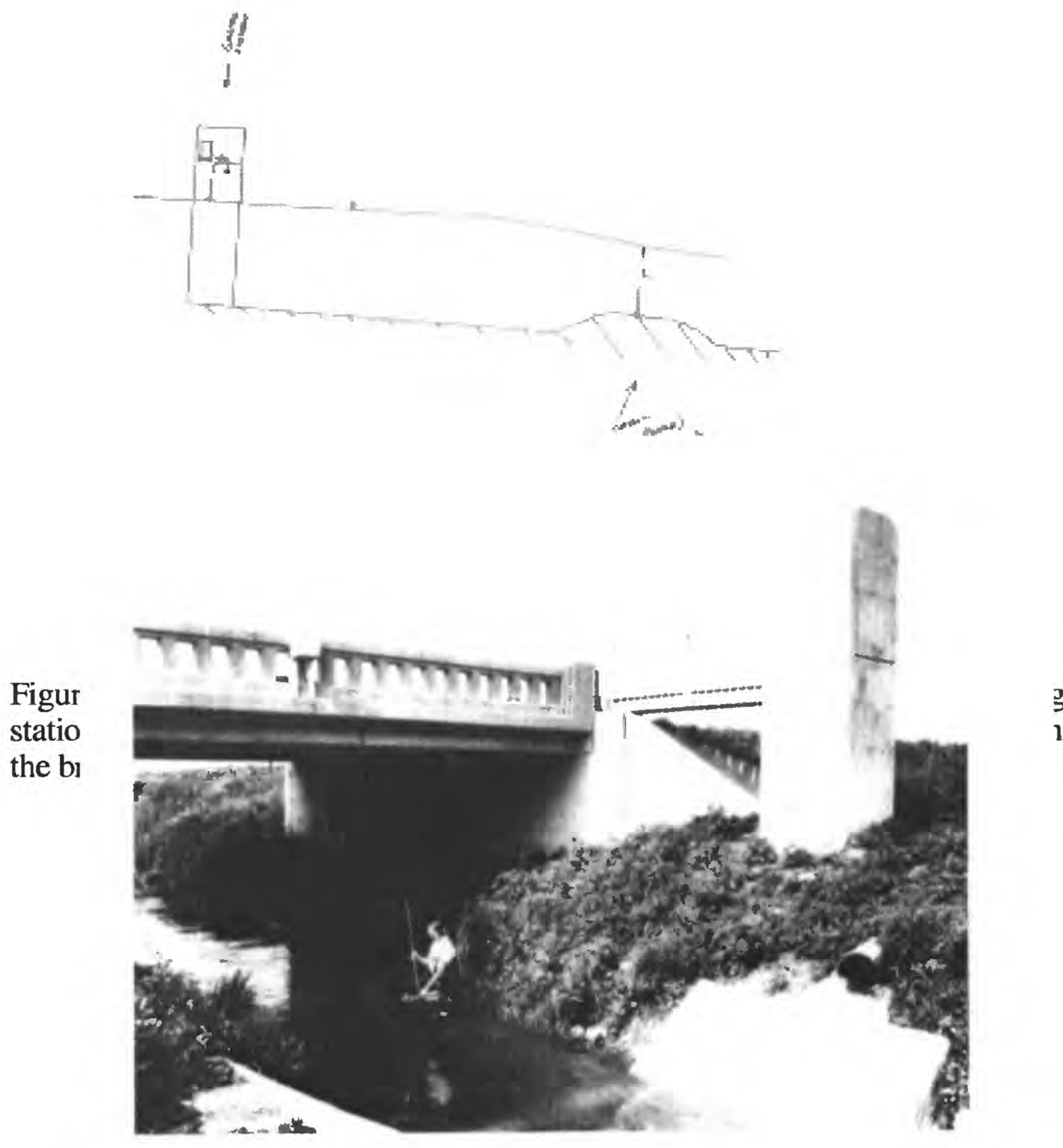


\section{Rating Curve Theory}

As has been discussed in the preceding discussion, stage-discharge ratings are based on basic hydraulic principles. Most ratings however are developed empirically by plotting several discharge measurements versus stage for a variety of stages. Once enough measurements are plotted, a curve fit to the data typically takes on the form of a power function that looks like:

$$
\mathrm{Q}=\mathrm{p}(\mathrm{h}-\mathrm{e})^{\mathrm{b}}
$$

Where $p=$ constant which is numerically equal to the discharge when the $(h-e)=1.0$

$\mathrm{h}=$ gage height

$\mathrm{e}=$ gage height of zero flow(also called the point of zero flow(PZF)) for a section control of regular shape, or the gage height of effective zero flow for a channel control or a section control of irregular shape $\mathrm{b}=$ slope of the rating curve

Note: (h-e) is the head or depth of water on the control.

The effective gage height of zero flow (e) is a value that, when subtracted from the mean gage height of the discharge measurements, will cause the logarithmic rating curve to plot as a straight line. This value (e) is also called the scale offset. For regular shaped section controls, the effective gage height of zero flow will be nearly the same as the actual gage height of zero flow. For irregular shaped section controls, the effective gage height of zero flow is greater than the actual gage height of zero flow. For those parts of the rating curve where the control changes from one section to another (or to channel control), the effective gage height of zero flow will usually change also. This results in the need to analyze the rating curves in segments (separate log-log plots for each control condition).

The ratings are typically plotted in log-log space the medium to high flow and on arithmetic coordinate space for low flow. Log-log space for medium to high flow is used because it makes a power function into a straight line of the form:

$$
\log Q=\log p+b \log (h-e)
$$

which is the equation for a straight line (figure 23). 


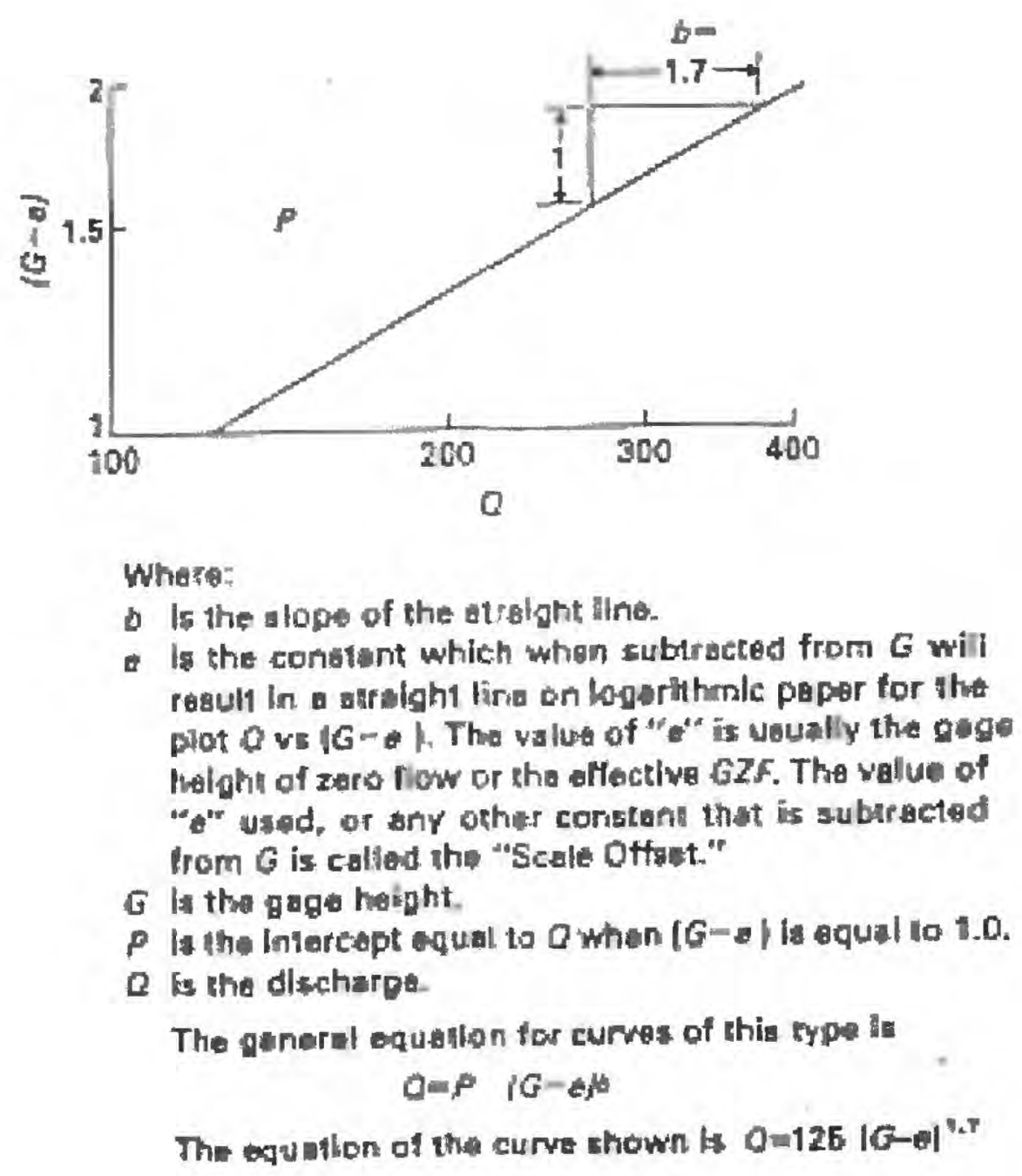

Figure 23.-Example of a stage-discharge rating which is linear in log space

If the scale offset is chosen properly, then the measurements plotted in log-log space will be approximately linear. To utilize the scale offset on log paper, the value of the offset is added to each of the regular values on the gage height axis. Figure 24 demonstrates how this is done for a scale offset of 1.0. The 1.0 location on the log scale now becomes 2.0 , the 2.0 now becomes 3.0, the 10.0 values now becomes 11.0 , etc. The offset is adjusted until the curve is as linear as possible. This allows the engineer to adjust the rating curve with fewer discharge measurements. 


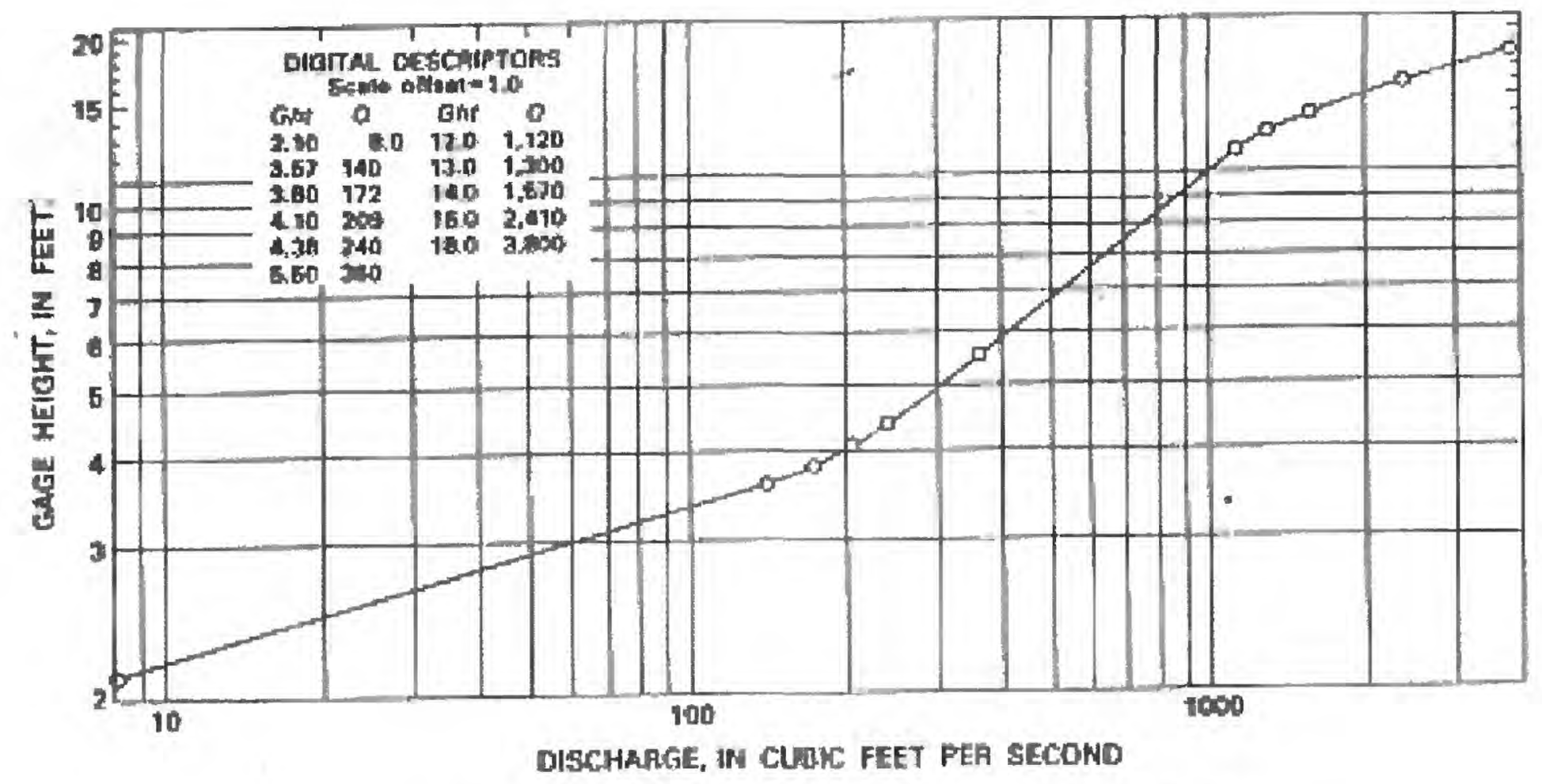

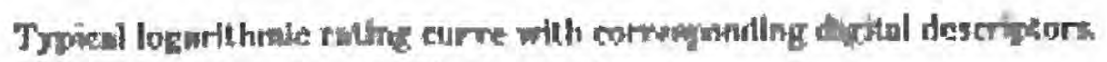

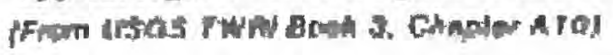

Figure 24.-Stage-discharge relation using a scale offset of 1.0

For the low flow, the rating is plotted in arithmetic coordinates, because zero discharge cannot be plotted in log-log space. Knowing the point of zero flow (the measurement of which was discussed in an earlier section of these notes), helps to draw the low flow rating curve in arithmetic coordinates.

Figures 25 shows how the rating curves should be shaped with various control situations. For section controls, the slope (measured in this case as the run over the rise instead of the typical rise over run) will almost always be greater than 2 . For channel controls, the slope will usually be between 1.5 and 2.0 .

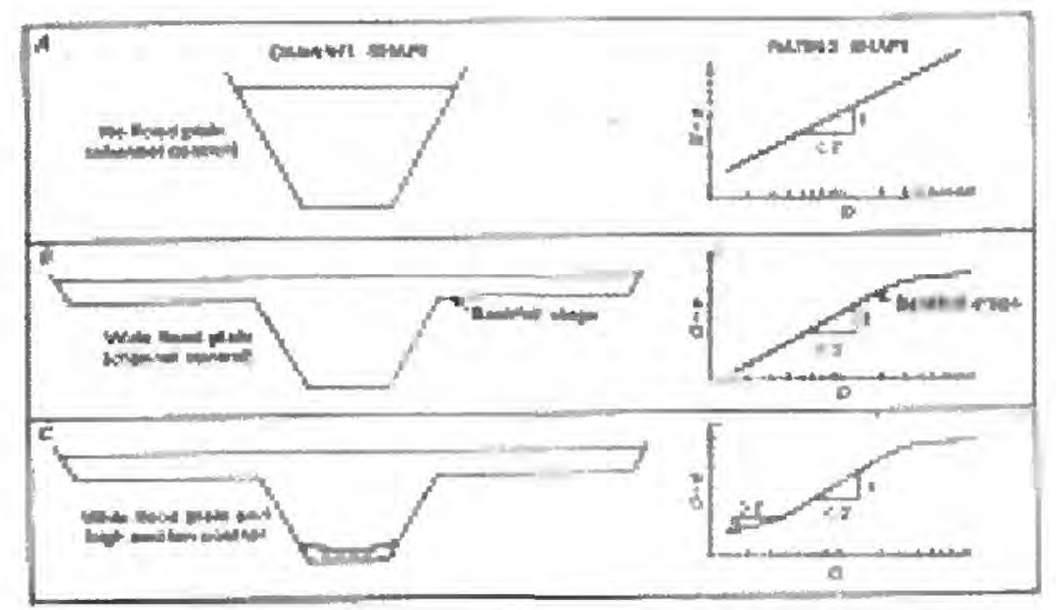

Figure 25.-Relation of rating curve shape to cross section properties

\section{Steps In Developing a Rating Curve}

1. Gather all available discharge measurements. Also, gather any old rating curves for the stream that may be available. These can help determine shape of the rating curve.

2. Obtain all pertinent measurements of "Point of Zero Flow" (PZF). 
3. Draw the low flow portion of the rating on arithmetic coordinates, tying the curve into zero discharge at the $\mathrm{PZF}$.

4. For the medium and high flows, select the log scales so that the entire range of stage and discharge is included.

5. Separate scales, or plots, may be needed for high and low parts of the rating.

6. Discharge scale should always be the abscissa, and the gage height scale should always be the ordinate.

7. Determine the offset for the gage height scale (the discharge will always use a normal log scale (scale offset $=0$ ))

- Generally the scale offset will be near the PZF

- Formula for determining Offset by Johnson's method, see figure 26

- The best scale offset is one that produces a log-log rating that is a straight line in the range of most frequent use. For the lower flow end of the log-log rating, the PZF works fairly well as the scale offset.

- Figure 27 shows the impact of various scale offsets on a rating curve shape

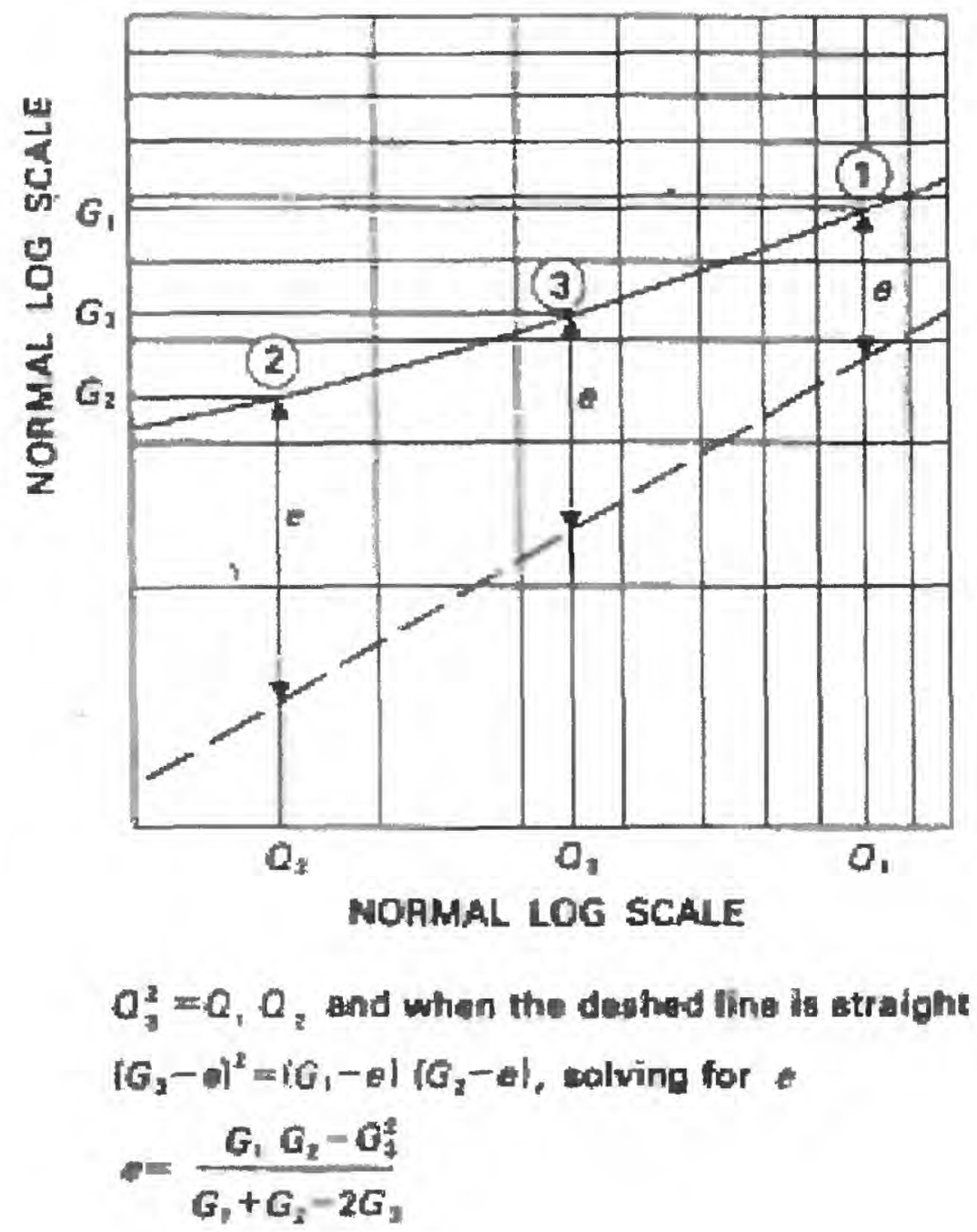

Figure 26.-Determination of scale offset by Johnson's method 


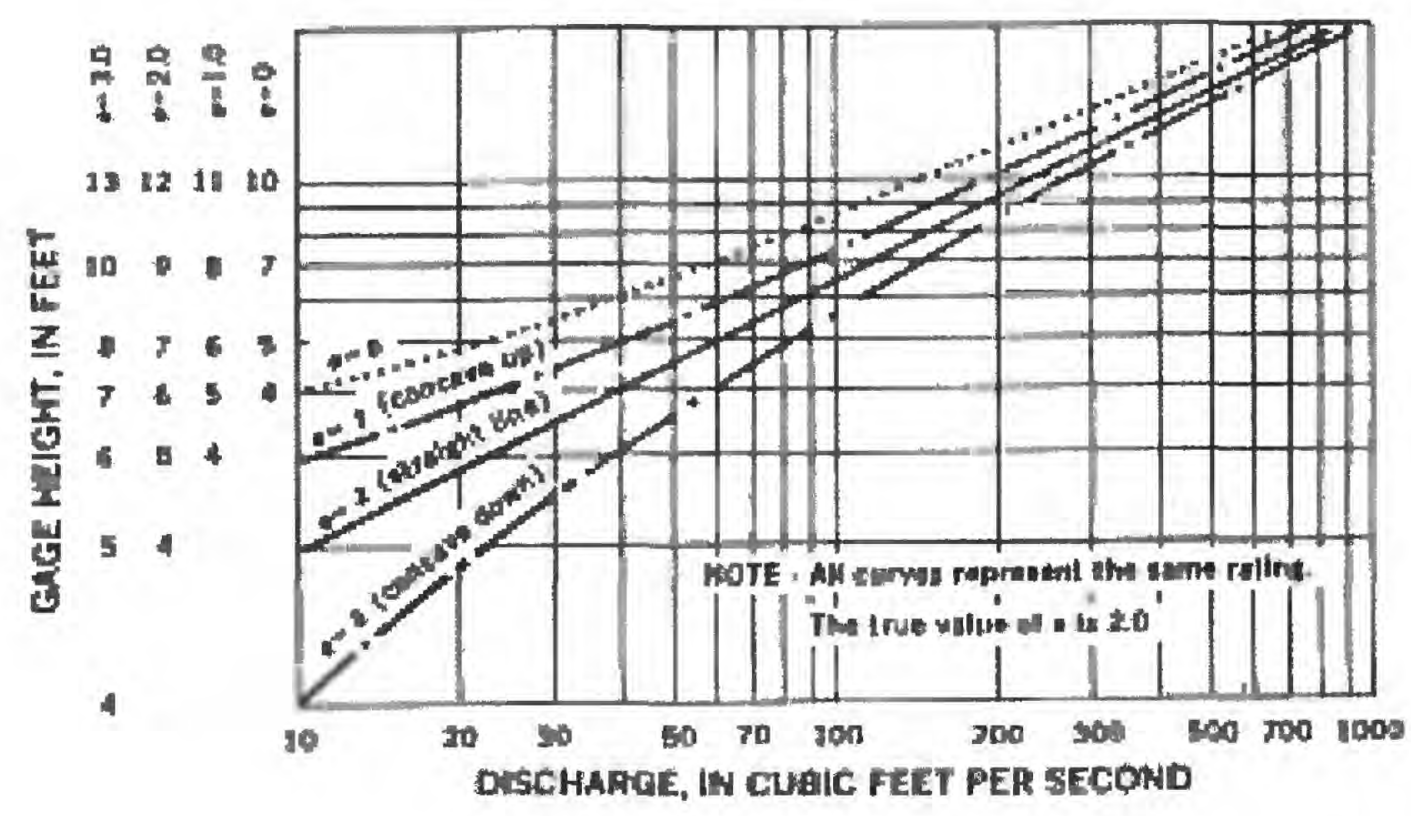

Figure 27.-Rating curve shapes resulting from various scale offsets

8. Plot the applicable measurements

- Those that define the stable control

- All those greater than a certain discharge

- Lowest measurement or two

- PZF measurement

9. If old rating curve existed for this site, draw the old rating as a dashed line

10. Draw new rating curve based on:

- Control characteristics

- Measurement accuracy

- Measurement Date

- PZF

11. Have curve reviewed and measurement plotting accuracy checked

12. Generate a table from the graphical rating curve

- Pick points from curve to be used for computation of expanded rating table (USGS has a data base/analysis package called ADAPS that does this)

- Check the expanded rating table against the rating curve

13. Document the rating

- List all measurements, along with the dates made, to determine the rating curve

Kennedy (1984) contains much more details regarding stage-discharge rating curves.

\section{Complex Ratings}

The preceding discussion only involved simple stage-discharge ratings. There are other types of ratings, including loop ratings, slope ratings, and velocity-index ratings. A complex rating is one where the water-surface profile is variable, therefore, no simple relation exists between stage and discharge. Complex ratings often require more discharge measurements than simple ratings to define the rating. 


\section{Loop Rating}

A loop rating is a rating where the the for the same stage, more discharge occurs on the rising limb than on the falling limb of a flood event hydrograph. This has a couple of possible causes. The most understandable is that the energy slope is greater on the rising limb of the hydrograph than on the falling limb. Recall that in the Manning Equation, discharge is proportional to the energy slope. Figure 28 is an example of a loop rating.
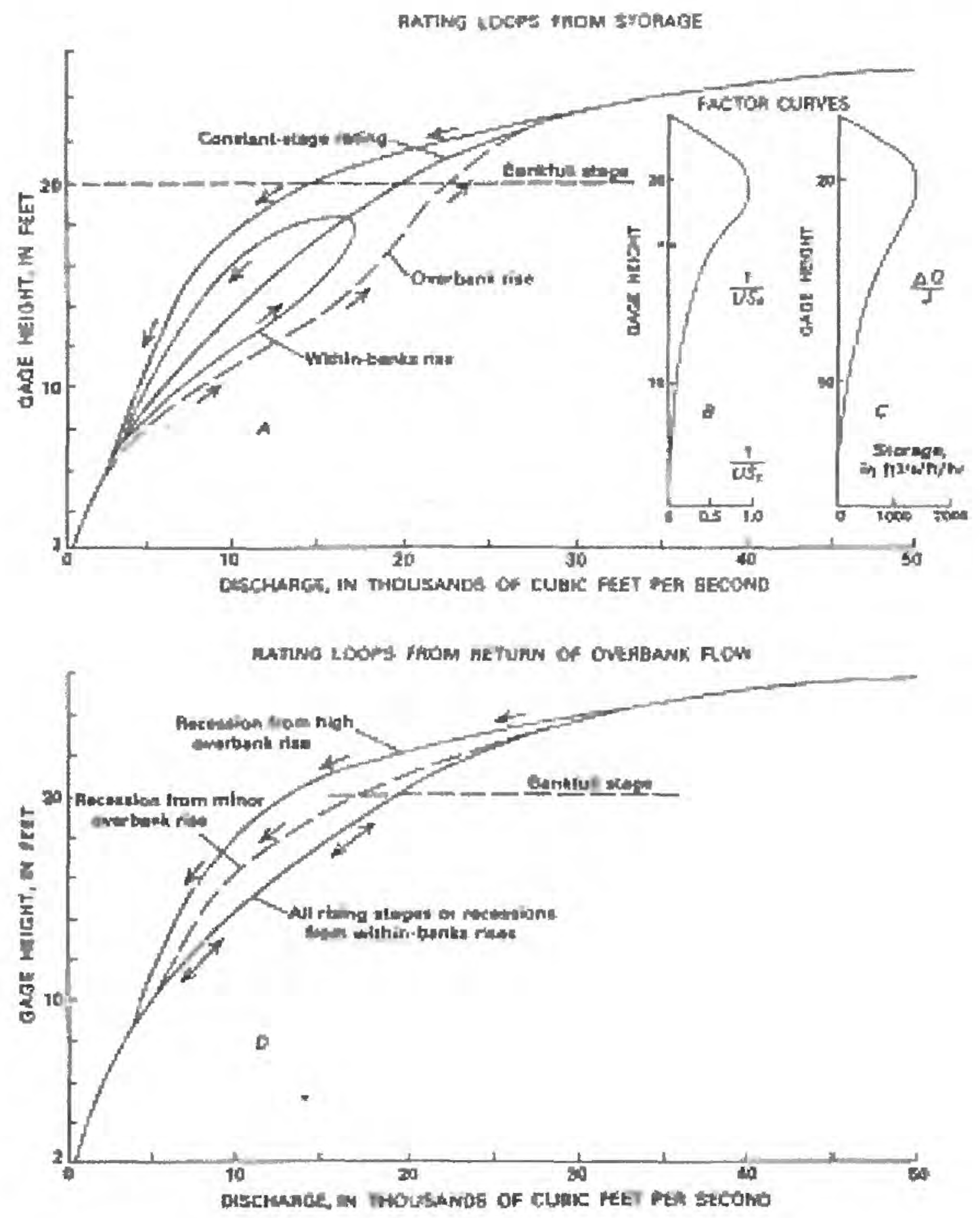

Figure 28.-Typical shapes of single-storm loop ratings and factor curves

\section{Slope Rating}

Slope ratings occur on streams affected by variable backwater or on flat gradient streams that are subject to backwater from tributaries or return of overbank flow. Two gages in the 
reach of interest are needed to define slope. The discharge is dependent on two independent variables, stage and the slope of the water surface.

\section{Velocity Index Rating}

Generally used where variable backwater exists and the water surface is to flat to develop a slope rating. Also used where reverse flow exists. Basically this is the method used for the AVM that was discussed previously. The AVM is used to monitor continuous discharge at sites where conventional stage-discharge ratings are not possible. A relation is developed between the line velocity and the mean streamflow velocity by making several discharge measurements, calculating the mean velocity of the measurement, and relating this to the line velocity collected by the AVM during the measurement of discharge. In addition to the line velocity/mean streamflow velocity relation, a relation between stage and cross sectional area must also be developed. After these relations are developed, as the AVM collects line velocities and stage, the discharge can be determined by multiplying the mean velocity (determined from the relation between line velocity and mean velocity) and the area (determined from the relation between stage and area of the channel cross section). 


\section{Computation of Discharge}

Once a rating curve is established, the rating curve is applied to the time series of gage height record to determine the time series of discharge. However, this is not always straightforward in the field situations because of control shifts throughout the year. For example, a rating has been established for a particular stream that has a concrete weir. In mid winter, a beaver colony built a dam on top of the weir to back water up a little higher, but a spring flood washed the dam out. The beaver dam affected the stage-discharge relation for the period when the dam was intact. However, since the dam was washed out during the spring, instead of drawing a new rating for the period when the beaver dam was present, we determine a temporary shift to the rating curve to compute the discharge during this period.

\section{Shifts}

Some of the natural events that may cause shifts in the rating curve to occur:

- Scouring of channel bottom

- Deposition of sediment

- Drift lodging on control

- Sloughing of banks

- Aquatic growth

- Flood-plain encroachment

- Beaver dams

- Ice

Figure 29 shows graphically how a shift is determined for a measurement.

Assume that measurement 19 had a stage of $500 \mathrm{ft}^{3} / \mathrm{sec}$ for a gage height of $4.75 \mathrm{ft}$. Assume that the rating in figure 29 , for a gage height of $4.75 \mathrm{ft}$, the rating discharge was supposed to be $550 \mathrm{ft}^{3} / \mathrm{sec}$. Using these values the percent difference would be $-10 \%$ (see figure 29 for formula). The percent difference is a useful measure to assess the validity of both the measurement and the rating curve. If a measurement is made, the engineer rates the measurement good, one would expect that if the rating is still good, the percent difference would be no more than $5 \%$. If a measurement is made and has a percent difference of $8 \%$, then the engineer would want to consider making a check measurement to make sure no errors were made in the measurement. 


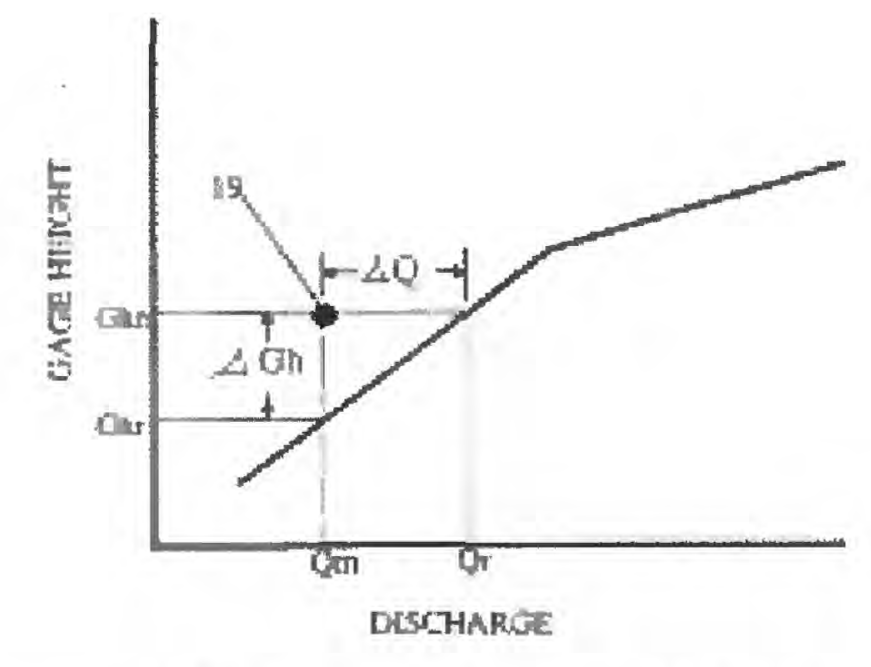

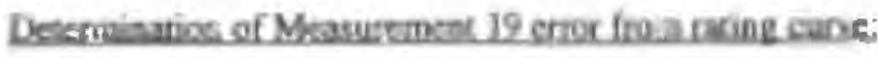

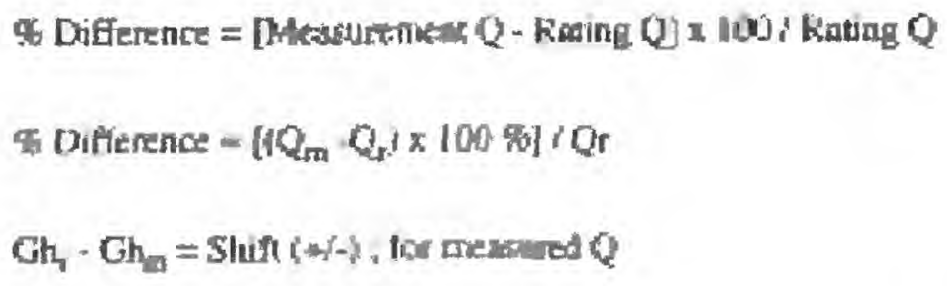

Figure 29.-Example of shift determination for a discharge measurement

For the same measurement, assume that for a discharge of $500 \mathrm{ft}^{3} / \mathrm{sec}$, the gage height according to the rating curve should have been $4.50 \mathrm{ft}$. The computed shift would then be $-0.25 \mathrm{ft}$. This would mean that for the period of time that this measurement was made, for all the stage collected on the data logger, the engineer would need to subtract $0.25 \mathrm{ft}$ from the stage before applying the rating curve to the stage to get the discharge.

To apply shifts when working records, shift curves are developed. These curves are then applied by stage at various times of the year to the stage data before applying the rating curve to determine the discharge. Figure 30 illustrates a shift curve at the top and how it effects the rating curve at the bottom. Kennedy (1983) contains a complete discussion of discharge records computation. Figure 31 is a schematic of the process followed to compute records of discharge by the USGS. 

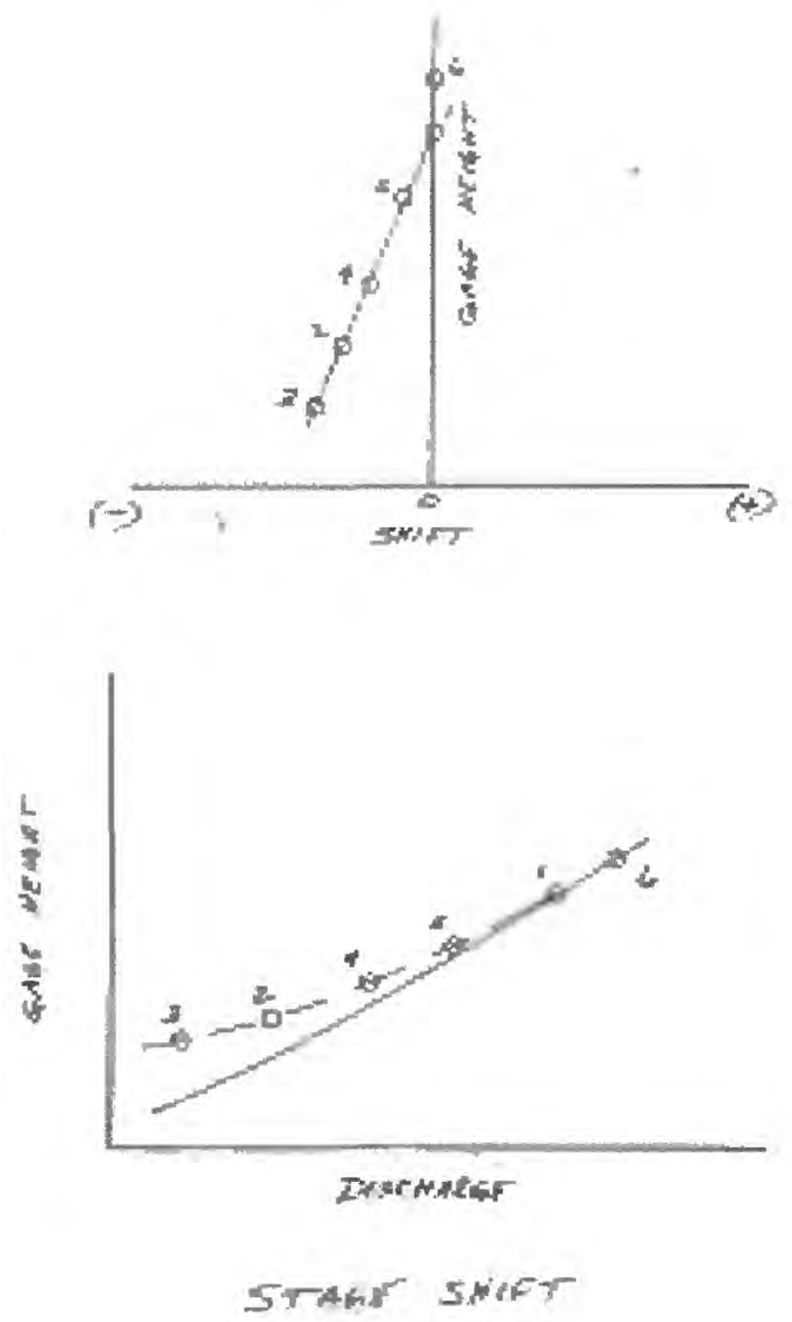

Figure 30.-Example of a shift curve

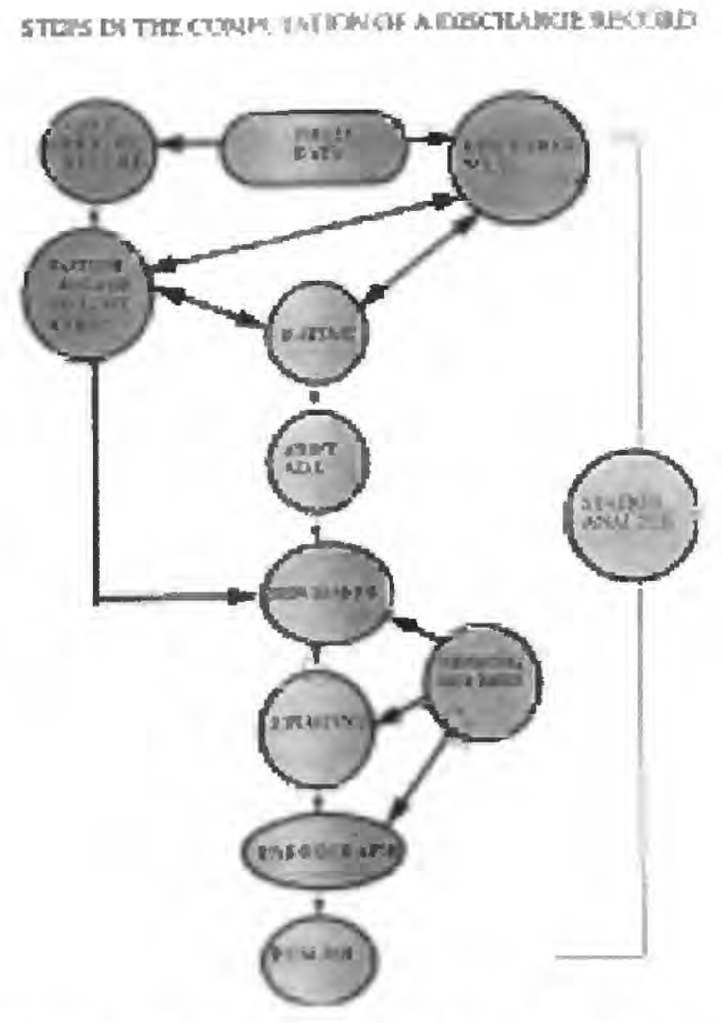

Figure 31.-Steps in the computation of a discharge record 


\section{Sediment Transport}

It is important to know the nature and magnitude of sediment transport in streams and rivers for a number of reasons:

- Water Quality Assessment

- Biological Assessment of the impact on wildlife

- Reservoir Design

- Channel Stability

- Bridge Design

Fluvial sediment moves in two modes:

- Suspended-Sediment Load-That part of the sediment load which is carried in suspension in the water column

- Bed-load-That sediment which is carried in contact with the bed by skipping, sliding, and rolling

The sediment load past a point can also be categorized by the source material that the sediment stems from:

- Bed-material Load---That part of the total stream sediment load which is comprised of particle sizes found in appreciable quantities in the bed material of the stream.

- Wash Load---The part of the total stream sediment load comprised of particles which are found only in small quantities in the bed material of the stream. Typically usually finer than $0.062 \mathrm{~mm}$ (less than sand size).

Various sizes of sediment are characterized by the USGS as follows:

- Clay sized particles--<0.004 mm

- Silt sized particles-ranges from $.004 \mathrm{~mm}$ to $.062 \mathrm{~mm}$

- Sand sized particles---ranges from $.062 \mathrm{~mm}$ to $2 \mathrm{~mm}$

- Gravel sized particles-2 $\mathrm{mm}$ to $64 \mathrm{~mm}$

It is beyond the scope of this course to discuss in much detail the mechanics behind sediment transport. Some useful references to further investigate this phenomena are:

Graf, W.H., 1971, Hydraulics of Sediment Transport, McGraw-Hill, New York, 513p.

Vanoni, V.A., 1975, Sedimentation Engineering, ASCE Manual and Report on Engineering Practice Number 54, New York, 745 p.

Yalin, M.S., 1977, Mechanics of Sediment Transport, Pergamon Press, New York, 298 p. 


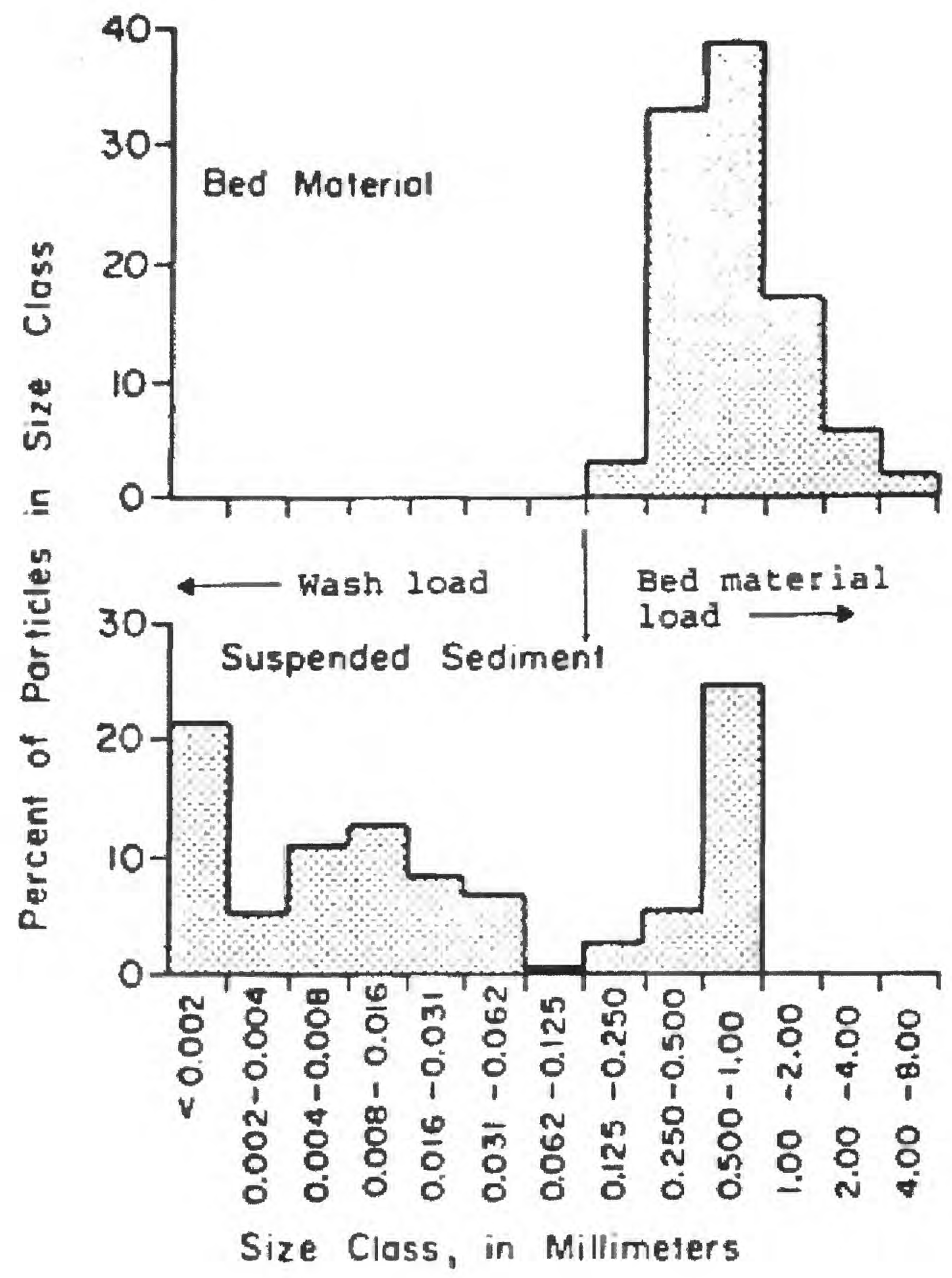

Figure 32.-Size distribution of suspended sediment and bed material showing distinction between wash load and bed material load 


\section{Sampling Theory}

To determine the amount of a constituent (sediment in this case) being transported downstream, the best method for doing this would be to capture the entire flow for a period for a discrete segment of time and analyse the entire sample for the concentration of the sediment. Obviously, this is impossible for all but the smallest of streams. Therefore, a sampling procedure and methodology must be designed whereby the samples are collected that are representative of the sediment concentration of the entire stream.

Stepping back a moment, consider if the problem was to determine the mean age of everyone in a particular classroom. This could be done in one of two ways.

1. Conduct a survey to determine everyone's age and compute the "true" mean age from the entire population.

2. Obtain a small "representative" sample of the population, compute the average age of the sample and assign that age to the whole population. This would obviously have some error, unless we got real lucky.

The question becomes, how do we obtain a representative sample? There are two broad classes of sampling to choose from:

1. Random Sampling-allows data analysis using generally accepted standard statistical techniques for defining data characteristics and errors (i.e., mean, median, standard deviation, modality, standard error, etc.)

2. Non-Random or Systematic Sampling-this requires some prior knowledge about the population

For the classroom age problem, no special knowledge of the population was available, therefore a random sampling of the population (classroom) would be conducted, the ages determined, an average of that sample set computed, and the assumption that the sample average equaled the population average.

For the problem of determining the average concentration of suspended sediment in stream cross-section, a systematic sampling procedure is desirable because some characteristics of the suspended sediment in streams are know.

1. Suspended sediment moves with the flow.

2. Suspended sediment moves faster in areas of the stream having higher velocities than in areas of the stream having lower velocities.

3. If the stream carries a load of suspended sand, distribution of that concentration may be very non-uniform, both laterally and with depth. Generally, higher concentrations are found nearest the streambed and in parts of the cross section having higher velocity (although often the variations are also very supply dependent).

- Slower velocities of sediment movement at the bottom 
- Higher concentration of sediment at the bottom

- Sediment particles should be coarser near the bed and fine upward

- Laterally across the stream, the suspended sediment may be coarser in the areas of higher velocity

4. If the stream carries a load of suspended silt and clay, distribution of its concentration within the cross section is expected to be more uniform both laterally and with depth.

5. A stream transporting a mixture of both fine (silt-clay) and coarse (sand) suspended sediment, will exhibit variations in concentration showing both characteristics mentioned in 3 and 4.

6. In looking at 1-5 above, one can see that although the sediment moves with the flow, relations governing the transport of sediment are very complex.

From the characteristics above, the design of sampling schemes for suspended-sediment revolves around weighting the samples either by velocity or by discharge, because flow influences the distribution of the sediment in suspension. The methods for obtaining a representative average suspended-sediment concentration will be discussed later in these course notes under Suspended-Sediment Sampling Methods. 


\section{Sediment Samplers}

Sediment samplers were standardized through the efforts of several Federal Agencies starting in 1939. Before this standardization effort, each fluvial sediment investigator and agency developed samplers and methods as needed (Edwards and Glysson, 1988). The standardization effort helped move the science of sedimentation into allowing more consistent data for comparison between agencies and projects. In 1956, the group of agencies is now called the Federal Interagency Sedimentation Project (F.I.S.P).

The samplers developed by the F.I.S.P. are designated by the following codes:

- US-United States standard sampler-In these lecture notes, this is typically dropped from the designation of the sampler

- D-Depth Integrating

- P-Point Integrating

- H-Hand held by rod or line (this code is placed after the primary letter designation and is omitted when referring to cable- and reel-suspended samlpers)

- BM-Bed Material Sampler

- Year-last two digits of the year in which the sampler was developed

There are many samplers available from the F.I.S.P. and the Hydrologic Instrumentation Facility of the USGS.

\section{Suspended-Sediment Samplers}

As was noted in the discussion on velocity distribution in the vertical and shown on figure 14 , the magnitude of water velocity decreases as the bed of the channel is approached. The reverse is true for the suspended-sediment concentration, the suspended-sediment concentration increases (especially for sand-sized and greater particles) as the bed is approached (figure 33).

As should be noted, the coarser the sediment, the more marked this increase in concentration as the bed is approached (figure 33). The clay and silt sized particles have a concentration distribution that is more uniform because these particles stay in suspension longer and are typically being "washed" through the system, hence the term wash load. 

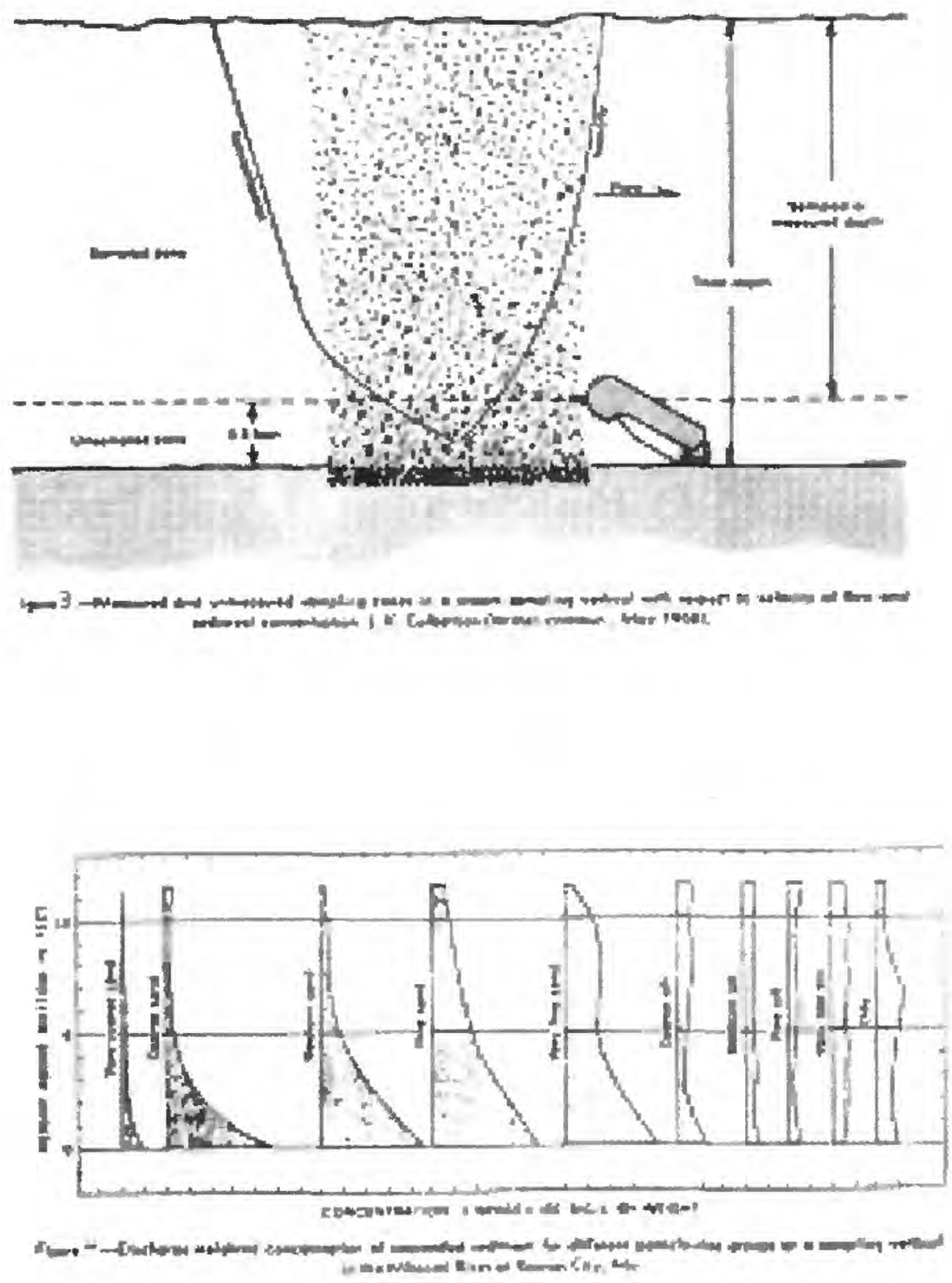

Figure 33.-Distribution of the velocity and the suspended-sediment concentration (top diagram). Distribution of various particle sizes through the water column for the Missouri River at Kansas City, MO (bottom diagram)

A Suspended-sediment sampler primarily consist of a weighted hydrodynamic apparatus constructed in such a way to allow a sample container to collect a representative sample throughout the water column. The sample is weighted according to velocity. A nozzle 
serves as the conduit to allow the water into the sampler container. For many of the samplers, multiple size nozzles are available to interchange dependent on sampling conditions. According to Edwards and Glysson $(1988$, p 6), "the purpose of a suspendedsediment sampler is to obtain a representative sample of the water-sediment mixture moving in the stream in the vicinity of the sampler." To fulfill this goal, the F.I.S.P. set up the following criteria:

1. Allow the water to enter the nozzle isokinetically, ie the water entering the nozzle undergoes no change in velocity from that of the stream velocity (Figure 34)

2. Permit the sampler nozzle to reach a point as near to the streambed as possible

3. Minimize the sampler disturbance to the flow field in the stream.

4. Adapt the samplers to existing streamgaging equipment

5. Simplicity and maintenance free.

6. Accommodate a standard bottle (glass pint, glass quart, etc)

A submerged sampler has the nozzle pointed directly into the flow, thus water enters the nozzle and fills the bottle, with air exhausting out of the bottle by way of a separate exhaust hole. The "rules" of sampling have been set so as to ensure that the samplers perform as intended. Ensuring that the sampler is collecting an isokinetic sample is very important, especially when sand-sized sediments are entrained in the flow and are being sampled. If the velocity in the nozzle is faster than the ambient stream velocity near the sampler, the concentration of the suspended sediment will be lower than that of the ambient stream suspended-sediment concentration. Vice versa, if the velocity in the nozzle is lower than the ambient stream velocity, the concentration of suspended sediment will be lower than the ambient concentration of the stream.
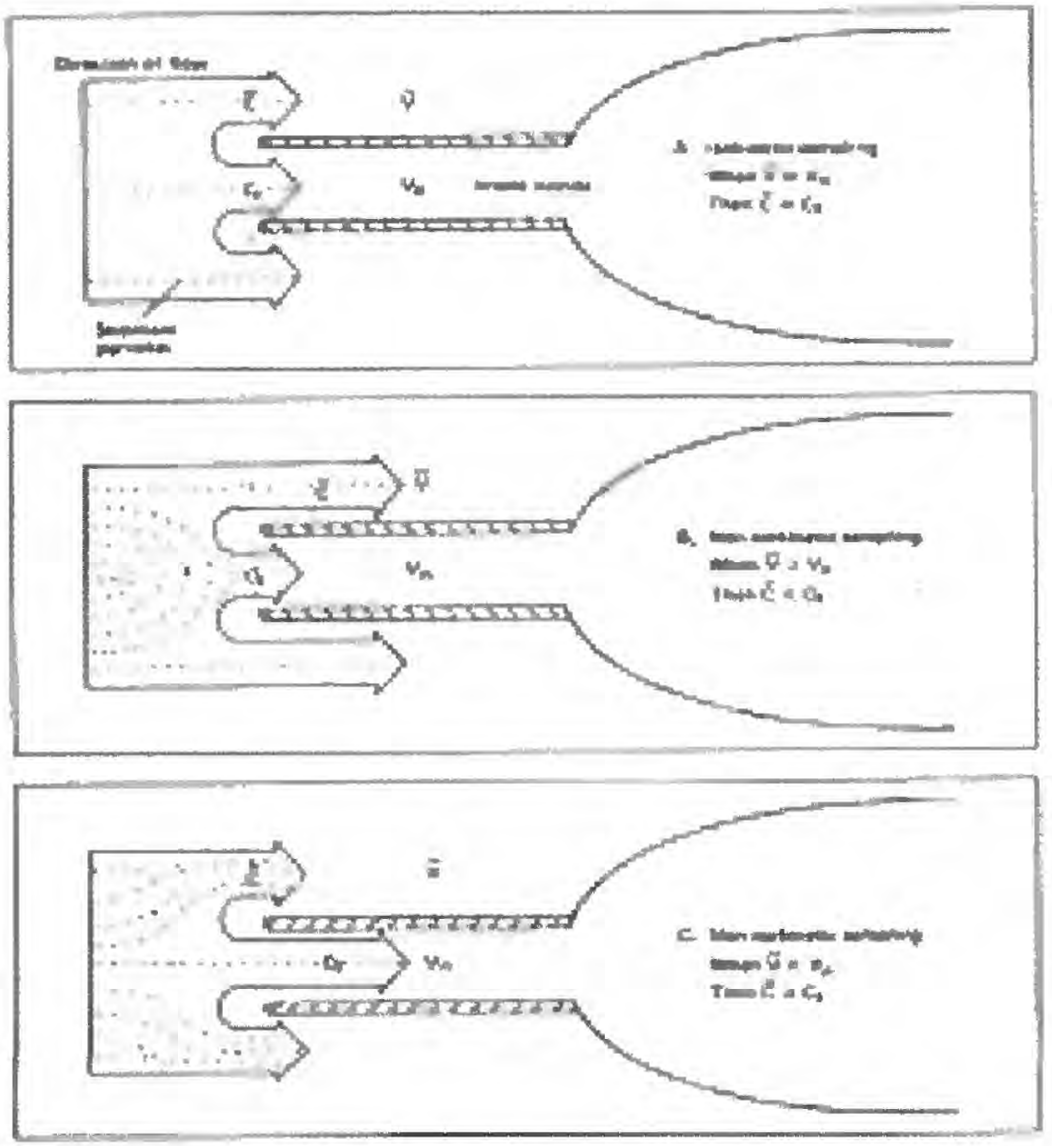

Figure 34.-Relation between intake velocity and sample concentration for isokinetic and non-isokinetic sample collection 
The sample obtained by passing the sampler throughout the full depth of a stream is quantitatively weighted according to the velocity through which it passes. Therefore, if the sampling vertical represents a specific width of flow, the sample is considered to be discharge-weighted because, with a uniform transit rate, suspended sediment carried by the discharge throughout the sampled vertical is given equal time to enter the sampler. As will be emphasized later, because of this weighting by discharge (velocity) it is very important to keep the transit rate constant throughout at least a single direction of travel (ie, the descending or the ascending).

There are two types of suspended-sediment samplers: depth-integrating samplers and point-integrating samplers. The depth-integrating sampler is designed to isokinetically and continuously accumulate a representative sample from the stream vertical while transiting the stream at a uniform rate. The depth-integrating sampler collects a velocity weighted sample as it is lowered and raised, because the faster the water is moving, the more water will enter at that point in the vertical. The sampler is lowered to the bed and raised back to the surface, at a rate that is slow enough to allow an isokinetic sampler and fast enough that the bottle does not overfill. Overfilling of the sample bottle causes errors in the determination of the suspended-sediment concentration.

In all of the suspended-sediment samplers, there is a 3 inch unsampled zone at the bottom of the stream because of the design of the sampler (figure 33). Some of the available depthintegrating samplers are:

- DH-48 - handheld wading sampler, pint bottle, _ inch nozzle only option --8.86 depth limitation

- DHS-48-DH-48 with fins and suspended on a hand line for sampling off of a structure (bridge, culvert head wall, etc), pint bottle, $5 \mathrm{lbs}$ is sampler weight, inch nozzle only (figure 35)

- DH-59-hand line sampler, $22 \mathrm{lbs}$, pint bottle, 1/8,3/16,1/4 inch nozzle -9-19 ft depth limitation

- D-74-62 lbs, uses quart or pint bottles, 1/8,3/16,1/4 inch nozzles, $19 \mathrm{ft}$ depth limitation

- D-77-75 lbs, uses 3 liter bottle, 5/16 inch nozzle - $15.5 \mathrm{ft}$ depth limitation

- DH-81-Wading version of the D-77, 1/8, 3/16, 1/4, 5/16 nozzles available, pint bottle (figure 36)---9 ft depth limitation 


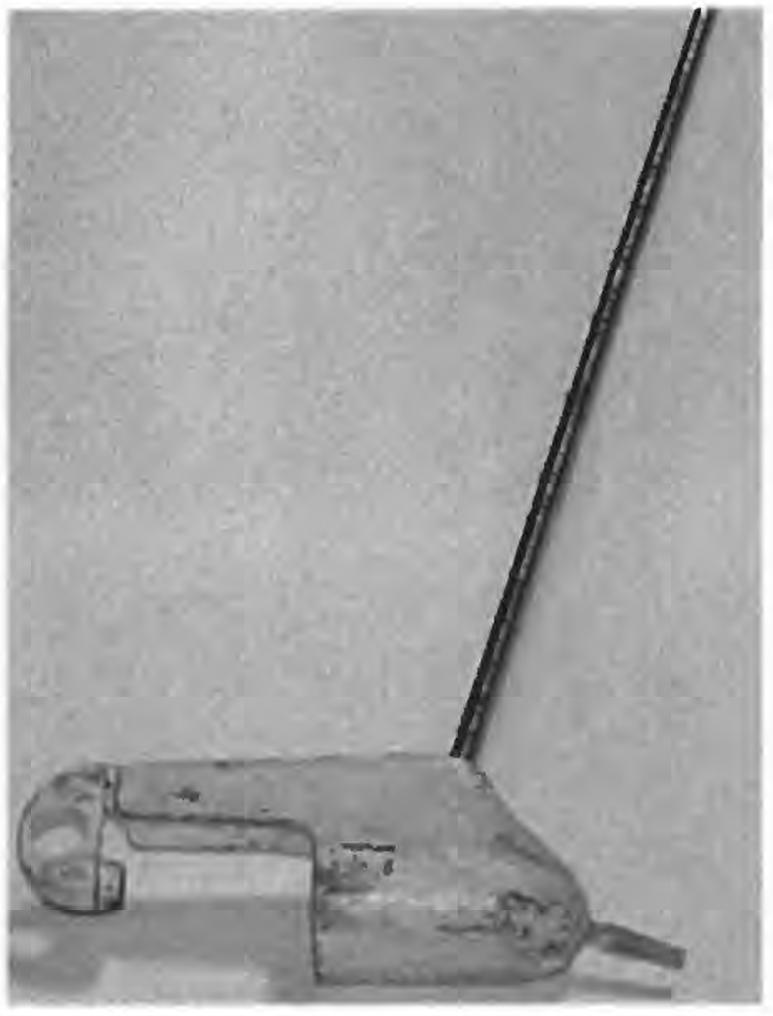

Figure 35-US DH-48 depth-integrating sampler

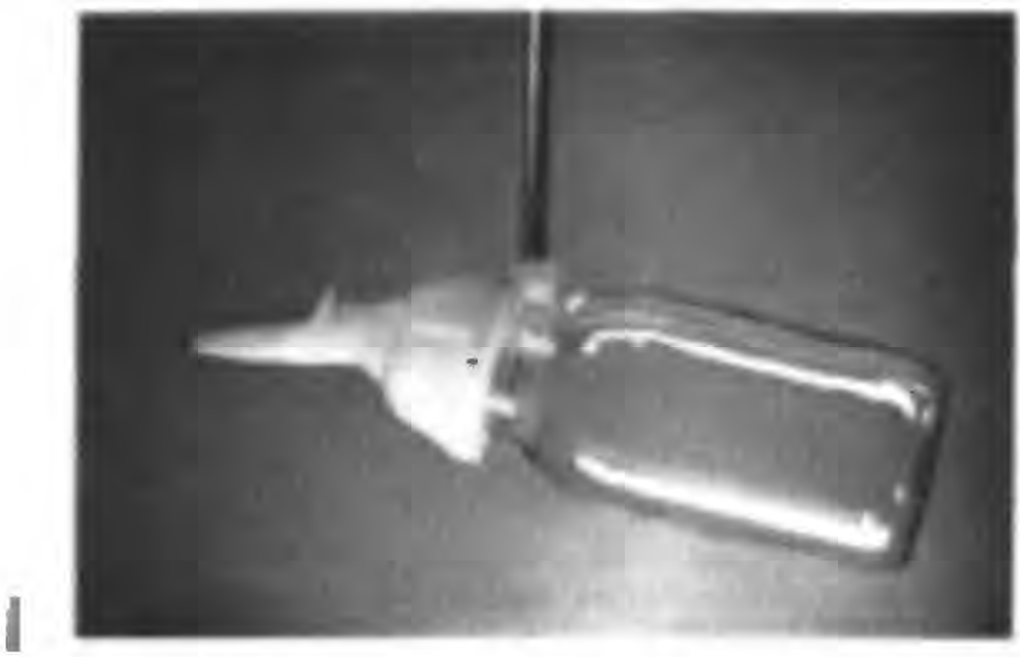

Figure 36.-US DH-81 hand held depth-integrating suspended-sediment sampler

The point-integrating sampler uses an electrically activated valve, which allows the selection of the location in the vertical at which an isokinetic sample could be collected. By activating the valve to the open position, the point-integrating sampler can be used as a depth-integrating sampler. The point sampler can sample in much deeper flows, because of the added versatility of the electrically activated valve. For example, if the stream was 30 feet deep, the typical depth-integrating sampler could not be used as the bottle would overfill before the sampler could complete the transit to the bed and back to the water surface. With the point-integrating sampler, the water column could be sampled until the sampler neared the bed, then the valve could be shut, thus not allowing any more water to enter the sampler. Once the sampler was brought to the surface, a new bottle could be inserted and the sampler lowered to the bed (with the valve shut). Once near the bed, the valve could be opened and raised to the surface, collecting an additional depth integrated sample. The point-integrating samplers are:

- P-61-105 lb, pint or quart bottles, 3/16 inch nozzle, $180 \mathrm{ft}$ depth limitation because has the diving bell pressure eqaulization 
- P-63-200 lb, pint or quart bottles, $3 / 16$ inch nozzle, $180 \mathrm{ft}$ depth limitation

- P-72-41 lb, pint or quart bottles, $3 / 16$ inch nozzle, $72.2 \mathrm{ft}$ depth limitation

(figure 37)

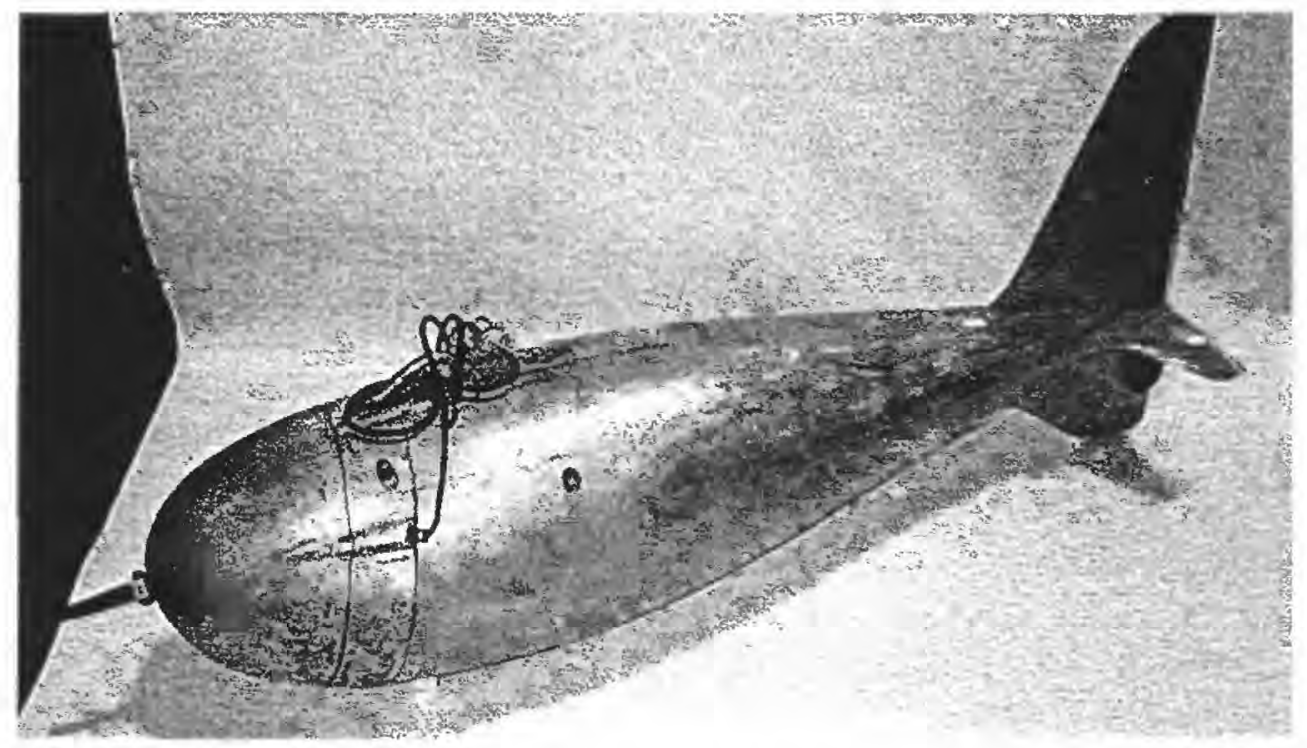

Figure 37.-P-72 point-integrating sampler

\section{Quality Assurance of Suspended-Sediment Samplers}

Before sampling it is necessary to assure that the sampler is functioning properly. Before beginning sampling:

1. Check the seal

- ---For depth-integrating sampler, place the sample bottle inside sampler, attach tubing to nozzle and cover the exhaust port. A good seal will not allow one to blow into the tubing while covering the exhaust port.

---For point-integrating sampler, place the sample bottle inside the sampler and lower the sampler to the bed of the river and back with the valve closed. The bottle should be checked for water contents, no water inside bottle indicates a good seal.

2. Inspect nozzle

- Should have no chips or ground down ends

- Should be aligned with flow

\section{Bed Material Samplers}

Knowledge of bed material is important. Following are some of the available bed material samplers:

- BMH-53-Hand-held piston type bed sampler designed to use when wading and sampling in sand and finer grain material, poor in gravel sized bed sediments

- BM-54---Cable suspended $100 \mathrm{lbs}$, rotary type sampler, maximum bed particle size that can be accurately sampled is $16 \mathrm{~mm}$ gravel, When sampler 
hoisted to surface, ensure that bucket was completely shut as any gap in bucket will allow fines to be washed out

- BM-60 - Cable suspended 32 lbs version of BM-54

- BMH-80-Hand-held with hand-activated rotary scoop designed for use in sampling sand and fine gravel (figure 38)

- Shovel-Obvious limitations because it can only be used in shallow water depths

- Ponar (dredge sampler)-Suspended from a cable, designed for use in sampling fine, soft sediments, such as sand, silt, and clay found in lakebed or estuary. Bulky, non-streamlined sampler, not for use in flowing water.

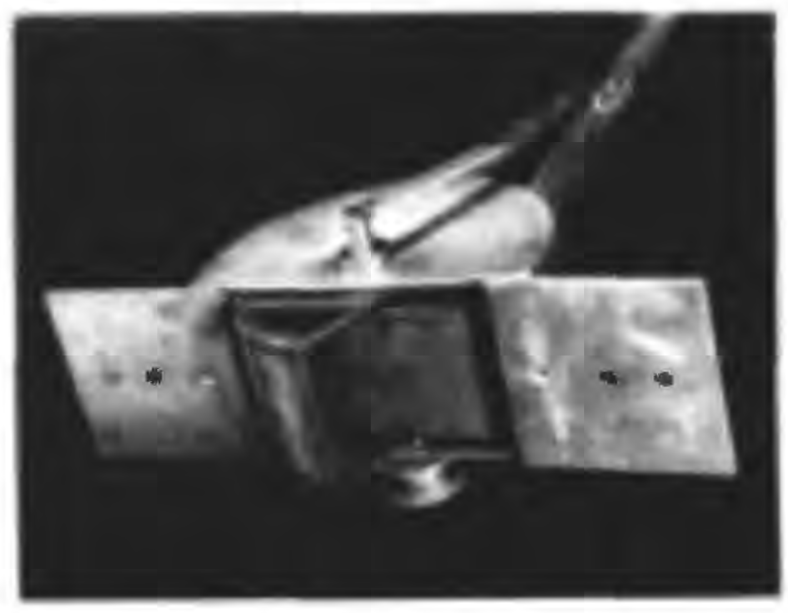

Figure 38.-US BMH-80 Bed-Material Sampler

\section{Bedload Samplers}

Bedload has traditionally been sampled by placing samplers in contact with the bed and allowing the bedload to accumulate inside the sampler before it is raised to the surface. More recently, advances in remote sensing allows determination of bedload transport by non-contact methods. Some of the contact bedload samplers are:

- Helley-Smith---66 lb sampler with a 3x3 inch opening and a flare ratio of 3.22 , and a sample bag with mesh size of $0.2 \mathrm{~mm}$ serves as the catch for the bed material (figure 39)

- FISP sampler-3x3 opening and a flare ratio of 1.40

- TR2---220 lb sampler with a 6x12 inch opening, designed and used by the USGS on the North Fork of the Toutle River below Mt. St. Helens

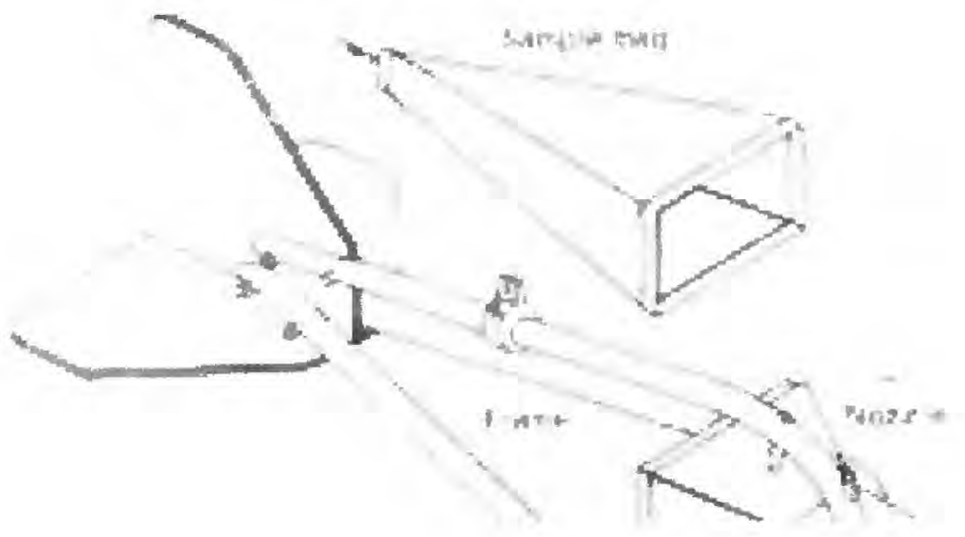


Figure 39.-Helley-Smith Bedload Sampler 


\section{Suspended-Sediment Sampling Methods}

Edwards and Glysson (1988) describe various methods for sampling of fluvial sediments. A major purpose of sampling sediments is to determine the mean instantaneous suspended-sediment concentration of the cross section. Two methods exist for sampling a stream cross section to determine the mean suspended-sediment concentration: EqualDischarge Increment method (EDI) and Equal-Width Increment Method (EWI). Both these methods involve taking samples of water at discrete locations along the cross section, but differ in the way the location of sampling verticals are selected.

The EWI method (Edwards and Glysson, 1988, pp61-64) divides the cross section into between 10 and 20 equal width increments. At each of the increments, a sample is collected using the same transit rate (speed that the sampler is lowered and raised through the water column) at each of the vertical. By using the same transit rate consistently across the cross section, the samples are being weighted according to the velocity of the stream. For example, in parts of the stream where the water is moving faster, the samples contain more of that water because since the transit rate is the same, more water moves into the sampler. EWI is typically used when no apriori information at new sites where discharge measurements have not been made. When laboratory analysis is done, all the bottles from an EWI cross section are composited for determination of the average suspended-sediment concentration. Generally, the more variable the concentration across the stream requires more verticals. Figure 40 contains the EWI sampling scheme.

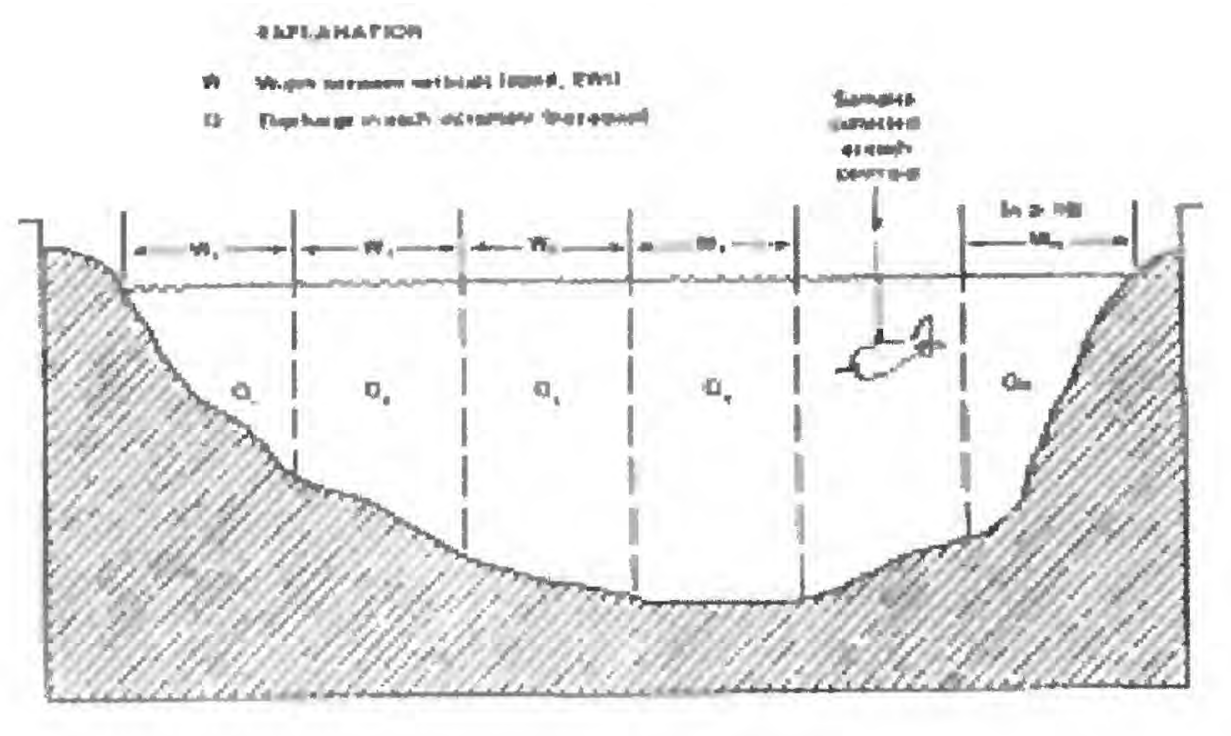




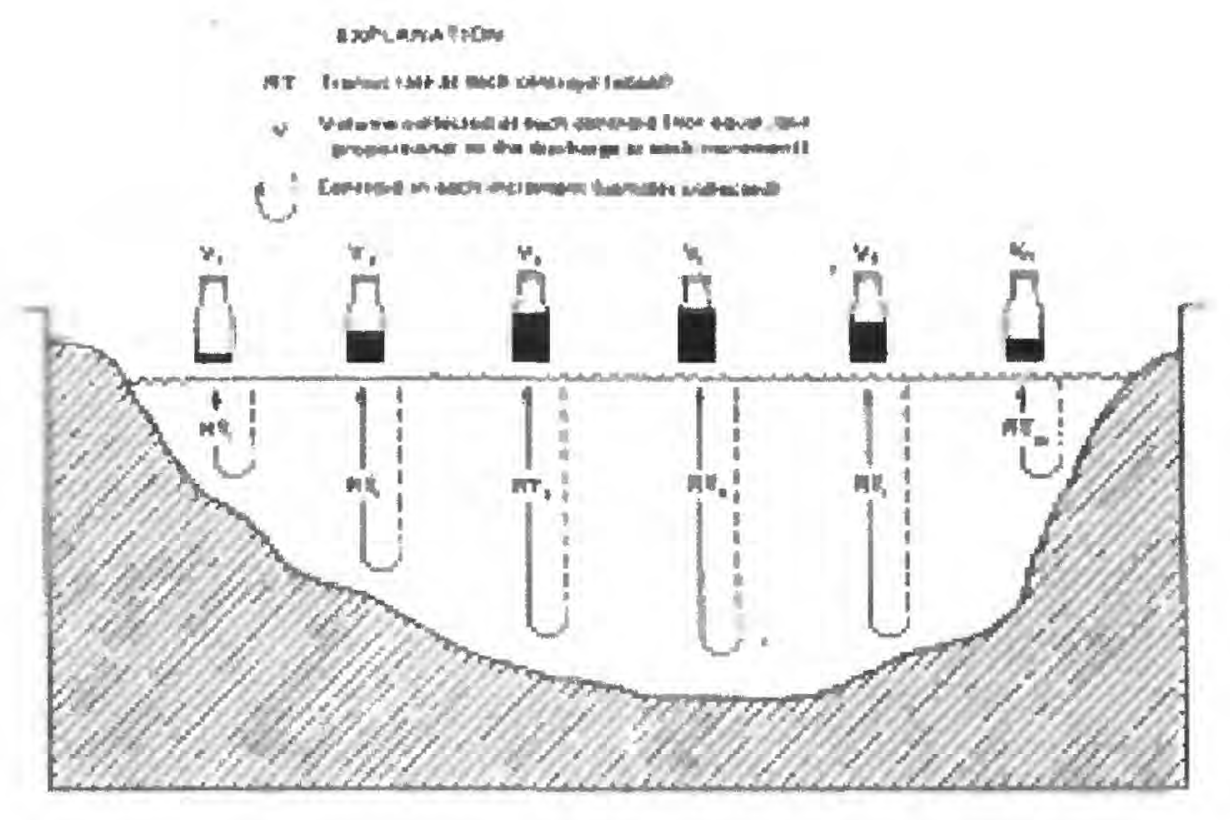

Figure 40.-EWI Method

The EDI method (Edwards and Glysson, 1988, pp 54-61) samples at points in the cross section of equal discharge. This requires the knowledge of the distribution of the discharge in the cross section before sampling can be conducted. This method requires a minimum of 4 verticals and a maximum of 9 verticals. The verticals are located at the centroids of equal discharge. This method assumes that the sample collected at the centroid of the subsection is representative of the mean concentration in that subsection. The transit rate us varied from subsection to subsection, as the goal is to get the same amount of sample volume in each sample. The samples are being weighted by the placement of the verticals in the centroid of equal discharge as opposed to the EWI has the stream velocity do the weighting. Figure 41 contains the EDI sampling scheme. Once the number of verticals to be sampled is determined, the total discharge is divided by the number of vertical $(Q / n=q)$. The first vertical is located at $q / 2$ to be sampling at the centroid of the first equal discharge increment. The second vertical is located at the vertical that corresponds to $q / 2+q$, the third vertical is located at $q / 2+q+q$, and so on.

The transit rate is not constant for all verticals. Because the samples are already weighted by determining equal increments of discharge, the main objective is to select the transit rate such that the volume of water collected in each vertical is the same. 

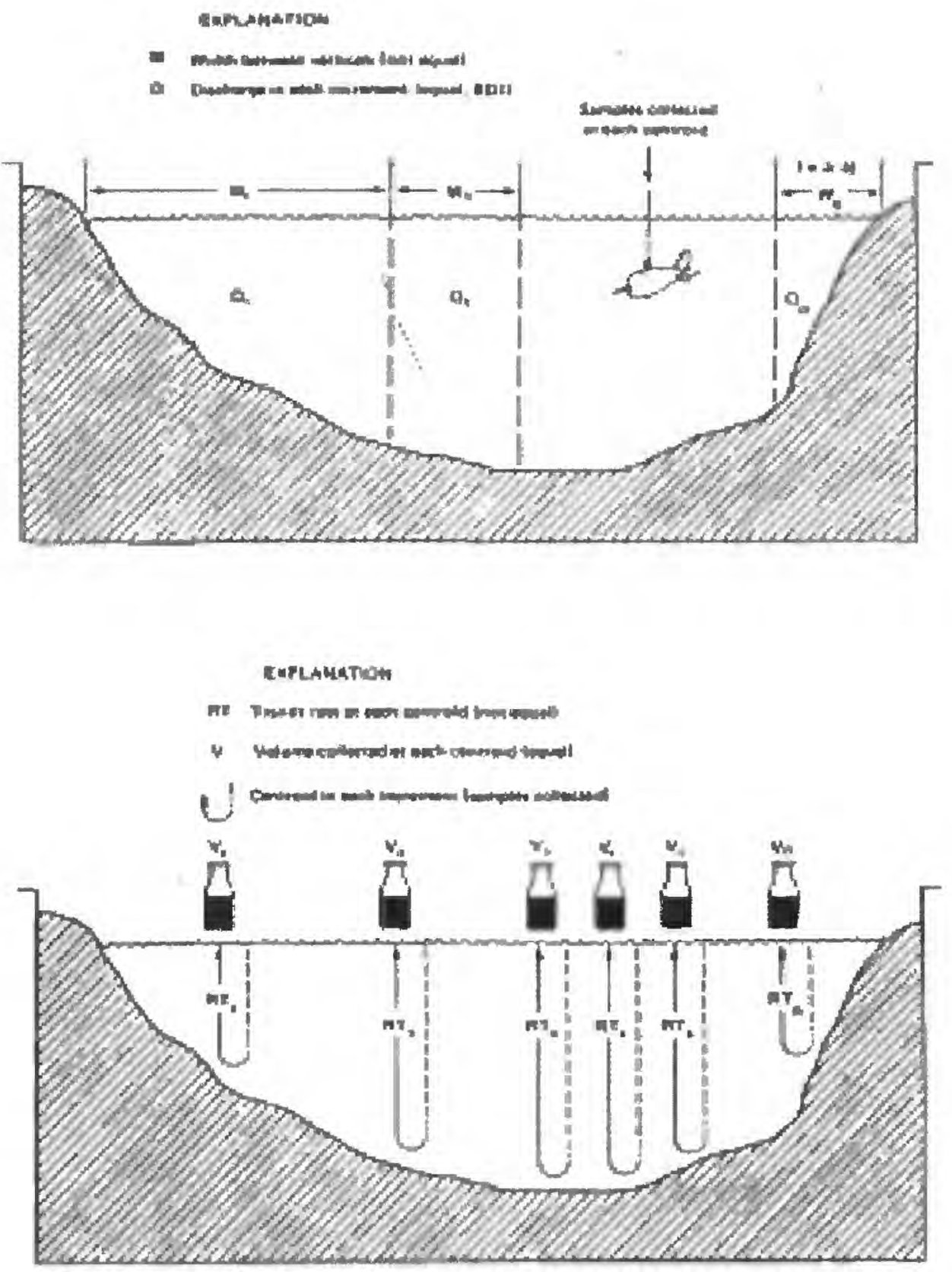

Figure 41.-EDI Method

\section{Proper Suspended-Sediment Sampling in a Vertical}

In each vertical, the purpose of sampling is to determine the instantaneous mean dischargeweighted suspended-sediment concentration of the vertical at the time of the sampling. The methods used to do this depends on the flow conditions and particle size of the suspended 
sediment being transported. Each of these cases are listed below (Edwards and Glysson, 1988, pp49-53).

CASE 1 - low velocity $(<2 \mathrm{ft} / \mathrm{sec})$ and no sand being transported (no sediments $>0.062 \mathrm{~mm}$ )

- Because no sand is present, the distribution of suspended sediment in the water column from bed to water surface is relatively uniform. Therefore the sampling error is reduced. Therefore, it is not as important to collect the sample isokinetically.

- In shallow streams, the sample at the vertical may be collected by submerging an open mouthed bottle into the stream by hand. The mouth should be pointed upstream and the bottle held at a 45 degree angle from the streambed. The bottle should be filled by moving it from the surface to the streambed and back. A 3 inch unsampled zone should be maintained to match the unsampled zone of the regular suspended sampler (figure 33).

CASE 2-velocities between $2 \mathrm{ft} / \mathrm{sec}$ and $12 \mathrm{ft} / \mathrm{sec}$ and depths less than 15 feet

- Depth integrating (or point-integrating) samplers must be used. Depth integration is accomplished by traversing the entire depth of the stream from surface to the bed and back to the surface.

- Use the proper transit rate for the sampler. The transit rate is dependent on bottle size, nozzle size, and stream velocity. Determination of the transit rate will be discussed below.

CASE 3-velocities between $2 \mathrm{ft} / \mathrm{sec}$ and $12 \mathrm{ft} / \mathrm{sec}$ and depths greater than $15 \mathrm{feet}$

- Point samplers must be used. Depth samplers should not be used because by using the proper transit rate at depths greater than 15 feet, the bottles will overfill before the sampler can traverse the entire depth of the vertical.

- For depths of 15 to 30 feet, using the point sampler, take a depth integrated sample from the surface down to the bed. The sampler valve should be shut off. The sampler should be brought to the surface and the bottle changed. The sampler should then be lowered to the bed (with the valve closed), then opening the valve, an integrated sample should be collected from the bed to the surface.

- For depths greater than 30 feet, split the vertical into 2 segments and use 4 bottles to sample the vertical, 2 bottles for descending and 2 bottles for the ascending.

- Use the proper transit rate for the sampler.

CASE 4 -velocities greater than $12 \mathrm{ft} / \mathrm{sec}$

- In velocities this large, it is often impossible to sample the entire depth (unless it is shallow) and often there is a great amount of debris. Sample the top 2/10 depth only. As soon as it is possible to sample the entire depth, collect another sample of the top $2 / 10$ depth followed immediately by a sample of the entire depth at the same vertical. This will allow a correction factor to be determined and applied to the Case 4 sample.

An isokinetic sample is a must to properly sample suspended-sediment. If a sample is not isokinetically sampled, then it will be biased high or low, depending on if the velocity in the nozzle is too fast or too slow compared to the ambient stream velocity near the sampler. 
Ensuring isokinetic conditions requires selecting the proper transit rate for the sampler to travel through the water. If the proper transit rate is exceeded, the pressure in the bottle does not equilibrate with external water fast enough, thus causing a slower velocity in the nozzle than in the stream. On the other hand, if too slow a transit rate is used, the bottle would be overfilled.

The proper transit rate is dependent on nozzle size, bottle size, depth, and water velocity. Figures 42-47 are graphs that are used to select the proper transit rate. Figure 42 is for a $1 / 8$ inch nozzle and pint bottle. If the stream depth was $10 \mathrm{feet}$, the optimal transit rate divided by the mean velocity is around 0.11 . If the stream velocity was $5 \mathrm{ft} / \mathrm{sec}$, the optimal transit rate would be 0.11 multiplied by $5 \mathrm{ft} / \mathrm{sec}$. This would result in an optimal transit rate of $0.55 \mathrm{ft} / \mathrm{sec}$. If transit rate tables are not available, then the general rule of thumb is that the absolute maximum transit rate is 0.4 times the stream velocity (note: the majority of the time the transit rate will be much less than 0.4 times the stream velocity). 


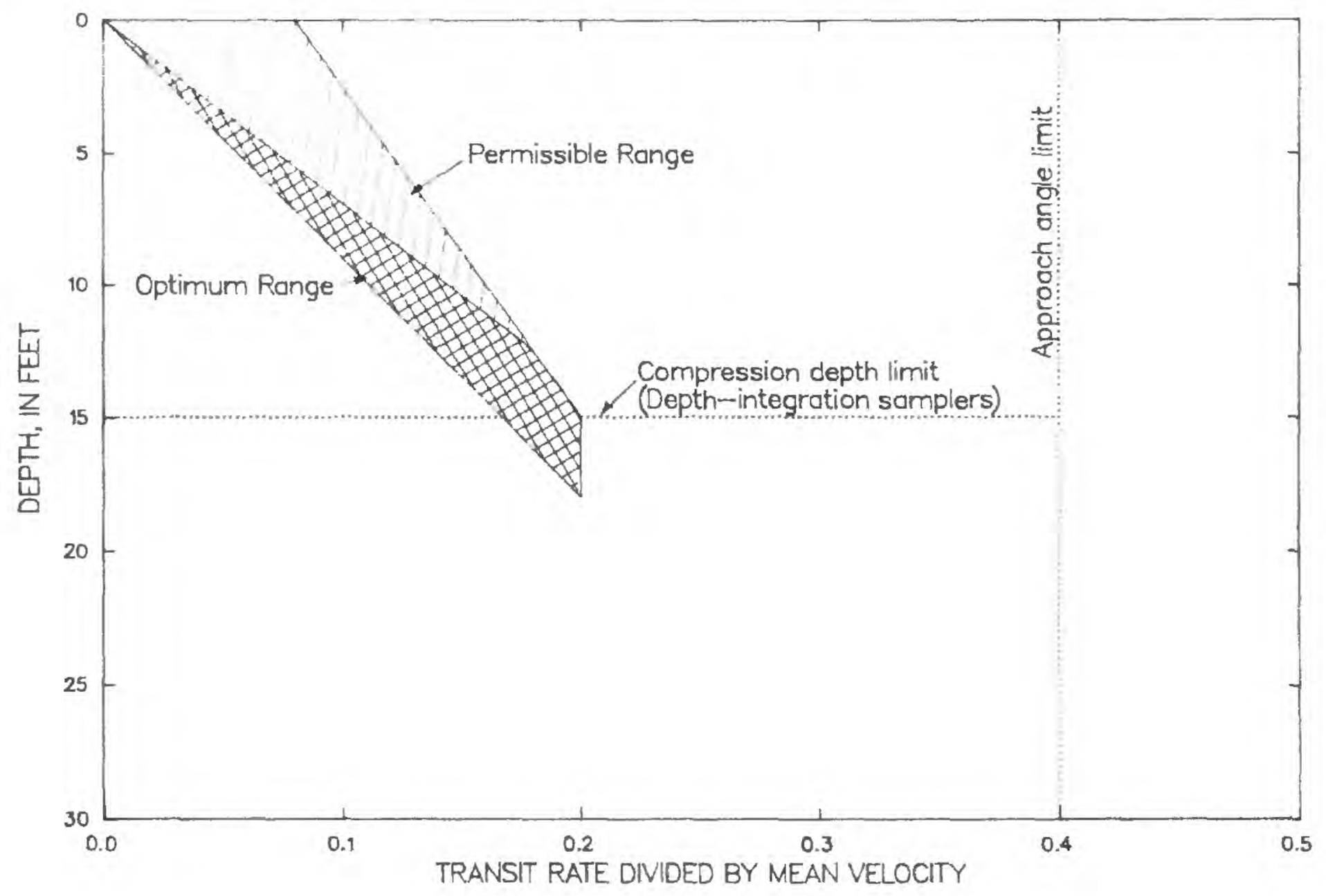

Figure 42.- Transit rate determination for $1 / 8$-inch nozzle and pint bottle

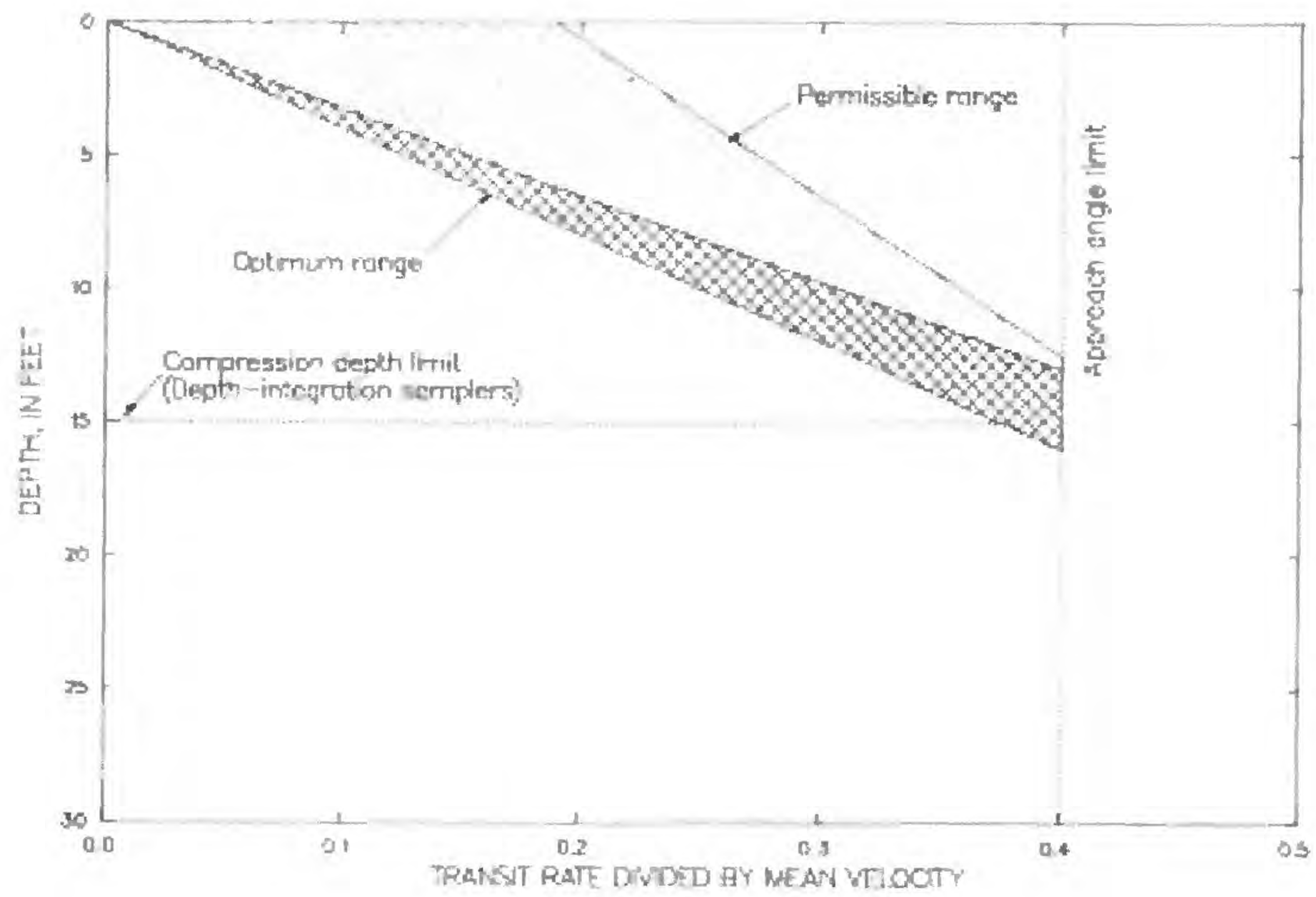

Figure 43.--Transit rate determination for 3/16-inch nozzle and pint bottle 


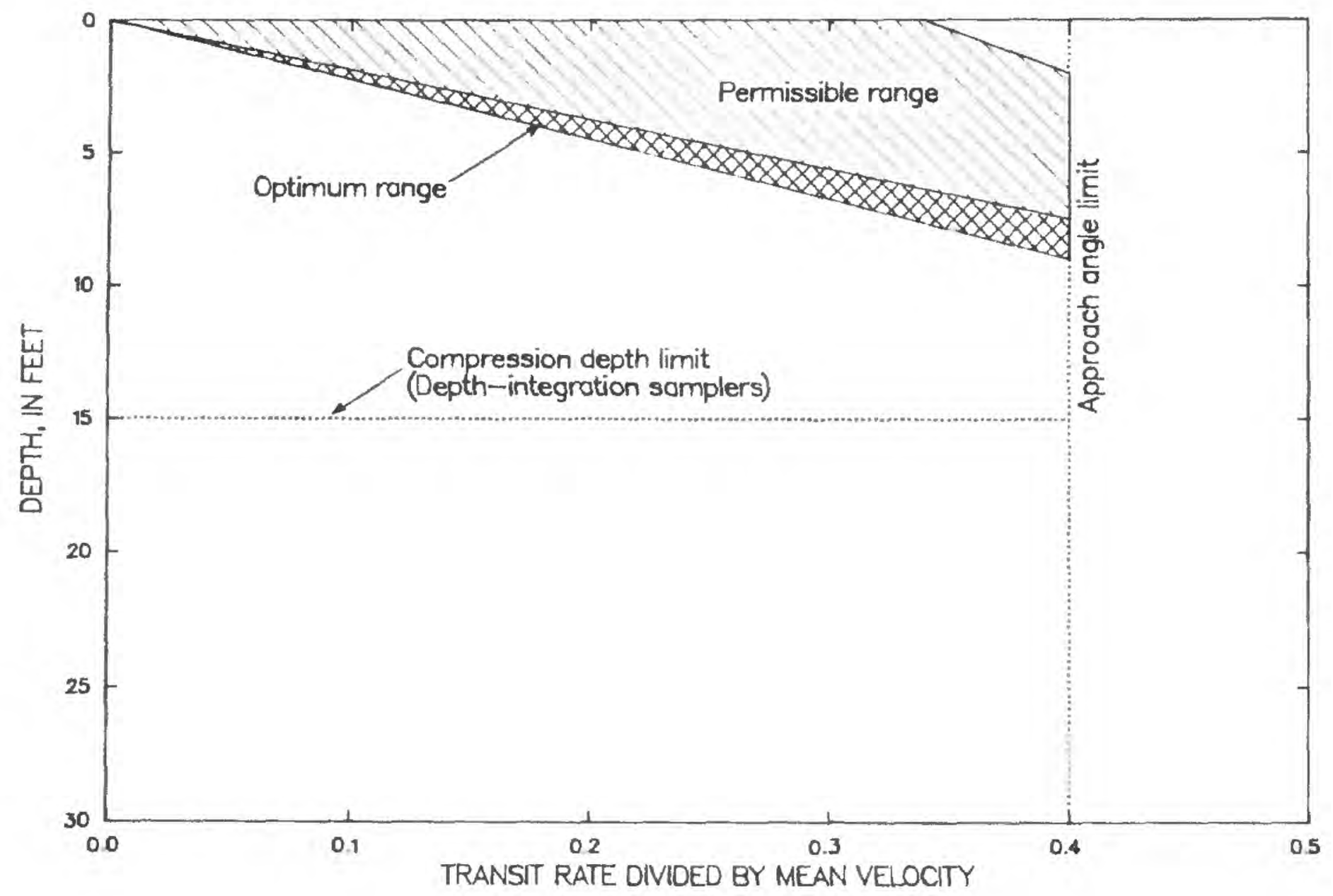

Figure 44. - Transit rate determination for _-inch nozzle and pint bottle

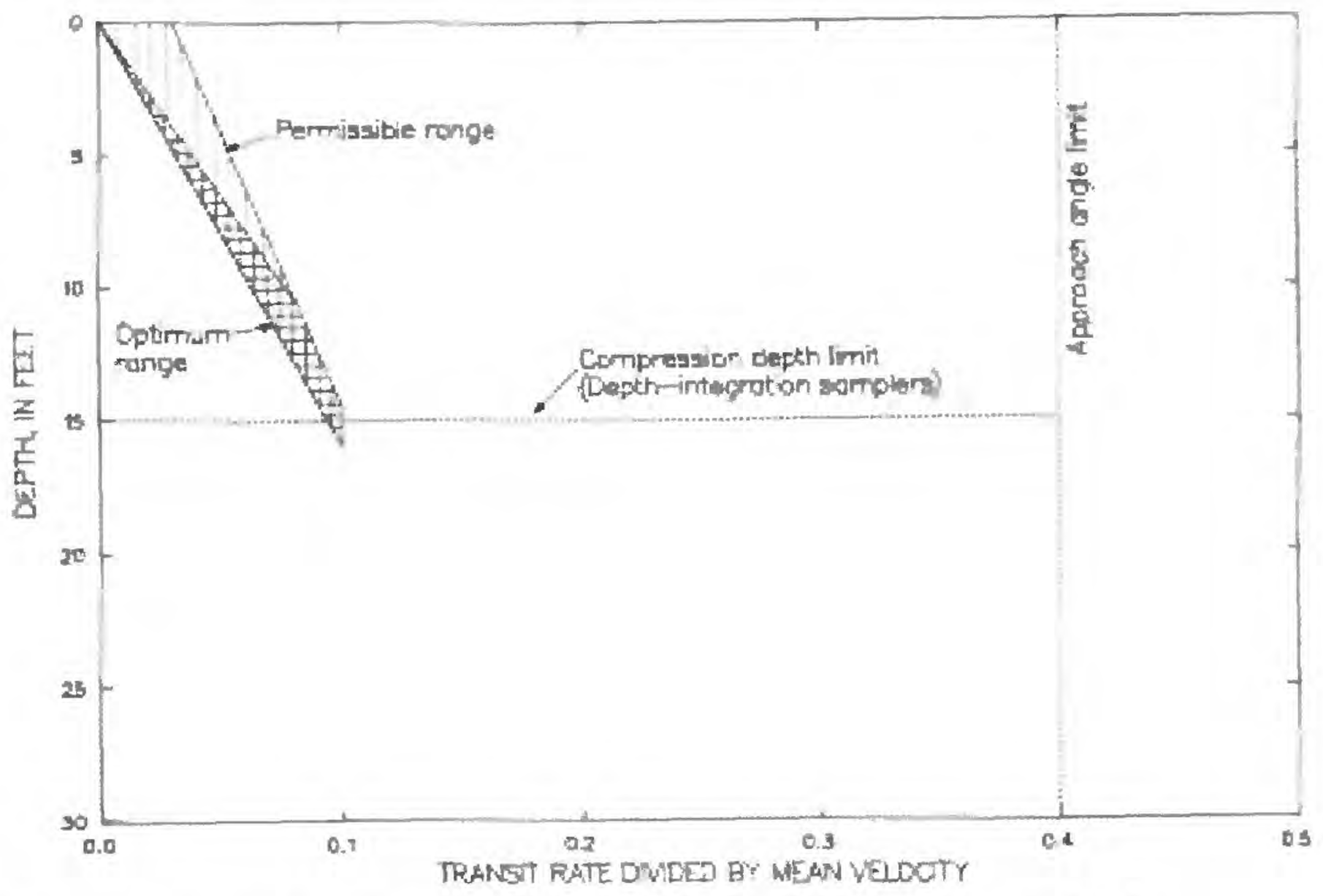

Figure 45.-Transit rate determination for $1 / 8$-inch nozzle and quart bottle 


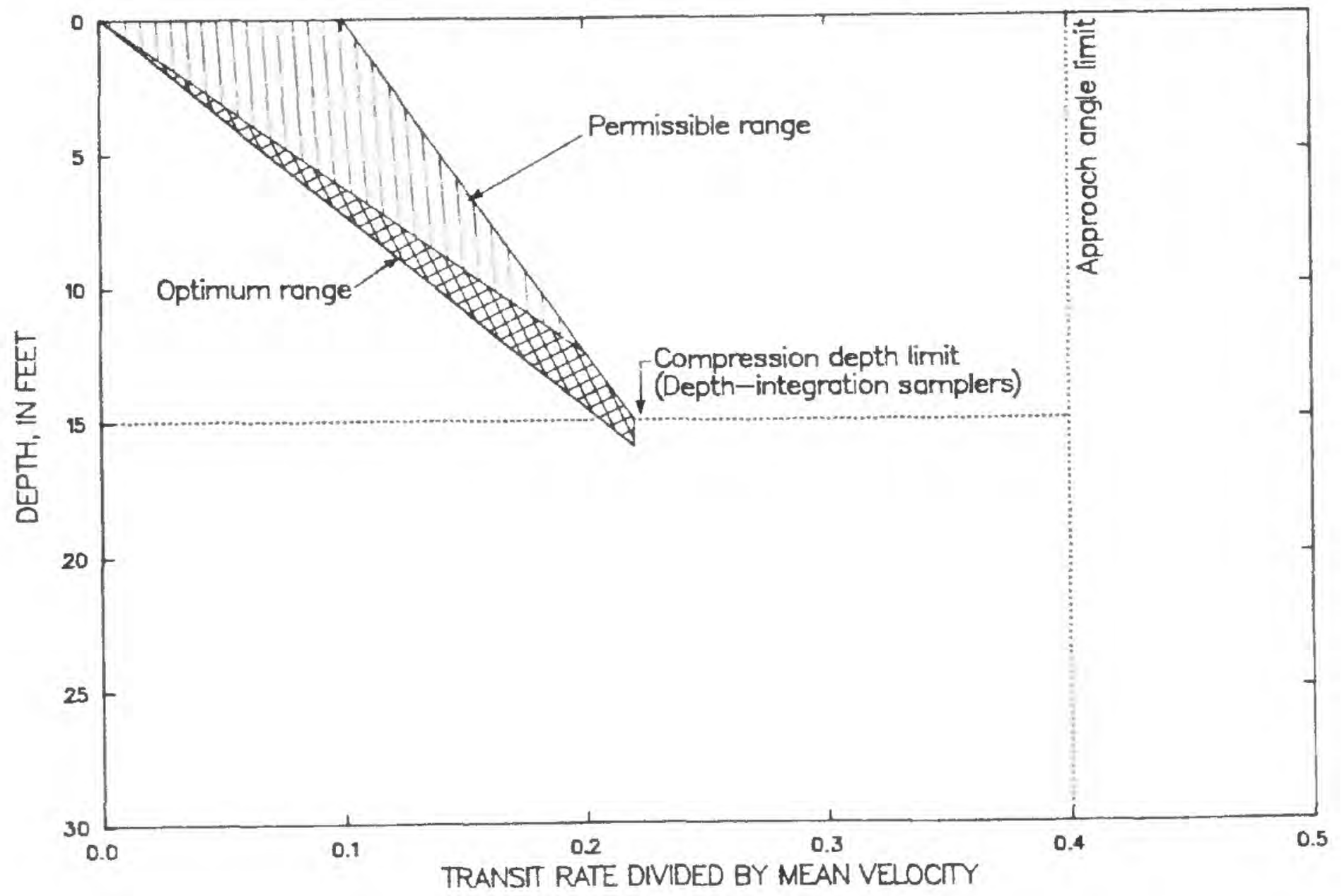

Figure 46.-Transit rate determination for 3/16-inch nozzle and quart bottle

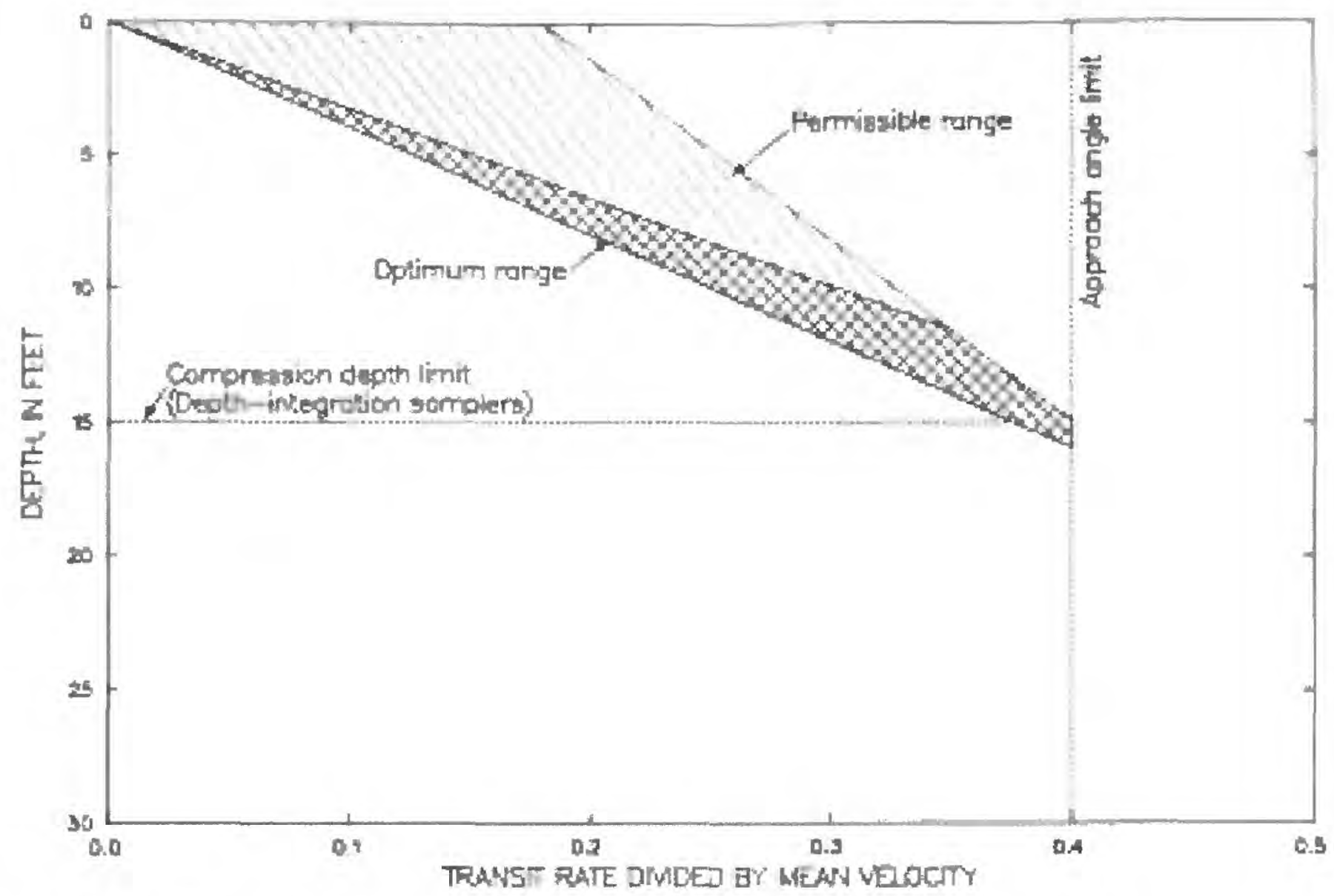

Figure 47. - Transit rate determination for_-inch nozzle and quart bottle 


\section{Bed Material Sampling Methods}

Bed-material samples are collected and a variety of data can be extracted from the samples. Among these types of data are: particle-size distribution, bulk density of a sample volume, particle lithology and mineralogy, particle density, particle dimensions (form, roundness, sphericity), sediment chemistry, etc. The types of bed-material samples collected are:

- Surface sample

- Sub-surface sample

- Bulk sample

The type of bed-material sample to be collected depends on the type of data to be extracted (as listed above), the field conditions (samples collected under water, above the water line, etc), particles sizes in the bed, and the resources of the project (funds, personnel, and equipment).

When using a mechanical sampler, bed-material samples are collected at verticals selected in the same way as suspended-sediment samples, EWI or EDI methods. These methods are explained in Suspended-Sediment Sampling Methods section. At the present time, no mechanical bed-material sampler is adequate to obtain a representative sample of coarse gravel-sized material in water that is too deep to wade.

If particle size is of interest, for those sites above the water line, particle counts can be conducted. A template of some type has be used to guide selection of various particles at 100 sites within the sample area. A tape measure is used to determine the secondary axis size. When all 100 particles have been measured, a particle size distribution can be determined.

To collect subsurface samples, the most common method of collection is using a shovel at locations above the water line. Other methods require specialized equipment such as a drill rig (split spoon samples) or pipe coring rig. 


\section{Bedload Sampling Methods}

There are many different opinions on how to properly sample for bedload, as this subject has been debated for many years. Edwards and Glysson (1988, pp91-107) discuss some of the methods that have been used over the years. The Single Equal Width Increment (SEWI) method is outlined as an example as follows:

1. Divide the cross section by 20 which equals $b$

2. The first sample is taken at $b / 2$ from the streambank, the second sample is collected at $b / 2+b$, etc.

3. At each vertical, lower the sampler to the bottom and allow the sampler to stay on the bottom for a set length of time

4. Each vertical should have the sampler on the bottom for the same length of time.

5. The sample collected at each vertical should be weighed

To calculate the bedload transport rate at a vertical, the following process should be used:

$$
R_{i}=\frac{K M_{i}}{t_{i}}
$$

Where $R_{i}=$ bedload transport rate, as measured by the bedload sampler at vertical $i$, in tons per day per foot;

$M_{i}=$ mass of sample collected at vertical $i$, in grams;

$t_{i}=$ time the sampler was on the bottom at vertical $i$, in seconds;and

$\mathrm{K}=\mathrm{a}$ conversion factor used to convert both the sampler width and the metric units into a unit of tons per day per foot. It is computed as:

$$
K=\left(86,400 \frac{\mathrm{sec}}{\text { day }}\right)\left(\frac{\text { tons }}{907,200 \text { grams }}\right)\left(\frac{12 \text { inches }}{\text { NozzleWidth }}\right)
$$

For a 3-inch nozzle width, $\mathrm{K}=0.381$.

Bedload transport for the total cross section could be made using one of three methods: total cross-section, midsection, or the mean-section method. These methods are explained in Edwards and Glysson (1988, pp 103-106). The total cross-section method assumes that (1) sample times at each vertical are equal, (2) verticals were evenly spaced across the cross section, and (3) the first sample was collected at one-half the sample width. The total crosssection method is given below:

$$
Q_{h}=K \stackrel{W_{\text {G) }}}{=} M_{r}
$$


Where $\mathrm{Q}_{\mathrm{b}}=$ bedload discharge, as measured by the bedload sampler, in tons per day; $\mathrm{W}_{\mathrm{T}}=$ total width of the stream, in feet; $\mathrm{T}=$ total time the sampler was on the bed, in seconds; $\mathrm{M}_{\mathrm{T}}=$ total mass of sample collected from all verticals; and $\mathrm{K}=$ conversion factor as defined in preceeding discussion, for nozzle 3-inch width, $\mathrm{K}=0.381$. 


\section{Sediment Records Computation}

\section{Daily Estimates of Suspended-Sediment Transport}

By sampling for suspended-sediment often enough to determine a continuous sedimentconcentration hydrograph (figure 48), a daily record of suspended-sediment load calculated. In addition, the continuous water-discharge hydrograph must also be known. For each time interval, the time series data from both of these concurrent data sets are multiplied together and then by the time interval (a units conversion coefficient of 0.0027 is also used to have the units of tons per day). The daily suspended-sediment load is then estimated as the sum of all the incremental loads throughout the 24 hour period.

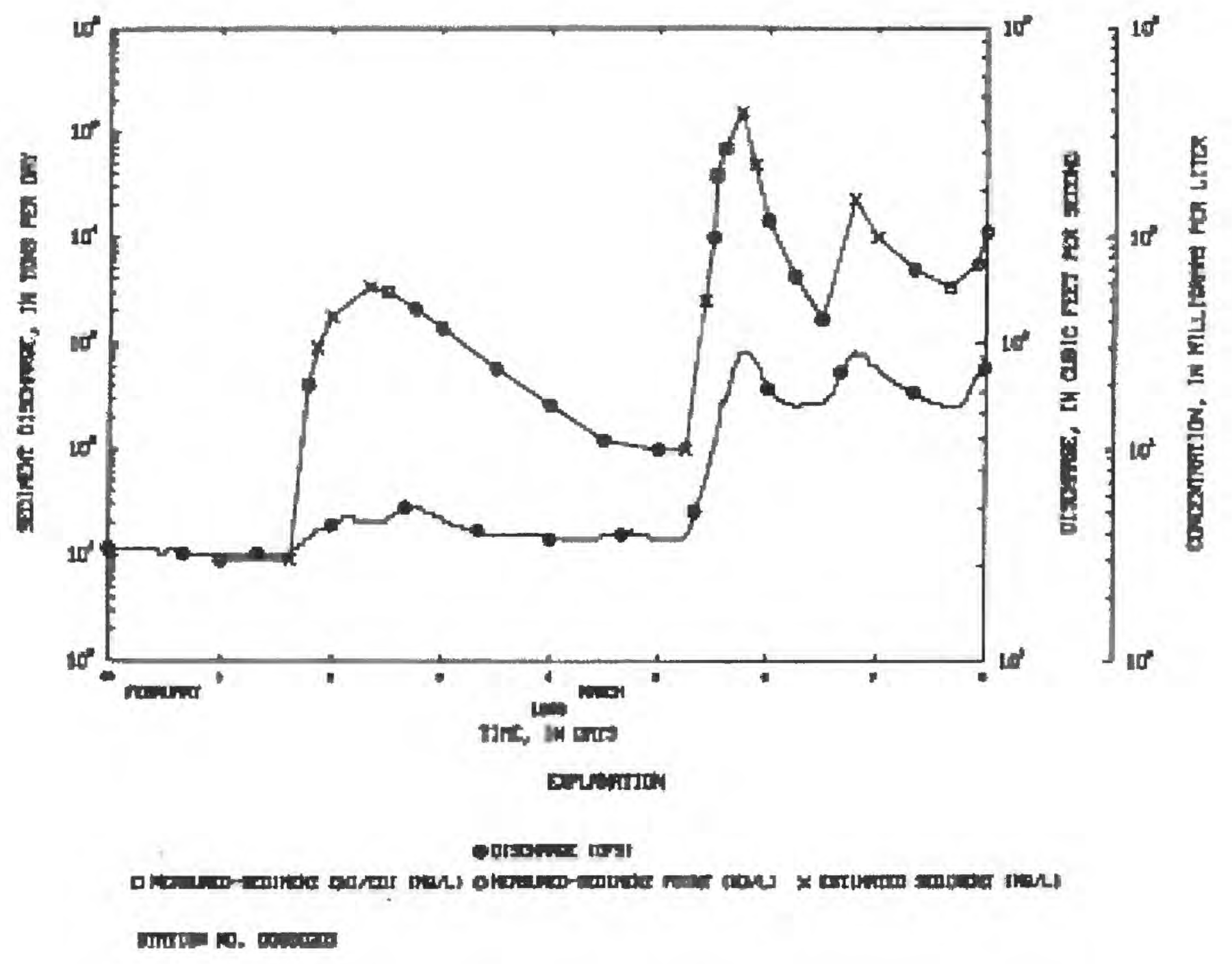

Figure 48.- Sample time series plot of sediment concentration and water discharge 


\section{Bedload Transport Computation}

Bedload is usually not computed on a daily basis, but rather estimated for periods longer than a day. This is because of the necessity to use a bedload transport relation based either on bedload samples collected over various hydraulic conditions or theoretical equations to compute the bedload based on other hydraulic and geometric parameters. Figure 49 shows as the relations of bedload and discharge for various theoretical estimates of bedload for various locations on the Mississippi and Missouri Rivers
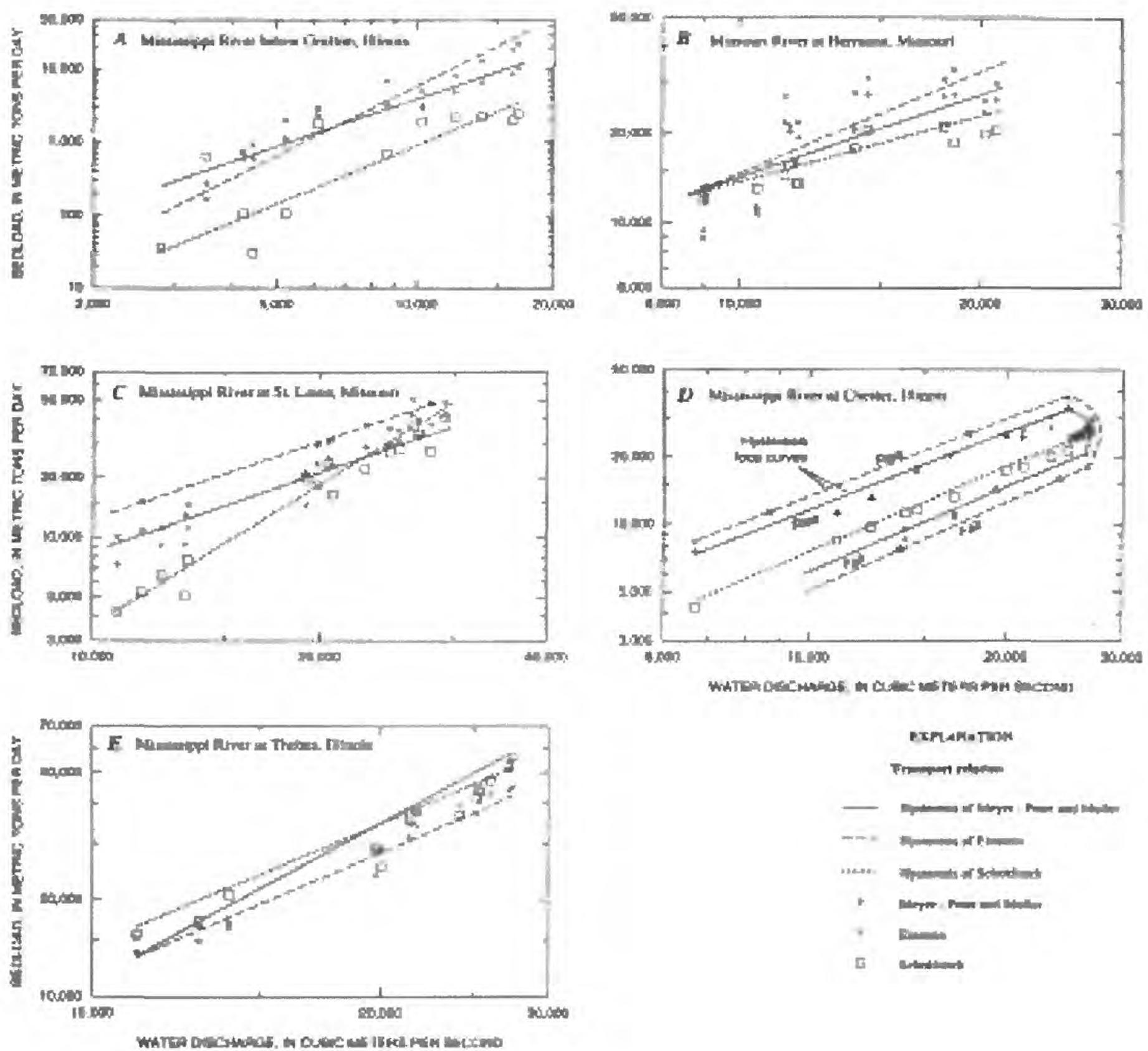

Figure 49.-Theoretical bedload transport relations computed for the 1993 flood at various locations on the Mississippi and Missouri Rivers (Holmes, 1996) 


\section{Periodic Estimates of Suspended-Sediment Transport}

When a continuous hydrograph of sediment concentration is not known, but enough samples of suspended-sediment have been taken at enough variation of hydraulic conditions, an estimate of sediment load for periods larger than a day can be made. This is accomplished by constructing a suspended-sediment transport curve. (Figure 50-52) When the water discharge is known, an estimate of suspended-sediment transport can be made for that time period. The estimates from this method increases in accuracy the longer the period of estimation. For example, a monthly estimate of suspended-sediment load is more accurate than a weekly estimate and a yearly estimate is more accurate than a monthly estimate. This is because the errors tend to average out.

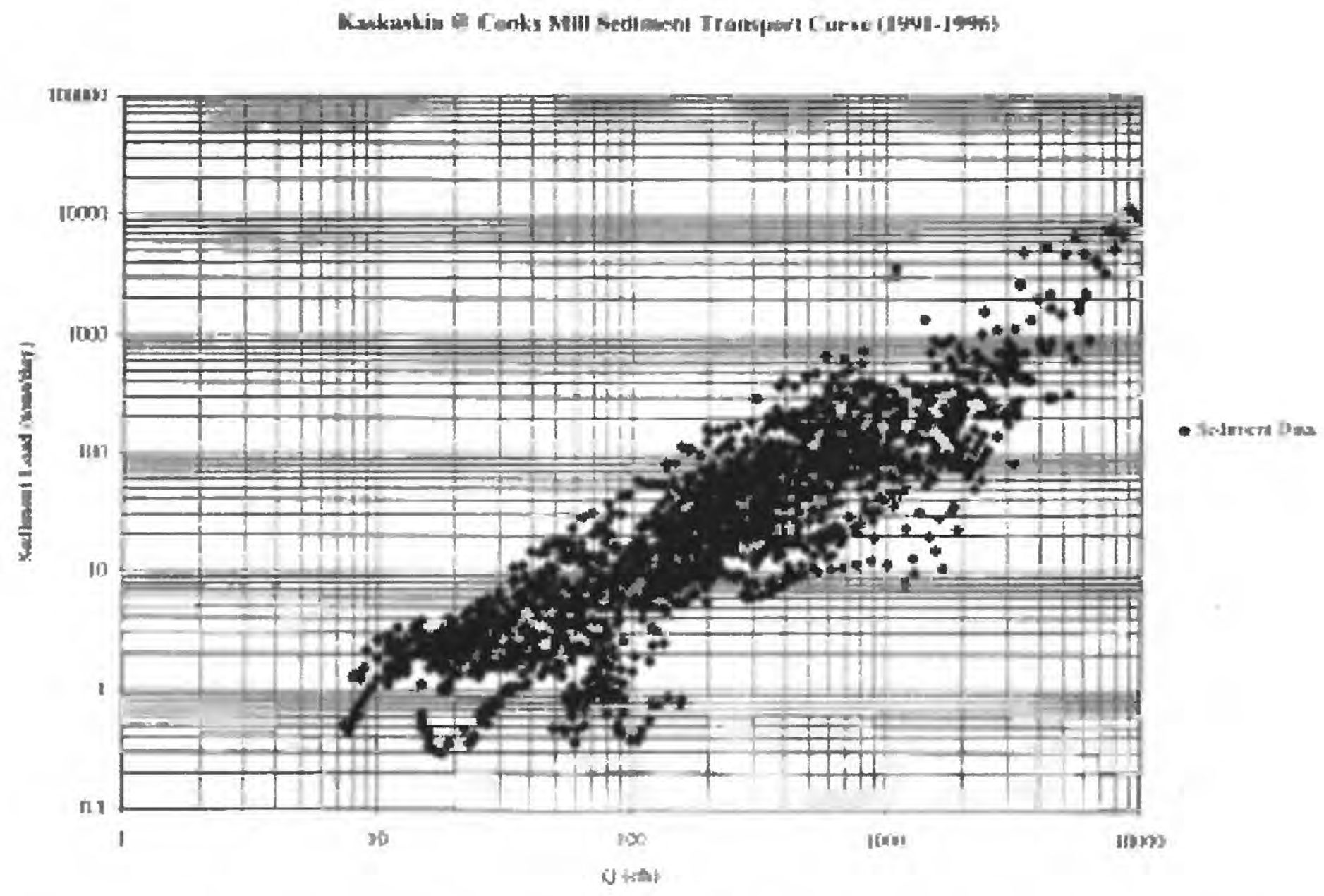

Figure 50.-Plot of sediment load versus water discharge for the Kaskaskia River at Cooks Mills, Illinois 


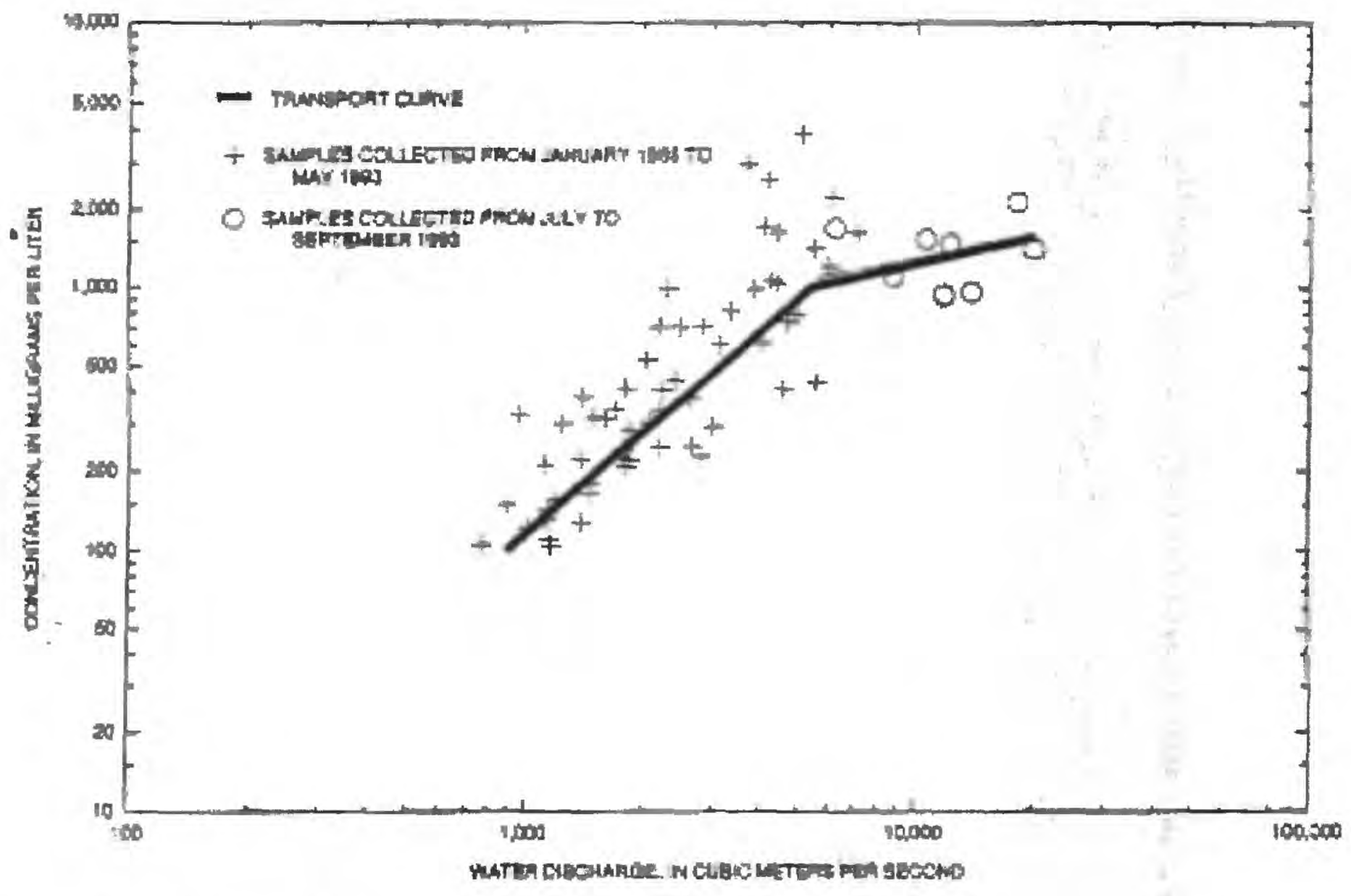

Figure 51.-Discontinuous sediment transport relation used for the Missouri River at Hermann, Missouri for the 1993 flood (Holmes, 1996) 


\section{Bibliography}

Benson, M.A., and Dalrymple, Tate, 1967, General field and office procedures for indirect discharge measurements: USGS-TWRI Book 3, Chapter A1, 30 p.

Bodhaine, G.L., 1968, Measurement of peak discharge at culverts by indirect methods: USGS-TWRI Book 3, Chapter A3, 60 p.

Buchanan, T.J., and Somers, W.P., 1968, Stage measurement at gaging stations: USGS-TWRI Book 3, Chapter A7, 28 p.

Buchanan, T.J., and Somers, W.P., 1969, Discharge measurements at gaging stations: USGS-TWRI Book 3, Chapter A8, 65 p.

Carter, R.W., and Davidian, Jacob, 1968, General procedure for gaging streams:

USGS-TWRI Book 3, Chapter A6, 13 p.

Chow, V.T., 1959, Open channel hydraulics, 680 p.

Dalrymple, Tate, and Benson, M.A., 1967, Measurement of peak discharge by the slopearea method: USGS-TWRI Book 3, Chapter A2, 12 p.

Davidian, Jacob, 1984, Computation of water-surface profiles in open channels:

USGS-TWRI Book 3, Chapter A15, 48 p.

Graf, W.H., 1971, Hydraulics of sediment transport: McGraw-Hill, New York, 513 p.

Guy, H.P., 1970, Fluvial sediment concepts: USGS-TWRI Book 3, Chapter C1, 55 p.

Guy, H.P., and Norman, V.W., 1970, Field methods for measurement of fluvial sediment: USGS-TWRI Book 3, Chapter C2, 59 p.

Guy, H.P., 1969, Laboratory theory and methods for sediment analysis: USGS-TWRI Book 5, Chapter C1, 58 p.

Henderson, F.M., 1966, Open channel flow, 522 p.

Holmes, Jr., R.R., 1996, Sediment transport in the lower Missouri and the central Mississippi River: USGS-Circular 1120-I, 23 p.

Hulsing, Harry, 1967, Measurement of peak discharge at dams by indirect methods: USGS-TWRI Book 3, Chapter A5, 29 p.

Jobson, H.F., and Froehlich, D.C., 1988, Basic hydraulic principles of open-channel flow: USGS-Open File Report 88-707, 150 p.

Kennedy, E.J., 1984, Discharge ratings at gaging stations: USGS-TWRI Book 3, Chapter A10, $59 \mathrm{p}$. 
Kennedy, E.J., 1983, Computation of continuous records of streamflow: USGS-TWRI Book 3, Chapter A13, 53 p.

Kennedy, E.J., 1990, Levels at streamflow gaging stations: USGS-TWRI Book 3, Chapter A19, 31 p.

Kilpatrick, F.A., and Wilson, J.F., Jr., 1989, Measurement of time of travel in streams by dye tracing: USGS-TWRI Book 3, Chapter A9, 27 p.

Kilpatrick, F.A., and Schneider, V.R., 1983, Use of flumes in measuring discharge: USGS-TWRI Book 3, Chapter A14, 46 p.

Kilpatrick, F.A., and Cobb, E.D., 1985, Measurement of discharge using tracers: USGS-TWRI Book 3, Chapter A16, 52 p.

Koltun, G.F., Gray, J.R., and McElhone, T.J., 1994, User's manual for SEDCALC, a computer program for computation of suspended-sediment discharge: USGS Open File Report 94-459, $46 \mathrm{p}$.

Laenen, Antonius, 1985, Acoustic velocity meter systems: USGS-TWRI Book 3, Chapter A17, 38 p.

Latkovich, V.J. and Leavesley, G.H., 1993, Automated Data Acquisition and Transmission, Chapter 25, in Handbook of Hydrology, 1993, D.R. Maidment, Editor, McGraw Hill

Maidment, D.F., 1993, Handbook of hydrology: McGraw Hill, New York

Matthai, H.F., 1967, Measurement of peak discharge at width contractions by indirect methods: USGS-TWRI Book 3, Chapter A4, 44 p.

Porterfield, George, 1972, Computation of fluvial-sediment discharge: USGS-TWRI Book 3, Chapter C3, 66 p.

Rantz, S.E., and others, 1982, Measurement and computation of streamflow:

USGS-Water Supply Paper 2175, V. 1, 2

Riggs, H.C., 1973, Regional analyses of streamflow characteristics:

USGS-TWRI Book 4, Chapter B3, 15 p.

Smoot, G.F., and Novak, C.E., 1969, Measurement of discharge by the moving-boat method: USGS-TWRI Book 3, Chapter A11, 22 p.

Smoot, G.F., and Novak, C.E., Calibration and maintenance of vertical-axis type current meters: USGS-TWRI Book 8, Chapter B2, 15 p.

Vanoni, V.A., 1975, Sedimentation Engineering: ASCE Manual and Report on Engineering Practice Number 54, New York, 745 p.

Wagner, C. Russel, 1995, Stream-gaging cableways: USGS-TWRI Book 3, Chapter A21, 56 p. 
Wilson, J.F., Jr., Cobb, E.D., and Kilpatrick, F.A., 1986, Fluorometric procedures for dye tracing: USGS-TWRI Book 3, Chapter A12, $34 \mathrm{p}$. 


\title{
Field Methods for Hydrologic and Environmental Studies
}

\author{
Chapter 2
}

Water Quality Data Collection

Paul J. Terrio 


\section{Water Quality - Introduction}

Water quality is a value judgement that is related to the intended purpose of the water body and based on the physical, chemical, and/or biological attributes of the water body.

Water quality may be defined by a single or multiple characteristics.

\section{History of Water Quality}

Pre-historic Realization of the importance of water and safe drinking water

3000 B.C. Earliest record of central water supply and waste disposal in Nippur of Sumeria

98 A.D. First books on water supply and treatment (Roman)

Early 1800's First treatment of wastewater

1847

Outbreak of cholera in India caused examination of sewage systems

Late 1800's Development of germ theory incorporated into water treatment

Early 1900's Drinking water becomes safer through treatment by sand filtration and chlorination

1940-70 Focus on point source pollution discharges and wastewater from industry and municipalities

$1970 \quad$ First Earth Day

1970's Interest begins on non-point source pollution discharges

1980's Combined sewer overflows

1990's Watershed and ecosystem approaches

Chlorination by-product concerns

Endocrine disruption

Hypoxia issues

Microbial concerns: pathogens, protozoans, viruses

What Affects Water Quality?

Stream hydraulics

Geology

Geomorphology

Land use

Input sources

Atmosphere

Climate

Biology

Stream use

Other? 


\section{Variability in Water Quality}

Spatial - varies between different locations as a result of natural or anthropogenic factors, environmental conditions, and source locations.

Temporal - varies in time

- long-term changes (changes in land use, climate, assimilative processes...)

- seasonally (climatic variabiltiy, land-use practices...)

- daily (anthropogenic and natural processes)

\section{Water Quality - Why?}

- Characterize water bodies

- Identify changes or trends over time

- Identify specific existing or emerging problems or issues

- Determine compliance with regulations

- Determine effectiveness of pollution control actions or management practices

- Responses to emergencies, spills, or floods

- Research and modeling efforts

- Water resource management

- Determine fate and transport of pollutants

\section{Water Quality - Who?}

Regulatory interests - Federal, State, and Local agencies and the public Research interests - Governmental, academic, scientific, corporate...

Management interests - Natural resource agencies, water authorities, lake managers, water suppliers, farmers...

Private entities- Volunteers, watershed associations, environmental groups, residents...

\section{Water Quality - What?}

Physical descriptors - Temperature, $\mathrm{pH}$, dissolved oxygen, specific conductance, turbidity, alkalinity.

Nutrients - Nitrogen, phosphorus, silica, and others

Major ions - Calcium, carbonate, magnesium...

Trace elements - Metals, arsenic...

Organic compounds - Industrial, agrichemical, commercial

Sediment - Suspended and bottom material

Microbial - Bacteria, protozoans, viruses

Biological - Fish, algae, invertebrates, macrophytes, mollusks, biological indices (IBI) 
Water Quality - HOW (the big question)

- Monitoring design

- Sampling network

- Collection frequency

- Collection methods

- Equipment

- Analytical requirements

- QA practices

\author{
Sample Collection Methods \\ Grab or Dip sample \\ Integrated sample \\ $\uparrow$ width integrated \\ $\uparrow$ depth integrated \\ Composite sample \\ $\uparrow$ Time composited \\ $\uparrow$ Flow composited \\ Point sample (specific location or depth) \\ End-of-pipe sample (point sources) \\ Continuous___sampling (probe measurments)
}

\title{
Other Sampling Considerations
}

- Whole sample versus filtered sample

- Sample processing methods

- Sample preservation methods

\section{Selection of Sampling Site}

Ideal sampling sites are seldom present. Selection of a sampling site should consider the following characteristics and the importance of each to the study objectives and how each may affect the quality of the sampling results, based on study objectives.

- At or near gaging station - discharge data for computing loads, relating QW to flow

- Straight reaches with uniform flows and even bottom contour

- Far enough above and below confluences and inputs to avoid poorly mixed sections

- Upstream from bridges and other structures that are potential contamination sources

- In sections of unidirectional flow

- At or near transect where other data are collected

- At a location where samples can be collected during all flow conditions.

- Confirm transect selection with field measurements at various locations across the sampling transect (may vary seasonally) 


\section{Section 2.1}

\section{PREPARATIONS FOR WATER SAMPLING}

\section{FIELD-PERSONNEL RESPONSIBILITIES}

Before sample collection begins, field personnel must take steps to ensure that the samples collected will be representative of the aqueous system being investigated. A representative water sample is a sample that typifies ("represents") that part of the aqueous system to be studied and is delineated by the objectives and scope of the study. Data-collection efforts take may take a whole-system approach, meaning that data-collection methods ensure representation of an entire stream reach or aquifer volume. A modified approach is needed for studies in which samples are representative of a specific part or aspect of an aqueous system instead of the entire system. For example, a study of aquatic ecology may establish nearshore boundaries on the system, and an oil-spill study may target only the surface of a water-table aquifer within a designated boundary or circumference.

\section{FIELD-TRIP PREPARATIONS}

All details of a field trip need to be planned well in advance. Adequate time must be scheduled to review data requirements and make field-trip preparations-a common mistake is to put off these activities until the last minute.

\section{Before selecting sites or making other preparations:}

1. Understand the purpose for which the various types of data will be collected and the aqueous system that each sample should represent.

2. Review the study workplan, especially types of measurements and samples needed.

3. Make field reconnaissance trips before selecting sampling sites, if possible.

4. Note conditions that could affect sampling operations (such as the seasonal high or low streamflow, flowing wells, or site-access peculiarities).

5. Evaluate potential sources of contamination at the site, based on target analytes to be collected.

6. Review site files and field folders. (Note site location, description and access, and review any previously collected physical, chemical, and biological data.)

7. Obtain and keep current with training and the laboratory requirements associated with your data-collection activities. 


\section{Before selecting equipment:}

- Understand the physical and chemical limitations of each piece of equipment, in order to meet data-collection objectives and data-quality requirements. Verify and test, if possible, the operational range of the sampling equipment to be used.

\section{Before starting field work:}

- Review site files and update and review the field folder for each site from which samples and ancillary data will be collected.

- Review the safety plan and be sure that you have the training needed if you will be working at sites designated as hazardous

- Plan ahead! Take adequate time to prepare.

\section{DATA-QUALITY PLANS AND PREPARATIONS}

Every study should have a written document that describes study objectives, data-quality requirements, and a quality-assurance plan.

Field personnel are responsible for determining whether the equipment and methods being used could impair sample quality. For the most part, this determination involves collecting qualitycontrol samples and analyzing the results. Field personnel must plan and prepare for routine checks on data quality.

Examine field and laboratory results as soon as possible, preferably before the next samplecollection field trip. Results indicating potential bias in the data will alert you to the changes needed in equipment, equipment-cleaning procedures, or field methods used.

Be prepared to collect additional blanks, replicates, or other field quality-control samples, based on your judgment of the effects of field conditions on sample collection. Field conditions are unpredictable, and adverse or unexpected conditions could necessitate additional steps to document data quality.

Quality-control samples are collected either in the office laboratory or at the field site, depending on their specific purpose. Field personnel must be familiar with the various types of qualitycontrol samples and know how and when to collect them in order to comply with qualityassurance requirements.

In preparation for collection of quality-control samples, solutions of the appropriate type and quality must be obtained for blank and standard reference material samples. Laboratory certification should indicate that the blank water has target-analyte concentrations that are less than the method-detection limits.

Equipment blanks are processed through clean equipment in the controlled setting of an office laboratory. Process an equipment blank at least once a year for each set of samplecontacting equipment. This applies to new equipment to be used for the first time, to equipment that will be cleaned with a new cleaning procedure, and to equipment that has not been tested with an equipment blank for 1 year. Do not collect or process environmental samples until the annual equipment blank data have been reviewed.

The field personnel or other responsible party needs to ensure that the equipment blanks are either free of contamination or have concentrations small enough to be insignificant at the current analytical limits. 
Collect field blanks at the field site under the same conditions as environmental samples. Field blanks can provide information on the efficacy of the equipment cleaning procedures used and on ambient atmospheric contamination.

Data quality begins before the first sample is collected — be aware of data-quality requirements and potential sources of contamination.

\section{SELECTION OF SAMPLING SITES}

Before sample collection, sampling sites must be selected. For each sampling site, background files and a field folder should be established. Careful and complete documentation of site information and data collected should be input to appropriate files.

The study team is responsible for selecting sampling sites and conditions (such as time of year, flow rate or stage) that will yield samples representative of the aqueous system being studied. Each body of flowing and still surface water has a unique set of conditions that needs to be identified and considered in the site-selection process.

Field personnel should be trained in the correct and current water-quality data-collection procedures and must exercise judgment gained from field experience in order to make appropriate site selections.

Once fieldwork has begun, field personnel must select the point(s) or transect(s) at which samples will be collected. In most bodies of flowing or still water, a single sampling site or point is not adequate to describe the sampling area's physical properties and the distribution and abundance of chemical constituents or biological communities. Location, distribution, and number of surface-water sampling sites can affect the quality of resulting data. Generic guidelines for selecting flowing-water and still-water sites are described in this section.

\section{When selecting surface-water sampling sites:}

- Safety of field personnel comes first.

- Consider the study objectives, types of data needed, equipment needs, and sampling methods.

- Obtain all available historical information.

- Consider physical characteristics of the area, such as size and shape, land use, tributary and runoff characteristics, geology, point and nonpoint sources of contamination, hydraulic conditions, climate, water depth, and fluvial-sediment transport characteristics.

- Consider chemical and biological characteristics of the area (aquatic and terrestrial). 


\section{Flowing-Water Sites}

Flowing-water sites refer to streams (fast or slow, intermittent, ephemeral, or perennial), canals, ditches, and flumes of all sizes and shapes, or to any other surface feature in which water moves unidirectionally. All or parts of reservoirs and estuaries that flow unidirectionally are considered to be flowing water.

\section{Flowing-water sampling sites ontimally are located:}

- At or near a stream-gaging station, to obtain concurrent surface-water discharge data required for computing constituent-transport loads and to determine discharge/constituentconcentration relations. (Measure discharge at time of sampling if a stream-gaging station is not at or near the sampling site or if discharge cannot be rated or estimated with sufficient accuracy.)

- In straight reaches with uniform flow, with a uniform and stable bottom contour, and where constituents are mixed along the cross section.

- Far enough above and below confluences of streamflow or point sources of contamination to avoid sampling a cross section where flows are poorly mixed or not unidirectional.

- In reaches upstream from bridges or other structures, to avoid contamination from the structure or from road surfaces.

- In unidirectional flow that does not include eddies. (If eddies are present within the channel, sample only the unidirectional flow.)

- At or near a transect in a reach where other data are collected (such as data for suspended sediment, bedload, bottom material, or biological material) and (or) for which historical data are available.

- At a cross section where samples can be collected at any stage throughout the period of study, if possible.

After a tentative selection of a sampling site, develop a preliminary profile of field measurements at various locations along the cross section. The field-measurement profile is used to indicate reach homogeneity. Final site selection is based on a comparison of these field measurements with the data requirements of the study.

TECHNICAL NOTE: The preferred sampling method and number of verticals to be sampled within the stream cross section that are needed to obtain a sample that is sufficiently representative depends on stream homogeneity as indicated by the field-measurement profile and stream-discharge or other data, as well as by study objectives. Also, it might be desirable to move to a sampling site upstream or downstream to adjust for seasonal variation or extreme flow conditions.

The guidelines used for selecting sampling sites on ephemeral and intermittent streams are the same as those for perennial streams. Ephemeral and intermittent stream sites need additional planning and examination to account, for example, for conditions related to rapidly changing stage and discharge that can occur as a result of flash flooding or urban runoff.

CAUTION: Any stream, including an ephemeral or intermittent stream, can rapidly become too deep and swift to wade safely. 


\section{Still-Water Sites}

Still-water sites refer to all sizes and shapes of lakes, reservoirs, ponds, swamps, marshes, riverine backwaters, or any other body of surface water where water generally does not move unidirectionally. All or parts of reservoirs that do not flow unidirectionally could be considered to be still water.

When locating still-water sampling sites:

- Use in situ field measurements to help determine vertical and spatial distribution of sampling locations.

- Avoid areas near structures such as harbors, boat ramps, piers, fuel docks, and moored houseboats (to avoid point sources of contamination), unless these structures are part of the study.

- Select sites with a record of historical data, if possible.

\section{Field Folders}

Selected information that is needed for reference while at a surface-water site is kept in a field folder. The field folder contains information needed by trained personnel to locate and safely collect and process water samples. The field folder is taken along on each sampling trip. The folder should be customized according to study needs (table 1). 


\begin{tabular}{|c|c|c|}
\hline & rtem & Comentems: \\
\hline & 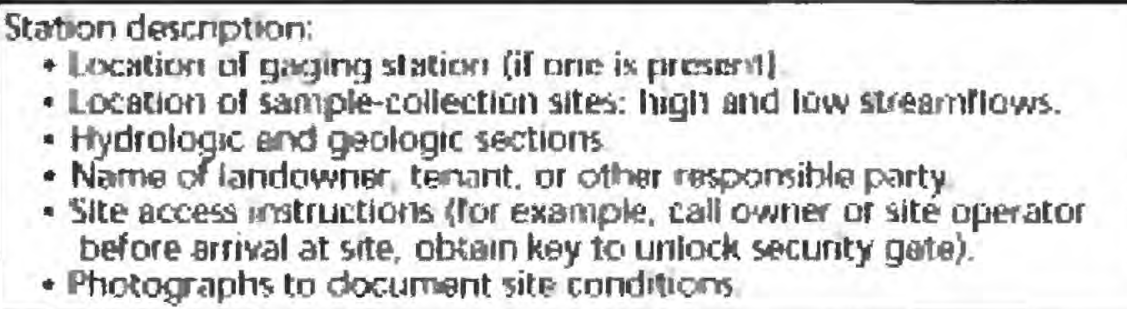 & \\
\hline & Maps to site [State and local'? & \\
\hline & 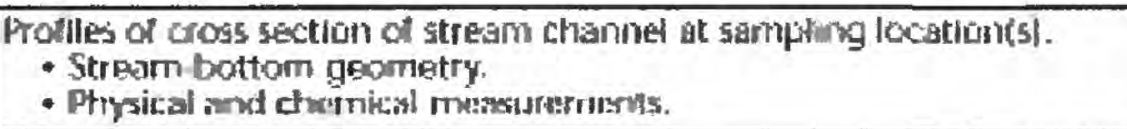 & \\
\hline & 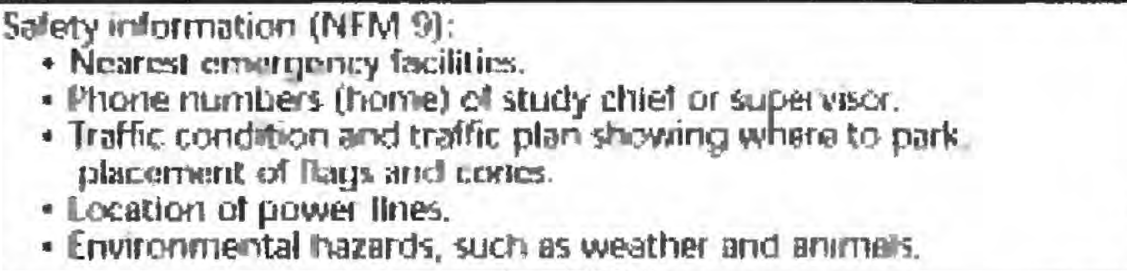 & \\
\hline & 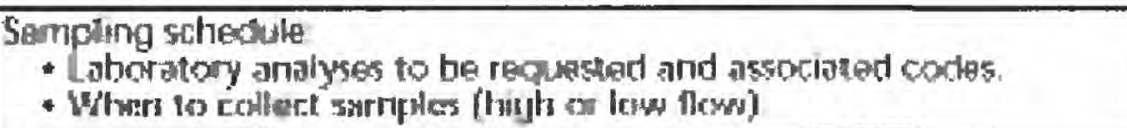 & \\
\hline & Bottle types mendlad for abch amalnical schedulg & \\
\hline & Analytical Servicas Request form(s) and example of a complated form & \\
\hline & 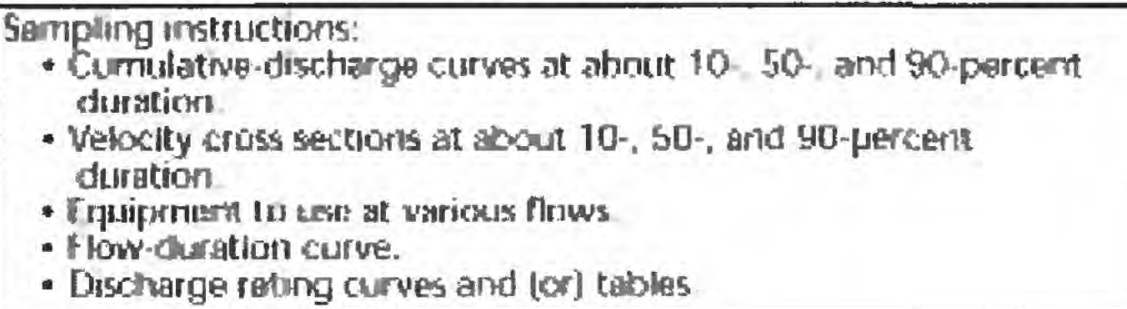 & \\
\hline & 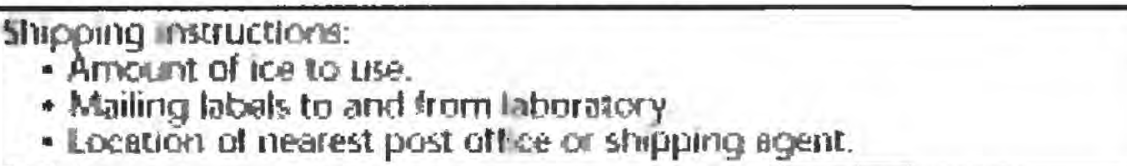 & \\
\hline & 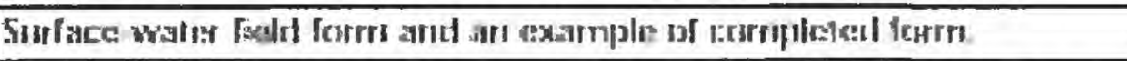 & \\
\hline & 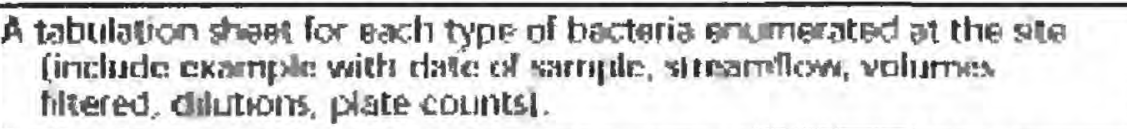 & \\
\hline & 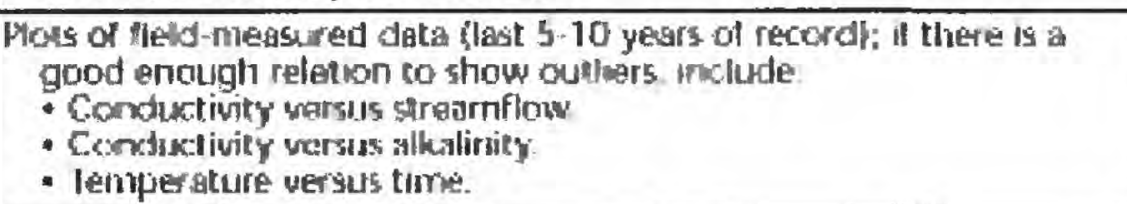 & \\
\hline & 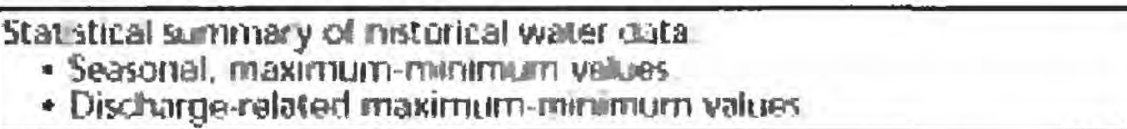 & \\
\hline & $\begin{array}{l}\text { Special equapmant noeded to address site-specific conditions } \\
\text { : Sarmpling } \\
\text { - Safery. }\end{array}$ & \\
\hline
\end{tabular}

Vater Data Collection

Table 1. . Checklist for contents of stuface-water-sampling field folder. 


\section{Section 2.2}

\section{EOUIPMENT FOR WATER-OUALITY SAMPLING}

\section{CHEMICAL COMPATIBILITY OF EQUIPMENT AND THE WATER SAMPLE}

The materials used to construct equipment can directly affect sample. Equipment designed for water-quality work commonly is constructed of a combination of materials, the most inert being used for components that will contact the sample. Nonsample-wetted components also can be a source of sample contamination, and field personnel must use techniques to minimize potential contamination, implement quality-assurance procedures, and quantify potential effects by using quality-control sample analysis.

Materials used in equipment can include plastics, glass, and metals. Chemical reactivity varies widely within the same group of materials, depending on the chemical composition, the physical configuration, and the manufacturing process. Thus, regarding reactivity with water and most other chemical substances, plastics such as fluorocarbon polymers are less reactive than plastics such as polyethylene, and 316-type stainless steel (SS 316) is less reactive than brass, iron, or galvanized steel. For plastics and metals in general: The softer or more flexible forms of any plastic or metal are more reactive than the rigid forms. The more polished the surface, the less reactive the material tends to be. Table 2 provides general guidelines for selection of appropriate sampling equipment materials.

When planning equipment use, consider having several sets of precleaned equipment available. A clean set of equipment for each sampling site prevents cross contamination between sites, eliminates the need for time-consuming equipment cleaning in the field, and serves as backup should equipment break or become greatly contaminated.

\section{SURFACE-WATER SAMPLING EQUIPMENT}

Study objectives, flow conditions, and sampling structures (such as a bridge, cableway, or boat) must be considered when determining which sample-collection equipment to use. The equipment selected depends on whether the stream can be waded (preferred) or not. To determine whether stream depth and velocity are too great to wade safely follow this rule of thumb:

RULE OF THUMB: Do NOT wade in flowing water when the product of depth (in feet) and velocity (in feet per second) equals 10 or greater.

Application of this rule varies among individuals according to their weight and stature, and to the condition of the streambed. 
Two primary types of surface-water samplers are used by the USGS:

- Isokinetic depth-integrating samplers

- Nonisokinetic samplers

\section{Isokinetic Depth-Integrating Samplers}

An isokinetic depth-integrating sampler is designed to accumulate a representative water sample continuously and isokinetically (that is, stream water approaching and entering the sampler intake does not change in velocity) from a vertical section of a stream while transiting the vertical at a uniform. Isokinetic depth-integrating samplers are categorized into two groups, based on the method of suspension: hand-held samplers and cable-andreel samplers.

Types and pertinent characteristics of isokinetic depth-integrating samplers recommended for sampling in flowing water are summarized in Table 3, illustrated on Figure 1, and described below.

\section{For collection of an isokinetic sample,minimum stream velocity must begreater} than 1.5 feet per second (ft/s) for a depth-integrating sampler with a rigid bottle, or $3.0 \mathrm{ft} / \mathrm{s}$ for a bag sampler.

The maximum allowable transit rate $(\mathrm{Rt})$ relative to mean velocity $(\mathrm{Vm})$ for a given sampler varies with nozzle size and sample-bottle size (table 2). Do not exceed the listed $\mathrm{Rt} / \mathrm{Vm}$ ratio for the given nozzle and bottle size. A lower $\mathrm{Rt} / \mathrm{Vm}$ is better for ensuring that a representative velocity-weighted sample is collected, but care must be taken to not overfill the sampler bottle.

The cap and nozzle assembly is available in fluorocarbon polymer and polypropylene. The same cap and nozzle can be used for the US DH-81, US D-95, and the US D-77. If the cap vent is plugged, the same cap and nozzle can be used for bag-type samplers. In addition, fluorocarbon polymer adapters are available to mate the cap to either 1-L or 3-L fluorocarbon polymer bottles.

Use the US DH-81, US D-95, US D-77, D-77 Bag, or Frame-Bag (FB) samplers to collect samples in flowing waters for all analyses except inorganic gases and volatile organic compounds.

- Samples of water for determination of metals and other trace elements (hereafter referred to collectively as "trace elements") must contact only noncontaminating materials, typically flurocarbon polymer or polypropylene.

- Samples of water for determination of organic compounds must contact only noncontaminating materials, typically metal (such as stainless steel), fluorocarbon polymers (such as TeflonTM), or ceramics (such as hard-fused microcrystalline alumina). 
Do not use the US DH-48, US DH-59, US DH-76, US D-49, US D-74, US P-61, US P63, and US P-72 samplers for collecting trace-element samples: they contaminate samples with measurable concentrations of trace elements.

- Some of these samplers may be acceptable for major ions, nutrients, and suspended sediments.

- Additional quality-control samples need to be collected if it is necessary to use any of these samplers. 


\begin{tabular}{|c|c|c|c|}
\hline \multicolumn{4}{|c|}{ 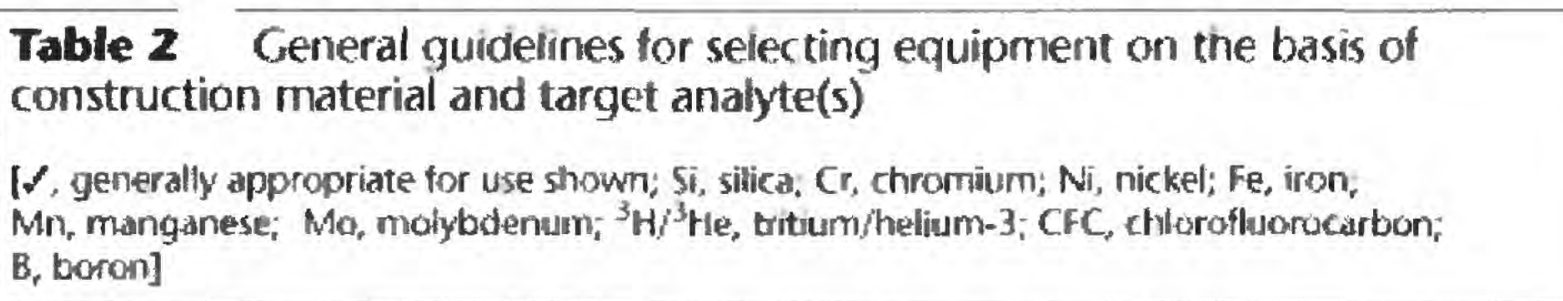 } \\
\hline \multicolumn{2}{|c|}{$\begin{array}{l}\text { Construction material for } \\
\text { campling equiponent } \\
\text { (does not apply to well casing) }\end{array}$} & \multicolumn{2}{|c|}{ Target analyte(s) } \\
\hline Materlal & Description & Inorganic & Organic \\
\hline \multicolumn{4}{|c|}{ ['lastics $^{1-}$} \\
\hline $\begin{array}{l}\text { Fluorocarbon } \\
\text { polymers (other } \\
\text { varieties available } \\
\text { for differing } \\
\text { applications) }\end{array}$ & $\begin{array}{l}\text { Chemically inert for most } \\
\text { analytes }\end{array}$ & $\begin{array}{l}\text { (Potential source of } \\
\text { fluoride.) }\end{array}$ & $\begin{array}{l}1 \\
\text { (Sorption } \\
\text { of some } \\
\text { organics.) }\end{array}$ \\
\hline Polypropylene & $\begin{array}{l}\text { Relatively inert for } \\
\text { inorganic analytes. }\end{array}$ & $\checkmark$ & Do not use. \\
\hline Polyethylene (linear) & $\begin{array}{l}\text { Relatively inert for } \\
\text { inorganic analytes. }\end{array}$ & $\checkmark$ & Do not use. \\
\hline $\begin{array}{l}\text { Polyvinyl chloride } \\
\text { (PVC) }\end{array}$ & $\begin{array}{l}\text { Relatively inert for } \\
\text { inorganic analytes. }\end{array}$ & $\checkmark$ & Do not use. \\
\hline Silicone & $\begin{array}{l}\text { Very porous. Relatively inert } \\
\text { for most inorganic } \\
\text { analyte(s). }\end{array}$ & (Patential source of $\mathrm{Si}$ ) & Do not use. \\
\hline \multicolumn{4}{|c|}{ Metasls $^{3}$} \\
\hline $\begin{array}{l}\text { Stainless steel } 316 \\
\text { (5S 316) }\end{array}$ & $\begin{array}{l}\text { 55-316- metal having the } \\
\text { greatest corrosion resis- } \\
\text { tance Comes in various } \\
\text { grades. } \\
\text { Used for submersible pump } \\
\text { casing }\end{array}$ & $\begin{array}{l}\text { (Potential source of } \mathrm{Cr}, \mathrm{Ni} \text {, } \\
\mathrm{Fe} \text {, and possibly Mn } \\
\text { and Mo) } \\
\text { Do not use for surface } \\
\text { water unless encased in } \\
\text { plastic (does not apply } \\
\text { to submersible pumps) }\end{array}$ & $\begin{array}{c}\text { Do not use if } \\
\text { corroded. }\end{array}$ \\
\hline Stainless steel 304 & $\begin{array}{l}\text { Similar to } 55316 \text {, but less } \\
\text { corrosion resistant. }\end{array}$ & Do not use. & $\begin{array}{l}\text { Do not use if } \\
\text { corroded. }\end{array}$ \\
\hline $\begin{array}{l}\text { Other metals: brass, } \\
\text { Iron, copper, } \\
\text { aluminum, } \\
\text { galvanized and } \\
\text { carbon steels }\end{array}$ & $\begin{array}{l}\text { Refrigeration grade copper or } \\
\text { aluminum tubing are used } \\
\text { routinely for collection of } \\
{ }^{3} \mathrm{H} s^{3} \text { He and CFC samples }\end{array}$ & $\begin{array}{l}\text { Do not use. } \\
\text { (except as noted for } \\
\text { isotopes) }\end{array}$ & $\begin{array}{l}\text { Routinely used } \\
\text { for CFCs } \\
\text { Do not use if } \\
\text { corroded. }\end{array}$ \\
\hline \multicolumn{4}{|c|}{ Gians } \\
\hline $\begin{array}{l}\text { Glass, borosilicate } \\
\text { (laboratory grade) }\end{array}$ & $\begin{array}{l}\text { Relatively inert. Potential } \\
\text { sorption of analytes. }\end{array}$ & $\begin{array}{l}\text { Potential spurce of } B \text { and } \\
\text { Si }\end{array}$ & $\gamma$ \\
\hline
\end{tabular}

TPlastics used in connection with incryanc trace-element sampling must be uncolored or white (Horowitz and others, 1994)

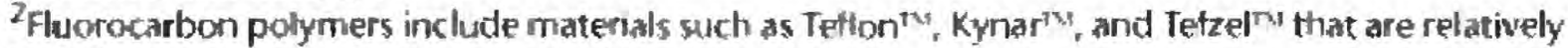
inert for sampling inorganic or organic analytes.

${ }^{3}$ Most submersible sampling pumps have slainless steet components. One can minimize eftects on inorganics sample by using fluorocarbon polymets in construction of sample-wetted components (for example, for a bladder, stator, inpefler) to the extent possible

${ }^{4}$ Corroded/weathered surfaces are active sorption sites for organic compounds. 


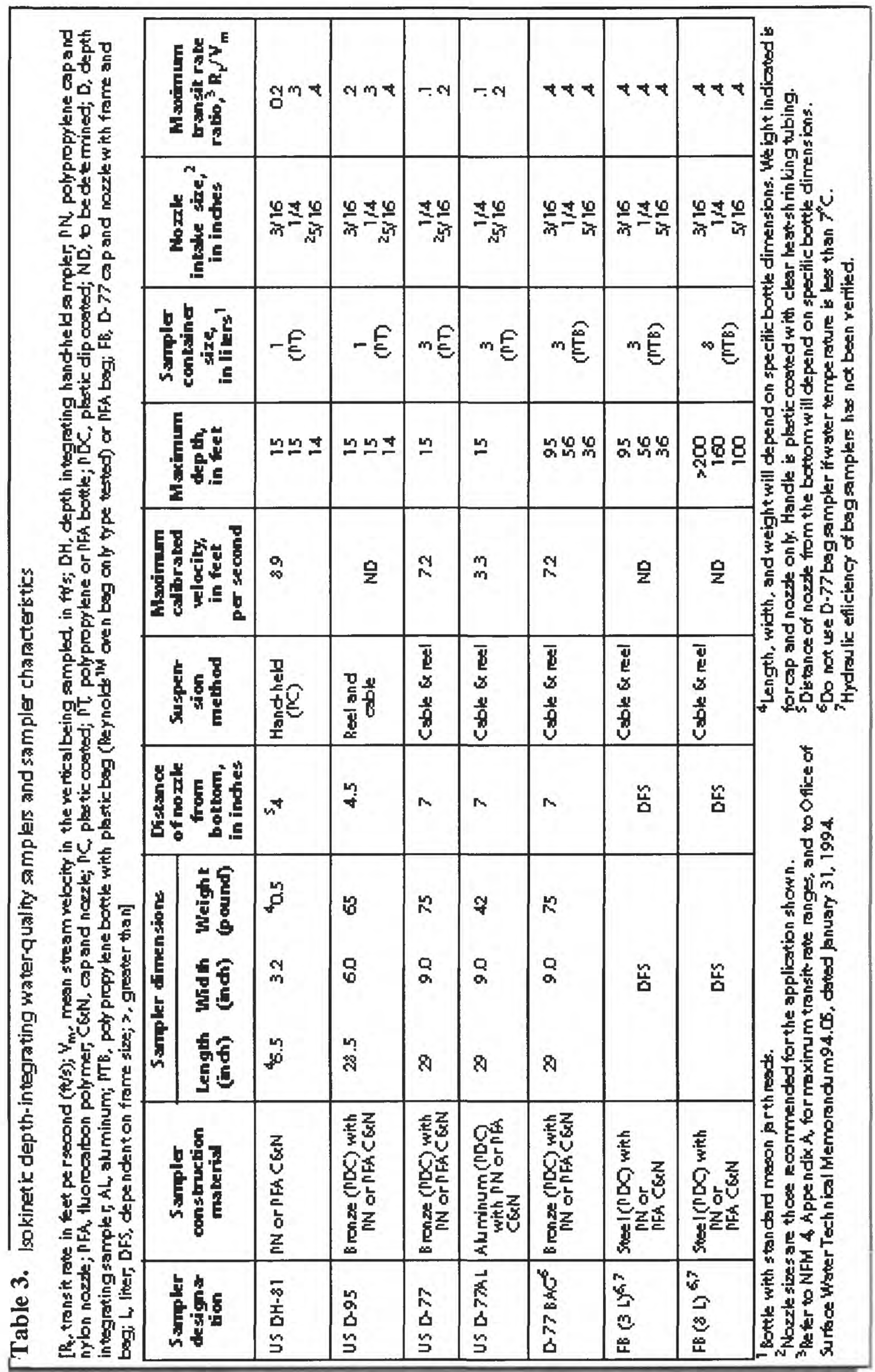



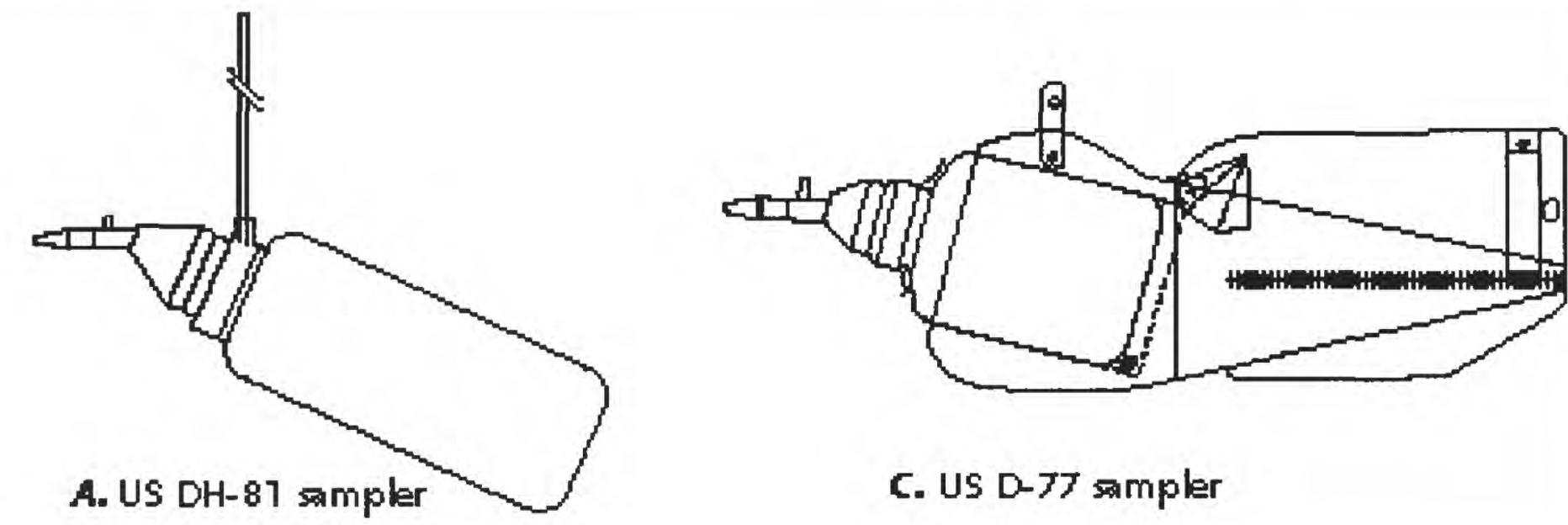

C. US D-TT sampler

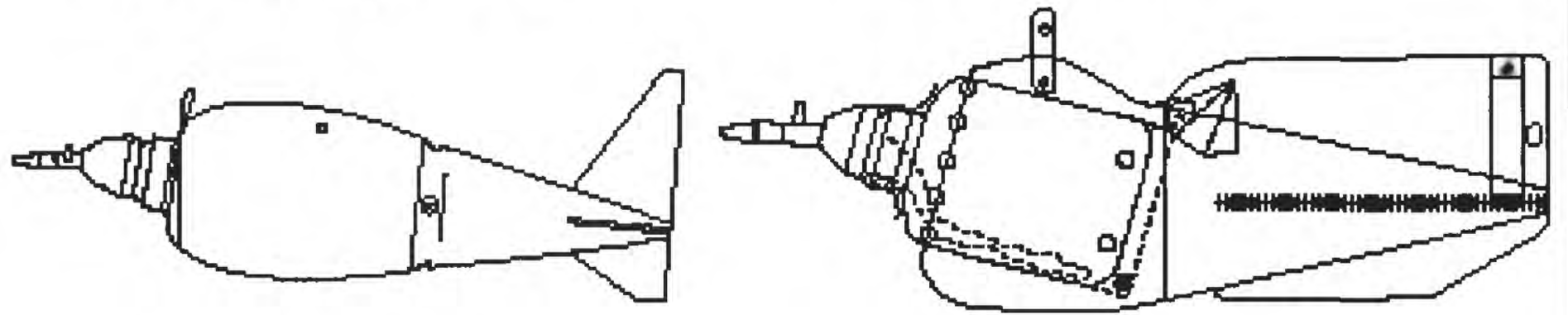

B. USD 95 smpler

D. D-TT bag sampler (current meter not a ttached)

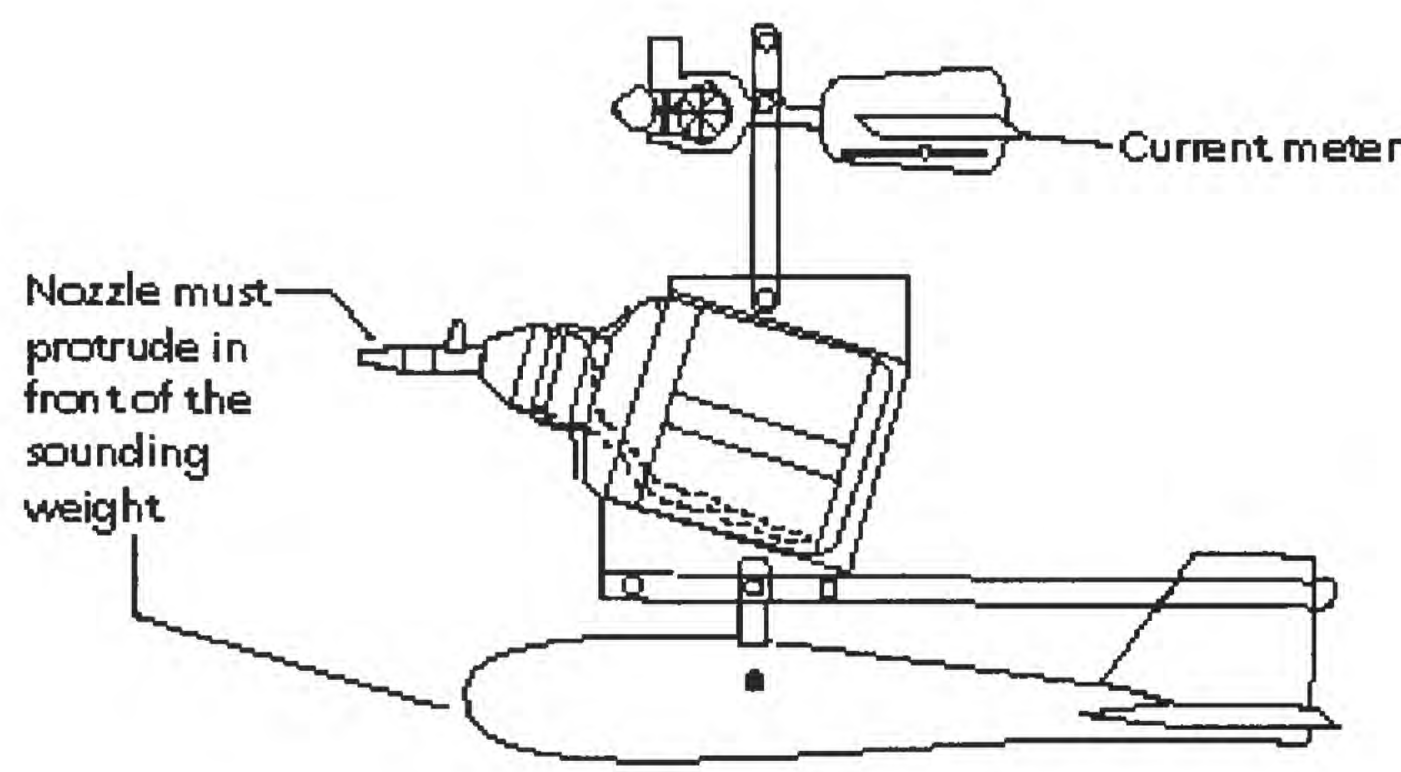

E. Frame-bag sampler with sounding weight (current meter attached)

Not to scale

Figure 1. Isokinetic depth-integrating samplers: (A) US DH-81, (B) US D-95, (C) US D-77, (D) D-77 Bag without current meter attached, and (E) Frame-Bag sampler with sounding weight and current meter attached. (lllustrations courtesy of Federal Interagency Sedimentation Project, Waterways Experiment Station, Vicksburg Miss.) 


\section{Hand-held samplers}

The US DH-81 (Fig. 1-A) or US D-95 (Fig. 1-B) sampler is used to collect water samples where flowing water can be waded or where a bridge is accessible and low enough to sample from. The sampler components (cap, nozzle, and bottle) are interchangeable. Both inorganic and organic samples can be collected with either sampler as long as the construction material of the sampler components (Table 2) does not affect ambient concentrations of target analytes. Isokinetic depth-integrated samples for bacteria analysis also can be collected with these samplers because the cap, nozzle, and bottle can be autoclaved.

When using the US DH-81:

- Use a $1 / 4$ - or 5/16-in. nozzle.

- Make sure that flow velocity exceeds $1.5 \mathrm{ft} / \mathrm{s}$ (to collect an isokinetic sample).

- Use the 1-L bottle (not the 3-L bottle).

When using the US D-95:

- Use either a 3/16-, 1/4-, or 5/16-in. nozzle.

- Make sure that flow velocity exceeds $1.5 \mathrm{ft} / \mathrm{s}$ (to collect an isokinetic sample).

- Use the 1-L bottle. 


\section{Cable-and-reel samplers}

Cable-and-reel samplers are used to collect water samples where flowing water cannot be waded. These include the US D-77, the D-77 Bag, and the Frame-Bag samplers. (Refer to Table 2 for sampler characteristics and sampling limitations.) Like the US DH-81 and US D-95, these samplers can be used for collecting inorganic and organic samples; however, sampler components (cap, nozzle, and bottle) must be selected so as not to bias concentrations of target analytes. Isokinetic depth-integrated samples for bacteria analysis also can be collected with these samplers because the cap, nozzle, bottle, and bags can be autoclaved.

The US D-77 sampler (Fig. 1-C) is used where water is less than $15 \mathrm{ft}$ deep. The D-77 Bag and the Frame-Bag (FB) samplers (Fig.1-D, E) are designed to collect isokinetic depth-integrated samples at depths greater than $15 \mathrm{ft}$. The capability of collapsible bagtype samplers to collect isokinetic depth-integrated water-quality samples is being evaluated by the USGS.

Metal parts of the US D-77 Bottle sampler and D-77 Bag and Frame-Bag samplers must be coated with plastic ("plasti-dip") and recoated periodically to prevent possible sample contamination from metallic surfaces.

When using the US D-77 bottle sampler:

- Use a 5/16-in. nozzle.

- Make sure that flow velocity exceeds $1.5 \mathrm{ft} / \mathrm{s}$.

- Use in water less than $15 \mathrm{ft}$ deep for an isokinetic, depth-integrated sample.

When using the D-77 Bag sampler:

- Use a 1/4- or 5/16-in. nozzle.

- Make sure that flow velocity exceeds $3 \mathrm{ft} / \mathrm{s}$ (to collect an isokinetic sample). Isokinetic capability decreases at flow

- velocities less than $3 \mathrm{ft} / \mathrm{s}$.

- Use in water with depth greater than $15 \mathrm{ft}$ for an isokinetic, depth-integrated sample.

- Make sure that a clean, noncontaminating object such as a glass (not rubber) bottle stopper is in the bag.

- Water temperature must be above $8^{\circ} \mathrm{C}$.

The D-77 Bag sampler uses a collapsible ReynoldsTM oven or fluorocarbon polymer bag that is placed in a special slotted 3-L bottle with a US D-77 cap and nozzle assembly in which the vent is plugged. The Frame-Bag sampler uses a collapsible bag that is placed in a special slotted 3- or 8-L bottle (Fig. 1-E) with a US D-77 cap and nozzle assembly in 
which the vent is plugged. The slotted bottle is held in a plastic-coated metal frame to which various sizes of sounding weights can be attached. The size of the weight depends on the stream velocity along the cross section that will be sampled. The advantages of the Frame-Bag sampler over the D-77 Bag sampler are that the Frame-Bag sampler can be used to collect a larger sample volume and, therefore, to sample greater depths; and it can be used to collect samples in streams with greater velocities because heavier weights can be attached to maintain proper orientation of the sampler in the stream. Another advantage of the D-77 Bag sampler over the Frame-Bag sampler is that use of the D-77 Bag sampler results in a smaller unsampled zone (distance between the nozzle and the bottom of the sampler).

When using the Frame-Bag sampler:

- Use a 3/16-, 1/4- or 5/16-in. nozzle (not a 1/8-in. nozzle).

- Make sure that flow velocity exceeds $3.0 \mathrm{ft} / \mathrm{s}$ (to collect an isokinetic sample).

- Keep a clean, noncontaminating object such as a glass bottle stopper or a fluorocarbon polymer-coated magnetic stirring bar in the bag. Do not use a rubber stopper.

- Water temperature must be above $8^{\circ} \mathrm{C}$. 


\section{Nonisokinetic Samplers}

\section{Open-mouth samplers}

Open-mouth samplers used for the collection of water samples include the hand-held bottle, the weighted-bottle sampler, the BOD sampler, and the VOC sampler (Fig. 2).

The hand-held bottle sampler is the simplest type of open-mouth sampler. A bottle is dipped to collect a sample (Fig. 2-A) where depth and velocity are less than the minimum requirements for depth-integrated samplers.

The weighted-bottle sampler is available in stainless steel (US WBH-96) (Fig. 2-B) or polyvinyl chloride. The weighted-bottle sampler can be used to collect samples where flow velocities are less than the minimum requirement for isokinetic depth-integrating samplers and where the water body is too deep to wade. An open bottle is inserted into a weighted holder that is attached to a handline for lowering. Sampling depth is restricted by the capacity of the bottle and the rate of filling.

The biochemical oxygen demand (BOD) sampler and the volatile organic compound (VOC) sampler (Fig. 2-C,D), are open-mouth samplers designed to collect nonaerated samples. The BOD sampler accommodates $300-\mathrm{mL}$ glass BOD bottles specifically designed to collect samples for dissolved-oxygen. The VOC sampler is specifically designed to collect nonaerated samples in $40-\mathrm{mL}$ glass septum vials for determination of volatile organic compounds.

\section{Thief samplers}

Thief samplers are used to collect instantaneous discrete (point) samples. Thief samplers have been used primarily to collect samples from lakes, reservoirs, and some areas of estuaries. Smaller versions, designed to collect ground-water samples, also have been used in still and flowing surface water. The most commonly used thief samplers are the Kemmerer sampler, Van Dorn sampler, and double check-valve bailer with bottomemptying device (Fig. 3). These samplers are available in various sizes, mechanical configurations, and in various types of construction material (such as stainless steel, glass, polyvinyl chloride, fluorocarbon polymer). Disposable fluorocarbon polymer bailers also are available. 

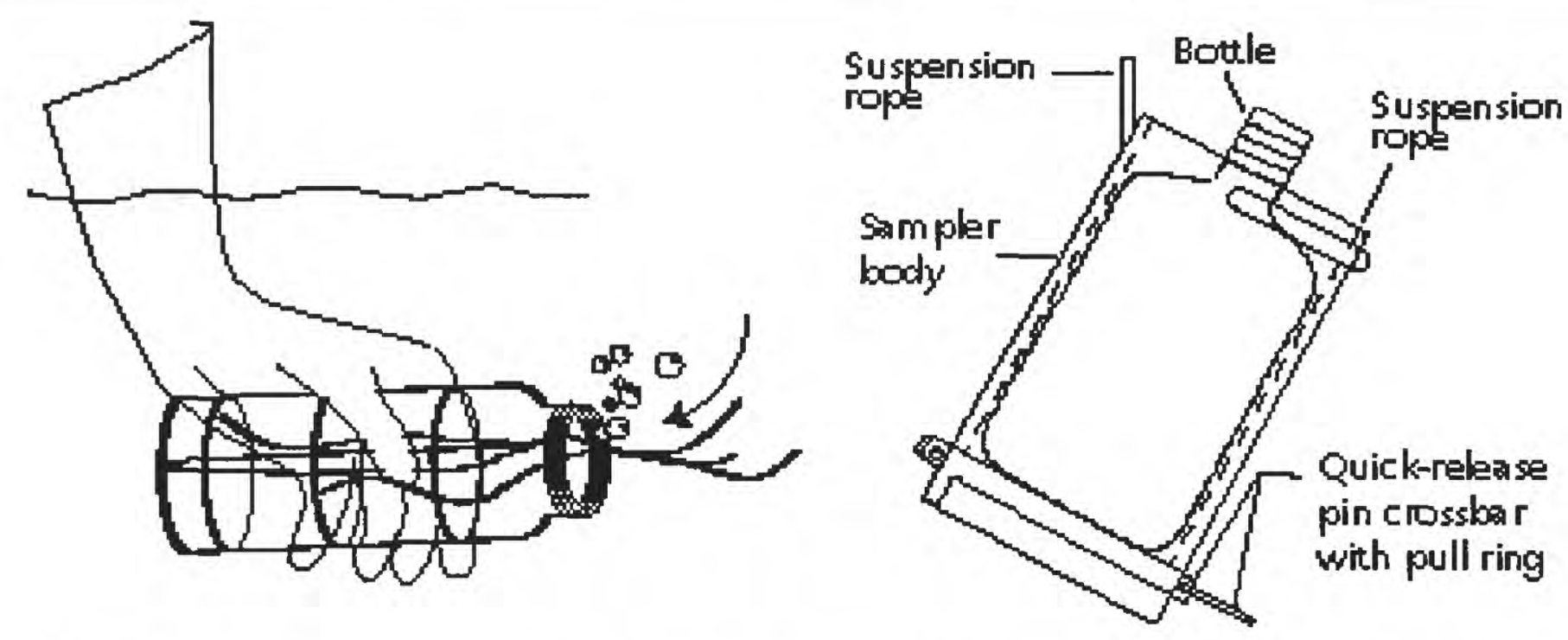

A. Hand-held open-mouth bottle sampler

B. US WBH-96 weighted bottle sampler

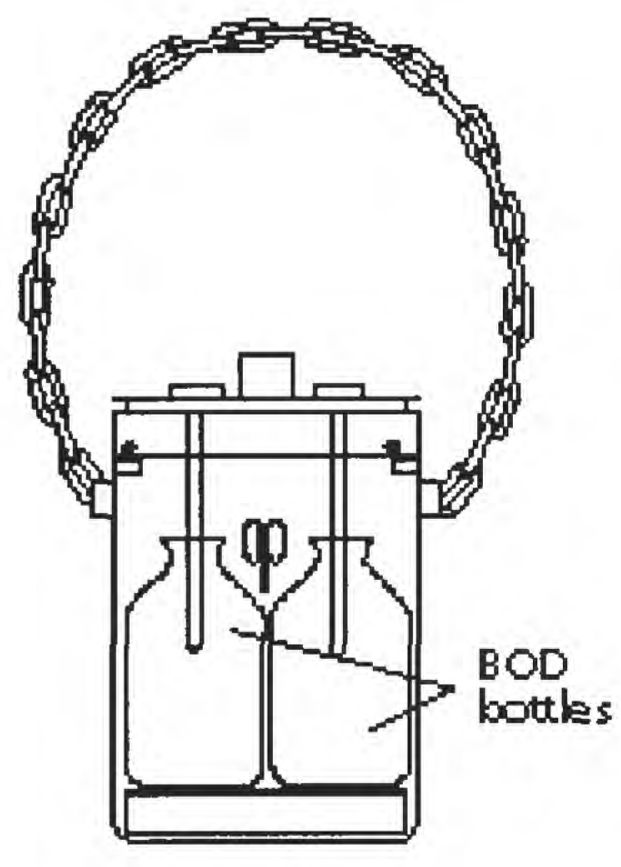

C. BOD sampler

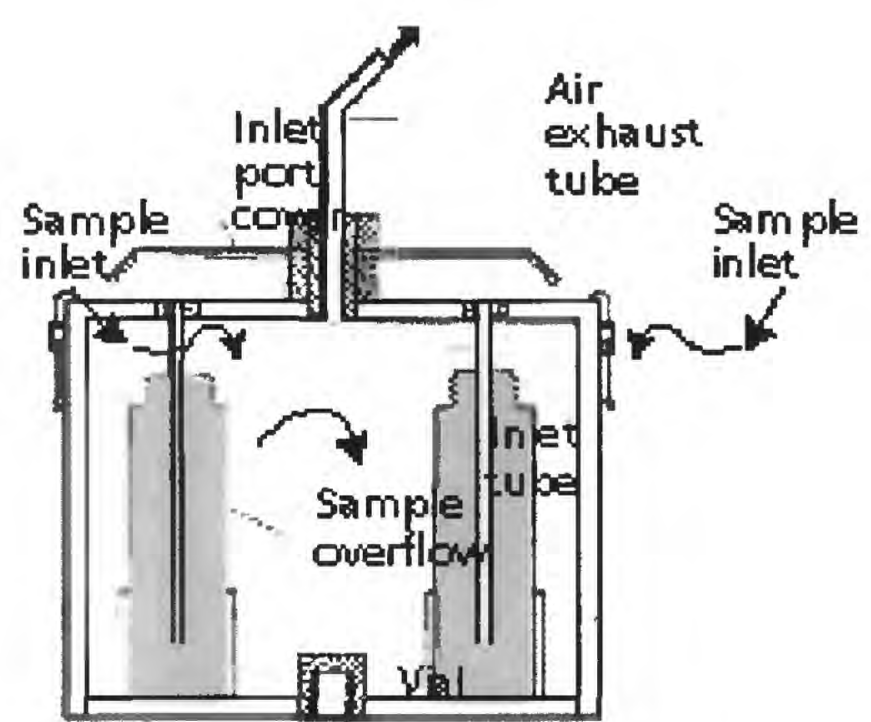

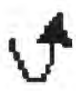

D. WOC mpler

Not to scak

Figure 2. Examples of nonisokinetic open-mouth samplers: (A) hand-held open-mouth bottle sampler, (B) US WBH-96 weighted-bottle sampler, (C) biochemical oxygen demand (BOD) sampler, and (D) volatile organic compound (VOC) sampler. (A, from U.S. Environmental Protection Agency, 1 982b; $B$ courtesy of Federal Interagency Sedimentation Project, Watenways Experiment Station, Vicksburg, Miss.; $C_{1}$ published with permission of Wildlife Supply Company; D, from Shelton, 1997.) 


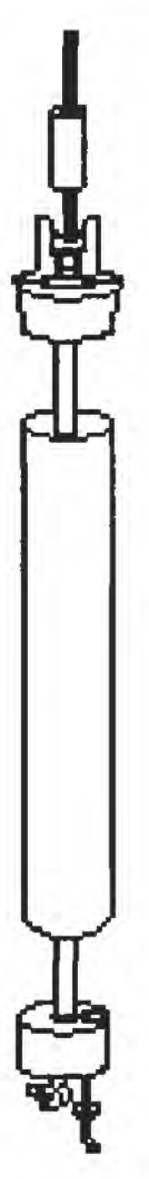

A. Kemmerer sampler
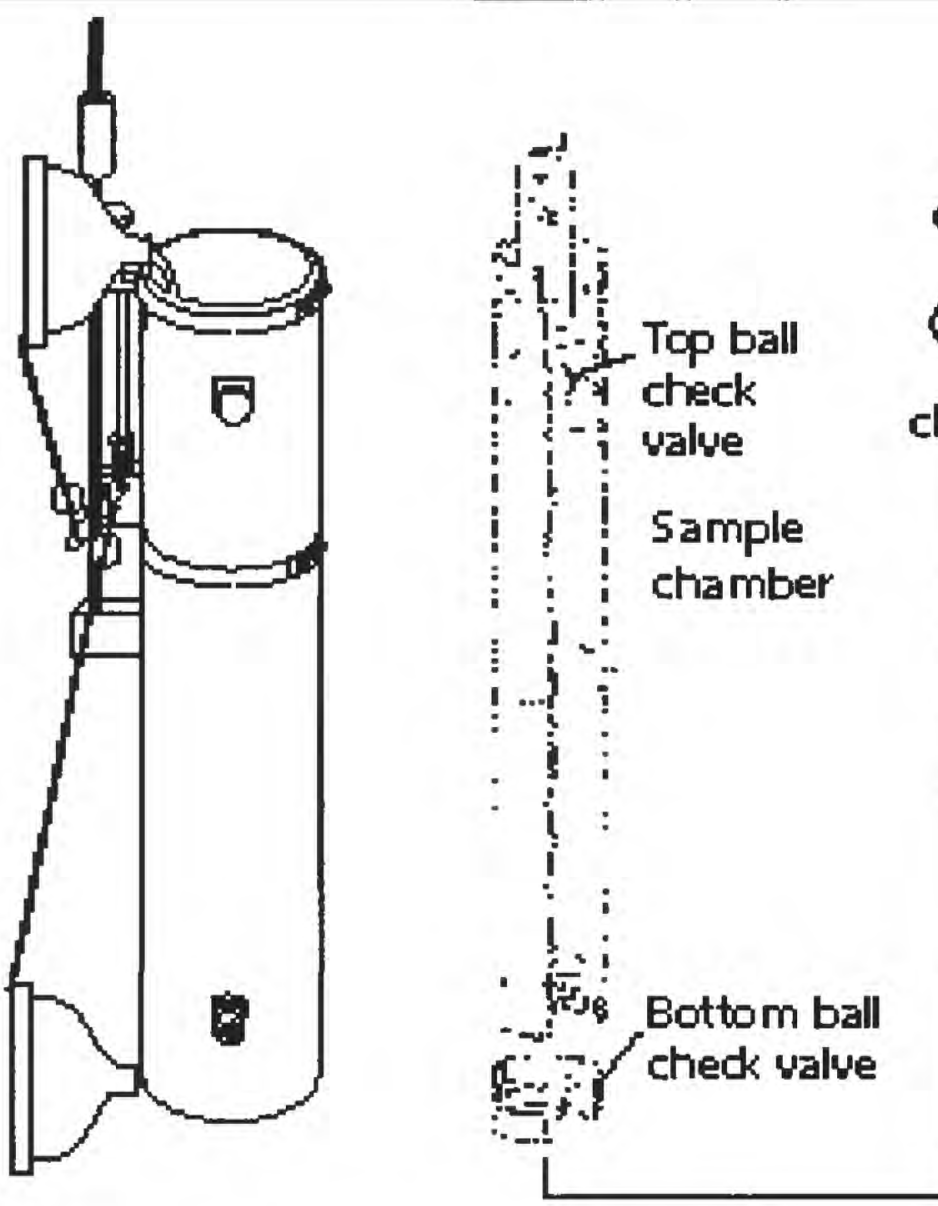

\section{Bottom-} emptying device (fit under bottom check value)

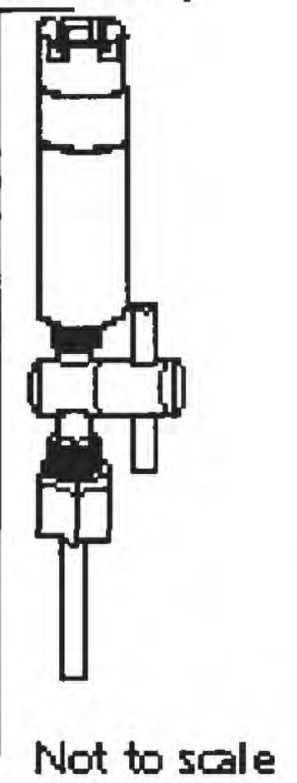

C. Double theck-yal ue bailer and bottom-e mptying device

Figure 3. Examples of nonisokinetic thief samplers: (A) Kemmerer sampler, (B) Van Dorn sampler, and (C) double check-valve bailer with bottom-emptying device. (A-B, from Standard Methods for Examination of Water and Wastewater, 18th Edition. Copyright 1992 by the American Public Health Association, the American Water Works Association and the Water Environment Federation. Used with permission.; C, published with permission of Timco Mfg. Inc.) 


\section{Automatic samplers and pumps}

Automatic pumping samplers with fixed-depth intake(s) are sometimes used to collect samples at remote sites; from ephemeral, small streams; or from urban storm drains where stage rises quickly. These samplers can be programmed to collect samples at preset time intervals or at selected stages, thus reducing the personnel requirements for time-intensive sampling. Whenever automatic samplers or pumps are used, the sample is considered to be a point or grab sample.

Pumps used for water sampling are grouped into two general categories: suction-lift pumps and submersible pumps. Pumps can be used to collect water samples from lakes, reservoirs, and.

\section{SAMPLE PROCESSING}

Water samples must be processed as quickly as possible after collection. The equipment most commonly used for sample processing includes sample splitters, filtration units or assemblies, solid-phase extraction systems, and chambers in which samples are processed and treated with chemical preservatives. Having several available sets of cleaned processing equipment is recommended.

\section{SAMPLE SPLITTERS}

The collection of surface water generally results in a single composite sample. A groundwater sample generally is not composited; instead the sample is pumped directly into separate bottles for designated analyses. There are exceptions. For example, a groundwater sample can be composited when the sample is collected using a nonpumping method (bailer or thief sampler).

Once a sample has been composited, the sample is often subdivided (split) into subsamples for analysis. Each whole-water subsample should contain suspended and dissolved concentrations of target analytes that are virtually equal to those in every other subsample.

\section{Churn Splitter.}

An 8 or 14-L plastic churn splitter is recommended to composite and split surface-water samples for trace-element analysis (Figure 4). Stainless steel and glass containers are used to composite samples for organic analysis. To avoid sample contamination, do not collect or extract samples for trace-element analyses from a metal container, or samples for organic-compound analysis from a nonflurocarbon-polymer plastic container.

Advantages of the churn splitter:

- Simple to operate.

- Easy to clean. 
Limitations of the churn splitter:

- Although it can be used to split samples with particle sizes $250 \mu \mathrm{m}$ and suspended-sediment concentrations $1,000 \mathrm{mg} / \mathrm{L}$, splitting accuracy becomes unacceptable for particle sizes $>250 \mu \mathrm{m}$ and

- suspended-sediment concentrations $>1,000 \mathrm{mg} / \mathrm{L}$.

- Sample volumes less than $3 \mathrm{~L}$ or greater than $13 \mathrm{~L}$ cannot be split for whole-water subsamples.

- Plastic (nonfluorocarbon polymer) churn splitters should not be used to composite samples for determination of organic compounds.

- Samples for bacteria determinations are not to be taken from a churn splitter because the splitter cannot be autoclaved.

\section{Cone Splitter}

The cone splitter is a pour-through device constructed entirely of fluorocarbon polymers (Figure 5). The cone splitter may be used to process samples with particle sizes $250 \mu \mathrm{m}$ and suspended-sediment concentrations $10,000 \mathrm{mg} / \mathrm{L}$. Its primary function is to split the sample simultaneously into as many as 10 equal-volume samples. Some cone splitters have a $2-\mu \mathrm{m}$ mesh screen in the reservoir funnel to retain large debris, such as leaves and twigs, that could clog or interfere with the splitting process. Below the funnel is a short standpipe that directs sample water in a steady stream, into a splitting chamber that contains a notched, cone-shaped splitting head with 10 equally spaced exit ports around its base. There should be no ridges, benches, or surfaces inside the splitting chamber that could retain material or interfere with the splitting process. The cone splitter is supported either by tripod legs or with an adjustable clamp and stand.

The cone splitter is built to very close tolerances in order to achieve accurate and reliable operation. Bias to data can result from splitter imperfections or improper operation; therefore, calibration and proper use is necessary when processing samples.

Advantages of the cone splitter:

- Used to process samples with suspended-sediment concentrations from 1,000 to $10,000 \mathrm{mg} / \mathrm{L}$.

- Samples as small as $250 \mathrm{~mL}$ can be split into 10 equal subsamples.

- Samples greater than $13 \mathrm{~L}$ can be processed.

- Samples to be analyzed for organic compounds (except for volatile organic compounds) can be processed through the fluorocarbon polymer cone splitter.

- Samples containing sediment particles ranging in size from very fine clay and silt ( 1 to $10 \mu \mathrm{m})$ to sand-size particles $(250 \mu \mathrm{m})$ can be split.

Limitations of the cone splitter:

- Accuracy of the volume equivalents must be verified before using a new or modified cone splitter 
- Splitter is awkward to operate and clean in the field.

- Sample is vulnerable to contamination from atmospheric sources or from improper operation.

- Splitting capability for sediment particles $>250 \mu \mathrm{m}$ must be quantified.

- Samples for bacteria determinations are not to be collected with the cone splitter because the splitter cannot be adequately sterilized.

- The cone splitter must be level for proper operation.

\section{PROCESSING AND PRESERVATION CHAMBERS}

Processing and preservation chambers reduce the possibility of random atmospheric contamination during sample splitting, filtration, and preservation. These chambers are required for samples for trace-element determinations. The processing chamber can serve also as a collection chamber for pumped samples. There is no standard design for either fixed or portable chambers; however, to prevent contamination of inorganic samples with metals, the materials used in their construction should be either nonmetallic or completel covered by or embedded in nonmetallic material. Plastic components have been tested and do not emit volatile substances that might contaminate a VOC sample. This can be further documented by collecting an ambient blank in the chamber(s).

Fixed chambers can be enclosures permanently installed in a field vehicle for the sole purpose of sample collection, processing, or preservation. Fixed chambers must not be used as a storage area. The portable chamber illustrated is inexpensive and easily constructed with 1/2-in. white polyvinyl chloride (PVC), tubes which are used to support a clear plastic bag (Fig. 6). The transparent bag forms a protective tent to work within while collecting, processing, or preserving samples. Another option is to purchase or construct a fixed or portable glove box. The glove box also should have no exposed metal parts. Glove boxes that can be filled with inert gas should be used for samples to be excluded from contact with atmospheric gases. 


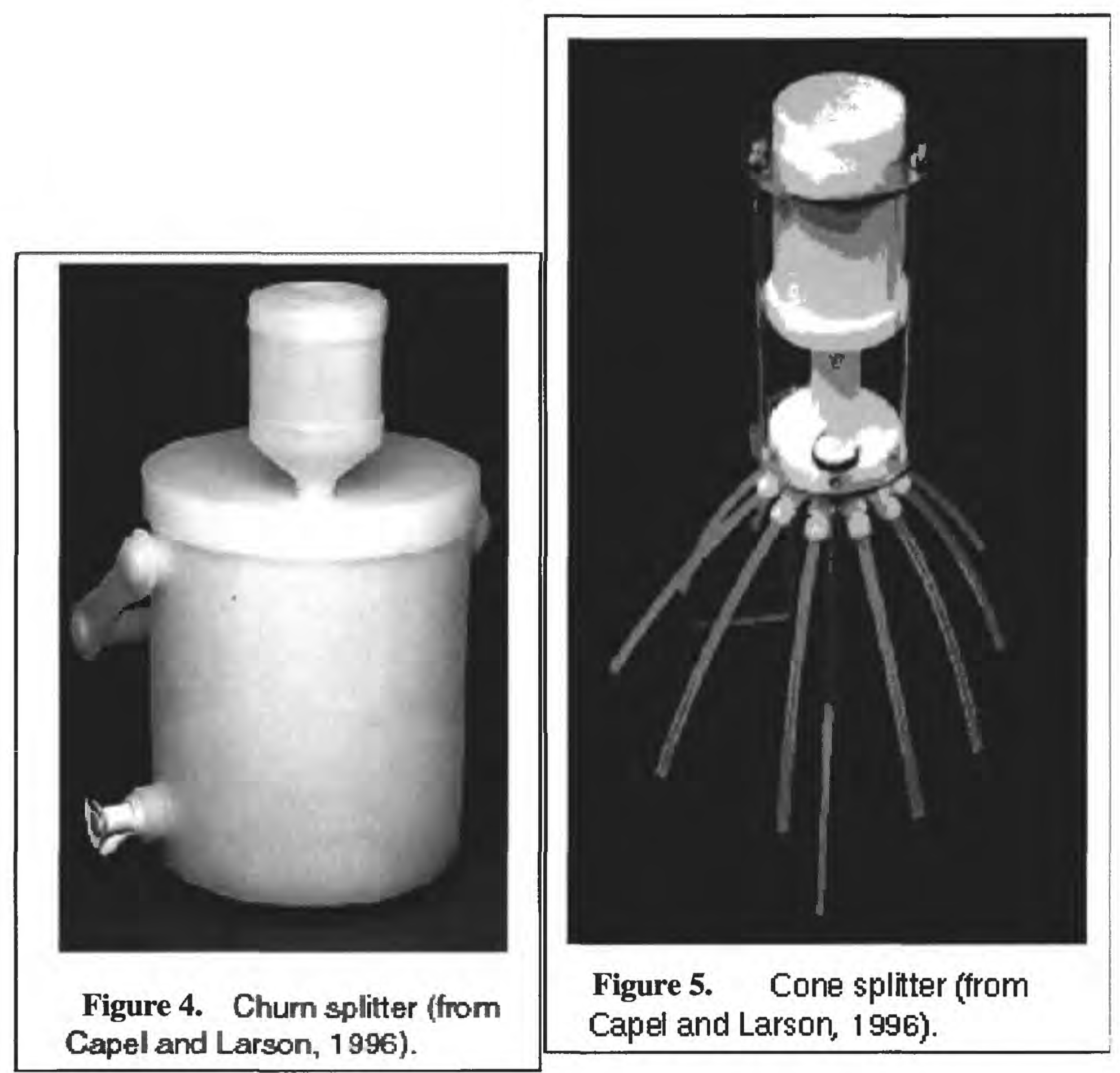




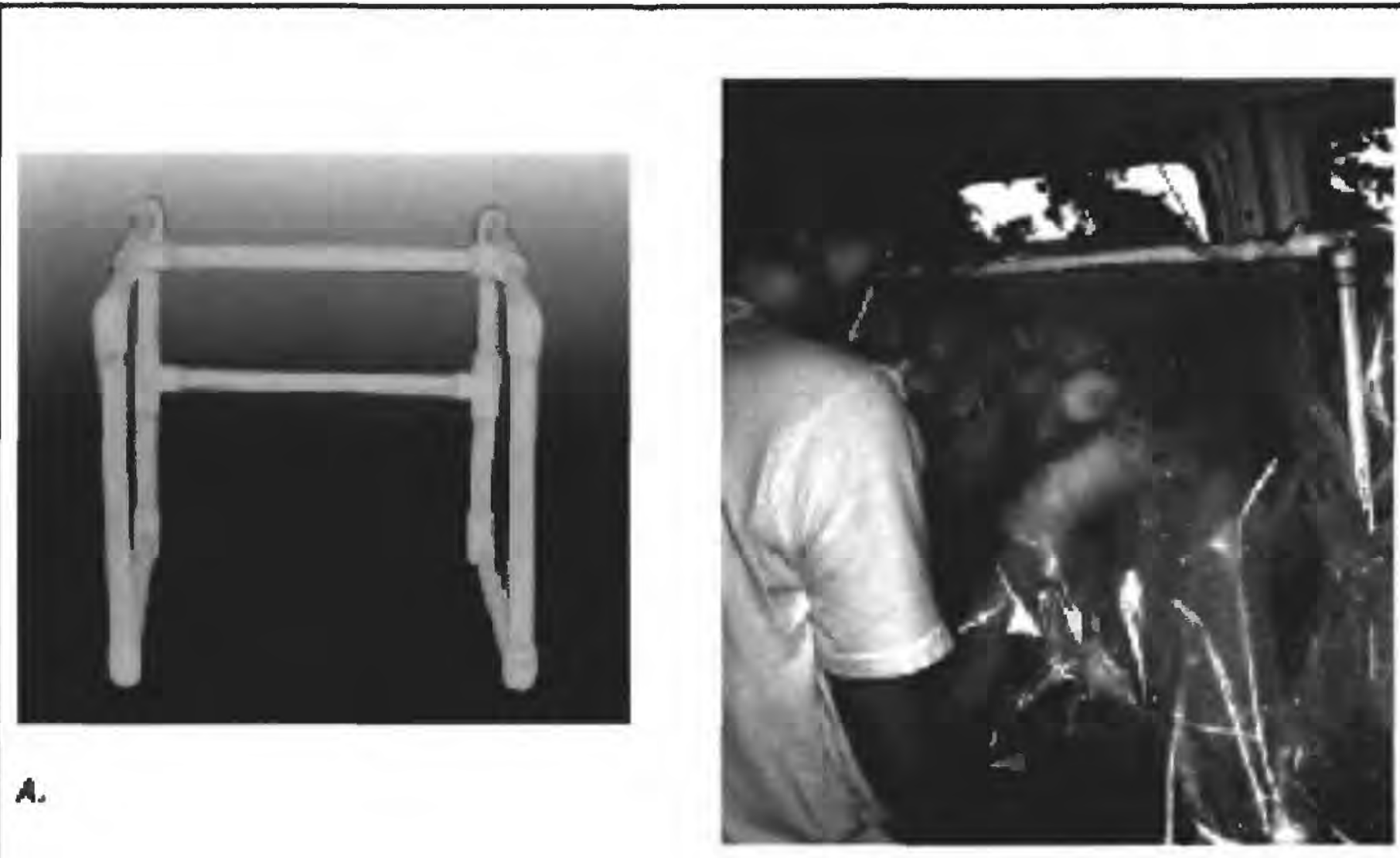

B.

Figure 6. Example of (A) a polyvinyl chloride frame of a processing or preservation chamber, and $(B)$ sample being processed within the chamber. (A, Photograph by B.A. Bernard; B, photograph by Jacob Gibs.) 


\section{FILTRATION SYSTEMS}

Filtration separates particulate substances (solid-phase and biological materials) from the solute or aqueous phase of a water sample. Water samples are filtered for analysis of inorganic constituents, organic compounds, and biological materials to help determine the environmental fate and quantify the transport of these target analytes.

For surface water, the most common filtration system consists of a reversible, variablespeed battery-operated peristaltic pump or a metering pump that forces the whole-water sample through tubing into a filter assembly. For ground water, the sample ordinarily is pumped through a sample line directly into a filter assembly. If the sample is collected by bailer, the sample generally is emptied through a valve with fluorocarbon polymer tubing and is transferred to the filter assembly by means of a peristaltic pump. Some bailers can be directly fitted with a filter and hand-pump system.

TECHNICAL NOTE: Separation of solid from aqueous phases can be achieved by methods other than filtration, and data requirements may dictate the need for an alternative method such as centrifugation, ultracentrifugation, dialysis or lipidmembrane separation, and reverse-flow osmosis and tangential-flow filtration.

The filter assembly to be used depends on the type of target analytes, which are discussed in the following sections. Membrane filters commonly used to filter inorganic samples generally are made of cellulose nitrate, polycarbonate polymers, or polyethersulfonebased media. These filter media are not suitable for filtering samples to be analyzed for organics; glass microfiber is the media used for filtering most organic samples (silver filters are used for dissolved-organic compound samples).

A filtered sample is defined operationally by the nominal pore size of the filter media used.

- The filter pore size selected depends on study objectives, data requirements, and industry standards.

- The standard pore sizes of filter media used by the USGS are:

- $\mu \mathrm{m}$ for pesticides, most other organic compounds, and some bacteria.

- $0.45 \mu \mathrm{m}$ for inorganic constituents (including major ions, radiochemicals, and trace elements), some bacteria, and dissolved organic carbon.

- $0.2 \mu \mathrm{m}$ or less for trace-element samples to be analyzed for some geochemical applications and interpretive studies and for nutrient samples for which exclusion of bacteria at the $0.2-\mu$ threshold is desirable. 


\section{Inorganic Constituents}

Samples for analyses of inorganic constituents are filtered by use of either a disposable capsule-filter assembly or a plate-filter assembly. Construction materials of filtering systems must not be a source of sample contamination with respect to the substances for which the sample will be analyzed.

\section{Disposable capsule filter}

The protocol for filtering a sample for analysis of inorganic constituents (inorganic sample) is to use a disposable capsule filter such as the Gelman 12175 ground-water sampling capsule (Figure 7). Use of a disposable capsule filter eliminates the potential for contamination from a reusable filter assembly (such as the plate filter) and also eliminates time-consuming field-cleaning procedures that are required for a reusable assembly after each sample is filtered.

Advantages of the disposable capsule filter compared to the plate-type filter:

- Capsule filters are sealed units; hence, the likelihood of contamination is reduced because the filter itself is not handled.

- Surface area of the capsule filter is roughly three times that of the $142-\mathrm{mm}$ plate filter and is less subject to clogging.

- Cleaning the filter between samples is not necessary because each capsule filter is used only once and then discarded.

\section{Plate-filter assembly}

Before 1994, the most common filtration assembly used for USGS studies for filtering inorganic samples was the nonmetallic backflushing plate-filter assembly designed to hold a 142-mm filter. Two screens support the filter media (one above and one below) and allow water flow in either direction without disruption of the membrane. A smoothtipped plastic forceps is needed to transfer the filter media to the plate of the filter assembly.

Types of plate-filter assemblies for inorganic samples include:

- Plastic backflushing assembly (described above), available for 47-mm, 142-mm, and 293-mm filters (Figure 8).

- Plastic vacuum filter assembly for 47-mm-diameter filter; used with either a hand vacuum pump or a peristaltic pump.

- Fluorocarbon polymer filter assembly designed for 47-mm-diameter filters; can be used for in-line filtering of inorganic or organic samples by changing to the appropriate filter media. 
The plate-filter assembly is no longer recommended for routine filtration of samples for analysis of inorganic constituents, but is still used to filter samples for analysis of major ions, nutrients, stable isotopes, and radiochemicals. 


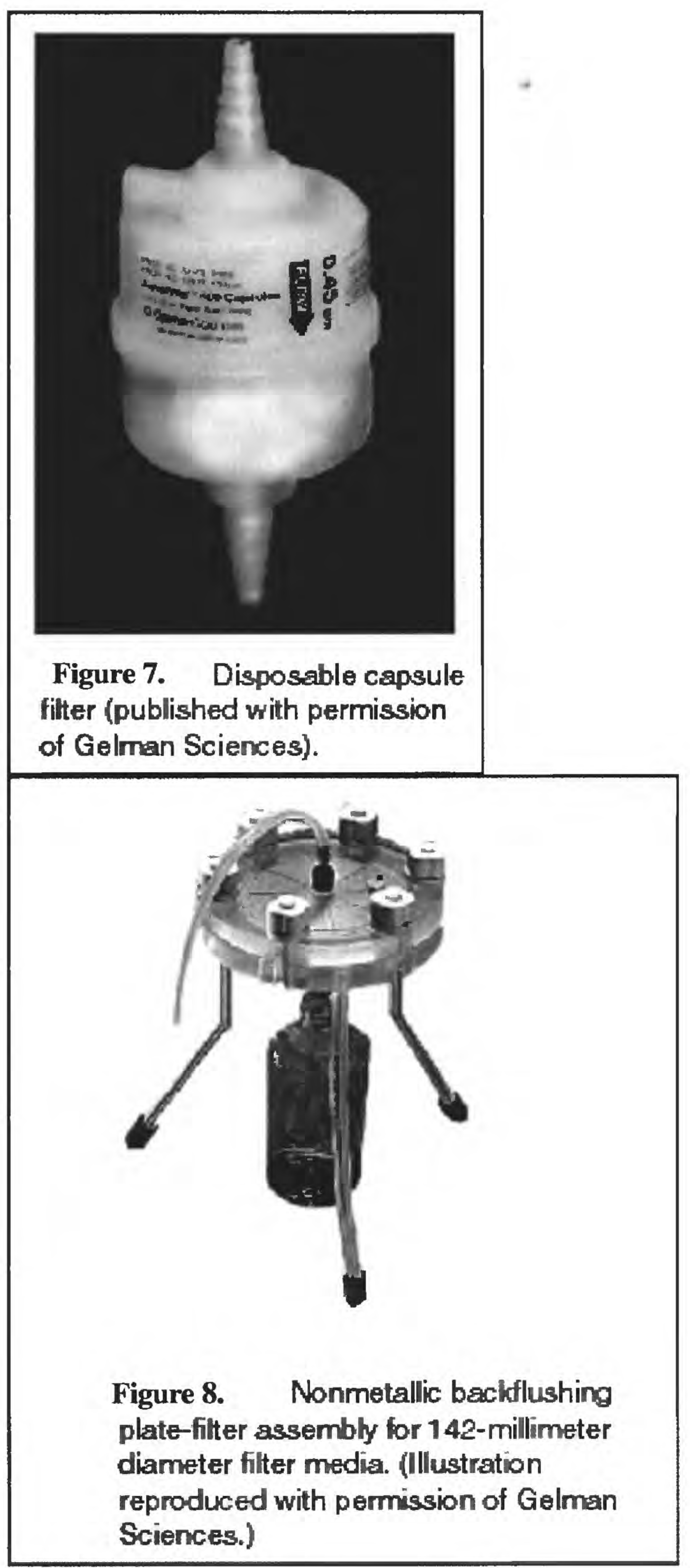




\section{Trace Organic Compounds}

Filtering whole-water samples isolates suspended solid-phase substances from the aqueous phase, thus allowing separate determinations of organic compounds in each phase.

As preparation for determining organic compounds that partition onto suspended matter (hydrophobic compounds)--Filtering primarily concentrates suspended materials on the filter, enhancing extraction efficiency and lowering analytical detection limits. This is especially useful for whole-water samples with small concentrations of suspended material where large volumes of sample ( 4 to $40 \mathrm{~L}$ ) must be filtered to provide an analyzable mass of suspended materials.

As preparation for determining organic compounds that are more water soluble (hydrophilic)--Filtering is used to remove suspended material, because it often contains interfering constituents that are co-extracted with target analytes.

Filtering also helps to preserve samples for organic determinations because microorganisms that could degrade compounds in the sample are removed (Ogawa and others, 1981).

Equipment needed to filter samples for determination of organic includes a positive displacement pump, an aluminum plate-filter assembly (Figure 9), the filter media, and metal forceps. Various filter assemblies may be required, depending on the specific analyses to be done. All equipment and components used for filtering whole-water samples for organic determinations should be made of materials that will not contaminate the sample or sorb analytes and that are suitable for use with organic cleaning solvents. Such materials include stainless steel or aluminum, fluorocarbon polymer, glass, and nonporous ceramics (hard-fused microcrystalline alumina). Other materials can be used, but they must not introduce contaminants or cause sorptive losses, and they must be sufficiently resistant to degradation by cleaning solvents. Use of plastics, rubber, oils and other lubricants are to be avoided because they can result in sample contamination, analytical interference, and (or) sorptive losses.

\section{Filtration assemblies}

The filtration equipment described in the following list includes various types of platefilter assemblies, one of which is used for solid-phase extraction.

- The most common plate-filter assembly consists of two machined aluminum or stainless steel plates, designed to hold a 142-mm-diameter filter, which are held together by locking bolts or a locking ring.

- The plates have fluorocarbon polymer-coated silicone or VitonTM O-rings set in grooves to seal the filter assembly. A stainless steel screen on the lower plate supports the filter.

- A valve is built into the upper plate to exhaust trapped air. Connectors are built into the center of the top and bottom plates so that inlet and outlet fluorocarbon polymer tubing can be attached. 
- Plate-filter assemblies are available for filters with diameters ranging from 13 to 293 $\mathrm{mm}$. The size selected is determined by the sample volume to be filtered and the concentration of suspended materials in the sample.

\section{Filter media}

Tortuous-path depth filters made of borosilicate glass fibers are used to filter most samples for organic determination because the filter materials are basically inert and can be precleaned with organic solvents or baked at $450^{\circ} \mathrm{C}$ for at least 2 hours. Depth filters also can process larger fluid volumes than membrane filters without clogging. Membrane filters (cellulose or polycarbonate polymers) commonly used to process samples for determination of nutrients and other inorganic constituents are not suitable for filtering samples for organic determinations, mainly because they are not resistant to organic solvents used to preclean sampling and processing equipment. Membrane filters made of silver metal with a $0.45-\mu \mathrm{m}$ pore size are resistant to organic solvents, but they become clogged too quickly for filtering the relatively large sample volumes ( 1 to $5 \mathrm{~L}$ ) often needed for determination of organic compounds.

Use only filters without binders. (Acrylic resin binders can leach and contaminate samples, or might not be completely combusted when baked at $450^{\circ} \mathrm{C}$.) Binder-free glassfiber filters are available in various diameters ranging from 13 to $293 \mathrm{~mm}$. 


\section{Dissolved and Suspended Organic Carbon}

A stainless steel or fluorocarbon polymer pressure filter assembly fitted with a $47-\mathrm{mm}$, $0.45-\mu \mathrm{m}$-pore-size silver membrane filter is used to separate dissolved from suspended phases of organic carbon (Fig. 10).

- Use a hand-pressure pump, peristaltic pump, or an organic-free nitrogen gas tank fitted with clean tubing to apply pressure to filter dissolved organic carbon (DOC) from suspended organic carbon (SOC) samples.

- Maintain gas pressure applied to the filter assembly at less than $15 \mathrm{lb} / \mathrm{in} 2$.

- Ensure that the gas is clean by way of gas-purveyor certification or by attaching an in-line 0.2-mm Gelman Acro 50 hydrophobic membrane filter disk. Do not use any other type of filter.

- Because the sample does not contact the in-line gas-filter disk, the disk can be used to filter gas used to process multiple samples, or until the disk clogs or is contaminated.

- Store in-line filter disk in a resealable plastic bag between uses.

\section{Pump Tubing}

Pump tubing refers to the sample lines used with peristaltic, metering, and submersible pumps. Field personnel are cautioned to evaluate possible artifacts in a sample associated with pump tubing and tubing connections.

- Silicone tubing is suitable when sampling for inorganic analytes only, and only after appropriate cleaning.

- C-FlexTM tubing is made from a thermoplastic elastomer and is suitable for use when sampling for all inorganic analytes.

- Fluorocarbon polymer tubing is recommended when sampling for most inorganic and organic analytes.Fluorocarbon polymer tubing is available in corrugated, convoluted, and straight-wall configurations.

- Polyvinyl chloride (PVC) tubing (TygonTM) is suitable for inorganic samples only, and it must be appropriately cleaned prior to contact with inorganic samples.

- NorpreneTM tubing is made from a thermoplastic elastomer (a polypropylene base with USP mineral oil) and is suitable when sampling for inorganic analytes only. It must be appropriately cleaned prior to contact with samples collected for inorganic analysis. 


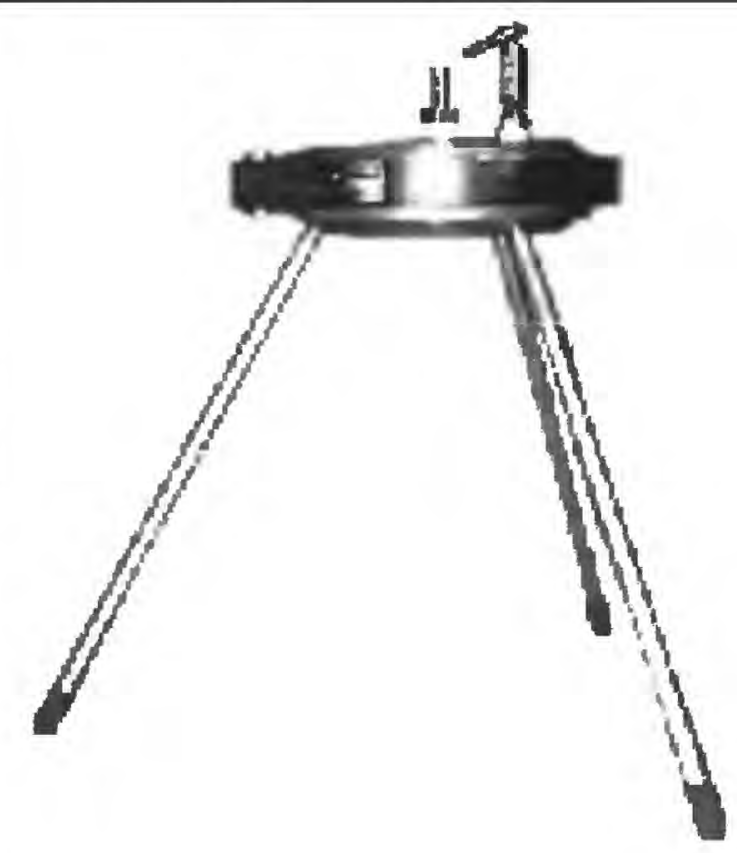

Figure 9. Aluminum plate-filter assembly for 142-millimeter diameter filter media. (Photograph published with permission of $\mathrm{G} e 0$ Tech Environmental Equipment, Inc.)

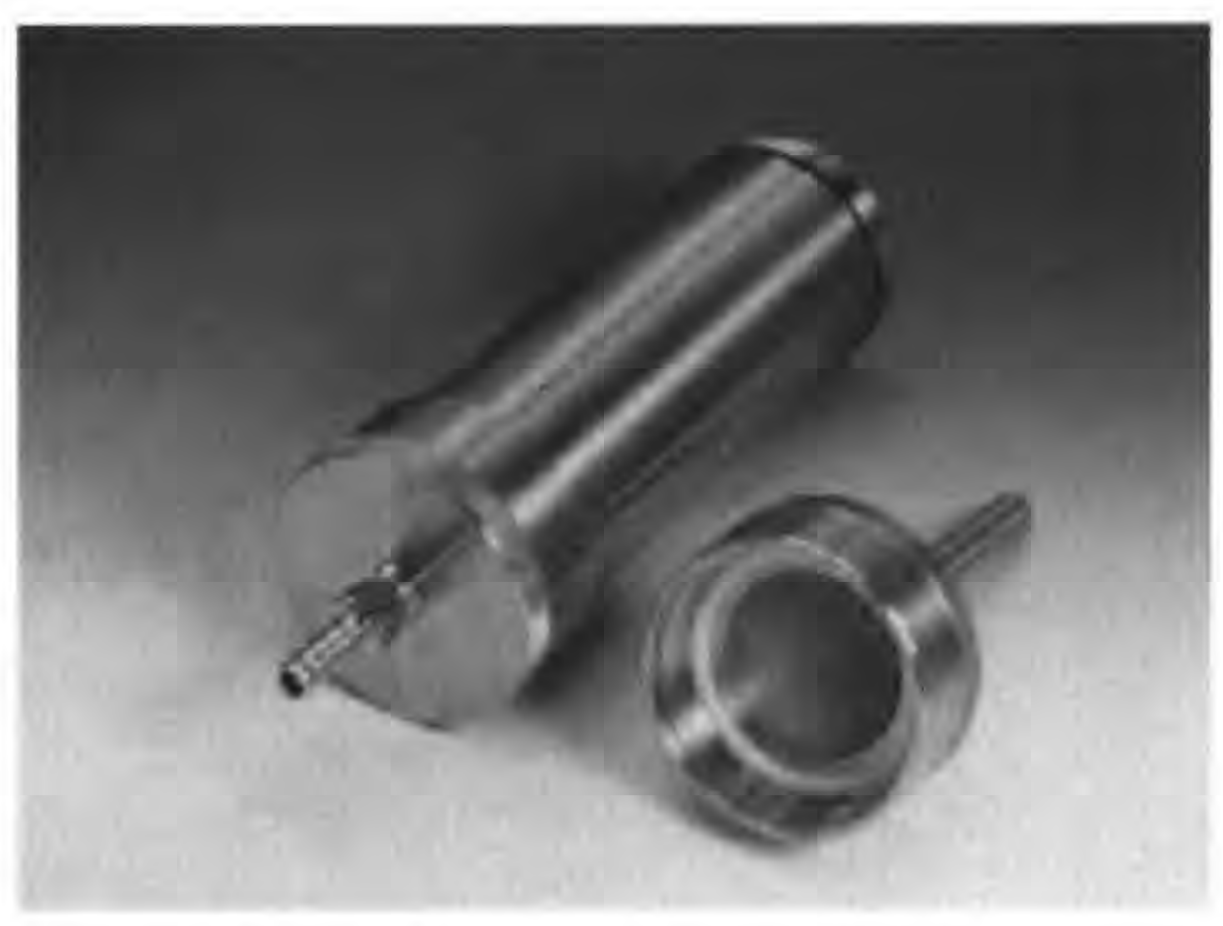

A. Stainless steel filter assembly

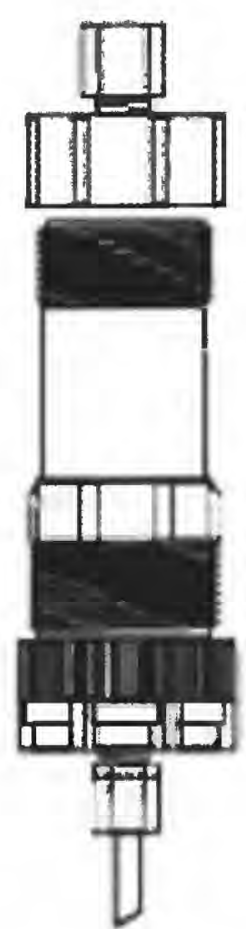

A. Fluorocarbon polyme vilter assembly

Figure 10. Apparatus for filtering samples for analysis of dissolved/ suspended organic carbon: (A) stainless steel pressure-filter assembly and (B) fluorocarbon polymer pressure-filter assembly. (Published with permission: A, Gelman Sciences; B, Savillex Corporation.) 


\section{Section 2.3}

\section{CLEANING OF EQUIPMENT FOR WATER SAMPLING}

Equipment for water samples be properly cleaned before contacting the sample and that the effectiveness of cleaning procedures be quality. The goal of equipment cleaning is to help ensure that the equipment is not a source of foreign substances that could affect the ambient concentrations or chemistry of target analytes in samples. Standard procedures are described in this chapter for when, where, and how to clean equipment constructed of various materials and to collect equipment blanks and field blanks for quality control. Space is commonly dedicated in an office laboratory for equipment cleaning and for storage of cleaning supplies.

Equipment cleaning (decontamination): applying cleaning solutions to the surfaces of equipment or using other nondestructive procedures (such as stream cleaning) to remove foreign substances that could affect the concentrations of analytes in samples.

- Clean all sample-collection and sample-processing equipment before use.

- Manufacturing residues must be removed from new equipment.

- Dust and any other foreign substances must be removed from equipment that has been in storage.

- Substances adhering to equipment from previous sampling must be removed.

Prevent cross contamination between sampling sites by rinsing equipment with deionized water (DIW) while equipment is still wet, and then clean equipment as prescribed in this chapter before transporting it to the next site.

Do not substitute field rinsing with sample water for the equipment-cleaning procedures described in this chapter.

Collect equipment blanks and field blanks for quality control. A minimum of one equipment blank per year is required for each piece of equipment. The frequency of collecting blanks normally is based on study objectives and site conditions.

For inorganic analyses, basins, brushes and other items used to clean sampling equipment should be constructed of a suitable nonmetallic material such as uncolored or white polypropylene or other plastic. For analyses of organic substances, cleaning equipment should be constructed of metal, glass, or plastic materials. Do not use substances or detergents that might leach, sorb, or leave residues that might interfere with the analyses. 
Some of the commonly used cleaning solutions include (also see Table 4):

8. Acid solution. A 5-percent, by volume hydrochloric acid solution is used to remove constituents (particularly metals) adhered to sampler and processing equipment surfaces.

9. Distilled/deionized water. Distilled or deionized water is used to wash and rinse equipment.

10. Detergent. Nonphosphate laboratory soap is used to scrub equipment.

11. Inorganic blank water. Water free of inorganic constituents. Used to rinse equipment and process inorganic blank quality-control samples.

12. Organic blank water. Water free of organic constituents. Used to rinse equipment and process blank organic quality-control samples.

13. Methanol. An organic solvent used to remove organic compounds from equipment.

\section{CLEANING PROCEDURES}

The cleaning procedure to be used depends on the type(s) of water samples that will be collected and processed. Figure 11 summarizes the sequence of cleaning procedures for equipment used to collect samples for inorganic and (or) organic analytes. 
Table 4. Supplies for cleaning equipment used for water-sampling activities

[ACS, American Chemical Society; DIW, distilled/deionized water; $\mu \mathrm{S} / \mathrm{cm}$, microsiemens per centimeter at 25 degrees Celsius; PBW, pesticidegrade blank water; VBW, volatiles and pesticide-grade blank water; IBW, inorganic-grade blank water; L, liter; cm, centimeter; TOC, total organic carbon; DOC, dissolved organic carbon; SOC, suspended organic carbon; NFM, National Field Manual; PVC, polyvinyl chloride; IBW, inorganicgrade blank water]

\begin{tabular}{|c|c|}
\hline Item & Description and Comments \\
\hline Acid solution $^{\top}$ & $\begin{array}{l}\text { Hydrochloric: ACS trace-element grade ( } 5 \text { percent by volume in } \\
\text { DIW). } \\
\text { Nitric: ACS trace-element grade ( } 10 \text { percent by volume in DIW). }\end{array}$ \\
\hline Aluminum foil & Organics only: Heavy duty, for work surfaces and equipment. \\
\hline Bags, plastic or fluorocarbon polymer & $\begin{array}{l}\text { Sealable bags with uncolored closure strips, various sizes. Recyclable } \\
\text { trash bags are recommended for large equipment storage. }\end{array}$ \\
\hline Noncolored plastic sheeting & Clean sheeting used to provide a clean work surface. \\
\hline Brushes and sponges & Uncolored; plastic components needed for inorganic work. \\
\hline Distilled/deionized water (DIW) & $\begin{array}{l}\text { Maximum specific electrical conductance, } 1 \mu \mathrm{S} / \mathrm{cm} \text { (usually District } \\
\text { produced; Office of Water Quality Memorandum 92.01). }\end{array}$ \\
\hline $\begin{array}{l}\text { Office-produced organic-grade deionized } \\
\text { water }\end{array}$ & $\begin{array}{l}\text { Usable only as a cleaning solution and only as specified in the text. } \\
\text { Must not be used to substitute for PBW or VBW. }\end{array}$ \\
\hline Detergent & Nonphosphate laboratory soap (for example, LiquinoxTM). \\
\hline Gloves, disposable & $\begin{array}{l}\text { Powderless, noncolored vinyl, latex, or nitrile (latex or nitrile for use } \\
\text { with methanol), assorted sizes. }\end{array}$ \\
\hline Inorganic-grade blank water (IB W) ${ }^{2}$ & $\begin{array}{l}\text { Blank water with certificate of analysis prepared and (or) quality } \\
\text { assured by the analyzing laboratory. IBW is required for blank } \\
\text { samples. }\end{array}$ \\
\hline Jerricans or carboys & $\begin{array}{l}\text { For waste solutions and as neutralization container. } \\
\text { Neutralization container: } 25 \text { - to } 30-\mathrm{L} \text {, polyethylene, wide-mouth, with } \\
\text { layer of marble chips. } \\
\text { Methanol waste container: Appropriate for flammable liquid. }\end{array}$ \\
\hline Methanol & $\begin{array}{l}\text { ACS pesticide grade. Methanol is the organic solvent in common use } \\
\text { for equipment cleaning, but study requirements might dictate use of a } \\
\text { different ACS pesticide-grade solvent. }\end{array}$ \\
\hline Neutralization materials & Marble landscape chips (1- to 2 -cm chips recommended) ${ }^{3}$ \\
\hline $\begin{array}{l}\text { Pesticide-grade blank water }(\mathrm{PBW})^{2} \text {; volatile- } \\
\text { grade blank water }(\mathrm{VBW})^{2}\end{array}$ & $\begin{array}{l}\text { Blank water prepared and (or) quality assured by the analyzing } \\
\text { laboratory; required for collecting blank samples as follows: PBW for } \\
\text { pesticide analysis; VBW for volatile compounds analysis and } \\
\text { pesticide analysis; and either PBW or VBW for TOC, DOC, and SOC } \\
\text { analyses. }\end{array}$ \\
\hline Safety equipment and guidelines & $\begin{array}{l}\text { For example, Material Safety Data Sheets (MSDS), safety glasses, } \\
\text { chemical spill kit, apron, emergency phone numbers. }\end{array}$ \\
\hline Standpipes for submersible pump & $\begin{array}{l}\text { Plastic, glass, or other suitable material; for example, pipette jars or } \\
\text { capped PVC casing; one standpipe labeled for blank water and one } \\
\text { each for each cleaning solution. (Do not use PVC for methanol.) }\end{array}$ \\
\hline Tapwater & $\begin{array}{l}\text { If quality is questionable, substitute DIW. Tapwater is more effective } \\
\text { for initial and rapid removal of detergent residue. }\end{array}$ \\
\hline Tissues & $\begin{array}{l}\text { Laboratory grade, lint free, various sizes (for example, } \\
\text { KimwipesTM). }\end{array}$ \\
\hline Wash bottles (dispenser or squeeze) & $\begin{array}{l}\text { Labeled to indicate contents (for example, ACID, DIW, TAP). } \\
\text { Fluorocarbon polymer needed for methanol, PBW, VBW, and IBW. }\end{array}$ \\
\hline
\end{tabular}

${ }^{1}$ Hydrochloric acid is required if analyzing for nitrogen species; otherwise, nitric acid is acceptable.

${ }^{2}$ PBW and VBW can be obtained from the USGS National Water Quality Laboratory (NWQL). IBW can be obtained from the USGS Quality of Water Service Unit.

${ }^{3}$ Agricultural limestone, soda ash, baking soda, and crushed shells are not recommended (Horowitz and others, 1994). 


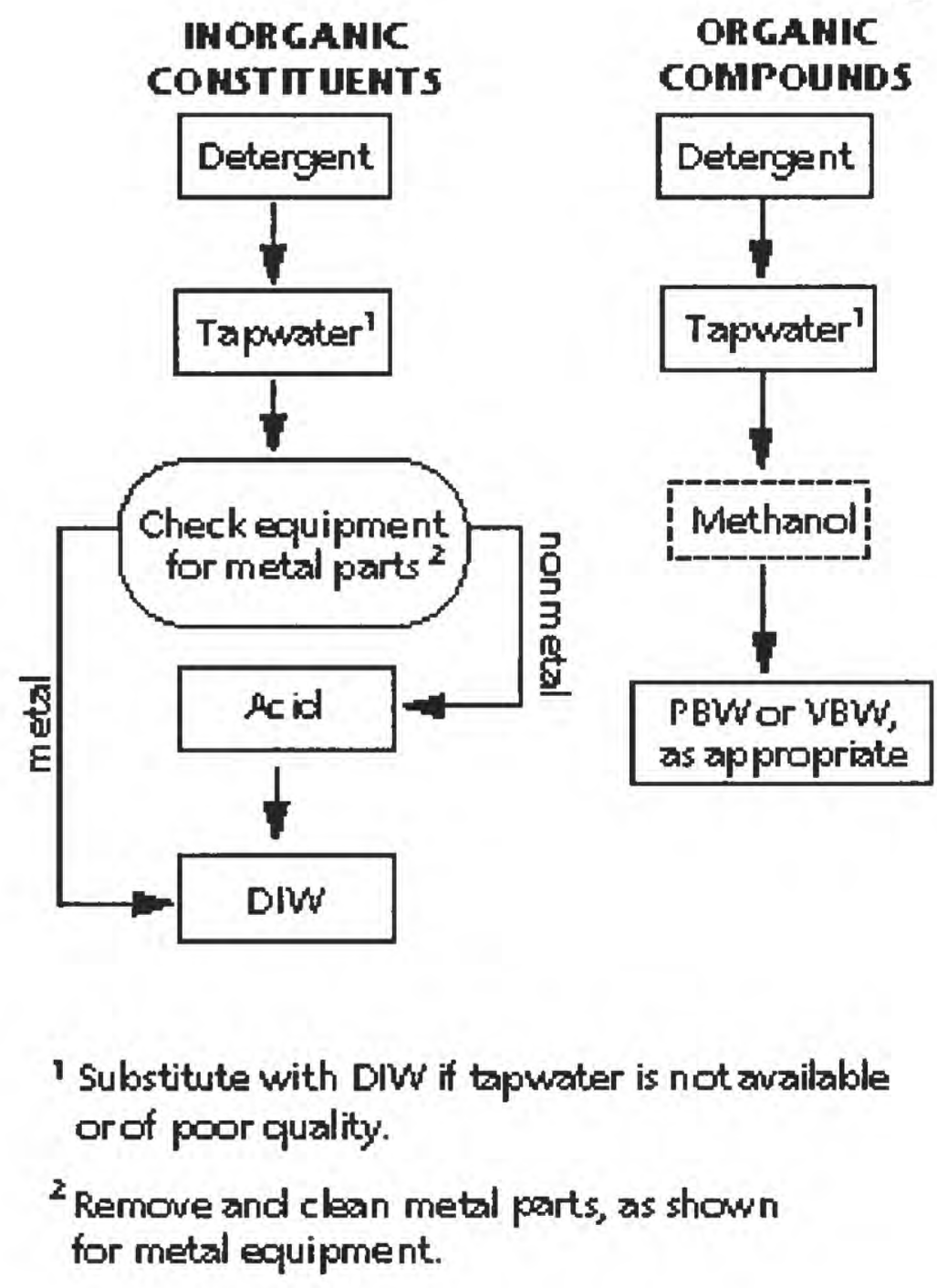




\section{Section 2.4}

\section{FIELD ANALYSES}

Measurements of specific conductance, water temperature, dissolved oxygen, $\mathrm{pH}$, and alkalinity could change dramatically within a few minutes or hours after sample collection. Immediate analysis in the field is required if results representative of in-stream conditions are to be obtained.

Water temperature and dissolved oxygen should be measured directly from the stream, and several readings are required in the cross section to obtain a stream average. Specific conductance, $\mathrm{pH}$, and alkalinity should be measured from a cone-split subsample so that these results will be from the same water matrix as the other chemical analyses. A single field meter that measures specific conductance, water temperature, $\mathrm{pH}$, and dissolved oxygen directly in the stream may be used if stream profiles are performed regularly. These profiles must confirm that the direct in-stream measurements are comparable to the values from a cone-split sample.

Maintain an instrument $\log$ and review it prior to each field trip. The operation and calibration of all field instruments (including back-up meters and electrodes) should be checked to ensure that all are in good working condition.

\section{TEMPERATURE}

The stream water temperature can affect density and gas solubility, and density affects the mixing of different water masses, especially seasonal stratification. Temperature also affects the rate of chemical reactions, biological activity, conductivity, dissolved oxygen, and $\mathrm{pH}$.

Because of possible environmental contamination if broken, mercury-filled thermometers are not acceptable for field use. The recommended procedure for determining field temperatures is a thermistor, an electrical device made of a solid semiconductor with a high temperature coefficient of resistivity. Thermistors can be constructed with a high sensitivity, but are subject to a variety of errors. Therefore, the calibration should be checked in the laboratory at several temperatures using an American Society for

Testing and Materials (ASTM) thermometer to ensure the required accuracy. Never carry a mercury-filled ASTM thermometer in the field.

Field measurements of temperature should include both air-temperature and water-temperature readings. Airtemperature readings should be made by placing a dry thermistor in a shaded area protected from strong winds, but open to adequate air circulation. Avoid areas that may have radiant heat such as near metal walls or sides of vehicles. Allow the thermistor to equilibrate 3 to 5 minutes before recording the temperature.

Water temperatures should represent the mean temperature of the stream at the time of observation. A horizontal and vertical cross-section profile will determine the variability, if any, that exists. Streams with highly variable temperature profiles should have several readings averaged to use as the mean and those variations should be documented. Streams with a fairly uniform temperature (less than $2^{\circ} \mathrm{C}$ variance 95 percent of the time) generally will have one measurement that can be made and reported as the stream temperature. Make this measurement by suspending (from a weighted line) or placing a thermistor in midstream. Shade the thermistor probe to prevent erroneous readings caused by direct solar radiation. The thermistor should be immersed in the stream for a minimum of 1 minute prior to making measurements. Report all routine 
temperature measurements to the nearest $0.5^{\circ} \mathrm{C}$. For special studies where more precision is required, verify the accuracy and report temperatures to the requested precision.

\section{SPECIFIC CONDUCTANCE}

Conductance is the reciprocal of resistance in ohms and is a measure of the capacity of water or other substance to conduct an electrical current. Specific conductance is the conductance measured at $25^{\circ} \mathrm{C}$ and is reported in microsiemens per centimeter at $25^{\circ} \mathrm{C}$. The specific conductance of water is determined by the types and quantities of dissolved substances in the water. Thus, specific conductance indicates the concentration of dissolved solids in water.

The specific conductance of water may change significantly with time because of pollution, precipitation, adsorption, ion exchange, oxidation, and reduction. Therefore, specific conductance should be measured in the field with an accurate conductivity meter. Many commercial conductivity meters are available on the market. All meters come with operating instructions, and users should be totally familiar with these instructions. The following are some important features and characteristics of a specific-conductance meter:

- Automatic temperature compensating (direct specific-conductance reading).

- Multiple measurement ranges from 0 to $200,000 \mathrm{uS} / \mathrm{cm}$ at $25^{\circ} \mathrm{C}$ with 1 -percent accuracy and threenumber digital readout.

- Platinum, carbon, stainless-steel, or gold electrode.

- Dip-type electrode.

Conductivity electrodes must be clean to produce accurate results. Because of the wide variety of electrode material, the instructions provided by the manufacturer should be followed. Rinse the electrode thoroughly with DIW after cleaning.

\section{Calibration}

Specific-conductance standards, 10 to $50,000 \mathrm{uS} / \mathrm{cm}$ at $25^{\circ} \mathrm{C}$, are for meter calibration. Prior to every waterquality field trip and again onsite, standards should be used to calibrate the meter and to check meter calibration. Document calibration checks in the instrument log. Used standards should not be returned to the stock container.

Calibration and operating procedures vary with meter types and manufacturers. The procedures described below are generalized steps that should be followed and will apply to most meters used for field measurements:

- Presoak electrode in DIW at least overnight.

- Choose two specific-conductance standards that will bracket the expected value of the sample to be measured.

- The standards should be approximately the same temperature as the sample to be measured. Standards are affected by temperature and standard values should be adjusted to the temperature of the sample (Table 5).

- Use the calibration standard closest to the expected value of the sample to be measured. Rinse the container and electrode with standard. Pour calibration standard into container holding the electrode. Allow a minute or two for equilibration and then discard the standard. 
- Calibration setting: Pour fresh calibration standard into the container holding the electrode. The electrode should not touch the sides or bottom of the container. Note the meter reading and ADJUST meter to the known standard value.

- Discard calibration standard into a waste container.

- Rinse electrode and container with the second standard. The second standard will bracket the range of expected stream conductance. Pour check standard into rinsed container holding the electrode. Allow to equilibrate, and then discard check standard into a waste container.

- Calibration check: Pour second standard into the rinsed container holding the electrode. This check reading should be within 5 percent of the known standard value. If not, repeat entire calibration procedures. Electrode cleaning or replacement, a different meter, or both might be needed.

NOTE: Switching meter calibration range will require recalibrating.

- Discard check standard into a waste container and then rinse electrode and container with DIW.

- Record all calibration information in the instrument log and on the field notes.

\section{Measurement}

Measurements of specific conductance at stream sites should be made from an unfiltered subsample from the cone splitter. If a direct in-stream measurement is made, several readings are necessary (vertically and horizontally) in the cross section to determine a mean value. Conductivity measurements are reported as specific conductance and are expressed as microsiemens per centimeter at $25^{\circ} \mathrm{C}$. Results are reported to three significant figures, whole numbers only. 
Table 5.

Correction factors for converting non-temper aturecompensated values to conductivity at 25 degrees Celsius, based on 1,000 microsiemens potassium chloride solution

[Use of potassium-based constants on non-potassium-based waters generally does not introduce significant errors for general purpose instruments used to measure conductivity]

\begin{tabular}{|c|c|c|c|c|c|}
\hline $\begin{array}{l}\text { Temperature } \\
\text { (degrees } \\
\text { Celslus) }\end{array}$ & $\begin{array}{l}\text { Correction } \\
\text { factor }\end{array}$ & $\begin{array}{l}\text { Temperature } \\
\text { (degrees } \\
\text { Cel slus) }\end{array}$ & $\begin{array}{l}\text { Correction } \\
\text { factor }\end{array}$ & $\begin{array}{l}\text { Temperature } \\
\text { (degrees } \\
\text { Celslus) }\end{array}$ & $\begin{array}{l}\text { Correction } \\
\text { factor }\end{array}$ \\
\hline 0.5 & 1.87 & 10.5 & 1.39 & 20.5 & 1.09 \\
\hline 1.0 & 1.84 & 11.0 & 1.37 & 21.0 & 1.08 \\
\hline 1.5 & 1.81 & 11.5 & 1.35 & 21.5 & 1.07 \\
\hline 2.0 & 1.78 & 12.0 & 1.33 & 22.0 & 1.06 \\
\hline 2.5 & 1.76 & 12.5 & 1.32 & 22.5 & 1.05 \\
\hline 30 & 1.73 & 13.0 & 1.30 & 23.0 & 1.04 \\
\hline 35 & 1.70 & 13.5 & 1.28 & 23.5 & 1.03 \\
\hline 40 & 1.68 & 14.0 & 1.27 & 24.0 & 1.02 \\
\hline 45 & 1.66 & 14.5 & 1.26 & 24.5 & 1.01 \\
\hline 5.0 & 1.63 & 15.0 & 1.24 & 25.0 & 1.00 \\
\hline 5.5 & 1.60 & 15.5 & 1.22 & 25.5 & 0.99 \\
\hline 6.0 & 1.58 & 16.0 & 1.21 & 26.0 & 0.98 \\
\hline 6.5 & 1.56 & 16.5 & 1.19 & 26.5 & 0.97 \\
\hline 7.0 & 1.54 & 17.0 & 1.18: & 27.0 & 0.96 \\
\hline 7.5 & 1.52 & 17.5 & 1.16 & 27.5 & 0.95 \\
\hline 8.0 & 1.49 & 18.0 & 1.15 & 28.0 & 0.94 \\
\hline 8.5 & 1.47 & 18.5 & 1.14 & 28.5 & 0.93 \\
\hline 9.0 & 1.45 & 19.0 & 1.13 & 29.0 & 0.92 \\
\hline 9.5 & 1.43 & 19.5 & 1.12 & 29.5 & 0.91 \\
\hline 10.0 & 1.41 & 20.0 & 1.11 & 30.0 & 0.90 \\
\hline
\end{tabular}




\section{pH}

The $\mathrm{pH}$ of a solution is a measure of the effective hydrogen-ion concentration (activity). In aqueous solutions, $\mathrm{pH}$ is controlled primarily by the hydrolysis of salts of strong bases and weak acids or vice versa. The $\mathrm{pH}$ is expressed in logarithmic units using a scale from 0 to 14 . Solutions having a $\mathrm{pH}$ of less than 7 are described as acid; solutions with a $\mathrm{pH}$ of more than 7 are described as basic or alkaline. Dissolved gases, such as carbon dioxide, hydrogen sulfide, and ammonia, appreciably affect $\mathrm{pH}$. Degasification (for example, loss of carbon dioxide), precipitation [for example, calcium carbonate $\left(\mathrm{CaCO}_{3}^{-1}\right)$ ], and other chemical, physical, and biological reactions may cause the $\mathrm{pH}$ of a water sample to change significantly within several hours or even minutes after sample collection. Immediate analysis of a $\mathrm{pH}$ in the field is REQUIRED if dependable results are to be obtained.

Some important features of the meters and electrodes include the following:

1. Digital (LCD) meter readout with $0.02 \mathrm{pH}$ unit accuracy.

2. Slope correction (preferably with percent of slope readout).

3. Plastic or glass, liquid-filled, combination $\mathrm{Ag} / \mathrm{Cl}$ electrode.

Because a large variety of $\mathrm{pH}$ meters and electrodes are available on the market, it is extremely important that operators are thoroughly familiar with the instruction manual provided by the manufacturer.

Electrodes must be clean and properly operating to produce accurate results. The liquid junction also must be free flowing, and the electrolyte solution in the electrode must be at the proper level. Because of the variety of electrodes available, follow the cleaning and storing instructions provided by the manufacturer. Never wipe the $\mathrm{pH}$ electrode membrane with anything or store it dry (check manufacturer's instructions).

\section{Calibration}

The standard buffers used to calibrate $\mathrm{pH}$ meters have values of $\mathrm{pH} 4,7$, and 10 with a relatively high ionic strength. Two $\mathrm{pH}$ buffers are needed to calibrate the $\mathrm{pH}$ meter (4 and 7 or 7 and 10). Document calibration checks in the instrument log. Used standards should not be returned to the stock container.

Because calibration and operating procedures vary with meter types and manufacturers, the procedures described below are generalized steps that will apply to most meters used for field measurements:

1. Remove filling plug on refillable electrodes prior to use. Use only the solution recommended by the electrode manufacturer when filling solution must be added. The liquid-filled $\mathrm{pH}$ electrodes should always be stored upright.

2 .Bring $\mathrm{pH}$ buffers to the temperature of the sample to be measured (within a few degrees). Apply temperature-correction factors when calibrating the $\mathrm{pH}$ meter.

3. Rinse electrode, thermistor, a small Teflon-coated magnetic stirring bar, and a glass beaker with $\mathrm{pH}-7$ buffer. Pour buffer into rinsed container holding electrode, thermistor, and stirring bar. Allow temperature to equilibrate for a minute and then discard buffer into a waste container.

4. Calibration: Pour fresh pH-7 buffer in the same beaker holding the equipment. The $\mathrm{pH}$ electrode must not be resting on the bottom or touching the sides of the container. Place the beaker on a magnetic stirrer. Measure temperature, remove thermistor, and adjust meter to the temperature of the buffer. With the stirrer on low (do not create a vortex), adjust meter reading to the known buffer value at the specific temperature. Discard $\mathrm{pH}$ buffer into a waste container. 
NOTE: Turn pH meter to "standby" (or "off" on meters without standby) position prior to removing electrode from a solution.

5. Select a second buffer to bracket the expected stream $\mathrm{pH}$. Use a $\mathrm{pH}-10$ buffer when expected $\mathrm{pH}$ is greater than 7 and a $\mathrm{pH}-4$ buffer when the expected $\mathrm{pH}$ is less than 7. Always use a $\mathrm{pH}-4$ buffer as the second buffer when titrating for alkalinity. Rinse electrode, thermistor, and stirring bar with DIW. Rinse another clean beaker, electrode, thermistor, and stirring with the second buffer ( $\mathrm{pH} 4$ or 10). Pour second buffer into that container. Allow temperature to equilibrate for a minute and then discard buffer into a waste container.

6. Slope adjustment: Pour fresh $\mathrm{pH}$ buffer in the same beaker holding the equipment. Measure temperature and remove thermistor. Set meter temperature to the buffer temperature and, the stirrer on low, adjust slope to the value of $\mathrm{pH}$ buffer. (Some meters have separate slope-adjustment knobs, whereas others use the temperature knob. Always refer to instruction manual when uncertain.) Discard $\mathrm{pH}$ buffer into a waste container.

7. Rinse electrode, thermistor, and stirring bar with DIW. Repeat steps 3 and 4 to ensure that any slope adjustments did not change the calibration adjustment. This is a check so adjustment should not be needed. If adjustment is required, repeat the entire calibration procedure.

8. Record all calibration information in the instrument $\log$ and on the field notes.

\section{$\underline{\text { Measurement }}$}

Measurements of $\mathrm{pH}$ at stream sites should be made from a raw (unfiltered) subsample from the cone splitter. If a direct in-stream measurement is made, several readings are necessary(vertically and horizontally) in the cross section to determine a mean value.

1. Rinse electrode, thermistor, stirring bar, and container with stream water. Pour stream water into container holding the electrode, thermistor, and stirring bar. Allow the temperature to and the electrode to precondition itself to the sample. Discard sample in waste container.

2. Measurement: Pour fresh sample into the same container holding the equipment. Measure and set temperature and remove thermistor. Measure $\mathrm{pH}$ and record on field notes. Discard sample in waste container.

3. Rinse electrode, thermistor, and stirring bar with DIW, and store electrode as recommended by the manufacturer.

4. Measurements of $\mathrm{pH}$ are reported in $\mathrm{pH}$ units. Results are reported to the nearest $0.1 \mathrm{pH}$ unit.

\section{ALKALINITY, BICARBONATE, AND CARBONATE}

Alkalinity refers to the capacity of water to neutralize an acid by means of chemical buffering. In most waters, alkalinity is caused primarily by the presence of bicarbonate $\left(\mathrm{HCO}_{3}^{-1}\right)$ and carbonate $\left(\mathrm{CO}_{3}{ }^{-2}\right)$ ions. Some noncarbonate contributors to alkalinity include hydroxide, silicate, borate, and organic ligands, especially acetate and propionate. Because bicarbonate and carbonate predominate in most waters, their determination is essential in studies involving carbonate-chemistry and equilibrium calculations. Alkalinity is commonly used in the determination of the cation/anion balance of a water sample.

Degasification, precipitation, and other chemical and physical reactions can cause the concentrations of bicarbonate and carbonate to change significantly within several hours or even minutes after sample collection. Consequently, field determinations of alkalinity, bicarbonate, and carbonate are needed in addition to laboratory determinations. Determine alkalinity, bicarbonate, and carbonate concentrations on a FILTERED sample. The section on filtration describes the proper method. 
Several methods can be used to determine total alkalinity, bicarbonate, and carbonate. All of the methods involve titrating a water sample with a standard solution of sulfuric acid and monitoring the change in $\mathrm{pH}$ as the acid is added to the sample. The presence and quantity of hydroxide (if sample $\mathrm{pH}$ is 10.4 or greater), carbonate (sample $\mathrm{pH}$ is approximately 8.3 or greater), and bicarbonate (sample $\mathrm{pH}$ approximately 4.5 or greater) is determined by the $\mathrm{pH}$ of the sample and the quantity of acid added. The two methods commonly used are the fixed end-point and incremental methods. Figure 12 summarizes the general procedure for alkalinity determinations.

\section{Fixed end-point method}

The fixed end-point method determines bicarbonate and carbonate by preselecting end points that correspond to true equivalence points under ideal conditions. Using sulfuric acid for titration, the sample $\mathrm{pH}$ is lowered to 8.3 for carbonate and 4.5 for bicarbonate. This method is not preferred because it is less accurate than the incremental method.

\section{Incremental method}

The incremental method, which determines alkalinity, bicarbonate, and carbonate values more accurately than the fixed end-point method. Rather than assuming the equivalence points to be at $\mathrm{pH} 8.3$ and 4.5 , the incremental method determines the actual equivalence points by constructing a titration curve (plotting $\mathrm{pH}$ and the volume of sulfuric acid) and selecting the inflection point of the curve as the end point. The end point also can be determined by plotting the change in $\mathrm{pH}$ divided by the change in volume of sulfuric acid added, noting the maximum rate of change of $\mathrm{pH}$ per volume of acid added. The dilute-acid titrant should be added using a digital titrator.

The incremental method for alkalinity using the digital titrator cosists of the following steps (example given in table 5 and figure 12):

- Calibrate $\mathrm{pH}$ meter (see section on $\mathrm{pH}$ ).

- Depending upon the expected alkalinity, select the sample volume and the appropriate strength titrant cartridge, 0.160 normal $(\mathrm{N})$ or $1.600 \mathrm{~N}$ sulfuric acid.

- Assemble the digital titrator by placing the titrant cartridge into the titrator and inserting a clear delivery tube into the cartridge. Turn delivery knob to release a few drops of titrant (into a waste container) from the end of the delivery tube, gently blot any droplets adhering to the end of the tube, and set digital counter to a ZERO reading. Inspect the delivery tube; if air bubbles are present, continue to turn knob, expelling the acid until bubbles are removed. Always make sure the delivery tube is below the water surface when dispensing acid into the sample.

- With a volumetric pipet put selected volume of FILTERED sample (50 or $100 \mathrm{~mL}$ ) into a clean beaker containing a thermistor and a small Teflon-coated, magnetic stirring bar. Record volume of sample that will be titrated on the field notes.

- Place pH electrode (previously rinsed with DIW) into sample to be titrated and place beaker on a magnetic stirrer.

- Measure temperature, remove thermistor, and set meter temperature to sample temperature.

- Turn on stirrer and adjust stirring rate to low (do not create a vortex). Turn on $\mathrm{pH}$ meter, allow reading to stabilize, and then read and record initial $\mathrm{pH}$ value.

NOTE: IF SAMPLE pH IS LESS THAN 8.3, OMIT STEP 8. 
- If sample pH is greater than 8.3 , add sulfuric acid by small increments ( 1 to 3 digital counts at a time) until the $\mathrm{pH}$ of the sample is below 8.0. Record $\mathrm{pH}$ and digital-counter reading after each addition of acid. Allow 15 to 20 seconds for equilibration between incremental additions. Sample should be gently stirred with a magnetic stirrer or appropriate stirring device.

- Titrate RAPIDLY to approximately pH 5.5. Allow 15 to 20 seconds for equilibration and record the digitalcounter reading.

- Add acid by small increments ( 1 to 3 digital units at a time) from pH 5.5 to 4.0. Allow 15 to 20 seconds for equilibration between incremental additions of acid and record $\mathrm{pH}$ and digital-counter readings.

- Construct a titration curve plotting the digital counts of titrant (sulfuric acid) as a function of $\mathrm{pH}$. The end points are the inflection points of the curve (near 8.3 or 4.5 ), the points at which the $\mathrm{pH}$ changes are greatest for volume of acid added. An alternate method is to plot the rate of change of $\mathrm{pH}$ with the change in digital counts to determine the inflection points as follows:

change in $\mathrm{pH}$

change in digital count

- Use the digital count at the maximum rate of $\mathrm{pH}$ change that represents the appropriate end points to determine the following:

For $1.600 \mathrm{~N}$ acid titration:

Carbonate $\left(\mathrm{mg} / \mathrm{L}\right.$ as $\left.\mathrm{CO}_{3}^{-2}\right)=2.40 \times$ DCA [50-mL sample] $=1.20 \times$ DCA [100-mL sample]

Bicarbonate (mg/L as $\left.\mathrm{HCO}_{3}^{-1}\right)=2.44 \times(\mathrm{DCB}-2 \times \mathrm{DCA})$ [50-mL sample] $=1.22 \times(\mathrm{DCB}-2 \times \mathrm{DCA})[100-\mathrm{mL}$ sample $]$

For $0.160 \mathrm{~N}$ acid titration:

Carbonate $\left(\mathrm{mg} / \mathrm{L}\right.$ as $\left.\mathrm{CO}_{3}^{-2}\right)=0.240 \times$ DCA [50-mL sample] $=0.120 \times$ DCA $[100-\mathrm{mL}$ sample]

Bicarbonate ( $\mathrm{mg} / \mathrm{L}$ as $\left.\mathrm{HCO}_{3}{ }^{-1}\right)=0.244 \times(\mathrm{DCB}-2 \times \mathrm{DCA})$ [50-mL sample] $=0.122 \times(\mathrm{DCB}-2 \times \mathrm{DCA})[100-\mathrm{mL}$ sample $]$

where

DCA is digital count near end point $8.3 \mathrm{pH}$ and

DCB is digital count near end point $4.5 \mathrm{pH}$.

Alkalinity $\left(\mathrm{mg} / \mathrm{L}\right.$ as $\left.\mathrm{HCO}_{3}^{-1}\right)=\left[(\mathrm{CO} 3-2 / 30)+\left(\mathrm{HCO}_{3}^{-1}-1 / 61\right)\right] \times 50$

- Report concentrations of alkalinity as equivalent calcium carbonate as $\mathrm{CaCO}$, in milligrams per liter, bicarbonate as $\mathrm{HCO}_{3}^{-1}$, in milligrams per liter, and carbonate as $\mathrm{CO}_{3}^{-2}$, in milligrams per liter, as follows: less than $1,000 \mathrm{mg} / \mathrm{L}$, whole numbers; $1,000 \mathrm{mg} / \mathrm{L}$ and above, three significant figures. 


\section{Calibrate pH system}

Collect representativa sample; filter subsamples for alkalinity.

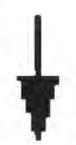

- Field rinse sample bottles with sample for filtrates.

- Fill bottles completely and cap tightly, maintain sample at ambient water temperat ure urtil titration.

- Rinse with DW only: electrodes, sensore, beaker, stir bar, delivary tube.

-Place small-size stir bar in beaker.

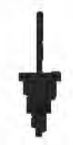

Select and record titration mathod, subsample volume, and titrant normality.

-Digital system: Assemble titrator, bleed dalivery t ube, set courter to zero.

- Burat system: Fill clean, dry burat with titrant-purge trapped air bubbles.

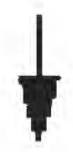

-Pipet appropriate volume of sample into beaker.

- Place beaker on stirrer.

- Insert electrodes and temperatura sensor, away fro m bottom or sides.

-Stir gently-do not splas h; minimize vortex.

- Record initial tima, $\mathrm{pH}_{\mathrm{r}}$ temperature, sample voluma, normalit $y_{\mathrm{r}}$ and counter reading if using digital system.

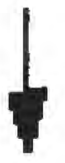

Add titrart, stir for 15-20 5800 ndE, read and record pH.

Repeat until titration is complete.

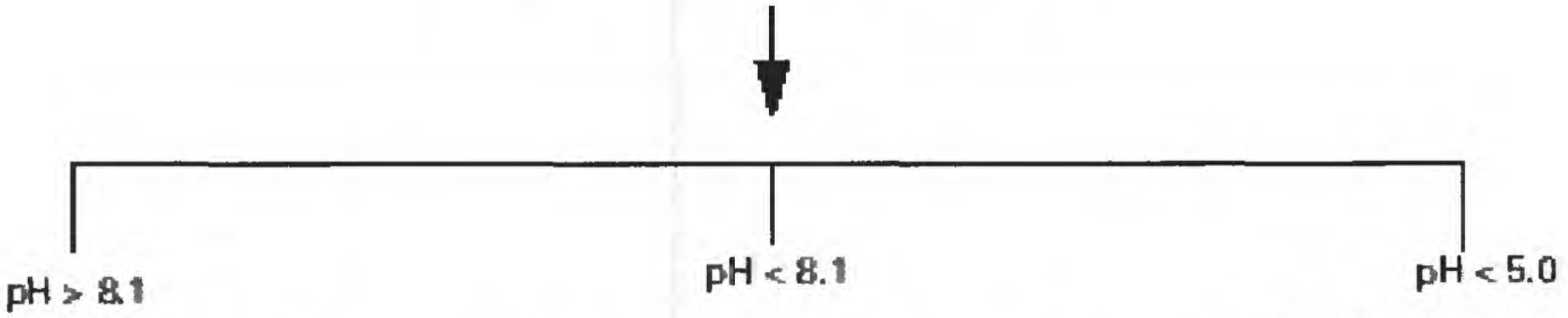

Titrate slowly (to determine carbonate species?. sinall increments, to $\mathrm{pH}=8.1$.

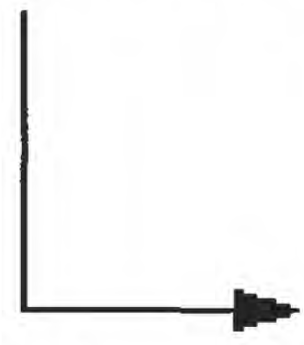

Titrate rapidly, large increments. to $\mathrm{pH}=5.6$ (for conductivity < $100 \mu \mathrm{S} / \mathrm{cm}$ ind nolessthan pH 6.0 in carbonate systems. Cont inue tit rat ion in small increments to $\mathrm{pH}-4$.<smiles>[CH]1CC1</smiles>

Determine and record equivalenca points.
Titrate cautiouslyr small increments: IPT to $\mathrm{pH}$ -40 or less: Gran to $\mathrm{pH}$ -3.5 or less. Titrate to lower $\mathrm{pH}$ if noncarbonate contribution is large.

Figure 12. Summary of alkalinity or ANC titration procedures. 
Table 6. Correction factors for converting non-temperaturecompensated values to conductivity at 25 degrees Celsius, based on 1,000 microsiemens potassium chloride solution

[Use of potassium-based constants on non-potassium-based waters generally does not introduce significant errors for general purpose instruments used to measure conductivity]

\begin{tabular}{|cccccc|}
\hline $\begin{array}{c}\text { Temperature } \\
\text { (degrees } \\
\text { Celslus) }\end{array}$ & $\begin{array}{c}\text { Correctlon } \\
\text { factor }\end{array}$ & $\begin{array}{c}\text { Temperature } \\
\text { (degrees } \\
\text { Celsius) }\end{array}$ & $\begin{array}{c}\text { Correction } \\
\text { factor }\end{array}$ & $\begin{array}{c}\text { Temperature } \\
\text { (degrees } \\
\text { Celslus) }\end{array}$ & $\begin{array}{c}\text { Correction } \\
\text { factor }\end{array}$ \\
\hline 0.5 & 1.87 & 10.5 & 1.39 & 20.5 & 1.09 \\
\hline 1.0 & 1.84 & 11.0 & 1.37 & 21.0 & 1.08 \\
\hline 1.5 & 1.81 & 11.5 & 1.35 & 21.5 & 1.07 \\
\hline 2.0 & 1.78 & 12.0 & 1.33 & 22.0 & 1.06 \\
\hline 2.5 & 1.76 & 12.5 & 1.32 & 22.5 & 1.05 \\
\hline 30 & 1.73 & 13.0 & 1.30 & 23.0 & 1.04 \\
\hline 3.5 & 1.70 & 13.5 & 1.28 & 23.5 & 1.03 \\
\hline 40 & 1.68 & 14.0 & 1.27 & 24.0 & 1.02 \\
\hline 4.5 & 1.66 & 14.5 & 1.26 & 24.5 & 1.01 \\
\hline 5.0 & 1.63 & 15.0 & 1.24 & 25.0 & 1.00 \\
\hline 5.5 & 1.60 & 15.5 & 1.22 & 25.5 & 0.99 \\
\hline 6.0 & 1.58 & 16.0 & 1.21 & 26.0 & 0.98 \\
\hline 6.5 & 1.56 & 16.5 & 1.19 & 26.5 & 0.97 \\
\hline 7.0 & 1.54 & 17.0 & 1.18 & 27.0 & 0.96 \\
\hline 7.5 & 1.52 & 17.5 & 1.16 & 27.5 & 0.95 \\
\hline 8.0 & 1.49 & 18.0 & 1.15 & 28.0 & 0.94 \\
\hline 8.5 & 1.47 & 18.5 & 1.14 & 28.5 & 0.93 \\
\hline 9.0 & 1.45 & 19.0 & 1.13 & 29.0 & 0.92 \\
\hline 9.5 & 1.43 & 19.5 & 1.12 & 29.5 & 0.91 \\
\hline 10.0 & 1.41 & 20.0 & 1.11 & 30.0 & 0.90 \\
\hline & & & & & \\
\hline
\end{tabular}




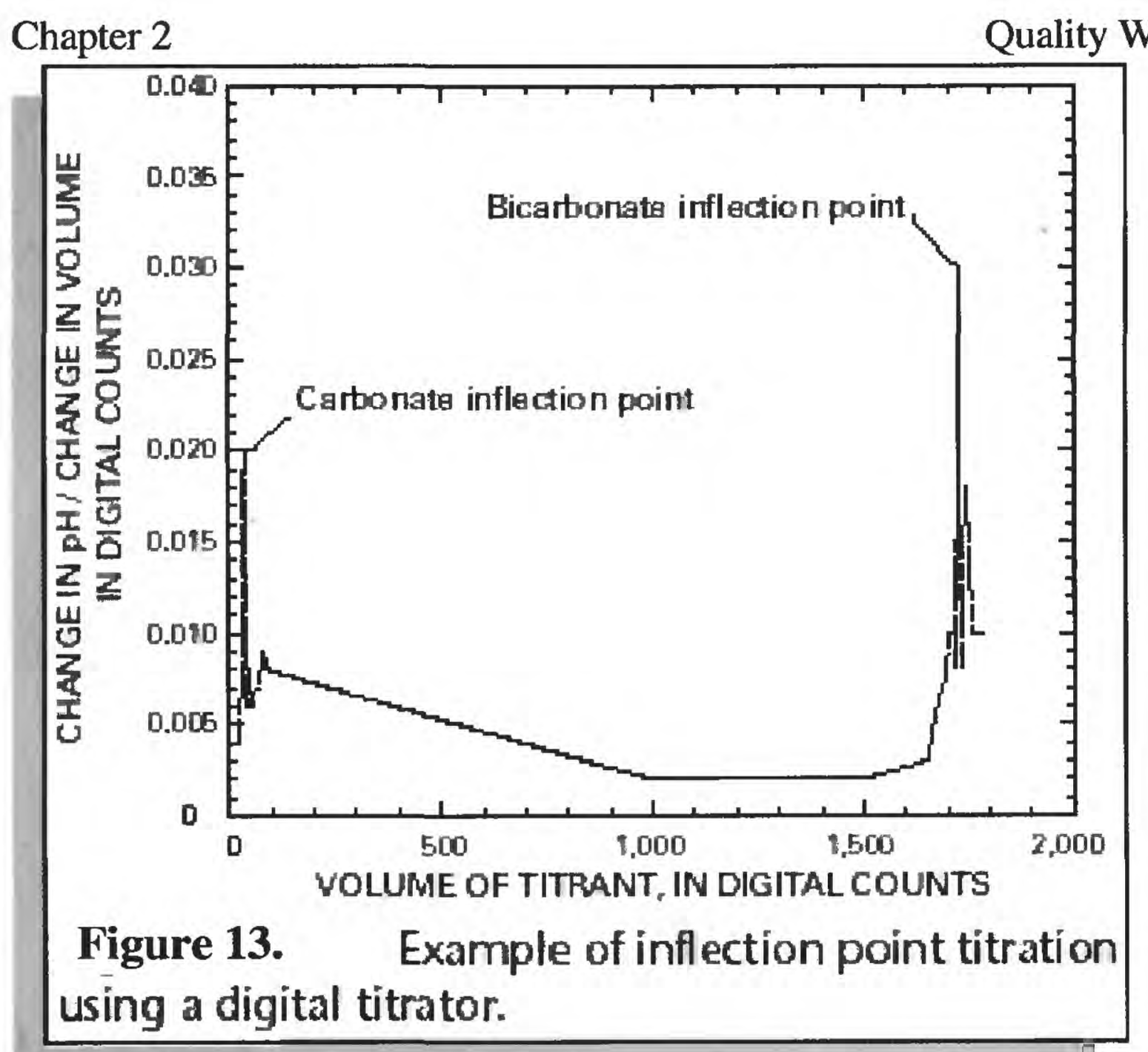




\section{DISSOLVED OXYGEN}

Oxygen dissolved in stream water is derived from the air and from the oxygen given off by aquatic plants in the process of photosynthesis. The solubility of oxygen in water is dependent upon the partial pressure of oxygen in the air, the temperature of the water, and the mineral content of the water.

The field method most commonly used for measuring dissolved oxygen in water is the cathode/electrometric method, which uses a membrane-type electrode. Oxygen passes through a membrane at a rate relative to the partial pressure of oxygen outside the membrane. When oxygen diffuses through the membrane, it is rapidly consumed at the gold cathode. The consumption

of oxygen causes a current to flow through the cell. The current is directly proportional to the quantity of oxygen consumed and can be converted to concentration units. The membrane is permeable to gases other than oxygen; therefore, halogens, hydrogen sulfide, sulfur dioxide, and helium will interfere with the ability of the probe to give correct readings. Several new methods

for determining in-stream dissolved oxygen are equally dependable. Follow the instructions provided by the manufacturer for calibration and measurements when using other methods for determining dissolved oxygen.

\section{Calibration}

Keep a log of calibration information for each meter and probe.

Calibrate the barometer with information from the nearest weather station or airport. The barometric-pressure readings reported by a weather station are adjusted to sea level, however, and must be converted to the elevation of the field site to enable comparison among location readings (see Table 7 and Figure 14.)

There are several methods used to calibrate dissolved-oxygen meters. These methods may vary with specific instrumentation. Users should calibrate meters according to manufacturer specifications.

\section{Measurement}

Dissolved-oxygen measurements should represent the mean dissolved-oxygen concentration at the time of measurement. Cross-sectional profiles will help to determine if the stream has a fairly uniform dissolvedoxygen concentration. If the stream cross section has uniform dissolved-oxygen concentrations, a single measurement can be made (usually at the centroid of flow). If the stream does not have uniform dissolved concentrations, or if a cross-sectional measurement has not been made, make several measurements and report an average (discharge-weighted average is preferred) concentration. Dissolved-oxygen measurements should not be made in or directly below stream sections with turbulent flow or in still water (near the streambank) because these conditions generally do not represent the majority of water flowing along the stream reach.

The dissolved oxygen should be measured with the probe immersed directly in the stream. If the stream velocity at the point of measurement is less than $1 \mathrm{ft} / \mathrm{s}$, use a stirrer or raise and lower the probe at a rate of approximately $1 \mathrm{ft} / \mathrm{s}$ (do not break the surface of the water). If the stream velocity is so high that the probe will not submerged, attach the probe to a small weight on a separate line.

- Turn on the dissolved-oxygen meter to any operational 1 hour before use to ensure stability of operation. Leave meter on until final measurement for the day is completed.

- Turn operation switch to the range used during calibration. 
- Read and record the dissolved-oxygen values after the reading on the meter has stabilized (at least 2 minutes).

- Remove the probe from the water, rinse with DIW, and store the probe tip in a storage bottle that contains a damp towel or immerse in DIW. Protect the probe from freezing.

- Turn the operation switch to the OFF position after the final measurement of the day.

- Report dissolved-oxygen concentrations to the nearest $0.1 \mathrm{mg} / \mathrm{L}$.

To express the results as percent saturation, use the following equation:

measured DO (mg/L)

DO $(\%$ saturation $)=$ $x 100$

DO at saturation $(\mathrm{mg} / \mathrm{L})$

where DO is dissolved oxygen.

\section{DOCUMENTATION}

Field activities should be documented on field.

Table 7. Factors used to correct atmospheric
pressures adjusted to sea level
\begin{tabular}{|c|c||}
\hline $\begin{array}{c}\text { Elevation of weather station } \\
\text { (feet above sea level) }\end{array}$ & $\begin{array}{c}\text { Value to subtract } \\
\text { (millimeters of mercury) }\end{array}$ \\
\hline 0 & 0 \\
\hline 1,000 & 27 \\
\hline 2,000 & 53 \\
\hline 3,000 & 79 \\
\hline 4,000 & 104 \\
\hline 5,000 & 128 \\
\hline 6,000 & 151 \\
\hline
\end{tabular}




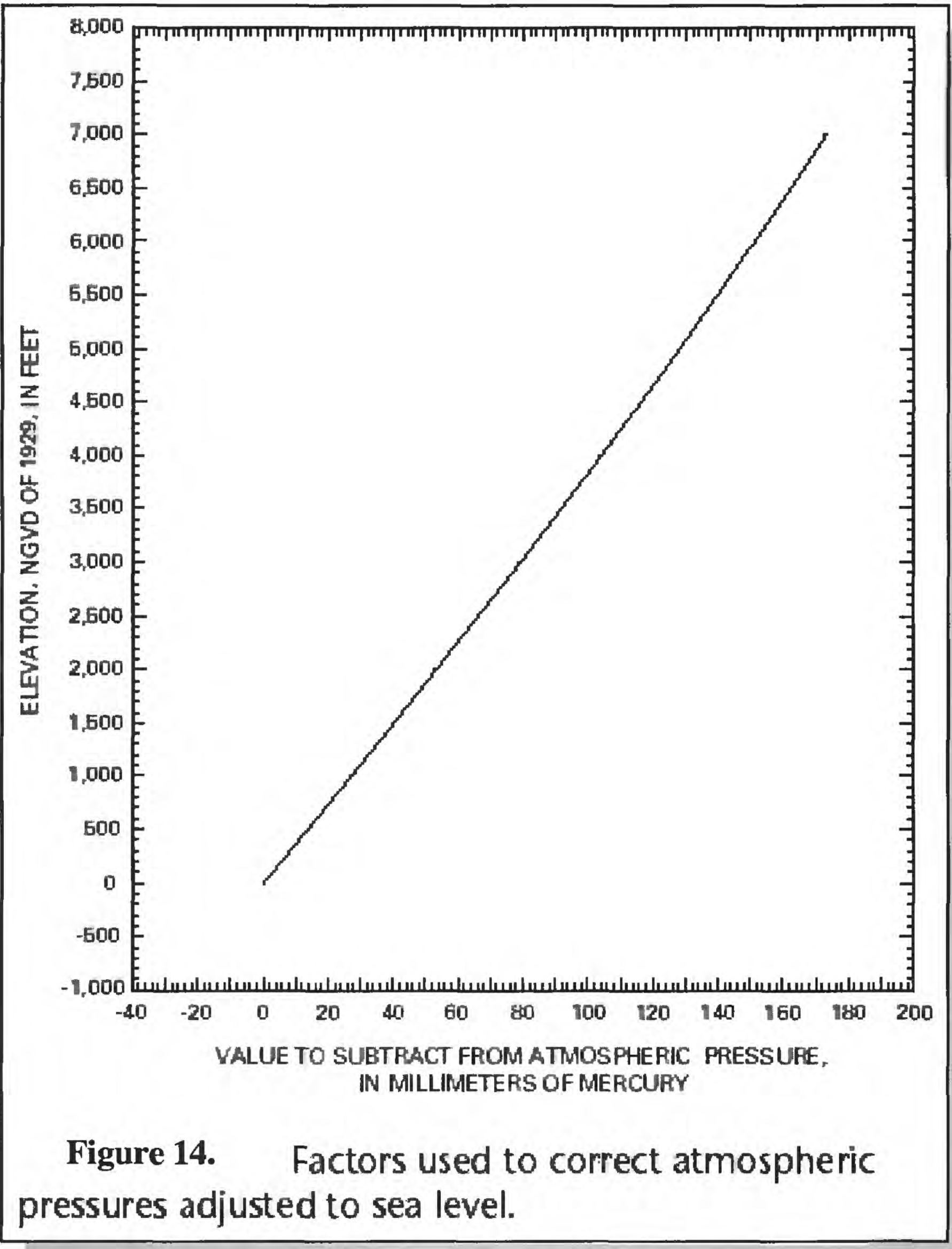


$\rightarrow$ a d क m

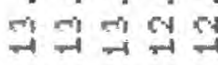

cis

$-7$

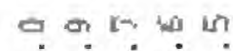

ت完宫

$\Rightarrow$ तो

a) in w w w का लो वर्ष

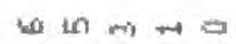

of $[$ is $\Rightarrow$ a d

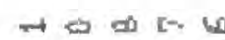

(4)

का को का

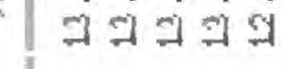

ฮ่ำำ

过告专出

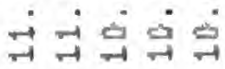

逭追

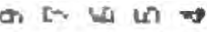

$\vec{a}$

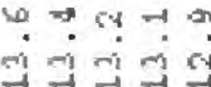

ㄴ: แn

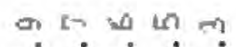

तo an a d

นक $\Rightarrow$ लो

वें बं के

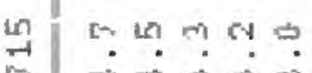

$\operatorname{sid}_{x \rightarrow d}$

퍼 거 퍼 거 거

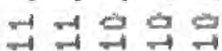

它曾完

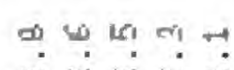

의 100

तो

wit in बत 4

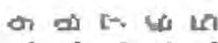

व) 195

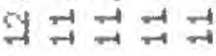

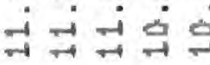

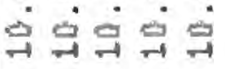

a $60 \mathrm{cot}$

an $5 \Rightarrow c$

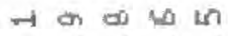

लाल का मा

[थ th th क ल

iो कों

मो लो

ल 에

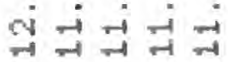

ज्ञन्यें

岳点点

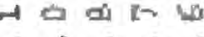

a w w

$\Rightarrow 0$ w w

c⿻一𠃋十

$\Rightarrow \rightarrow$ 의

둔 แ $\Rightarrow$

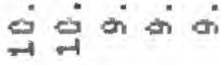

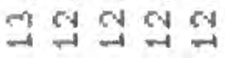

억 거 न न

ज्ञ ज्ञान

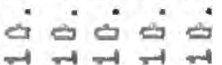

$\rightarrow$ 业

तो को का की

की लो का

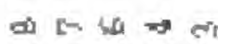

जो को को

E. - का लो

म वं बं

ब्ष

$\Rightarrow \rightarrow-1$ ने

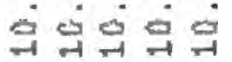

लन बक व

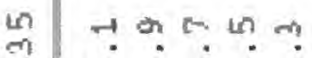

$x \leq$ on w

तो $\mathrm{N}=$

$\Rightarrow$ नी

$\Rightarrow$ तो ज्ञात

बन्न न्न

4. m क्ष

on at w w

दें

$\Rightarrow$ 舟

$\because \multimap$ ㄴ.

$\Rightarrow a r a b$

파 ज्ञा न्न

우룰워

तथ त क व

wa $\Rightarrow \mathrm{s} \Rightarrow$

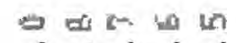

하구의

ज्ञनㄱำ 기

각ㄷำ

웍웍ㄱन

नंन्नंज्नंन

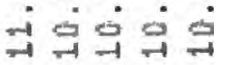

$\Rightarrow$ a न क व

$\rightarrow$ तर

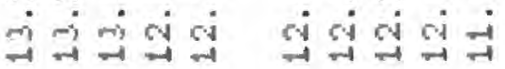

$06 \Rightarrow m$

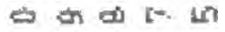

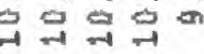

$\Rightarrow \rightarrow-i$

$\Rightarrow$ ? 다.

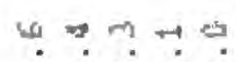

में

ज宇它完

- ल त $\mathrm{Na}$

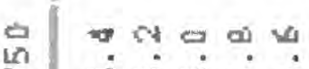

$\Rightarrow \min ^{\infty}$

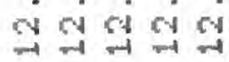

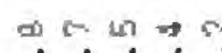

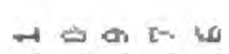

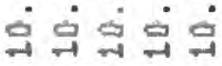

मनन ज्ञात

Lी तो

या एल

जो नो नो $\Rightarrow$

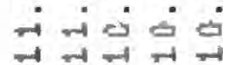

जी $\Rightarrow \rightarrow$

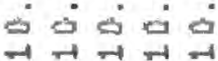

กी की ला $\rightarrow$ का

मां लो व

cid

का It. w th

व $\rightarrow$ a d o

6 ल ल ल

تं - $^{-1}$ -

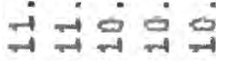

जे

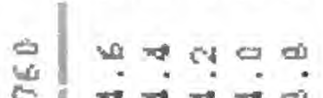

4. $\Rightarrow$ तn

ㄴ. 뭉.

$\Rightarrow$ वा ज०

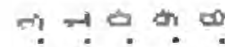

we w? तो

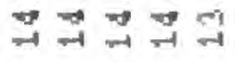

जो नो लो

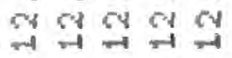

जन $\Rightarrow=-1$ न

퍼걱구리

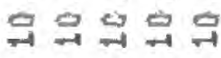

in $\mathrm{m}$ !n

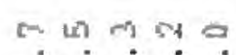

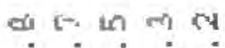

a on w w w w

ला तो 9

[- so wh $\rightarrow \mathrm{c}$

नो वनच

웍되워

वो

i - $=-1 \dot{-1}$

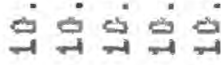

ह $4 \Rightarrow a \Rightarrow$

क्ष

aा In 60 m

w d a th w

\#ल लव

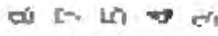
석 ल व

बงं

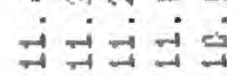

जिं

m| on

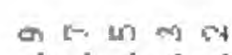

$\Rightarrow$ a s w $\Rightarrow$

तf $\rightarrow$ an a d

जा का को $\Rightarrow$

at $1=$ sa un नी तो

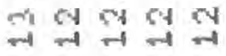

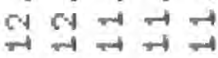

ज्ञ ज्ञजत ज्ञात

न नो जो

a बiा $\rightarrow$

जो क्ष की $\Rightarrow$

ता का का मा

औमल लै

aो वो $^{-1}$

मंन्यंज्यं

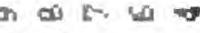

नन न्न न्न

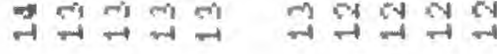

co

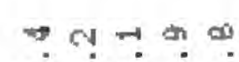

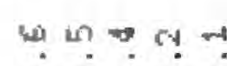

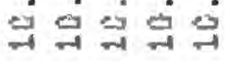

Lी

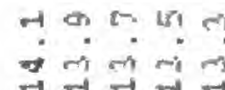

$\Rightarrow$ 억

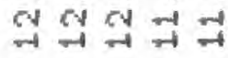

커 거

$\Rightarrow$ on the un

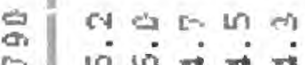

c)

न न क जै

$\Rightarrow m \rightarrow \Rightarrow$ का

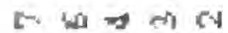

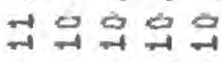

का मों $\rightarrow \vec{\phi}$

मनㅣㄱㅣ

거ำำ

बंध्यंघं

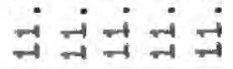

$\rightarrow$ an an to 10

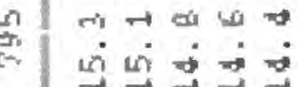

$\mathrm{c} \rightarrow$ an the w

$\rightarrow$ का का का

in $\Rightarrow$ का ना को

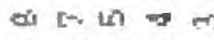

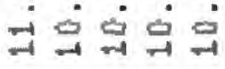

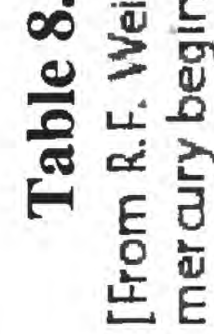

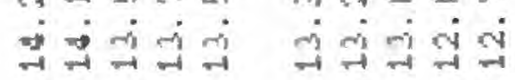

ब่ं

मेंज्ञनं

न1 0 क का 4

wo

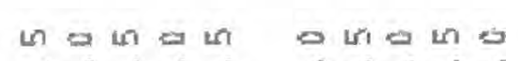

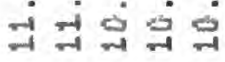




\begin{tabular}{|c|c|c|c|c|c|c|c|}
\hline & 总 & पी & की & मी & $a a^{2} x$ & $\Leftrightarrow \Leftrightarrow \Rightarrow$ & 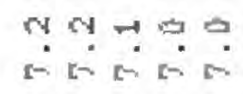 \\
\hline $\begin{array}{l}0 \\
\stackrel{0}{2}\end{array}$ & 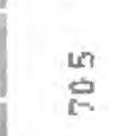 & 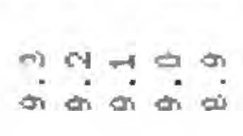 & 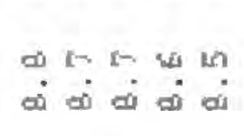 & 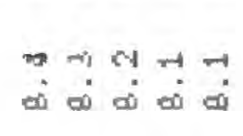 & 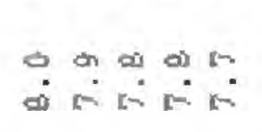 & 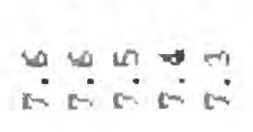 & 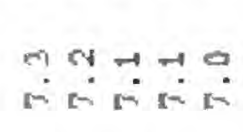 \\
\hline 등 & 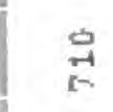 & 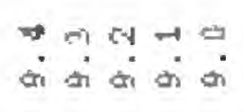 & 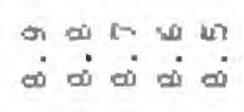 & 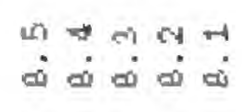 & $\Leftrightarrow a \cos 2$ & 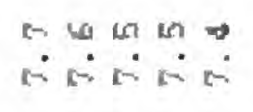 & 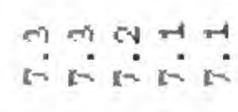 \\
\hline 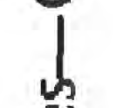 & 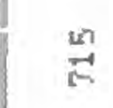 & 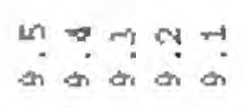 & $\therefore \circ$ & 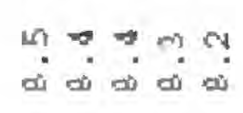 & H: & $\begin{array}{ll}2 \\
\therefore\end{array}$ & 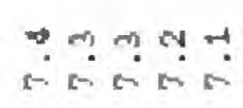 \\
\hline$\vec{s}$ & 롬 & की में के & 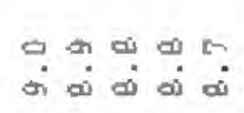 & 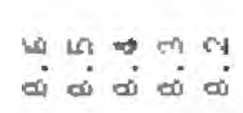 & वैं & 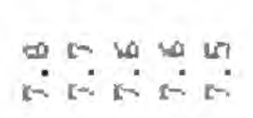 & $\Rightarrow$ \\
\hline 0 & 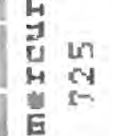 & $\begin{array}{lll}4 \\
0\end{array}$ & 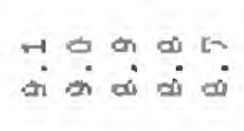 & 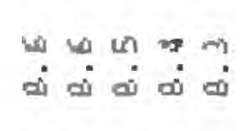 & 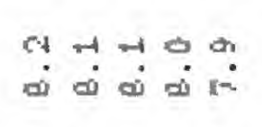 & 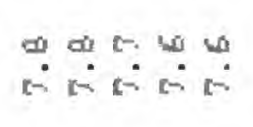 & 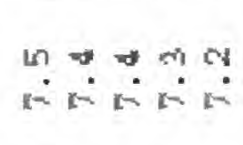 \\
\hline$\pi$ & 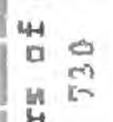 & 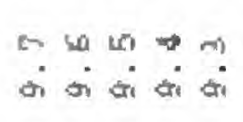 & $\begin{array}{ll}4 \\
\text { sin }\end{array}$ & 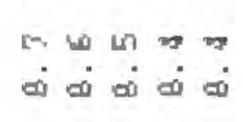 & 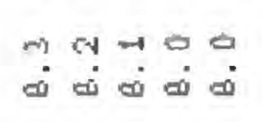 & 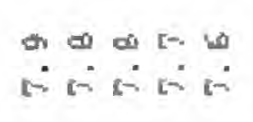 & 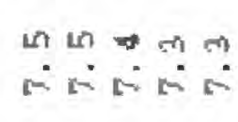 \\
\hline 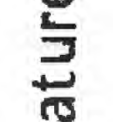 & 至 & 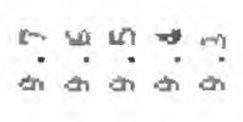 & 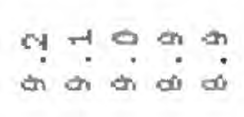 & $\begin{array}{c}0 \\
0 \\
0\end{array}$ & 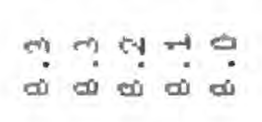 & 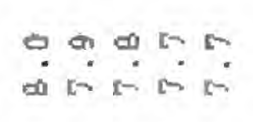 & 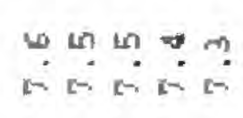 \\
\hline$\stackrel{\mathscr{U}}{E}$ & 官总 & 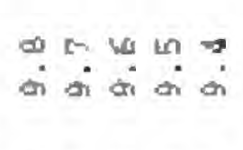 & 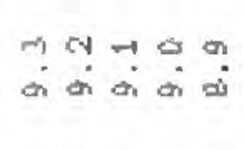 & 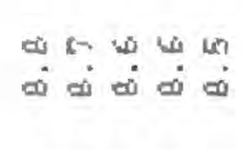 & 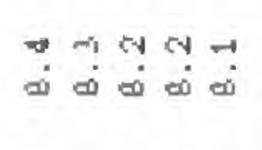 & 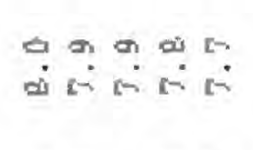 & 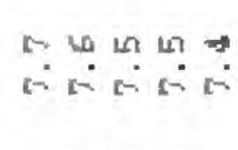 \\
\hline 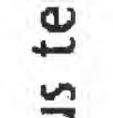 & 焉品 & की & 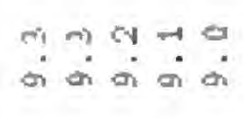 & 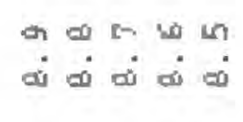 & की & 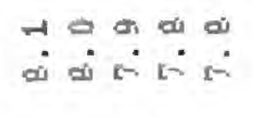 & $\therefore \therefore \therefore$ \\
\hline$\frac{5}{3}$ & 台噍 & 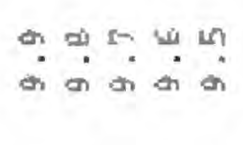 & 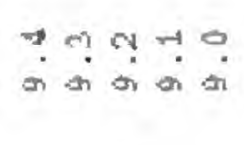 & की की की क्ष & 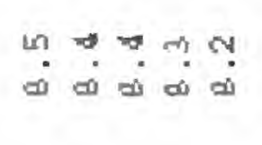 & $\Rightarrow$ & 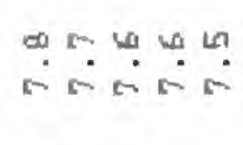 \\
\hline 2 & 点 & $\begin{array}{c}a \\
0\end{array}$ & 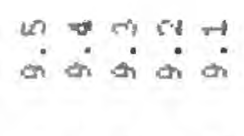 & 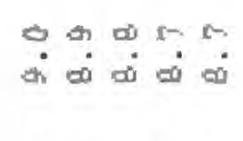 & वृ & 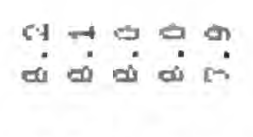 & 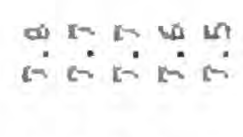 \\
\hline$\frac{\omega}{5}$ & 昜总 & $\begin{array}{ll}1 \\
\theta\end{array}$ & थी $\Rightarrow$ की & मे की & 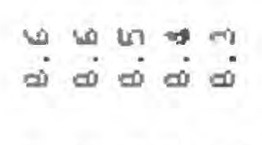 & 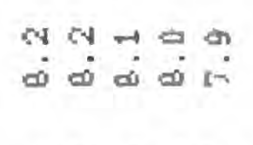 & 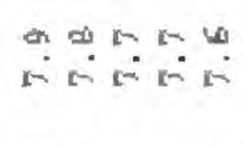 \\
\hline$\subseteq$ & 0 & 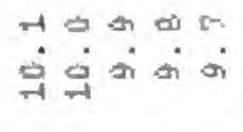 & 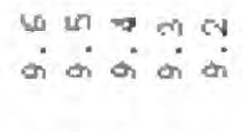 & 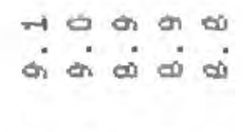 & 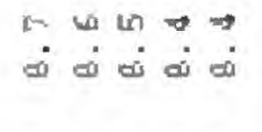 & 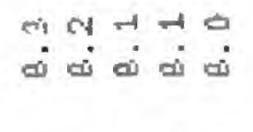 & $\therefore \rightarrow$ \\
\hline$\sum_{x}^{\circ}$ & $\stackrel{9}{20}$ & 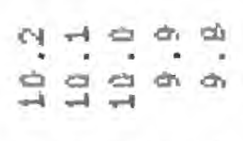 & 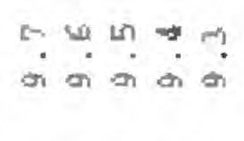 & 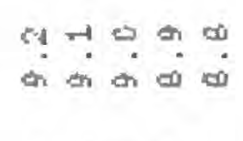 & की & 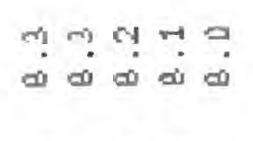 & 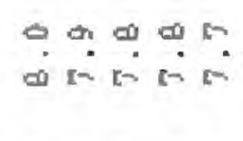 \\
\hline 范 & 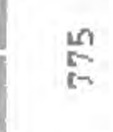 & 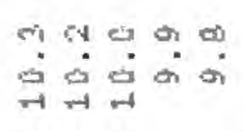 & 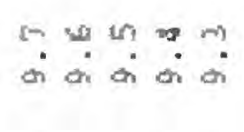 & 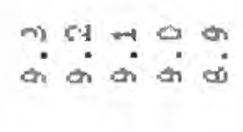 & $=0$ & 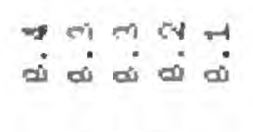 & वर्ष \\
\hline$\stackrel{\nexists}{\underline{\bar{a}}}$ & 总 & 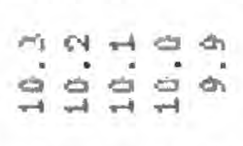 & की & 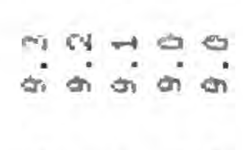 & की क⿺辶一兀 & 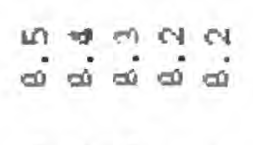 & 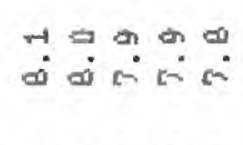 \\
\hline$\frac{2}{0}$ & 管 & 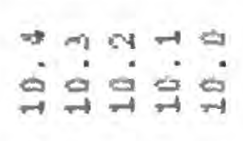 & की & $\Rightarrow \ddot{0}$ & 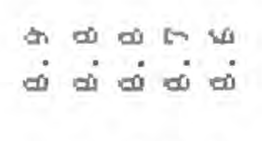 & पी $\Rightarrow=0$ & 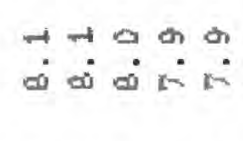 \\
\hline & 总 & 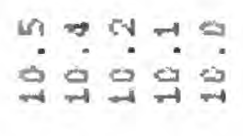 & की की को & 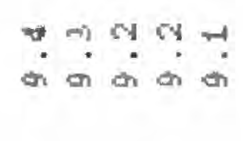 & 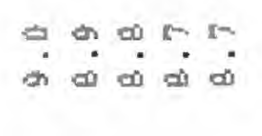 & 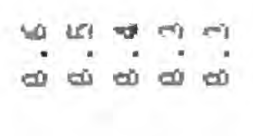 & a ta \\
\hline$\frac{1}{2}$ & $\stackrel{m}{g}$ & 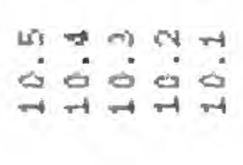 & 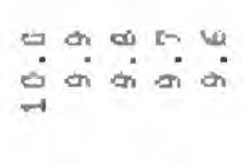 & 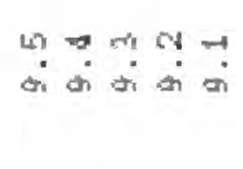 & 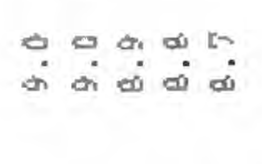 & 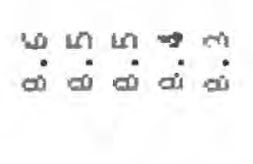 & a d a \\
\hline
\end{tabular}




\section{Section 2.5}

\section{QUALITY ASSURANCE AND QUALITY CONTROL}

\section{Quality Assurance / Quality Control}

Quality Assurance - Assesses processes and procedures

- Techniques and methods

Quality Control_- Means to check accuracy and quality

- QC samples

\section{Water Quality OC samples}

- Identify contamination from: collection, processing, shipping, or environment.

- Quantify the variability and bias resulting from: collection, processing, shipping, and analysis.

Blank samples - samples of water known to be free of target analytes.

Purpose - to identify potential sources of contamination and to evaluate the magnitude of the contamination with respect to the concentration of the target analytes.

Blanks are designed to demonstrate that (1) equipment-cleaning protocols adequately remove residual contamination from previous use, (2) sampling and sample-processing procedures do not result in contamination, and (3) equipment handling and transport between periods of sample collection do not introduce contamination.

Field blanks are collected immediately before processing native water through the sample-processing sequence for field samples. Preparation of field blanks requires passing a volume of organic-free or inorganic-free DIW through all sample equipment contacted by the actual sample.

- Field blank_- processed in the field

- Lab blank - processed in the laboratory

- Source-solution blank - processing water

- Equipment blank - sampling and processing equipment

- Trip blank - environment 
Replicate Samples_- environmental samples collected in duplicate, triplicate..., and are considered to be identical in composition.

Purpose - To identify / quantify the variability from the sample collection, processing, and analysis procedures

Sample replicates are designed to provide information needed to (1) estimate the precision of concentration values determined from the combined sample-processing and analytical scheme and (2) evaluate the consistency of identifying target analytes for pesticides. Each replicate sample is an aliquot of native sample water from a splitter and is processed immediately after the primary split sample using the same equipment; placed into the same type of bottle; prepared in the same way, if applicable; and stored and shipped in the same way.

- Concurrent replicates - simultaneous

- Sequential replicates - one follows the other

- Split replicates - sample divided into two or more equal subsamples (generally following processing)

Spikes- Environmental samples spiked with known concentrations of target analytes.

Purpose - to (1) assess recoveries from field matrices and (2) assist in evaluating the precision of results for the range of target analytes in different matrices.

A field-matrix spike is prepared by adding a standard spike solution to a split of sample water processed in the same way as the regular pesticide analysis..

- Used to measure the loss or gain of analyte due to water matrix, processing, shipping, or analysis

- Must be accompanied by an unspiked sample

- Measured loss or gain must be assessed in light of analysis precision.

Reference Samples - Samples with known concentrations of target analytes

- Used to assess variability and bias associated with processing, shipping, and analysis

- Generally submitted as blind samples or duplicate samples 


\section{Section 2.6}

\section{BIBLIOGRAPHY}

U.S. Geological Survey, National field manual for the collection of water-quality data: U.S. Geological Survey Techniques of Water-Resources Investigations, book 9, chaps. Al-A9, 2 v., variously paged. [Chapters were published from 1997-1999; updates and revisions are ongoing and can be viewed at: http://water.usgs.gov/owq/FieldManual/mastererrata.html]

Horowitz, A.J., Demas, C.R., Fitzgerald, K.K., Miller, T.L., and Rickert, D.A., 1994, U.S. Geological Survey protocol for the collection and processing of surface-water samples for the subsequent determination of inorganic constituents in filtered water: U.S. Geological Survey Open-File Report 94- 539, 57 p.

Capel, P.D., and Larson, S.J., 1996, Evaluation of selected information on splitting devices for water samples: U.S. Geological Survey Water-Resources Investigations Report 95-4141, 103 p.

Ogawa, I., Junk, G.A., and Scev, H.J., 1981, Degradation of aromatic compounds in groundwater, and methods of sample preservation: Talanta, v. 28, p. 725-729.

Weiss, R. F. (1970) The solubility of nitrogen, oxygen and argon in water and seawater. Deep-Sea Research 17: 721-735. 


\title{
Field Methods for Hydrologic and Environmental Studies
}

\author{
Chapter 3
}

\section{Biological Data Collection}

Mitchell A. Harris 
Section 3: Biological Data Collection ……….........................................................................................................136

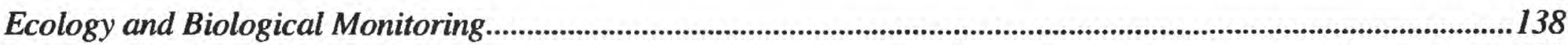

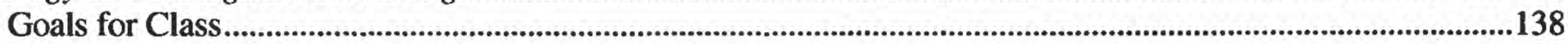

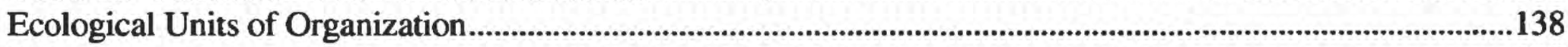

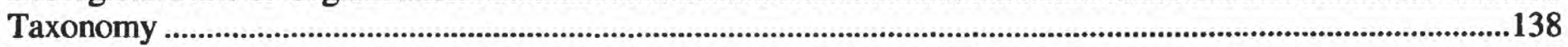

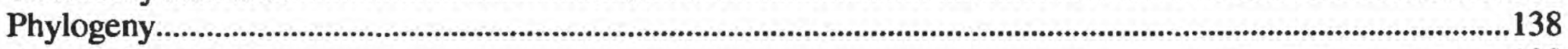

Aquatic Ecosystems.............................................................................................................................................138

Freshwater Systems .................................................................................................................................................139

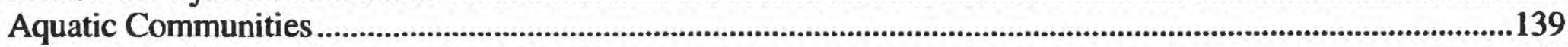

Hierarchical Nature of Stream Systems .......................................................................................................................140

Lotic Habitat Types ........................................................................................................................................................141

Biological monitoring................................................................................................................................................142

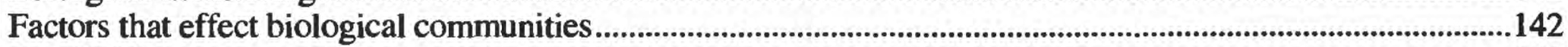

Food Web........................................................................................................................................................................143

River Continuum Concept.............................................................................................................................................145

Sampling Considerations..................................................................................................................................................145

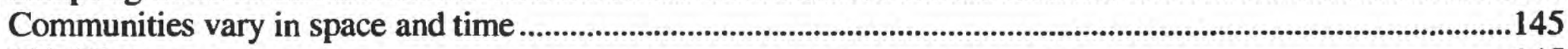

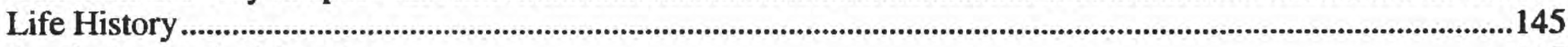

Exotic (nonnative) Species...........................................................................................................................................145

Endangered or Threatened Species .............................................................................................................................145

Commonness and Rarity .......................................................................................................................................145

Fish

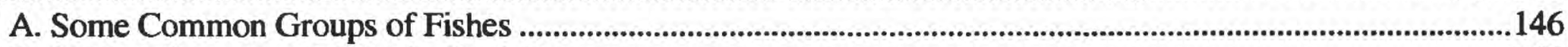

B. Habitat, Sampling Methods, Variables ...........................................................................................................146

C. Sample Analyses and the Index of Biotic Integrity (IBI) ....................................................................................147

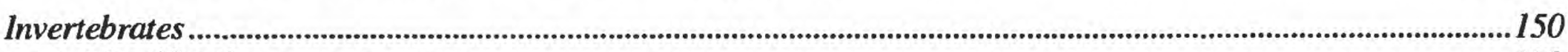

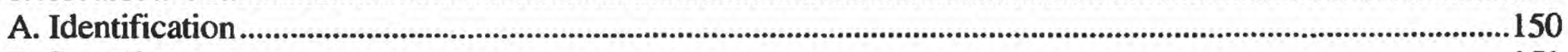

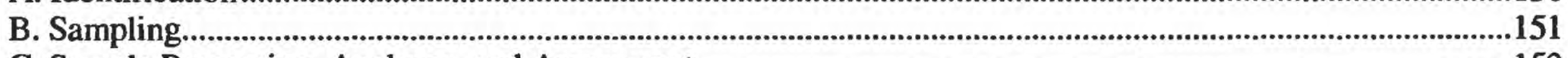

C. Sample Processing, Analyses, and Assessment .............................................................................................153

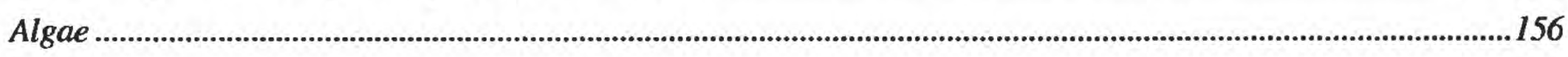

Habitat Assessment and Physicochemical Parameters.................................................................................................157

Bibliography ............................................................................................................................................................... 159

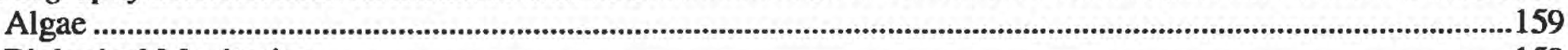

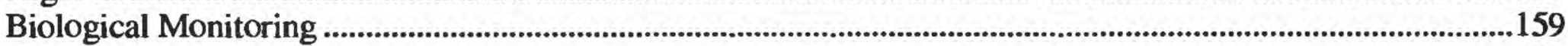

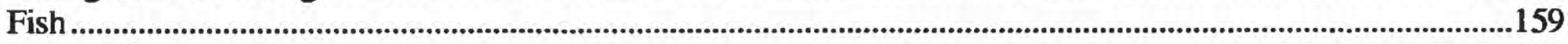

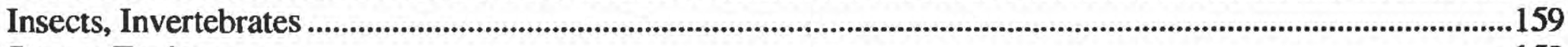

Stream Ecology

Hydrology, Physical Parameters, and Stream Geomorphology...................................................................................159 


\section{Ecology and Biological Monitoring}

\section{Goals for Class}

Look at stream from biologist's point of view

Explore some biological sampling techniques with focus on biological assessment of water quality using fish and benthic macroinvertebrates.

\section{Ecological Units of Organization}

Individual

single organism or unit

Population

group of organisms of one species, occupying a defined area and usually isolated to some degree from similar groups

Community

Assemblage of species that co-occur in the same habitat or area and interact through trophic and spatial relationships; typically characterized by reference to one or more dominant species

Properties:

richness

diversity (relative composition of species abundance)

Ecosystem morphological and physiological attributes trophic structure

community of organisms and their physical environment (abiotic such as climate,

\section{Taxonomy}

soil) interacting as an ecological unit

\section{Phylogeny}

Science of classification and naming

Study of evolutionary history of and relationship among taxonomic groups.

Taxonomic Hierarchy Example 1 (caddisfly)

$\begin{array}{lll}\text { Kingdom: } & \text { Animalia } & \text { animals } \\ \text { Phylum: } & \text { Arthropoda } & \text { "jointed legs" } \\ \text { Class: } & \text { Insecta } & \text { insect } \\ \text { Order: } & \text { Trichoptera } & \text { caddisfly } \\ \text { Family } & \text { Hydropsychidae } & \text { net-spinning caddisfly } \\ \text { Genus species } & \text { Hydropsyche morosa } & \end{array}$

Taxonomic Hierarchy Example 2 (Largemouth bass)

$\begin{array}{lll}\text { Kingdom: } & \text { Animalia } & \text { animals } \\ \text { Phylum: } & \text { Chordata } & \text { animals with backbones } \\ \text { Class: } & \text { Osteichthyes } & \text { bony fishes } \\ \text { Order: } & \text { Perciformes } & \text { basses, sunfishes, walleye, darters } \\ \text { Family: } & \text { Centrarchidae } & \text { sunfishes, basses } \\ \text { Genus species: } & \text { Micropterus salmoides } & \text { Largemouth bass }\end{array}$

\section{Aquatic Ecosystems}

Marine

Brackish 
Freshwater

Freshwater Systems

Lentic

standing water (lakes and ponds)

Lotic

flowing water (rivers and streams)

\section{Aquatic Communities}

Benthos

collectively all organisms that live on or in the bottom, e.g. worms, insects, diatoms, protists

Plankton

organisms that are suspended in the water column; movement depends on water Nekton currents, includes Phytoplankton (plants), Zooplankton (animals)

Neuston

free swimming organisms, e.g. fish, snakes, diving beetles, newts

organisms that live on water surface; never break surface tension, e.g. water striders,

Madricoles

organisms that live on rock faces in waterfalls or seepages 
Hierarchical Nature of Stream Systems (figure from Fitzpatrick and others, 1998)

Basin

Segment

Reach

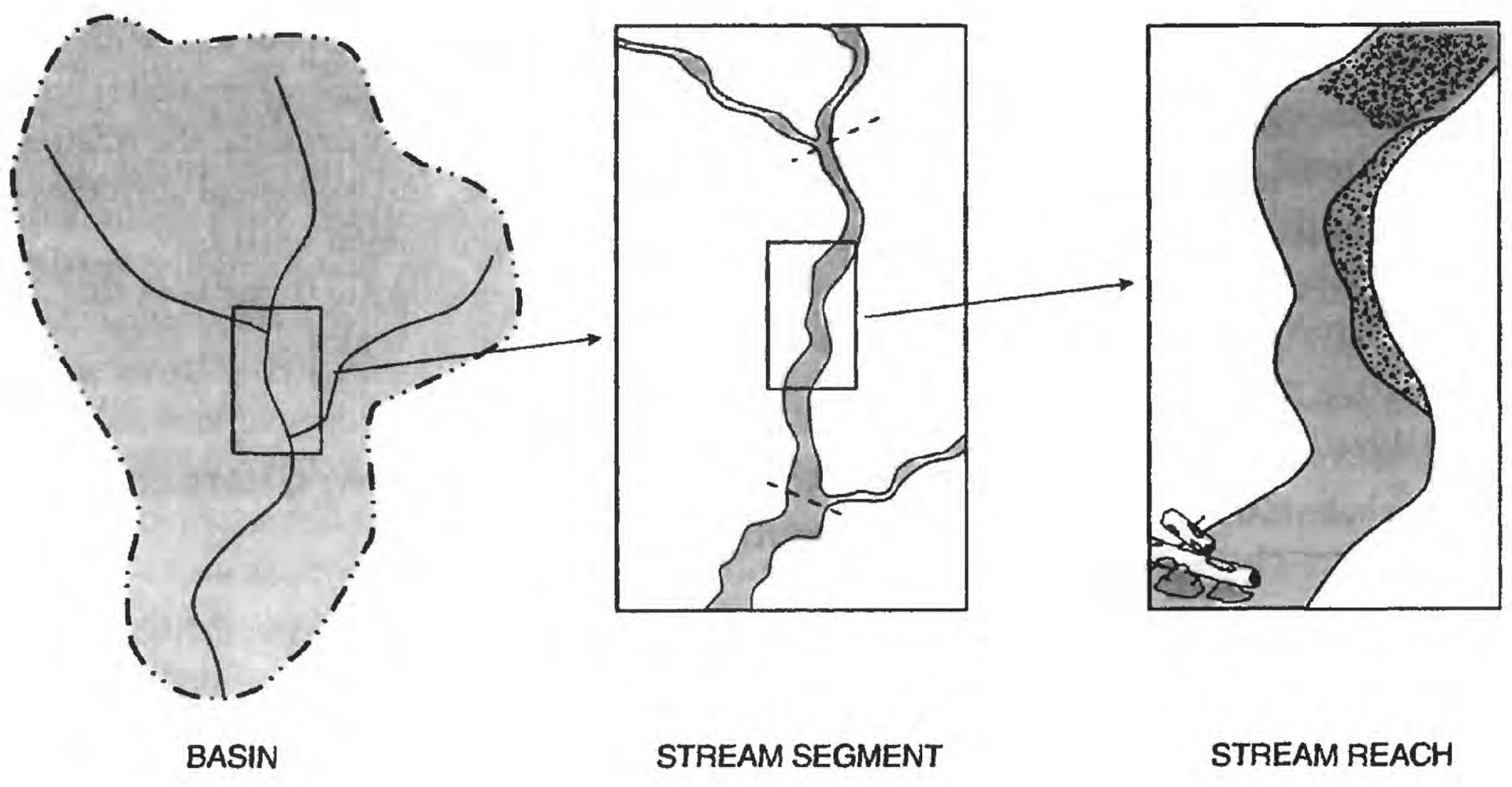


Lotic Habitat Types (figure from Fitzpatrick and others, 1998)

Riffle

Run

faster flowing, well-oxygenated water, coarse sediments

Intermediate characteristics

Pool

slower currents, deeper water, and finer, more homogeneous sediments

Side view

(A) Run

(B) Riffle

(C) Pool

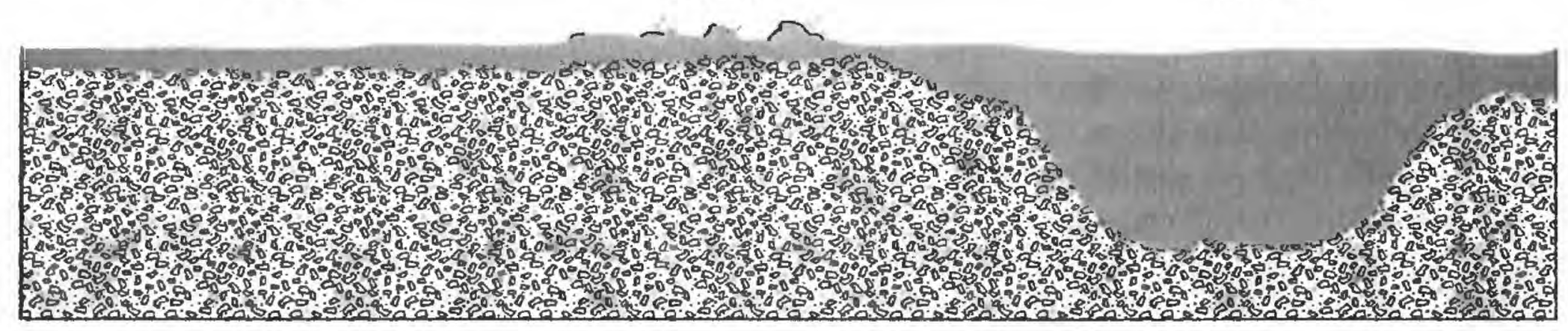

(A) Run

(B) Riffle

(C) Pool

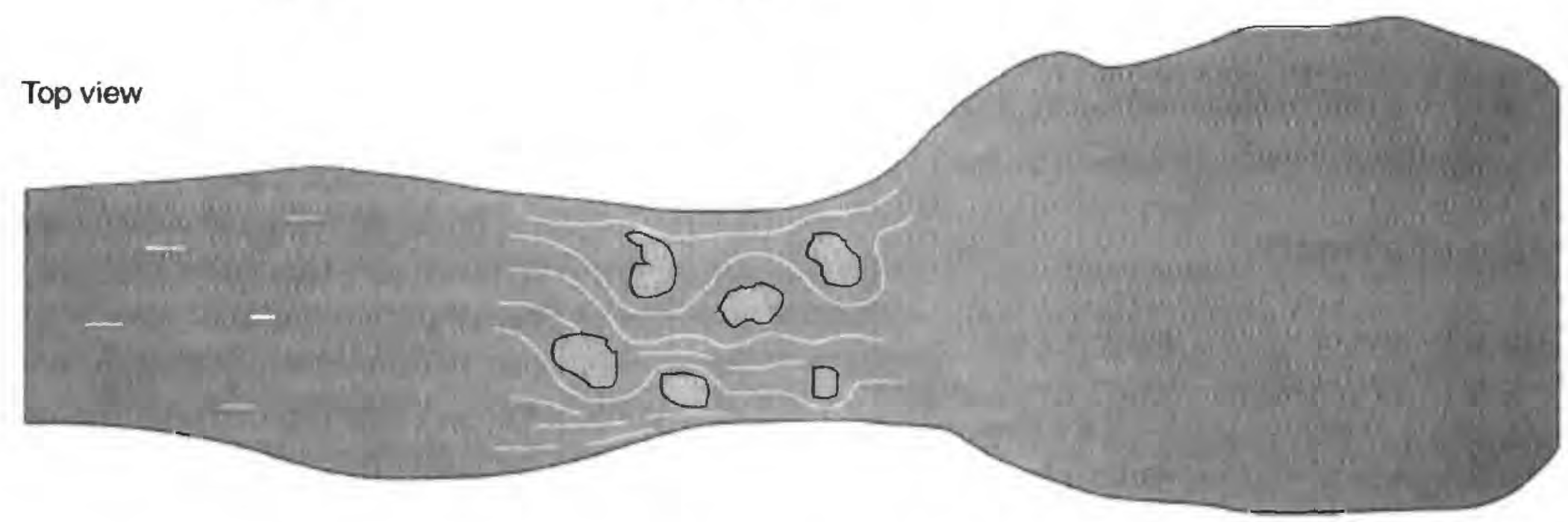

Diagram of the three main geomorphic channel units. (A) Run-A slow moving, relatively shallow body of water with moderately low velocities and little or no surface turbulence; $(B)$ Riffle-A part of the stream where the water flows swiftly over completely or partially submerged obstructions to produce surface agitation; (C) Pool-A part of the stream with reduced velocity, commonly with deeper water than surrounding areas (modified from Bisson and others, 1982). 


\title{
Biological monitoring
}

Systematic use of biological resources to evaluate changes in the environment with the intent to use this information in a quality control program. The primary objective of the National Clean Water Act (CWA) is to "restore and maintain the chemical, physical and biological integrity of the nation's waters".

In a multimetric evaluation, reference conditions are used to scale an assessment to the "best attainable" situation. A station of interest is classified on the basis of its similarity to expected conditions (reference condition), and its apparent potential to support an acceptable level of biological health.

Outside the scope of this class are toxicological studies and bioassays. These studies are traditionally laboratory studies where the response of a test organism is measured after exposure to a chemical or effluent.

\author{
Factors that effect biological communities \\ Water Quality \\ temperature \\ turbidity \\ dissolved oxygen \\ acidity \\ alkalinity \\ organic and inorganic chemical \\ heavy metals \\ toxic substances
}

Habitat structure

substrate type

water depth and current velocity

spatial and temporal complexity of physical habitat

flow regime

water volume

temporal distribution of flows

Energy source

type, amount, and particle size of organic material entering stream

seasonal pattern of energy availability

Biotic interactions

competition

predation

disease

parasitism

mutualism 


\section{Food Web}

Functional description of a community. Study of organic matter processing and community interactions. (Figure is adapted from "The Living Stream," a slide show by Bert Cushing, North American Benthological Society $<$ www.benthos.org/info/conserv/consslides.htm>).

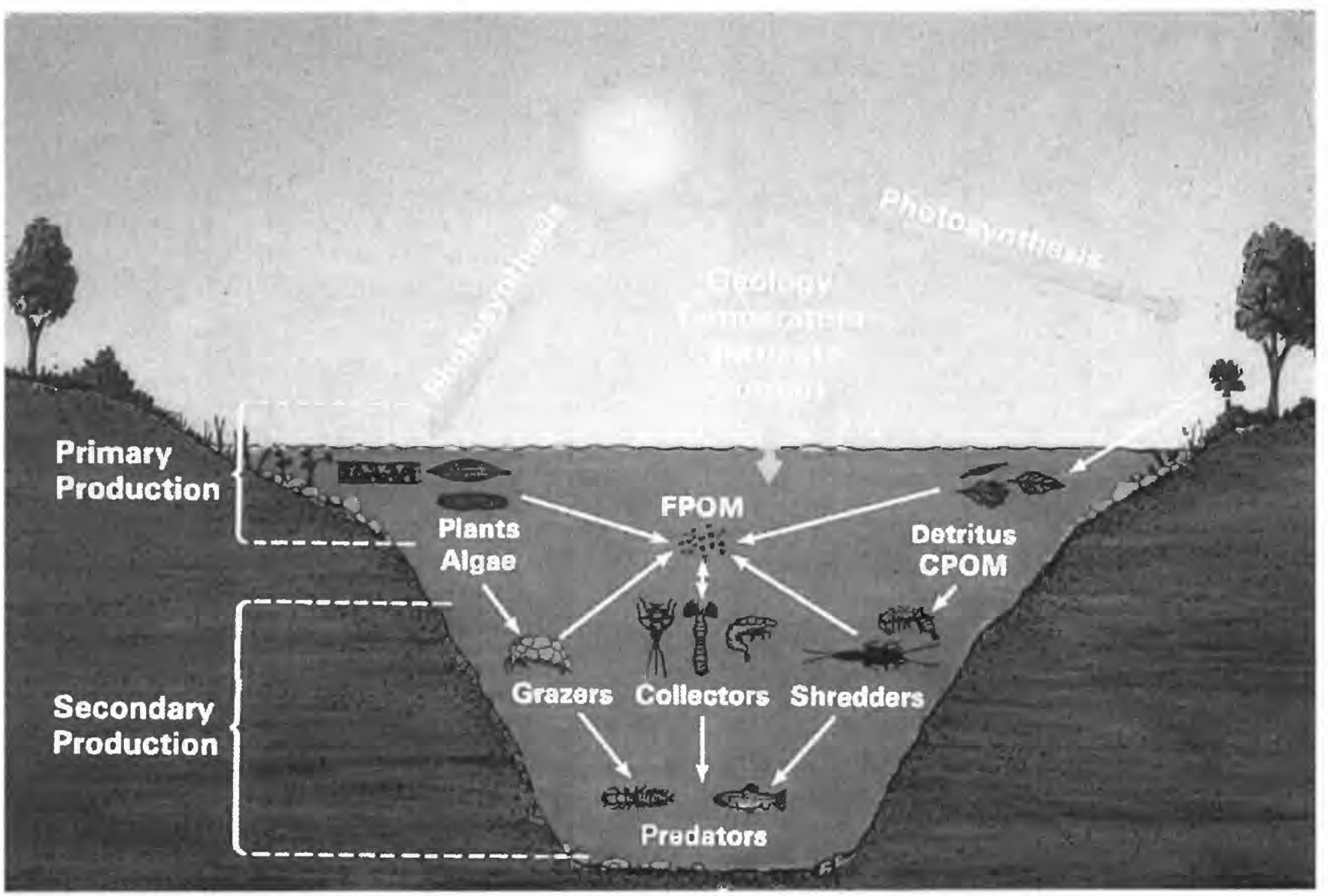




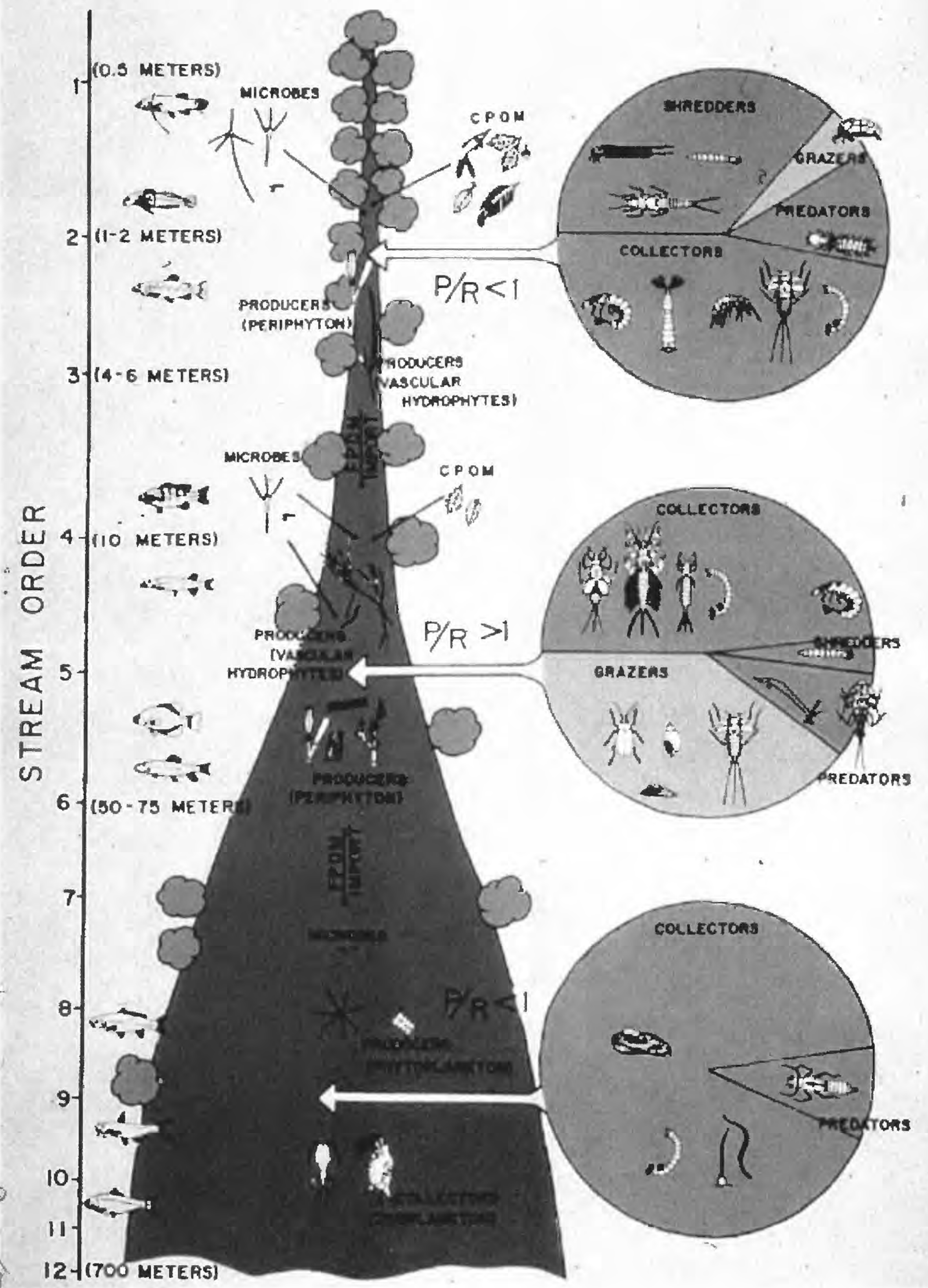


River Continuum Concept

Describes changes in structure and function of a stream along a longitudinal gradient. (Figure is adapted from The Living Stream," a slide show by Bert Cushing, North American Benthological Society <www.benthos.org/info/conserv/consslides.htm>).

Changes are a function of changes in geomorphic, physical, and biotic variables such as: stream flow channel morphology (especially width and depth) organic matter transport use of energy by the streams functional feeding groups thermal regimes autotrophic production nutritional sources

Sampling Considerations quantitative \#/area qualitative relative abundance $(\%)$ presence/absence

Communities vary in space and time spatial variation temporal variation (seasonal and annual)

\section{Life History}

events that govern the survival and reproduction of a species or population

Exotic (nonnative) Species

organism that is outside its native range

Endangered or Threatened Species legislative designation for a species that is threatened with extinction or extirpation

Commonness and Rarity 


\section{Fish}
A. Some Common Groups of Fishes
B. Habitat, Sampling Methods, Variables
C. Sample Analyses and the Index of Biotic Integrity (IBI)
A. Some Common Groups of Fishes (Page and Burr, 1991)
"Ancient Fishes"

Lampreys, sturgeons, gars, paddlefish, bowfin, shad, eel. An artificial collection of orders and families of fishes that are unrelated to each other. There are a number of interesting and distinctive species in these groups. These orders are evolutionarily older than others that we will look at.

\section{Salmoniformes}

Salmonidae (salmon, trout, whitefish). Live in cool streams, many commercially important species. Recognized by fleshy adipose fin.

Esocidae (pickerel, muskellunge). Elongate, predatory fish, with "duck bill" mouth.

\section{Cypriniformes}

Cyprinidae (minnows and carps). Minnows are largest family (have the most species) of freshwater fishes. Varied both ecologically and morphologically.

Catostomidae (suckers). Suckers have a small mouths and large thick lips which are used in most species to "vacuum" invertebrates from stream and lake bottoms. Many suckers are large in size and they are usually abundant, so in many water bodies suckers account for the largest biomass of any group.

\section{Siluriformes}

Ictaluridae (catfishes, bullheads, madtoms). These fish are recognized by having no scales, four pairs of barbels, an adipose fin, and fins with spines. Madtoms feed on aquatic invertebrates and tend to be found in clean, flowing water. Madtom fin spines have a mild venom (watch out for these when collecting!).

\section{Perciformes}

Centrarchidae (sunfishes, basses, crappies). These are laterally compressed fishes. They have two joined dorsal fins, the first with spines and the second with rays. Many popular sportfishes are in this family. Centrarchids typically construct circular nests in the gravel, where the male guards the eggs

Percidae (walleye, sauger, yellow perch, darters). The second most diverse freshwater fish family in North America (after Cyprinidae). All but a few species in this family are darters. Darters do not have swim bladders, and they frequent the bottom of riffles where they ingest insects and crustaceans. Breeding males can be colorful.

\section{B. Habitat, Sampling Methods, Variables Variables that effect what you fish you find}


geographic location, fish distribution

stream size and depth

habitat

margin, substrate size

stream morphology

pools, run, riffle

Factors Responsible For Disappearance Of Native Fish Species (Smith, 1971)

Excessive siltation

loss of water clarity, disappearance of aquatic vegetation, deposition of silt over rock or sand substrates

Drainage

loss of wetlands

Desiccation

lowering of water table causes small streams, seeps, and spring to dry up, and relatively larger rivers become smaller

Species interaction

Pollution

introduced species, ecologically labile native species

industrial, domestic, agricultural

Dams and impoundments

habitat loss, blocking migration

Temperature

higher temps due to channelization, loss of riparian vegetation

Sampling Methods

seine

electrofishing

net

visual (snorkling, SCUBA)

toxicants

hook and line

C. Sample Analyses and the Index of Biotic Integrity (IBI)

Properties of fish community

Richness

Diversity

number of species

relative composition of species abundances

Trophic structure

Morphological and physical attributes 
Table: Fish trophic structure 
Multimetric indexes

An index created from multiple measures or metrics. Different metrics are sensitive to different perturbations. For example, municipal effluents may alter the trophic structure of a community, while habitat modifications may first effect the darters.

Metrics used in the Original Index of Biotic Integrity (Karr and others, 1986)

Species Richness and Composition Metrics

1. Total number of fish species

2. Number of darter species

3. Number of sunfish species

4. Number of sucker species

5. Number of intolerant species

6. Percent green sunfish

Trophic Composition Metrics

7. Percent omnivores

8. Percent insectivorous cyprinids

9. Percent piscivores (top carnivores)

Abundance and Condition Metrics

10. Number of individuals

11. Percent hybrids

12. Health and condition: percent individuals with disease, tumors, fin damage, skeletal anomalies 


\section{Invertebrates}
A. Identification
B. Sampling
C. Sample Processing, Analyses, and Assessment
A. Identification
Life Cycle (of an insect)
eggs
larvae (multiple instars)
pupae (in holometabolous orders)
adults

Identification of Macroinvertebrates

Taxonomy can be at any level, but should be consistent among samples.

Genus/species will provide more accurate information on

ecological/environmental relationships and sensitivity to impairment. Most organisms are identified to the lowest practical level (generally genus or species) by a qualified taxonomist using a dissecting microscope. Midges (Diptera:

Chironomidae) are mounted on slides in an appropriate medium and identified using a compound microscope. Family level will provide a higher degree of precision among samples and taxonomists, requires less expertise to perform, and accelerates assessment results.

Representative Invertebrates

Phylum

Class

Order

Porifera sponges

Platyhelminthes

Mollusca

Turbellaria flatworms

Gastropoda snails

Bivalvia clams, mussels

Annelida

Oligochaeta aquatic worms

Hirudinea leeches

Arthropoda

Insecta (approximate number of aquatic and semiaquatic species in North

America north of Mexico) (McCafferty, 1981)

Ephemeroptera (700) mayflies

Odonata (450) damselflies, dragonflies

Plecoptera (500) stoneflies

Hemiptera (400) water bugs

Megaloptera (50) fishflies, dobsonflies, alderflies

Neuroptera (6)

Trichoptera (1200)

Coleoptera (1000) beetles 


\section{Lepidoptera (50) \\ Diptera (350) \\ Malacostracta}

Amphipoda

Isopoda

Decapoda aquatic moths

midges, mosquitoes, aquatic gnats and flies

B. Sampling

Habitat Types (Barbour and others, 1999)

The major stream habitat types used here are in reference to those that are colonized by macroinvertebrates and generally support the diversity of the macroinvertebrate assemblage in stream ecosystems. Some combination of these habitats would be sampled in a multihabitat approach to benthic sampling.

Cobble (hard substrate) - Cobble is prevalent in the riffles (and runs), which are a common feature throughout most mountain and piedmont streams. In many highgradient streams, this habitat type will be dominant. However, riffles are not a common feature of most coastal or other low-gradient streams. Sample shallow areas with coarse (mixed gravel, cobble or larger) substrates by holding the bottom of the dip net against the substrate and dislodging organisms by kicking the substrate for $0.5 \mathrm{~m}$ upstream of the net.

Snags - Snags and other woody debris that have been submerged for a relatively long period (not recent deadfall) provide excellent colonization habitat. Sample submerged woody debris by jabbing in medium-sized snag material (sticks and branches). The snag habitat may be kicked first to help dislodge organisms, but only after placing the net downstream of the snag. Accumulated woody material in pool areas is considered snag habitat. Large logs should be avoided because they are generally difficult to sample adequately.

Vegetated Banks - When lower banks are submerged and have roots and emergent plants associated with them, they are sampled in a fashion similar to snags. Submerged areas of undercut banks are good habitats to sample. Sample banks with protruding roots and plants by jabbing into the habitat. Bank habitat can be kicked first to help dislodge organisms, but only after placing the net downstream.

Submerged macrophytes - Submerged macrophytes are seasonal in their occurrence and may not be a common feature of many streams, particularly those that are high-gradient. Sample aquatic plants that are rooted on the bottom of the stream in deep water by drawing the net through the vegetation from the bottom to the surface of the water (maximum of $0.5 \mathrm{~m}$ each jab). In shallow water sample by bumping or jabbing the net along the bottom in the rooted area, avoiding sediments where possible.

Sand (and other fine sediment) - Usually the least productive macroinvertebrate habitat in streams, this habitat may be the most prevalent in some streams. Sample banks of unvegetated or soft soil by bumping the net along the surface of the substrate rather than dragging the net through soft substrates; this reduces the amount of debris in the sample. 
Some important variables influencing invertebrate distribution.

permanence of aquatic habitat

size of habitat

water depth

presence vegetation for protection and habitat

bottom composition

current

water temperature

food

predators

Videotape: Sampling Aquatic Insects (Resh and others, 1990)

Devices that can be used for sampling aquatic insects in lotic and lentic habitats are demonstrated in this video. This provides an introduction to the process of selecting samplers for aquatic insect studies. The appropriate habitat and methods of operation for the various samplers are discussed. In designing a research project or sampling program, the overall study design, appropriate statistical analyses, as well as the advantages and limitations of specific samplers should be given careful consideration.

The following samplers are demonstrated in video:

In-Flow

These samplers utilize the current to carry organisms into a net. Typically they are used in riffles in shallow streams.

\section{Surber Sampler \\ Hess Sampler \\ T-Sampler \\ Kick Screen}

Multihabitat

\section{D-frame net}

The D-frame dip net can be used in many habitats and can be used like a kick net or by "jabbing", "dipping", or "sweeping". It is often useful for qualitative collecting. Dimensions of frame are $0.3 \mathrm{~m}$ width and $0.3 \mathrm{~m}$ height and shaped as a " $D$ " where frame attaches to long pole. Net is cone Drift or bag-shaped for capture of organisms.

A net suspended in the water column may sample drift, an activity where organisms enter the water column and are transported downstream. Studies of drift may examine macroinvertebrate colonization and dispersal.

\section{Hyporheic}

Drift Net

Many invertebrates spend some or all of their lives beneath the stream bottom substrate.

Lentic, Deep water

Hyporheic Corer

Grab samplers are used in lentic and deep-water habitats, and typically have jaws that snap shut.

\section{Ekman Grab}




\author{
Ponar Grab \\ Vegetation \\ Typically, vegetation is a difficult habitat to sample. \\ Pull-up Vegetation Sampler \\ Mosquito \\ Moosejaw Vegetation Sampler \\ Visual \\ Mosquito Dipper
}

Benthic View Box

Artificial Substrates

These samplers provide a standard substrate for sample comparison. They must be left in the stream for a colonization period.

Clay Quarry Tiles

Substrate Implants

Hyporheic Pot Sampler

\title{
Adult Insects
}

These samplers are used to sample the adult stages of aquatic insects. Adult stages of insects are usually easier to identify than immature stage. These samplers are used for studies of reproductive behavior, dispersal, and species distribution.

Sweep Net

Beating Sheet

Pan Trap

Pyramid Emergence Trap

Pheromone Trap

Malaise Trap

Light Trap

\section{Sample Processing, Analyses, and Assessment \\ Sample Processing \\ Sorting \\ Identification}

Metrics (measures) used for Benthic Macroinvertebrate Communities (Barbour and others, 1999)

Metrics used in multimetric indices evaluate elements and processes within a macroinvertebrate assemblage. Metrics and protocols need to be calibrated for different regions, and sometimes, for different impact types (stressors) and metrics are typically evaluated with respect to reference conditions.

Taxa richness, or the number of distinct taxa, reflect the diversity of the aquatic assemblage. Taxa richness usually consists of species level identifications but can also be evaluated as designated groupings of taxa, often as higher taxonomic groups (i.e., genera, families, orders, etc.) in assessment of invertebrate assemblages. Increasing diversity correlates with increasing health of the assemblage and suggests that niche space, habitat, and food source are adequate to support survival and propagation of many species. Measures of composition (or relative abundance) provide information on the make-up of the assemblage and the relative contribution of the populations to the total fauna. The premise is that 
a healthy and stable assemblage will be relatively consistent in its proportional representation, though individual abundances may vary in magnitude.

Tolerance/Intolerance measures are intended to be representative of relative sensitivity to perturbation and may include numbers of pollution-tolerant and intolerant taxa or percent composition. Tolerance may or may not be focused on a specific type of stressor, such as organic pollution or sedimentation.

Example: Hilsenhoff Family Biotic Index

$$
\begin{gathered}
(1 / N) * \sum n_{i} t_{i} \\
N \text { - number of individuals in sample } \\
\mathrm{n} \text { - number of individuals in family } \\
\mathrm{t} \text { - tolerance score of family }
\end{gathered}
$$

Feeding measures or trophic dynamics, provide information on the balance of feeding strategies (food acquisition and morphology) in the benthic assemblage. Invertebrates are classified by their feeding orientation into functional feeding groups (scrapers, shredders, gatherers, filterers, and predators). Invertebrates may also be classified by their food types, including the relative abundance of herbivores, carnivores, omnivores, and detritivores. Without relatively stable food dynamics, an imbalance in functional feeding groups will result and reflect stressed conditions. 
Table: Invertebrate trophic relations 
Algae (Alga - singular; algae - plural) is an umbrella term for a number of groups of photosynthetic organisms. These groups include diatoms (Bacillariophyta), green algae (Chlorophyta), blue-green algae (Cyanophyta or Cyanobacteria), yellow-green algae (Chrysophyta) and red algae (Rhodophyta). Algae are found on almost any surface receiving light including rocks (epilithic), plants (epiphytic), wood (epidendric), fine sediment (epipelic), sand (epipsammic), and animals (epizooic). Benthic algae take on a variety of sizes and growth forms. As primary producers they form a base of the aquatic food chain.

Periphyton (attached algae) are primary producers and are sensitive indicators of environmental change in lotic waters. Because periphyton is attached to the substrate, this assemblage integrates physical and chemical disturbances to the stream reach. The periphyton assemblage serves as a good biological indicator because of naturally high number of species and a rapid response time to both exposure and recovery. Diatoms in particular are useful indicators of biological condition because they are ubiquitous and found in all lotic systems. In addition, most periphyton taxa can be identified to species by experienced biologists, and tolerance or sensitivity to specific changes in environmental condition are known for many species. By using algal data in association with macroinvertebrate and fish data, the strength of biological assessments is optimized. The objectives of periphyton sampling could include assessment of biomass (chlorophyll $a$ or ashfree dry mass), species composition, and biological condition of periphyton assemblages (Barbour and others, 1999).

Other photosynthesizing groups are phytoplankton (algae suspended in water column) and aquatic vascular plants. 


\section{Habitat Assessment and Physicochemical Parameters}

(Adapted from Barbour and others, 1999)

An evaluation of habitat quality is critical to any assessment of ecological integrity and should be performed at each site at the time of the biological sampling. In the truest sense, "habitat" incorporates all aspects of physical and chemical constituents along with the biotic interactions. Often the definition of "habitat" is narrowed to the quality of the instream and riparian habitat that influences the structure and function of the aquatic community in a stream. The presence of a degraded habitat can sometimes obscure investigations on the effects of toxicity and/or pollution. The assessments performed by many water resource agencies include a general description of the site, a physical characterization and water quality assessment, and a visual assessment of instream and riparian habitat quality. Some states include quantitative measurements of physical parameters in their habitat assessment. Together these data provide a comprehensive and integrated picture of the biological condition of a stream system.

Habitat assessment is defined as the evaluation of the structure of the surrounding physical habitat that influences the quality of the water resource and the condition of the resident aquatic community. For streams, an encompassing approach to assessing structure of the habitat includes an evaluation of the variety and quality of the substrate, channel morphology, bank structure, and riparian vegetation. Habitat parameters pertinent to the assessment of habitat quality include those that characterize the stream micro-scale habitat (e.g., estimation of embeddeddness), the macro-scale features (e.g., channel morphology), and the riparian and bank structure features that are most often influential in affecting the other parameters.

When streams lose their ability to dissipate flow energy, there will be accelerated rates of channel erosion. The stability of channel morphology is influenced by these interrelated factors: channel width, channel depth, flow velocity, discharge, channel slope, roughness of channel materials, sediment load and sediment particle size distribution. Some of the habitat structural components that function to dissipate flow energy are sinuosity, roughness of bed and bank materials, presence of point bars (slope is an important characteristic), vegetative conditions of stream banks and the riparian zone, condition of the floodplain (accessibility from bank overflow and size are important characteristics).

Two types of habitat assessment approaches have been developed. The first type provides a relatively comprehensive characterization of the physical structure of the stream sampling reach and its surrounding floodplain by measuring various features of the instream, channel, and bank morphology. An example of this type of assessment are the methods used by the U.S. Geological Survey National Water Quality Assessment Program (Fitzpatrick and others, 1998). The second type is a more rapid and qualitative habitat assessment approach that was developed to describe the overall quality of the physical habitat. In this rapid assessment approach all parameters are evaluated and scored. The totals for a sampling reach are compared to a reference condition to provide a final habitat 
ranking. An example of this type of assessment may be found in the U.S. EPA Rapid Bioassessment Protocols (Barbour and others, 1999). 


\section{Bibliography}

Algae

Stephenson, R.J., Bothwell, M.L., and Lowe, R.L., 1996, Algal ecology, freshwater benthic ecosystems: New York, Academic Press, 753 p.

\section{Biological Monitoring}

Barbour, M.T., Gerritsen, Jeroen, Snyder, B.D., and Stribling, J.B., 1999, Rapid Bioassessment Protocols for Use in Streams and Wadeable Rivers: Periphyton, Benthic Macroinvertebrates and Fish, Second Edition. EPA 841-B-99-002. U.S. Environmental Protection Agency; Office of Water; Washington, D.C. Also, web site <www.epa.gov/owow/monitoring/rbp/>.

Davis, W.S., and Simon, T.P., eds, 1994, Biological assessment and criteria, tools for water resource planning and decision making: Boca Raton, Florida, Lewis Publishers, $415 \mathrm{p}$.

Karr, J.R., and Chu, E.W., 1999, Restoring life in running waters, better biological monitoring: Washington, D.C., Island Press, 206 p.

Karr, J.R., Fausch, K.D., Angermeier, P.L., Yant, P.R. , and Schlosser, I.J., 1986, Assessing biological integrity in running waters, a method and its rational:

Fish Champaign, Illinois Natural History Survey. Special Publication 5, 28 p.

Page, L.M., and Burr, B.M., 1991, A field guide to freshwater fishes, North America, north of Mexico: Boston, Houghton Mifflin Company, 432 p.

Smith, P.W., 1979, The fishes of Illinois: Urbana, University of Illinois Press, 314 p.

Insects, Invertebrates

Kellogg, L.L., 1994, Save our streams, Monitor's guide to aquatic macroinvertebrates: Izaak Walton League of America, $60 \mathrm{p}$.

McCafferty, W.P., 1981, Aquatic entomology, the fishermen's and ecologists' illustrated guide to insects and their relatives: Boston, Jones and Bartlett Publishers, $448 \mathrm{p}$.

Merritt, R.W., and Cummins, K.W., eds., 1996, An introduction to the aquatic insects of North America, Third Edition: Dubuque, Iowa, Kendall/Hunt Publishing Company, 862 p.

Resh, V.H., Feminella, J.W., and McElravy, E.P., 1990, Sampling aquatic insects: Videotape, Office of Media Services, University of California, Berkeley.

Thorp, J. H., and Covich, A.P., 1991, Ecology and classification of North American freshwater invertebrates: New York, Academic Press, 911 p.

\section{Stream Ecology}

Allan, J.D., 1995, Stream ecology, structure and function of running waters: New York, Chapman and Hall, $388 \mathrm{p}$.

Hauer, F.R. and Lamberti, G.A., eds., 1996, Methods in stream ecology: New York, Academic Press, 674 p.

Hydrology, Physical Parameters, and Stream Geomorphology

Fitzpatrick, F.A., Waite, I.R., D’Arconte, P.J., Meador, M.R., Maupin, M.A., and Gurtz, M.E., 1998, Revised methods for characterizing stream habitat in the National 
Water-Quality Assessment Program: U.S. Geological Survey Water-Resources Investigations Report 98-4052, $67 \mathrm{p}$

Gordon, N.D., McMahon, T.A., Finlayson, B.L., 1992, Stream hydrology, an introduction for ecologists: New York, John Wiley \& Sons, 526 p.

Leopold, L.B., 1994, A view of the river: Cambridge, Massachusetts, Harvard University Press, 298 p.

Waters, T.F., 1995, Sediment in streams: sources, biological effects, and control: American Fisheries Society Monograph 7. 


\title{
Field Methods For Hydrologic and Environmental Studies
}

\author{
Chapter 4
}

\section{Ground-Water-Data Collection}

Patrick C. Mills 


\section{INTRODUCTION}

Ground-water-data collection includes a wide variety of methods, which are intended to provide information about the physical framework (lithology stratigraphy, structure, dimensions), hydraulic properties (porosity, hydraulic conductivity, storativity), and water-quality of ground-water systems. In order to properly employ and fully benefit from most data-collection methods, an understanding of and integration with a variety of methods is essential. This course will emphasize several of the basic data-collection methods, including measurement of ground-water levels in monitoring and water-supply wells, single-well aquifer testing (slug testing) and analysis, and ground-water qualitysampling. In addition to the hands-on experience provided for these methods, demonstrations and (or) discussions will be provided in monitoring-well construction, borehole geophysical logging, packer testing, well purging, multiple-well aquifer testing, and data-collection planning. The issues of quality assurance will be addressed. 
Much of the material for the CEE 398 FM class notes presented in the sections on ground-water-study design, selection and installation of wells, and data documentation is drawn from:

- Lapham, W.W., Wilde, F.D., and Koterba, M.T., 1997, Guidelines and standard procedures for studies of ground-water quality: Selection and installation of wells, and supporting documentation: U.S. Geological Survey Water-Resources Investigations Report 96-4233, $110 \mathrm{p}$.

Much of the material presented in the section on water-quality sampling is drawn from materials prepared by Lapham, W.W., Wilde, F.D., and Koterba, M.T for a water-qualitysampling workshop for the U.S. Geological Survey National Water Quality Assessment program.

\section{SOME REASONS TO COLLECT GROUND-WATER DATA}

- Assessment of Ground-Water Availability

- Well-Field Design

- Monitoring of Drinking Water Quality

- Well-Head Protection/Capture-Zone Delineation

- Contaminant Distribution and Travel Times

- Ground-Water/Surface-Water Interaction

- Water Use

\section{TYPES OF GROUND-WATER DATA}

- Ground-Water Levels in Monitoring and Water-Supply Wells

- Hydraulic Gradients and Velocities

- Porosity

- Lithology of Geologic Materials

- Hydraulic Conductivity of Geologic Materials

- Structure (Fracture Patterns) of Geologic Materials

- Barometric Efficiency of Aquifers/Wells

- Water-Quality Parameters (Field Characteristics/Chemical Composition)

- Withdrawals

- Soil-Moisture Content and Pressure Head in the Unsaturated Zone

SOME AGENCIES THAT COLLECT GROUND-WATER DATA

- U.S. Geological Survey

- U.S. Environmental Protection Agency

- Illinois Department of Natural Resources, State Water Survey

- Illinois Department of Natural Resources, State Geological Survey 
- IllinoisEnvironmental Protection Agency

- Illinois Department of Public Health

\section{SOURCES OF GROUND-WATER DATA}

- U.S. Geological Survey

Ground-Water Site Inventory (GWSI)

Water-Quality Data Base (QWDATA)

- Illinois State Geological and Water Surveys

Drilling and well construction records

- Illinois State Geological Survey

Drill cuttings and rock-core collection

- Illinois State Water Survey

Hydraulic Properties Inventory

- Illinois Environmental Protection Agency

Leaking Underground Storage Tank records

Hazardous-waste-site studies

As in all scientific studies, the protection of data integrity is the guiding principle. For ground-water studies, the principle would apply to the full variety of data that may be collected, including water-quality and hydraulic-property data. Although the diversity of among ground-water studies in relation to study objectives, environmental settings, and spatial and temporal scales precludes the establishment of all-encompassing protocols, three protocols apply to all such investigations and will help ensure and document data quality:

- Design and implement each aspect of the study to reduce undesirable bias in the data collected

- Integrate quality-assurance procedures into work plans and activities

- Integrate documentation into each phase of the study

Most ground-water studies that require field data collection follow the following

\section{BASIC ELEMENTS IN PLANNING AND CONDUCTING THE STUDIES':}

- State the problem that initiated the study

- Define the purpose and scope of the study 
- Develop a conceptual framework for the study, including a description of the environmental setting

- Define the objectives of the study and formulate hypothesis to be tested

- Develop a scientific and technical approach for network design, data collection, and quality assurance

Incorporate a multidisciplinary perspective, if appropriate (for example, hydrogeological, geophysical, and statistical methods)

Use knowledge of site geology and hydrology to determine location of wells and samplecollection (screened or open interval)

- Implement the approach for network design, data collection, and quality assurance, including:

Complete site reconnaissance of geomorphology, surficial hydrologic features, and natural and anthropogenic environmental factors

Collect geologic and geophysical data

Select well locations and install wells

Determine aquifer characteristics and hydraulic properties

Collect water-quality and quality-control samples and related data

Complete supporting documentation of data collection

- Analyze and interpret data

- Report results 


\section{SITE RECONNAISSANCE AND HYDROGEOLOGIC FRAMEWORK}

An essential first step in beginning a field-data-oriented ground-water investigation is to establish a conceptual model of the study area. Such a model requires extensive research of available data and information, as well as reconnaissance of the study area. Review of the available data and the reconnaissance, ensures better conceptualization of the hydrogeologic framework the study area. A sound conceptual model is necessary for the selection of appropriate field methods, sampling locations, and sampling intervals.

\section{SITE RECONNAISSANCE}

Site reconnaissance involves a first-hand inspection of the study area. This usually includes a walk-over and drive-over of the site and surrounding area. If the study area is large, only a drive-over may be feasible. Site reconnaissance also may include a fly-over. The following hydrogeologic and land-use features should be noted:

- Areas of ground-water recharge and discharge (highlands, bedrock outcrops, lakes and streams)

- Surficial soil types and vegetation

- $\quad$ Land-use (agricultural, urban, industrial)

- Potential point and non-point sources of contamination (industries, service stations, liquid storage tanks, livestock operations, fertilizer-distribution facilities, intensely farmed areas)

- Present indications of contamination (stained soils, loss of or stressed vegetation)

- Well locations and conditions (verify on available USGS (or other) topographic Map - 1:24,000 scale or less; note location with GPS)

\section{AVAILABLE DATA AND INFORMATION}

Available sources of data may come from:

- Libraries -- professional, government-agency, and consultant reports, journal articles

- USGS - NWIS data bases (GWSI, QWDATA)

- ISGS/ISWS - Drilling and well construction records

- ISGS - Drill cuttings and rock-core collection; geophysical log collection

- ISWS - Aquifer property data base

- USEPA - STORET water-quality data base; hazardous-waste-site reports

- IEPA - Leaking underground storage tank records; hazardous-waste site reports

- Canvassing - Information from study area residents 


\section{HYDROGEOLOGIC FRAMEWORK}

- Stratigraphy and lithology are vital to the study of ground-water systems have been collected previously and interpreted for most settings in the U.S., and most are readily available.

- Stratigraphic and lithologic data are important because they describe basic characteristics of the solid part of the hydrogeologic system and help delineate the hydrogeologic units (aquifers and confining units).

- Stratigraphy identifies the sequence of rocks, which in Illinois occur as glacial deposits and flat-lying sedimentary rocks.

- Lithology identifies the texture and composition, including arrangement of grains and particles, grain size, and mineralogy.

THESE DATA DEFINE THE NATURE OF

GROUND-WATER FLOW, POROSITY, AND WATER-QUALITY
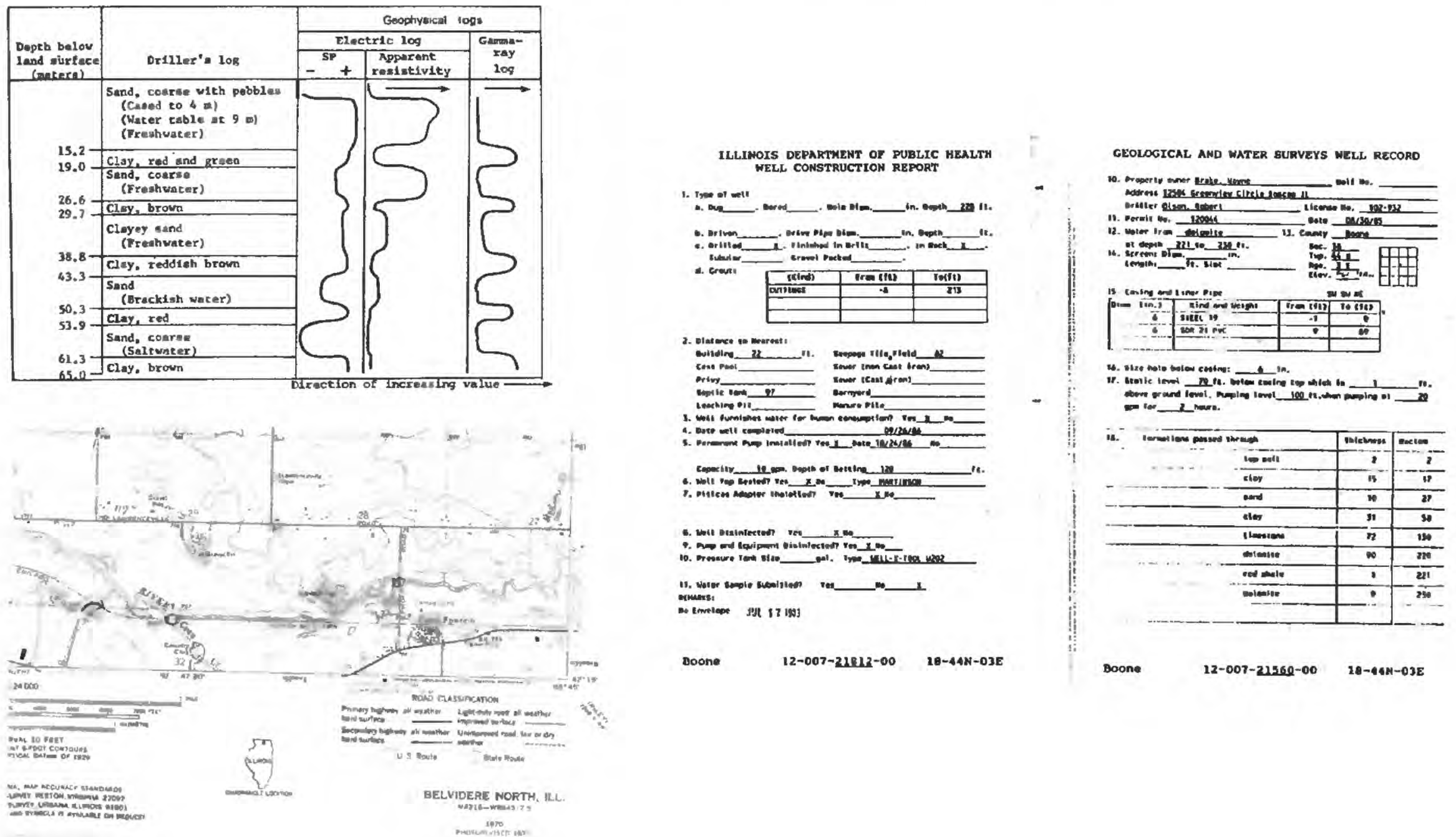

Figure - Examples of available data and information to be used for conceptualization of hydrogeologic framework of study area. Clockwise from top left: geophysical 
log, driller's log, USGS 1:24,000 topographic quadrangle map.

\section{CONCEPTUAL MODEL}

Determining the hydrologic framework of a study area is essential to developing a reliable conceptual model of the ground-water system. Model will focus data collection. Additional data will be used in iterative improvement of the conceptual model. Example of models include:

- Confined/Unconfined/Leaky or Semi-confined

- Porous/Fractured/Karstic/Dual Porosity

- Isotropic/Homogeneous/Heterogeneous

- Bounded/Locally Unbounded

\section{ISSUES OF SCALE IN DEFINING CONCEPTUAL MODEL AND PLANNING DATA COLLECTION}

Why do we care about scale and definition of aquifer system?

- Incorrect investigative techniques employed

- EX: Blind drilling of monitoring wells in fractured aquifers. Failure to double case wells in multiple aquifer systems.

- Faulty conclusions on aquifer characteristics resulting in wasted efforts and delays

- EX: Applying isotropic aquifer assumptions to aquifers in fractured systems or highly heterogeneous formations. Extrapolating information obtained in small study area to larger areas in heterogeneous formation.

- Inappropriate clean-up technologies employed or unreasonable expectations of technologies

- EX: Assuming pump and treat technologies will work without characterizing the flow system, boundaries, and nature of contaminants 


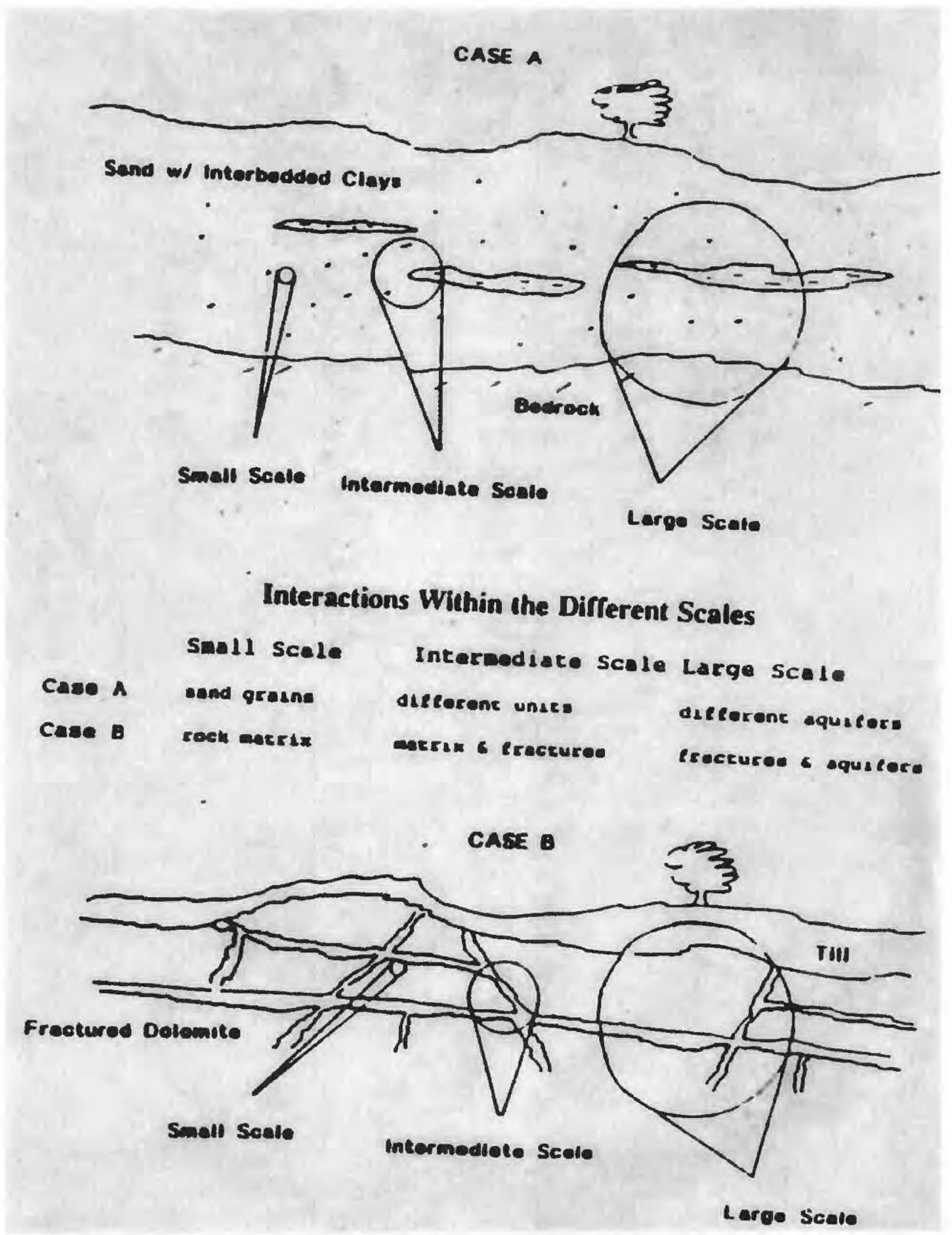

Figure-Conceptualization of the scale factor. 


\section{DRILLING AND WELL CONSTRUCTION}

Many ground-water studies, particularly those intended to determine, in detail, the distribution of contaminants or hydraulic properties of aquifers, require the installation of monitoring wells to supplement existing wells. Existing wells may be poorly constructed; not have available lithologic data (geologic units encountered) and construction information (well depth, length/type of open interval); may be used for water supply (which can affect the quality of samples collected); and (or) require special permission (or not permitted) for use).

Most wells installed for ground-water studies are two-inch diameter wells, which have the benefit of allowing the use of existing small diameter sampling pumps, limiting purge time and volume, and reducing installation costs. Larger-diameter wells (4- to 6inch diameter) also may be installed, generally as pumping wells for multiple-well aquifer tests and contaminant extraction systems (Lapham and others, 1977).

A properly constructed well is intended to provide water and pressure data from the aquifer of interest only will not contribute erroneous water-quality results because of leaching and adsorption by the well casing, screen, or backfilling materials, or from liquids or other additives used during drilling. (BEWARE THE "ENEMIES")

\section{USEFUL REFERENCES:}

Lapham, W. W., Wilde, F.D., and Koterba, M.T., 1997, Guidelines and standard Procedures for studies of ground-water quality: selection and installation of wells, and supporting documentation: U.S. Geological Survey Water-Resources Investigations Report 96-4233, $110 \mathrm{p}$.

U.S. EPA, 1991, Handbook of suggested practices for the design and installation of ground-water monitoring wells: EPA/600/4-89/034

Shuter, E. and Teasdale, W.E., 1989, Application of drilling, coring, and sampling techniques to test holes and wells: U.S. Geological Survey Techniques of WaterResources Investigations of the United States Geological Survey, Book 2, Chapter F1, $97 \mathrm{p}$.

The process of well installation requires:

- Establishing installation criteria

- to ensure wells installed for intended purpose and will yield data that accurately represents the hydrogeologic system and its water quality

- each aspect of well installation will comply with appropriate regulations, utilities; will be identified, safety issues considered

- Designing wells - compatibility with data objectives

- Whenever possible design well to meet needs of future studies

- Considerations

- nature of subsurface materials (unconsolidated?, fractured?) 
- relation between subsurface material/screen selection

- casing and screen material

- typically PVC or stainless steel, may be PTFE (NSF approved)

- leaching-sorption advantages/disadvantages

- avoid PVC solvents/cement

- flush threaded with o-rings

- aperture has sufficient open area

- screen length and type (affect water quality, hydraulic measurements)

- typically continuous wire-wound or machine slotted

- open area (aperture) sufficient to allow sample be withdrawn without entrainment of sediment; based on size of sediment (often 10-slot or $0.01 \mathrm{ft}$ aperture)

- diameter casing/screen/ or open hole

- depth to water

- depth to top of aquifer

- depth to monitoring interval (tensile strength important with depth)

- Schedule 80 PVC generally recommended for wells $>100 \mathrm{ft}$

- operational issues (budget, site accessibility; equipment access)

- well may be open hole w/ surface casing; open hole with packers; screen well and casing with filter pack, annular seal

- Decontaminating the equipment; selecting the appropriate drilling, construction, completion, and development methods.

\section{DRILLING FOR INSTALLING WELLS FOR WATER-QUALITY SAMPLING AND HYDRAULIC TESTING}

Select method that minimizes contamination of subsurface materials and pore water by foreign drilling fluids and minimizes cross contamination vertically between subsurface materials during drilling.

\section{AUGER DRILLING}

- Hollow-stem, continuous-flight augering 2

- Solid-stem, continuous flight augering 2

- Bucket augering 1

- Hand augering 1

ROTARY DRILLING

- Direct rotary with mud and air 3

- Direct rotary with advance casing 1

- Reverse circulation 3

- Dual wall reverse circulation 1 
- Air hammer 1

- Cable tool 1

- Jet wash 3

- Jet percussion 3

- Hand driving 1

1. Most preferred because avoids use of drilling fluids, and drill casing advanced during drilling

2. Avoid use of drilling fluids, but drill rod not advanced during drilling.

3. Least preferred because uses drilling fluids, and drill casing not Advanced during drilling.

\section{Consider these issues when selecting drilling method:}

- Introduction of air into aquifer (avoid air rotary?)

- Introduction of oil (from air) into aquifer (avoid air rotary?)

- Cross contamination between aquifers (use advanced-casing method?)

- Introduction of drilling fluids (bentonite mud) into aquifer (avoid mud rotary?)

- Cost and Speed

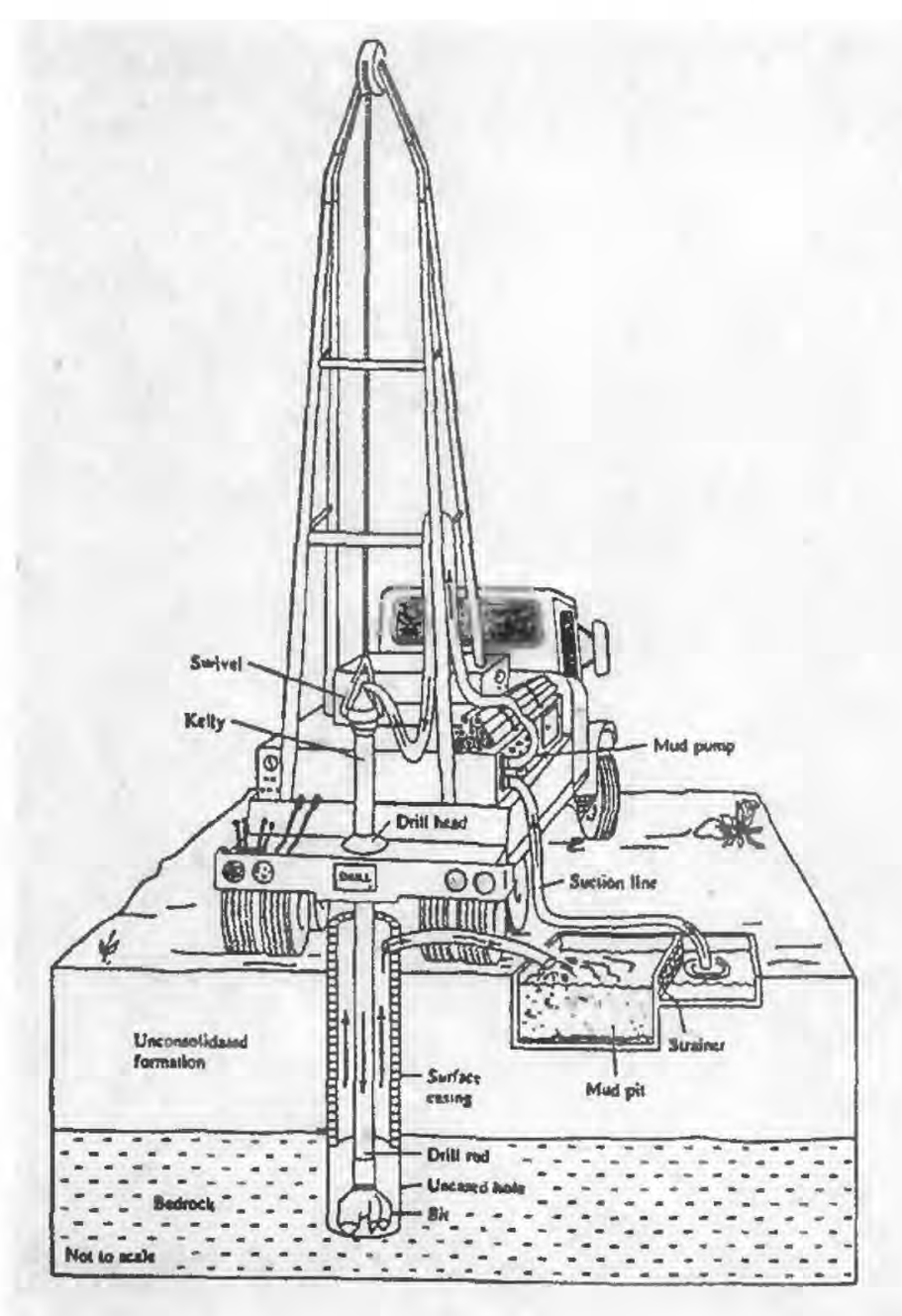

-Typical rotary water-well drilling rig and circulation of drilling fuid in mud-rotary drilling. (Fetter, 1993)
Table 1: Advantages and Disadvantages of Auger, Rotary, and Cable Tool Drillis

\begin{tabular}{|c|c|c|}
\hline Type & Advantages & Disadvantages \\
\hline Auger & $\begin{array}{l}\text { Minimal damage to aquifer } \\
\text { No drilling fluids required } \\
\text { Auger flights act as tempo- } \\
\text { rary casing stabilizing hole } \\
\text { for well construction (if } \\
\text { hollow stem) } \\
\text { Good technique for uncon- } \\
\text { solidated deposits } \\
\text { Continuous core can be } \\
\text { collected }\end{array}$ & $\begin{array}{l}\text { Cannot be used in consoli- } \\
\text { dated deposits } \\
\text { Generally limited to wells } \\
\text { less than } 150 \text { feet in depth, } \\
\text { depending on soil/regolith } \\
\text { thickness } \\
\text { May have to abandon holes } \\
\text { if boulders are excountered }\end{array}$ \\
\hline Rotary & $\begin{array}{l}\text { Quick and efficient method } \\
\text { Excellent for large and } \\
\text { small diameter holes } \\
\text { No depth limitations } \\
\text { Can be used in consoli- } \\
\text { dated and unconsolidated } \\
\text { deposits } \\
\text { Continuous core can be } \\
\text { collected }\end{array}$ & $\begin{array}{l}\text { Requires drilling fluids, } \\
\text { which alter water quality } \\
\text { Results in a mud cake on } \\
\text { the borehole wall, requir- } \\
\text { ing additional well devel- } \\
\text { opment, and potentially } \\
\text { causing changes in water } \\
\text { quality } \\
\text { Loss of circulation can } \\
\text { develop in fractured and } \\
\text { high-permeability material } \\
\text { May have to abandon holes } \\
\text { if boulders in unconsoli- } \\
\text { dated depasits are encoun- } \\
\text { tered }\end{array}$ \\
\hline
\end{tabular}


Figure - Rotary drill rig

Table-Comparison of auger and rotary drilling methods.

Rotary drilling will produce a skin of fine-grain materials (mud cake) on the borehole wall. The cake will consist of rock flour produced during drilling and drilling fluids (generally bentonite mud). The drilling fluid can penetrate into the formation. The drilling fluids and fine-grained materials in the "screened" interval must be removed upon completion of well installation.

\section{WELL CONSTRUCTION}
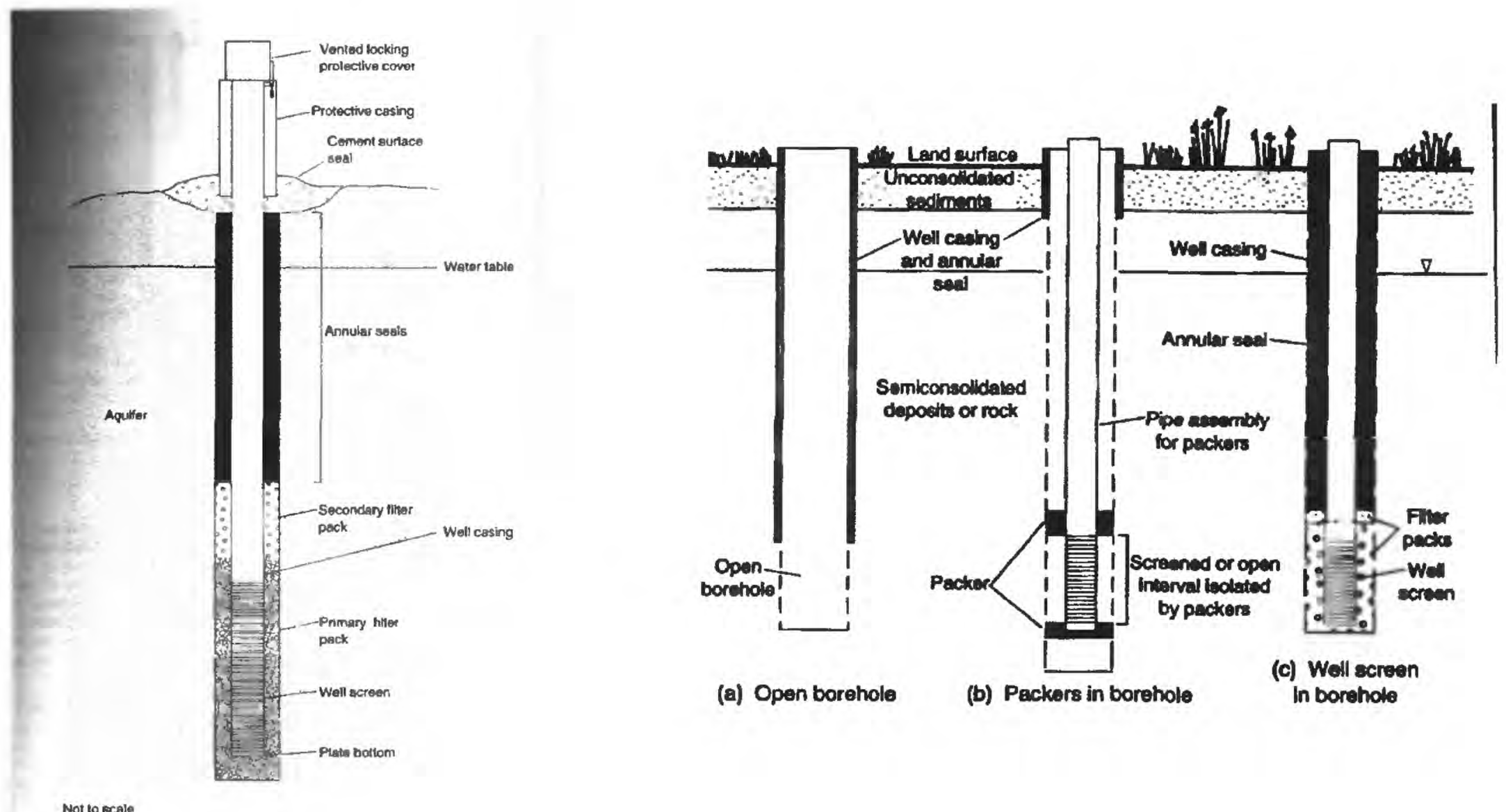

Figures - Examples of various well constructions

\section{WELL COMPLETION}

- Well completion consists of filling and sealing the annular space between the well casing and borehole wall to ensure that:

- The hydraulic head measured in the well is that of the "screened" interval

- Only the interval "screened" contributes water to the well

- There is no vertical conduit along the annulus for flow of water and contaminants 


\section{WELL SCREEN SLOT-SIZE SELECTION}

- On basis of grain-size distribution

- Effective size $=90 \%$ retained (D10)

- Uniformity coefficient $=$ ration of $40 \%$ retained (D60) to effective size

- Justify natural filter packs if:

- D10>0.01 inch

- $\mathrm{D} 60 / \mathrm{D} 10>3.0$

- Most designers install standard 10-slot screen; may lead to problems with well development and performance

\section{ARTIFICIAL FILTER PACK REQUIREMENTS}

- use if fine-grained materials present; with long screens in highly stratified, nonuniform sediments; in bedrock with fractures

- 20 -slot or less screen opening is required to retain $50 \%$ of material

- select filter-pack size/screen-opening size at same time

- too large a filter pack/slot size, fines are lost to well

- too small, filter pack lost to aquifer, unstable filter pack uniform pack = better filtering, better placement

\begin{tabular}{|l|}
\hline \multicolumn{1}{|c|}{ Table 13.12. Desirable Filter Pack Charaeteristics and Derived Adrantanges } \\
\hline Characteristic
\end{tabular}

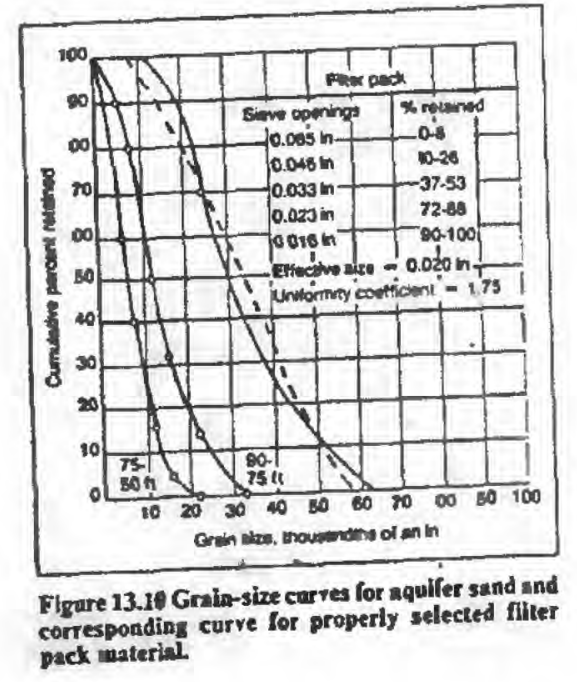


Table and figure. - Selection criteria for proper filter pack and screen size 
- Virgin PTFE readily sorbs some organic solutes (Parker and Ranney, 1994).

- Ideal material in corrosive environments where inorganic compounds are of interest.

- Useful where pure product (organic compound) or high concentrations of PVC solvents exist.

- Potential structural problems because of its low tensile and compressive strengths, low wear resistance, and the extreme fiexibility of the casing string as compared to other enginecring plastics (Driscoll, 1986, table 21.6; Dablow and others, 1988; Aller and others, 1989, tabie 25).

- Potential problems with obtaining a seal between the casing and the annular sealant because of PTFEs low coefficient of friction and antistick properties as compared to other plastics (Aller and others. 1989. p. 15I).

- Maximum string length of 2 -in. $(-5-\mathrm{cm})$ diameter schedule PTFE casing should not exceed about $375 \mathrm{ft}(\sim 115 \mathrm{~m})$ (Nielsen and Schalla, 1991, p. 262).

- Expensive.

\section{yvinylchlorido (PVC)}

- Leaching of compounds of tin or antimony, which are contained in original heat stabilizers during polymer formulation, could occur after long exposure.

- When used in conjunction with glued joints. leaching of volatile organic compounds from PVC primer and glues, such as THF (tetrahydrofuran), MEK (methylethylketone), MIBK (methylisobutylketone) and cyciohexanone could leach into ground water. Therefore, threaded joints below the water table, sealed with o-rings or Teflon tape, are preferred.

- Cannot be used where pure product or high concentrations of a PVC solvent exist.

- Maximum string length of 2-in. (-5-cm) diameter threaded PVC casing should not exceed 2,000 ft $(-610 \mathrm{~m})$ (Nielsen and Schalla, 1991, p. 250).

- PVC can warp and melt if neat cement (cement and water) is used as an annular or surface seal because of heat of hydration (Johnson and others, 1980; Driscoll, 1986, p. 324).

- PVC can volatilize CFCs into the atmosphere within the unsaturated zone, which can be a potential problem for studies of gas and moisture transport through the unsaturated zone.

- Easy to cut, assemble, and place in the borehole.

- Inexpensive.

\section{less steal (SS)}

- Generally has high corrosion resistance, which differs with type.

- Corrosion can occur under acidic and oxidizing conditions.

- Corrosion products are mostly iron compounds, with some trace elements.

- Primarily two common types:

(1) SS 304: Iron alloyed with the following elements (percentages): chromium (18-20 percent), nickel (8.11 percent), manganese ( 2 percent), silicon ( 0.75 percent), carbon ( 0.08 percent), phosphorus ( 0.04 percent), sulfur $(0.03$ percent). (2) SS 316: Iron alloyed with the following elements (percentages): chromium (16-18 percent), nickel (11-14 percent), manganese ( 2 percent), moiybdenum ( $2-3$ percent), silicon ( 0.75 percent), carbon ( 0.08 percent), phosphorus $(0.04$ percent), sulfur ( 0.03 percent).

- Corrosion resistance is good for SS 304 under aerobic conditions. SS 316 has improved corrosion resistance over SS 304 under reducing conditions (Parker, 1992).

Expensive. 


\section{GENERAL CHARACTERISTICS OF MATERIALS FOR WELL COMPLETION}

- Primary filter pack

- An envelope of sediment backfilled around the screen

- Grain size should be similar to the prevailing grain size of the screened unit

- Consists of well sorted quartz sand or gravel

- Should not contain carbonate material

- Should not contain organic material (wood fragments)

- Best placed by a tremie pipe, backfilling slowly from the bottom to $1-5 \mathrm{ft}$ above top of the screen

- Secondary filter pack

- Purpose is to prevent the overlying grout from infiltrating and clogging the primary filter pack

- Length of about $1 \mathrm{ft}$

- Alternative is a primary filter pack that extends a minimum of $5 \mathrm{ft}$ above the top of the screen

- Plugs consisting of a packing shoe or a cement basket shoe not be substituted because of possible effects on water quality

- Grain size of the secondary filter pack should be intermediate between the grain sizes of the primary filter pack and grout

- Consists of well-sorted quartz sand

- Should not contain carbonate material

- Best placed with a tremie pipe

- Grout

- Purpose is to seal annulus above secondary filter pack

- Ideal grout is chemically inert, permanent, stable, and resists chemical and physical deterioration

- Commonly used grouts are bentonite, cement,mixtures of bentonite and cement

- In general, high solids bentonite is recommended material

- Bentonite-cement mixture limits affect cement shrinkage

- Use Portland Type I cement - no additives

- Best placed with a tremie pipe

- Surface seal

- A cement platform providing a seal at land surface that:

- Prevents surface runoff down the well annulus

- Holds the protective casing in place

- Installed to a depth from land surface to prevent frost heaving (in general about $3 \mathrm{ft}$ )

- Bentonite not recommended because of likely desiccation

- Protective casing: steel casing with vented (weep hole), locking cover 


\section{WELL DEVELOPMENT}

Well development is a process of removing the fine grained material from the part of the filter pack around the well screen (Ideal filter pack $90 \%$ retained by screen $/ 10 \%$ will pass through the screen. Usually less retained) by pumping, surging, bailing, or otherwise removing many well-volumes of water from the well. This is necessary so that when the well is sampled, an absolute minimum of silt and slay will be present in the sample and the hydraulic characteristics of the filter pack do not limit accurate assessment of the hydraulic properties of the aquifer. The removal of the water needs to be at a rate sufficient to create velocities that will remove the fine particles. Generally, the well is pumped at a conservative rate so as not to create a severe gradient which could disturb the placement of the filter pack. If rotary drilling was used to construct the hole and drilling mud was used, well development can require days or weeks. This is usually not the case for shallow monitoring wells constructed in unconsolidated sediments or bedrock wells drilled by percussion or water rotary. The pumping or bailing associated with monitoring well development usually only continues until a minimum of turbidity is present.

Bedrock boreholes consisting of an open hole in the bedrock and a surface casing cemented into upper part of the bedrock unit and grouted where it penetrates the overlying unconsolidated deposits must be developed before the borehole can be sampled, used for hydraulic tests, or packer tested. Goals of development for these holes are similar to those for monitoring wells; pumping rates may greatly exceed those used for monitoring wells

- Objectives

- To remove fine-grained sediments and drilling fluids introduced into formations during drilling

- To provide water free of suspended solids to reduce pump wear

- To provide water free of suspended solids for sampling (fines may affect water-quality results, particularly trace metals)

- Eliminate bridging in filter pack

- Removes water introduced during drilling

- Goals

- Typically a minimum of 10 well volumes

- Typically a goal of 5 nephalometric turbidity units (NTU's)

- Typically a rate of $2.5-10$ gallons per minute; may approach $30 \mathrm{gal} / \mathrm{min}$ for bedrock boreholes

- Well Development Methods (often used in combination)

- Backwashing

- Water injected out into subsurface materials

- Surging (surge block)

- Water injected out into subsurface materials then drawn back into well 
- Pumping or Overpumping

- Well Development Methods (often used in combination)--continued

- Bailing

- Water withdrawn from well

- Water drawn back into the well

- Jetting with water or air

- Water, air, or both injected out into subsurface materials, then removed from the well

Well Development Methods in order of preference for water-quality sampling

- Best method includes surge in both directions combined with pumping

- Bailing

- Mechanical surging

- Pumping or Overpumping and Backwashing

- Indirect Eduction Jetting

- Backwashing

- Jetting or Surging with Water or Air

- Avoid methods that:

- introduce water into the aquifer

- introduce air into the aquifer (Fe bacterial/biologic activity)

- pushes fines into sandpack

\section{DRILLING SAFETY}

Reference: Drilling Safety Guide, International Drilling Federation

Drilling can be very dangerous. Heavy equipment is used that can injure back feet, hands, etc. Additionally, drilling in the immediate vicinity of electrical lines or underground utilities one risks, electrical shock, explosions, vaporous releases and other responses that could result in death.

- Safety guidelines

- To avoid electrical shock and arcing from power lines, maintain a minimum distance of $100 \mathrm{ft}$ between the drill rig and the lines. Lesser distances must be reviewed with local utilities (see OSHS Reg. 29 CFR 1910.180)

- Call underground utility locator (JULIE in Illinois) before drilling or excavating. Check to be sure all utilities are covered by JULIE - UI utilities not covered 
- Never operate the drill alone. Have a safety plan in place with local hospital identified 


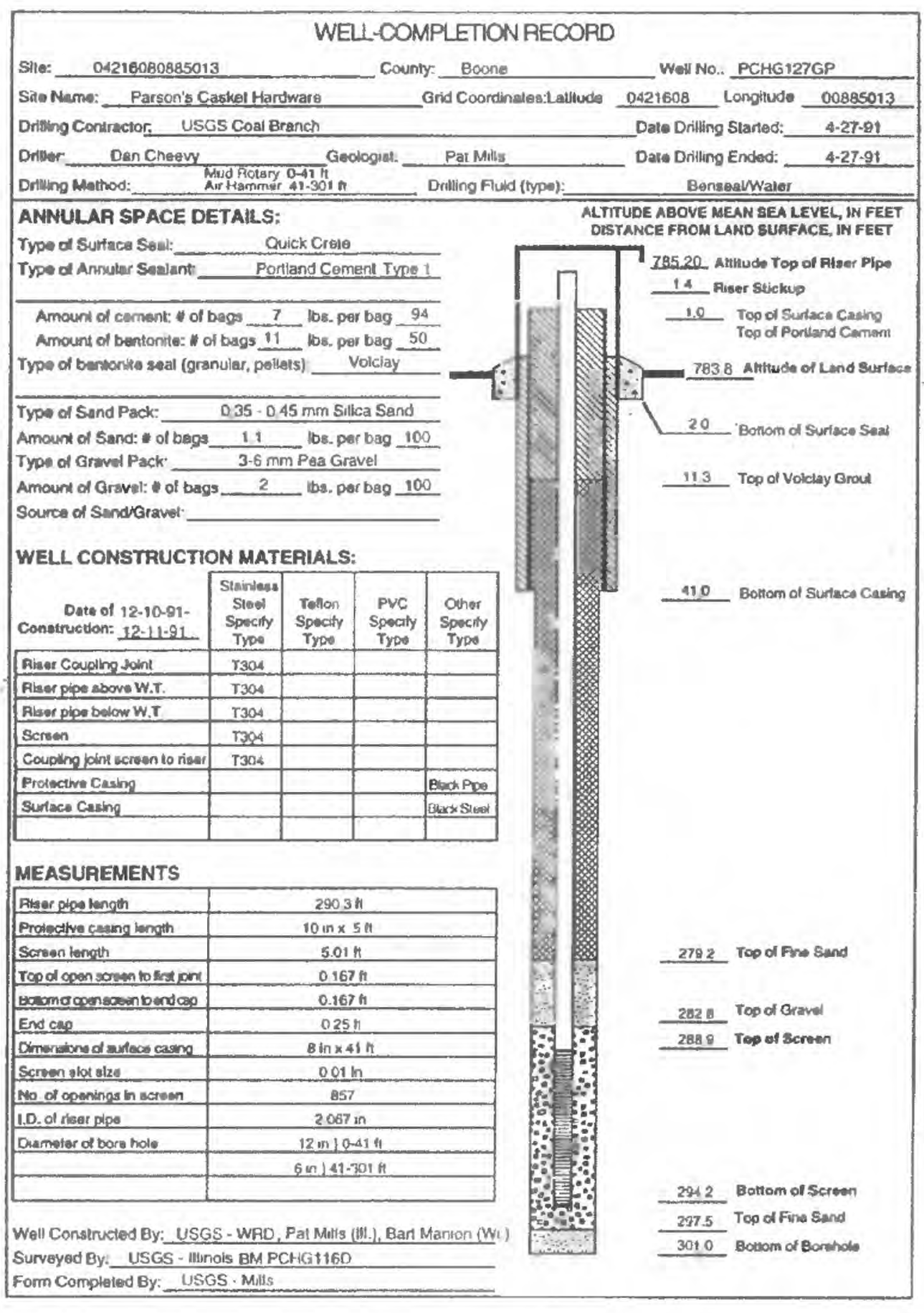

Figure - Example well construction record.

\section{DOCUMENTATION}

Well-drillings logs include:

- Borehole drilling methods and materials

- Well construction method and materials

- Well location (and datum if available) and ownership 


\section{BOREHOLE GEOPHYSICS}

After the well has been drilled, the cuttings have been analyzed and described, the drill-time/lithology log has been completed, the open, non-cased borehole provides an excellent access to the ground-water system at a single point. Borehole geophysical investigations provide excellent vertical-profile information on the lithology, flow components (production zones), structure, permeability, porosity, and water quality of the ground-water system. Multiple logs typically are collected to take advantage of their synergistic value: much more can be learned from a suite of logs than from individual analysis of the same logs. Geophysical logs provide unbiased, continuous and in-situ data and generally sample a larger volume than drilling samples.

Simply put, downhole measurements are taken with an electrically-powered probe connected to a cable with one or more conductors. Electrical voltage and data pulses are transmitted through the cable to and from a surface recording device. The surface equipment usually consists of a drawworks, depth encoder, power supply, series of electronic panels, computer, and an output device, such as a printer, monitor, or pen recorder. The probe is hoisted up or down the borehole at a constant speed while data are being sent to the surface and recorded. All also are recorded with depth, creating curves of borehole measurements. Some logging devices produce digital "pictures" of the borehole wall or measurements of vertical flow rates in the borehole.

Borehole geophysical logging techniques were developed in the petroleum industry, but the techniques and equipment have been modified or developed for the ground-water industry. A basic, portable, tuck-mounted system appropriate for most ground-water investigations can cost $\$ 5,000-\$ 10,000$. Commercial petroleum loggers may charge $\$ 3,000$ for two logs.

Surface geophysical techniques also have very useful applications to groundwater investigations, including determination of the depth and distribution of lithologic units, depth to ground water, presence and distribution of certain contaminants, buried objects (tanks), and land disturbances (cavities, reworked soils, edges of landfills, etc.) These techniques will only be briefly discussed in this course.

References:

Keys, W. Scott and MacCary, L.M., 1990, Application of borehole geophysics to waterresources investigations: U.S. Geological Survey Techniques of WaterResources Investigations of the United States Geological Survey, Book 2, Chapter E1. $126 \mathrm{p}$.

Driscoll, F.G., 1987, Groundwater and wells: Johnson Division, St. Paul, Mn., 1089 p.

Paillet, F.L. and Williams, J.H., 1994, Proceedings of the U.S. Geological Survey workshop on the applications of borehole geophysics to ground-water investigations, Albany, New, York, June 2-4, 1992: U.S. Geological Survey Water-Resources Investigations Report 94-4103.79 p. 
Zohdy, A.A.R., Eaton, G.P., and Mabey, D.R., 1990, Application of surface geophysics to ground-water investigations: U.S. Geological Survey Techniques of WaterResources Investigations of the United States Geological Survey, Book2, Chapter D1, $116 \mathrm{p}$.

\section{WHY LOG?}

- Delineation of hydrogeologic units

- Definition of ground-water quality

- Determination of well construction and conditions

\section{TYPES OF LOGS}

- Caliper logs

- Natural-gamma logs

- Single-point resistance logs

- Spontaneous-potential logs

- Normal-resistivity logs

- Electromagnetic-induction logs

- Fluid-resistivity logs

- Temperature logs

- Flowmeter logs (velocity measurements)

- Television logs

- Acoustic-televiewer logs 


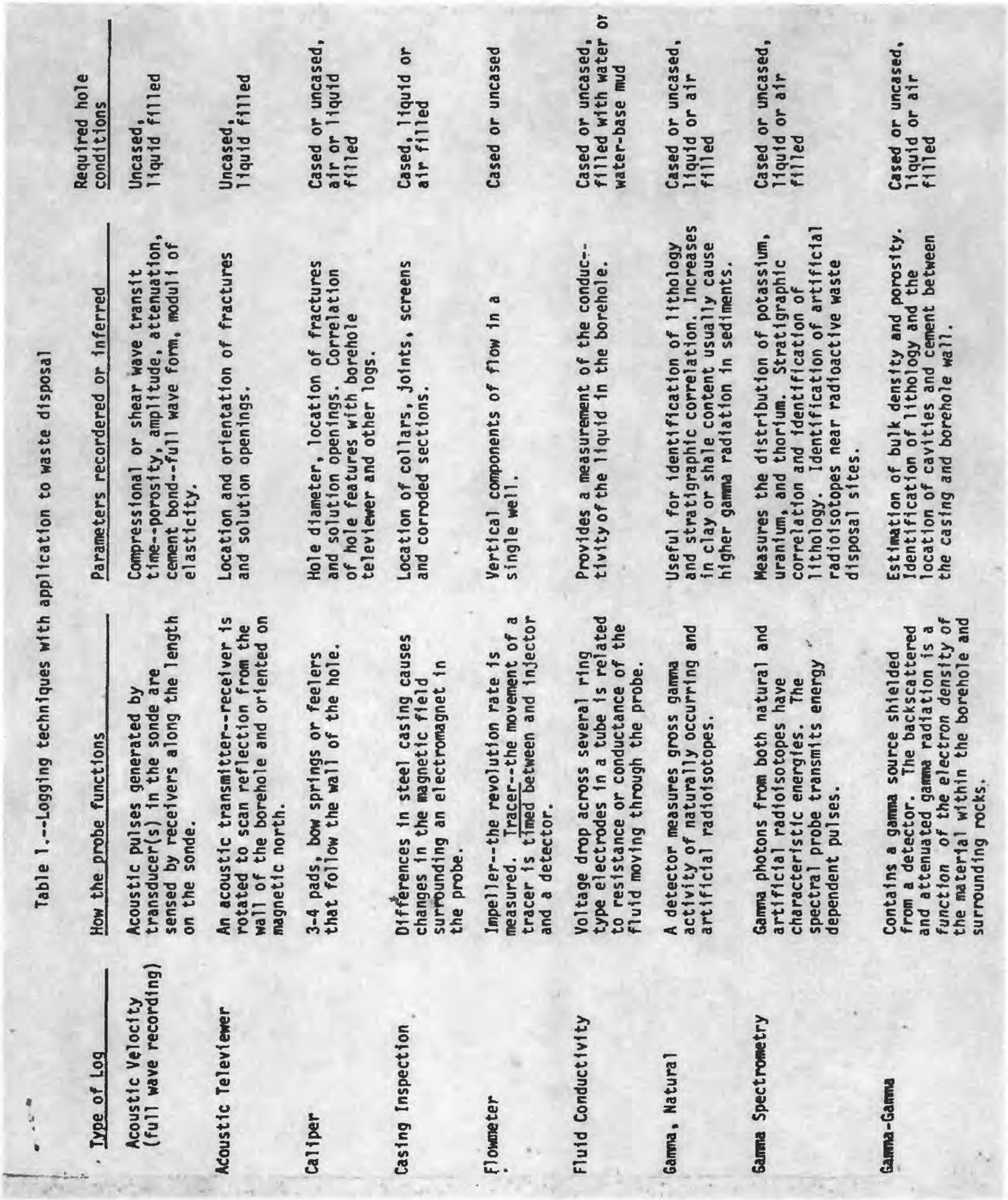

Table - Types of geophysical tools and their application to ground-water studies. 

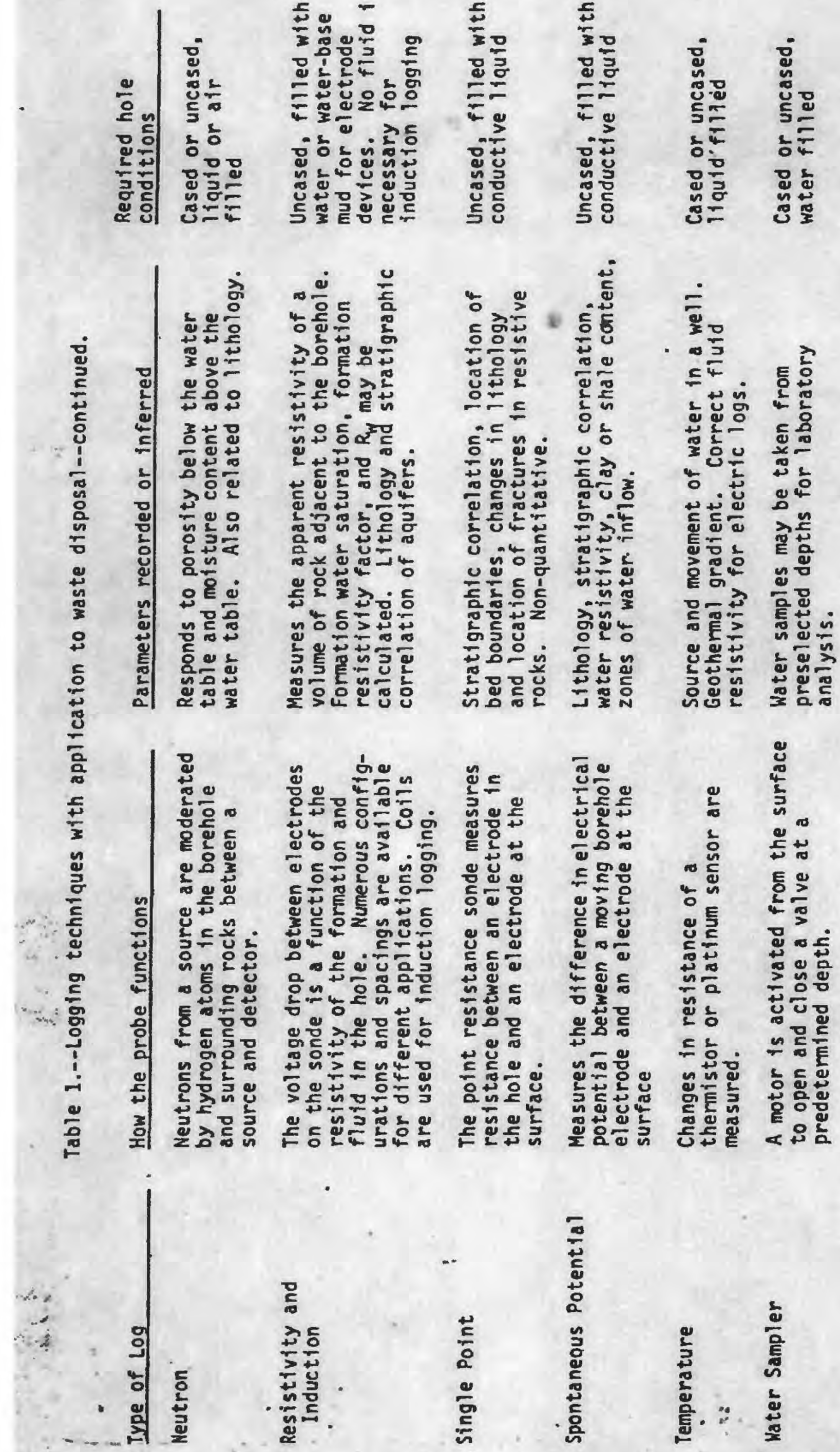

Table - Types of geophysical tools and their application to ground-water studiescontinued 


\section{Chapter 4}

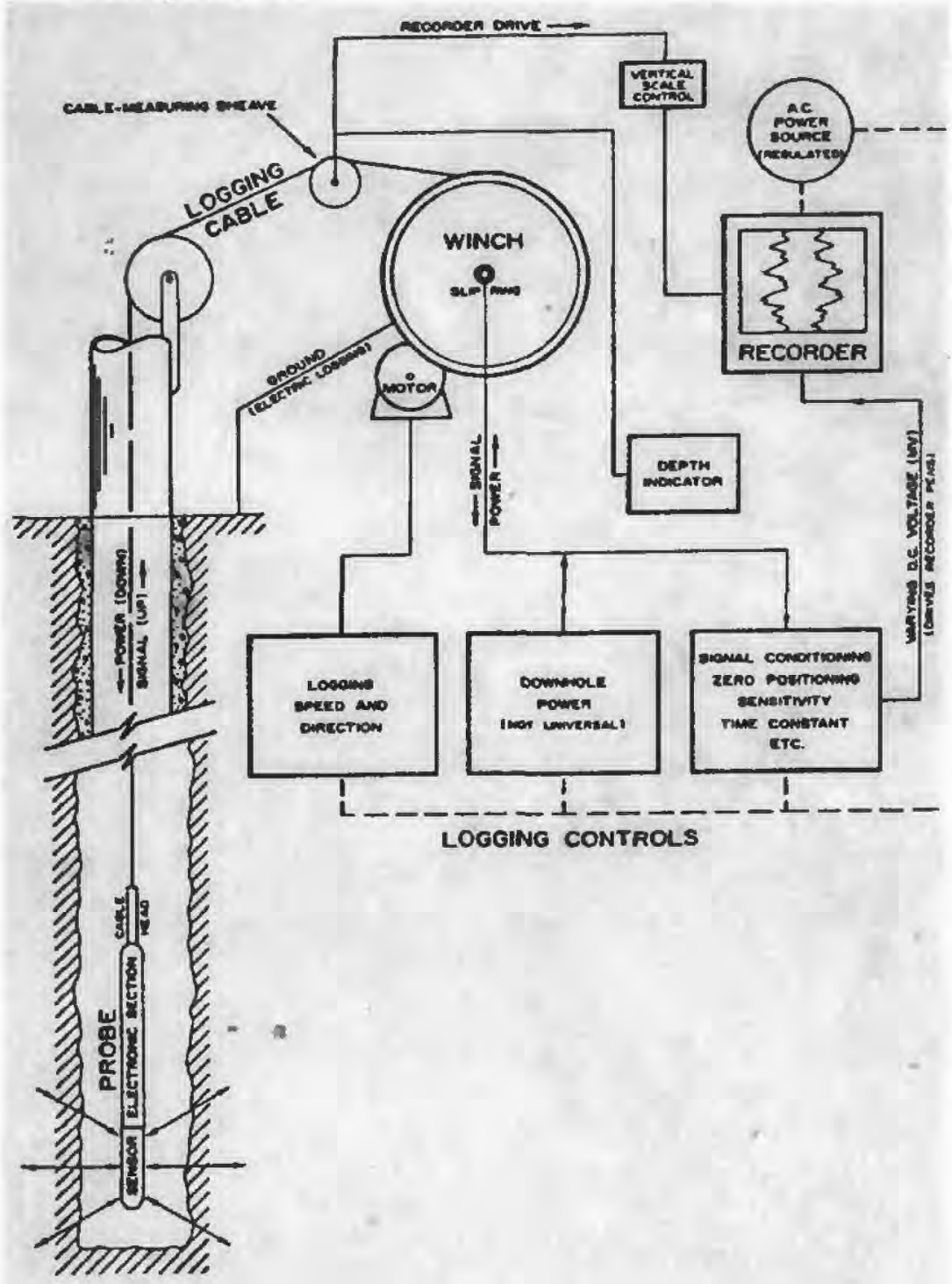

Figures - Schematic of geophysical logging system (above).

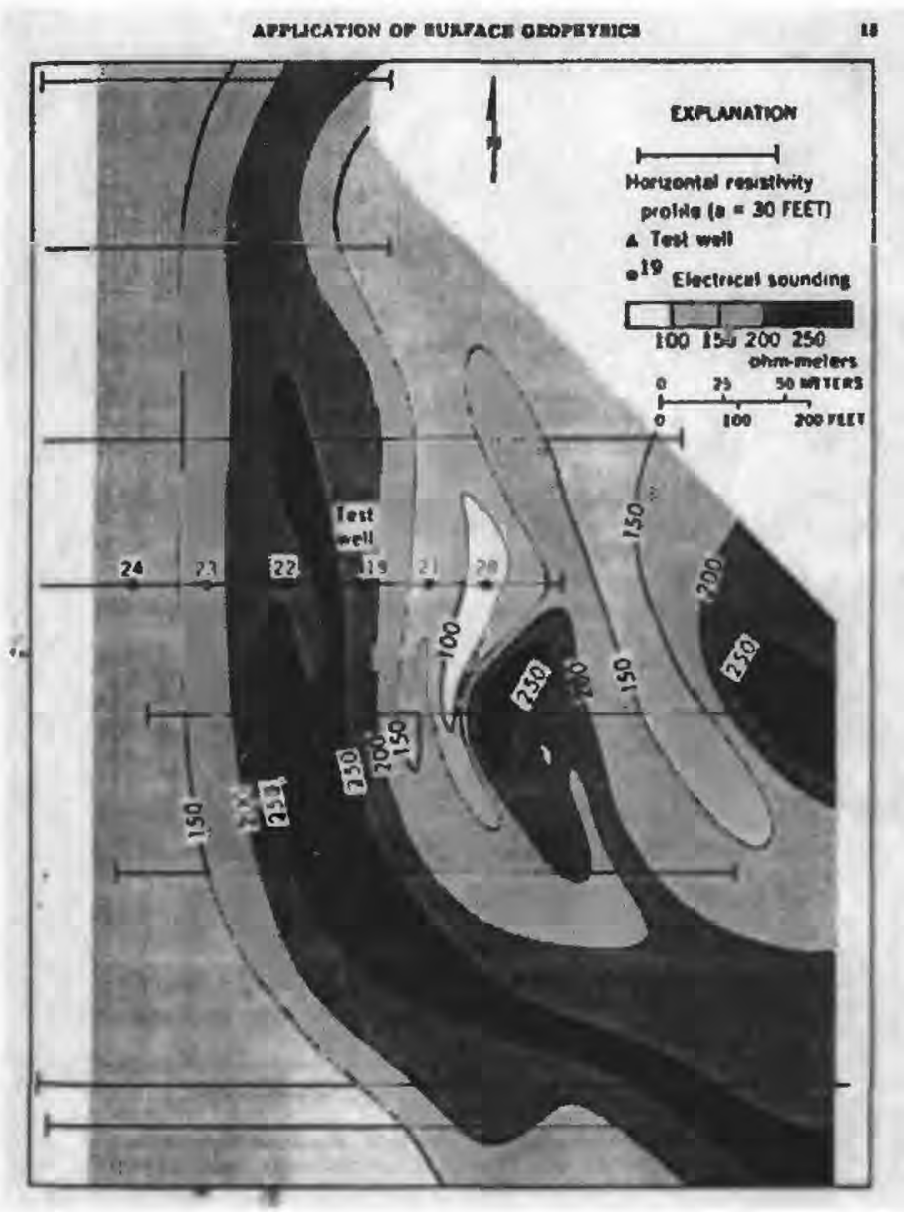

GROUND-WATER-DATA COLLECTION

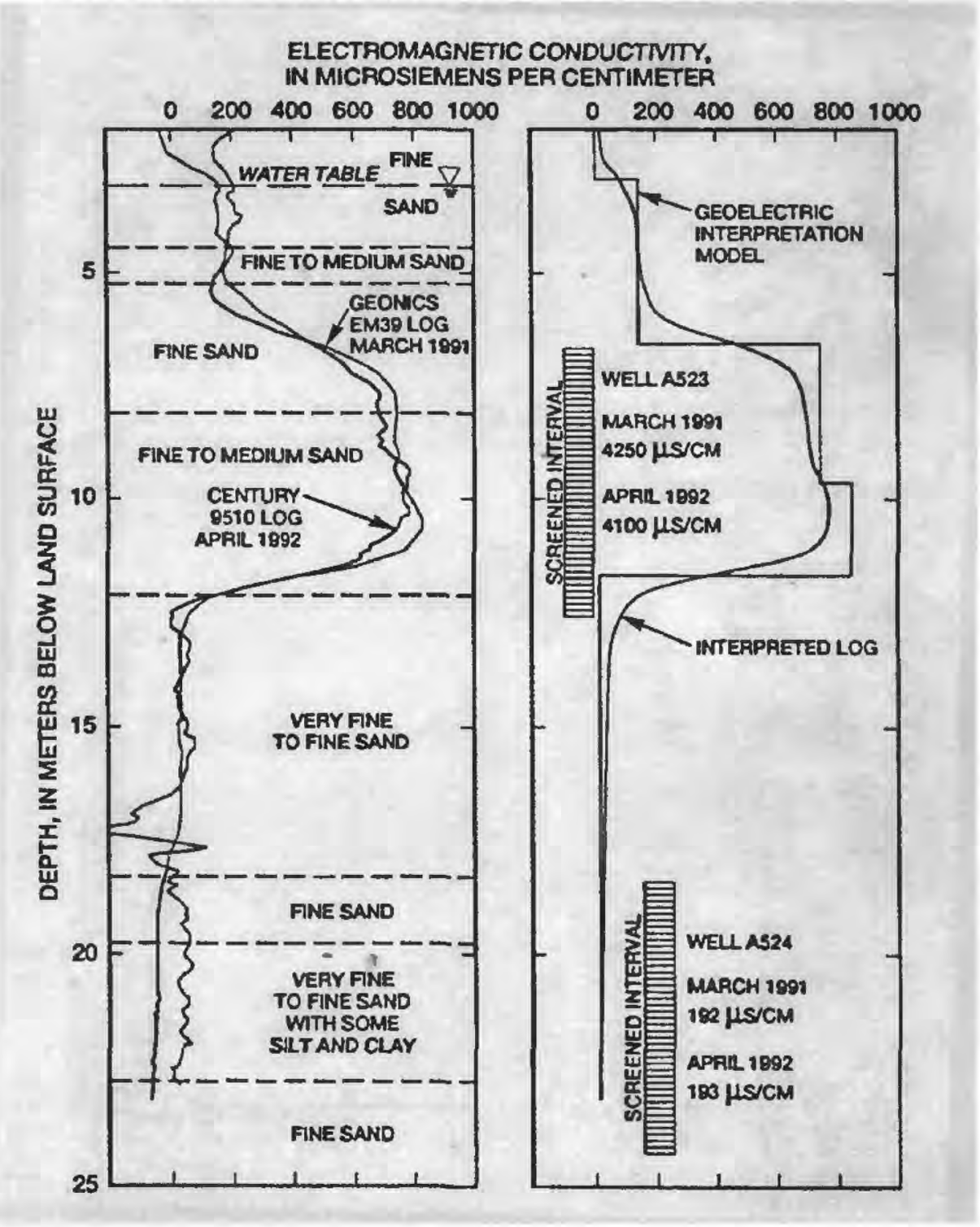

Figures - Electromagnetic-induction and lithologic logs, specific conductance of ground water, and geoelelectric section for a monitoring-well pair (above).

\section{Example of square-array resistivity survey (below).}

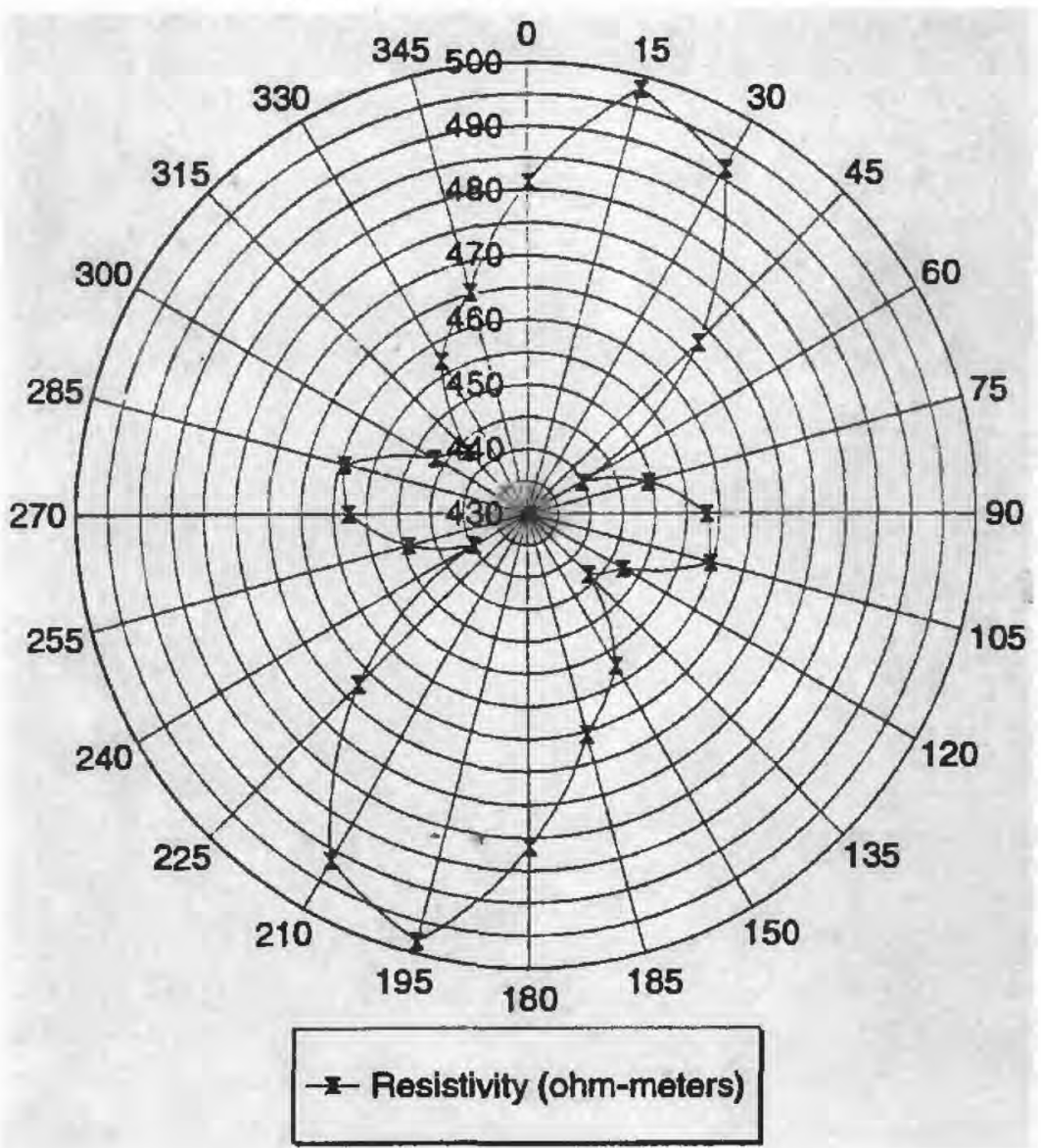




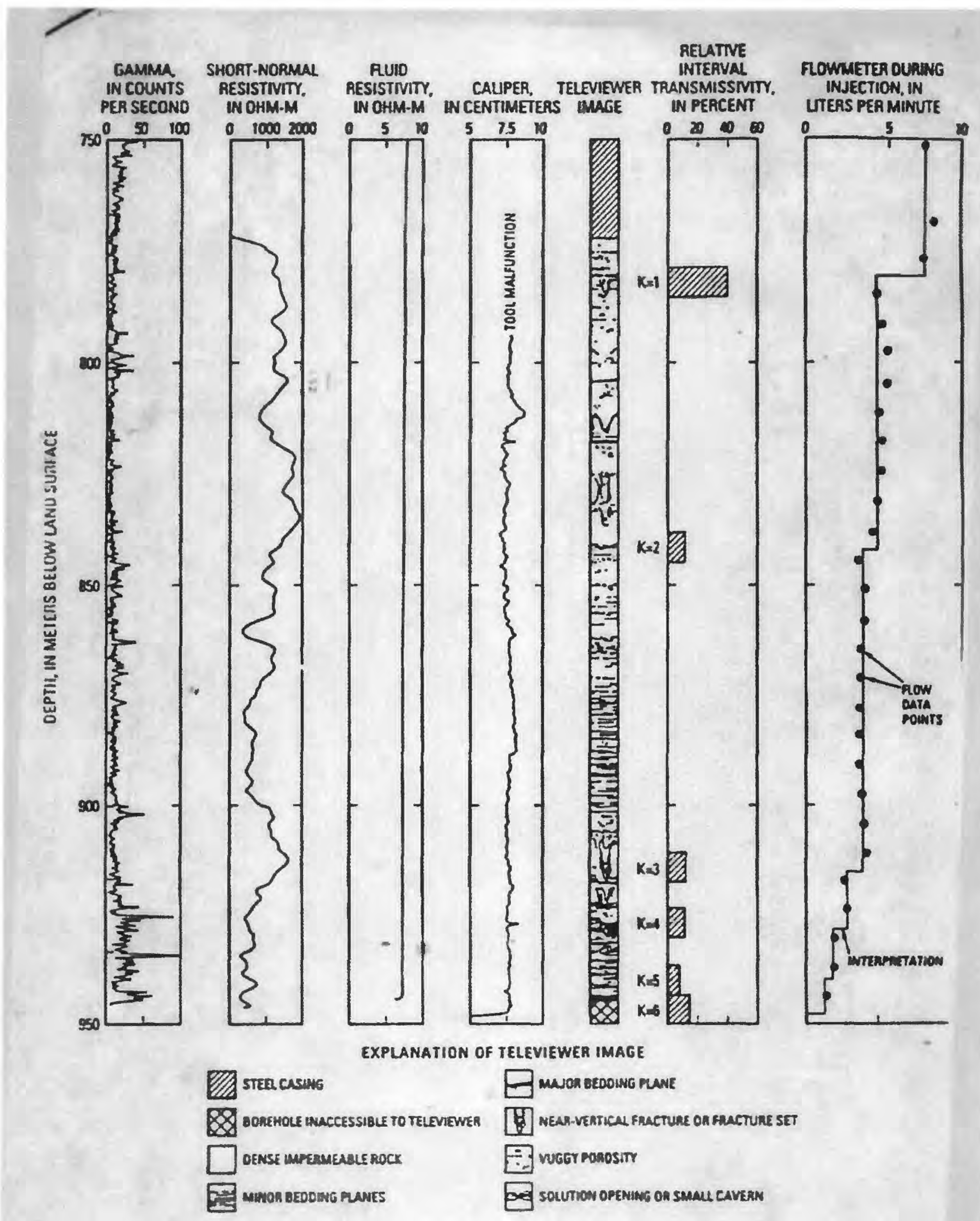

Figure - Suite of geophysical logs from a fractured-bedrock borehole. 


\section{GROUND-WATER-VELOCITY MEASUREMENT (TOOLS and TECHNIQUES)}

Several geophysical (downhole) tools are available for the measurement of ground-water velocity in boreholes or wells. In addition to the tools there are various other techniques that can be used for the measurement of ground-water-flow rates. Such techniques may include injection/tracer tests. Most methods determine vertical
flow rates.

\begin{tabular}{|c|c|c|c|}
\hline Technique & Physical principle & Application & Reference \\
\hline Conventional well & logs & & \\
\hline Temperature & Passive tracer & Vertical flow & $\begin{array}{l}\text { Keys (1990) } \\
\text { Keys and Brown (1978) }\end{array}$ \\
\hline $\begin{array}{l}\text { Fluid } \\
\text { resistivity } \\
\text { or } \\
\text { conductivity } \\
\text { probe }\end{array}$ & Pássive tracer & Vertical flow & $\begin{array}{l}\text { Paillet }(1991) \\
\text { Keys }(1990)\end{array}$ \\
\hline $\begin{array}{l}\text { Impeller } \\
\text { flowmeter }\end{array}$ & $\begin{array}{l}\text { Flow turns } \\
\text { impeller }\end{array}$ & Vertical flow & $\begin{array}{l}\text { Keys (1990) } \\
\text { Keys and Sullivan } \\
\text { (1979) } \\
\text { Schimschal (1981) }\end{array}$ \\
\hline $\begin{array}{l}\text { Brine } \\
\text { injection }\end{array}$ & $\begin{array}{l}\text { Tag/trace with } \\
\text { lons }\end{array}$ & Vertical flow & $\begin{array}{l}\text { Patten and Bennett } \\
(1962)\end{array}$ \\
\hline $\begin{array}{l}\text { Thermal-pulse } \\
\text { flowmeter } \\
\text { flow }\end{array}$ & $\begin{array}{l}\text { Tag/trace with } \\
\text { heat pulse }\end{array}$ & $\begin{array}{l}\text { Vertical or } \\
\text { hor1zontal }\end{array}$ & $\begin{array}{l}\text { Hess }(1986) \\
\text { Hess and Paillet } \\
(1990) \\
\text { Kerfoot (1988) }\end{array}$ \\
\hline $\begin{array}{l}\text { Hydrophysical } \\
\text { logging }\end{array}$ & $\begin{array}{l}\text { Replace fluid and } \\
\text { monitor conductivity }\end{array}$ & Vertical flow & $\begin{array}{l}\text { Tsang and others } \\
\text { (1990) }\end{array}$ \\
\hline $\begin{array}{l}\text { Electromagnetic } \\
\text { flowneter }\end{array}$ & $\begin{array}{l}\text { Currents induced by } \\
\text { flow through } \\
\text { generator }\end{array}$ & Vertical flow & $\begin{array}{l}\text { Young and Waldrop } \\
(1989) \\
\text { Molz and Young (1993) }\end{array}$ \\
\hline $\begin{array}{l}\text { Laser doppler } \\
\text { flowmeter }\end{array}$ & $\begin{array}{l}\text { Doppler shift of } \\
\text { reflected laser }\end{array}$ & $\begin{array}{l}\text { Vertical or } \\
\text { horizontal }\end{array}$ & $\begin{array}{l}\text { Momii and others } \\
\text { (1993) }\end{array}$ \\
\hline $\begin{array}{l}\text { Acoustic doppler } \\
\text { flowmeter }\end{array}$ & $\begin{array}{l}\text { Doppler shift of } \\
\text { acoustic beam }\end{array}$ & $\begin{array}{l}\text { Vertical flow } \\
\text { behind casing }\end{array}$ & Rambow (1991) \\
\hline $\begin{array}{l}\text { Active } \\
\text { listening }\end{array}$ & $\begin{array}{l}\text { Hovement of } \\
\text { scattering pattern }\end{array}$ & $\begin{array}{l}\text { Vertical flow } \\
\text { behind casing }\end{array}$ & Rambow (1991) \\
\hline
\end{tabular}

Table - Summary of high-resolution borehole-flow and related measurement techniques. 


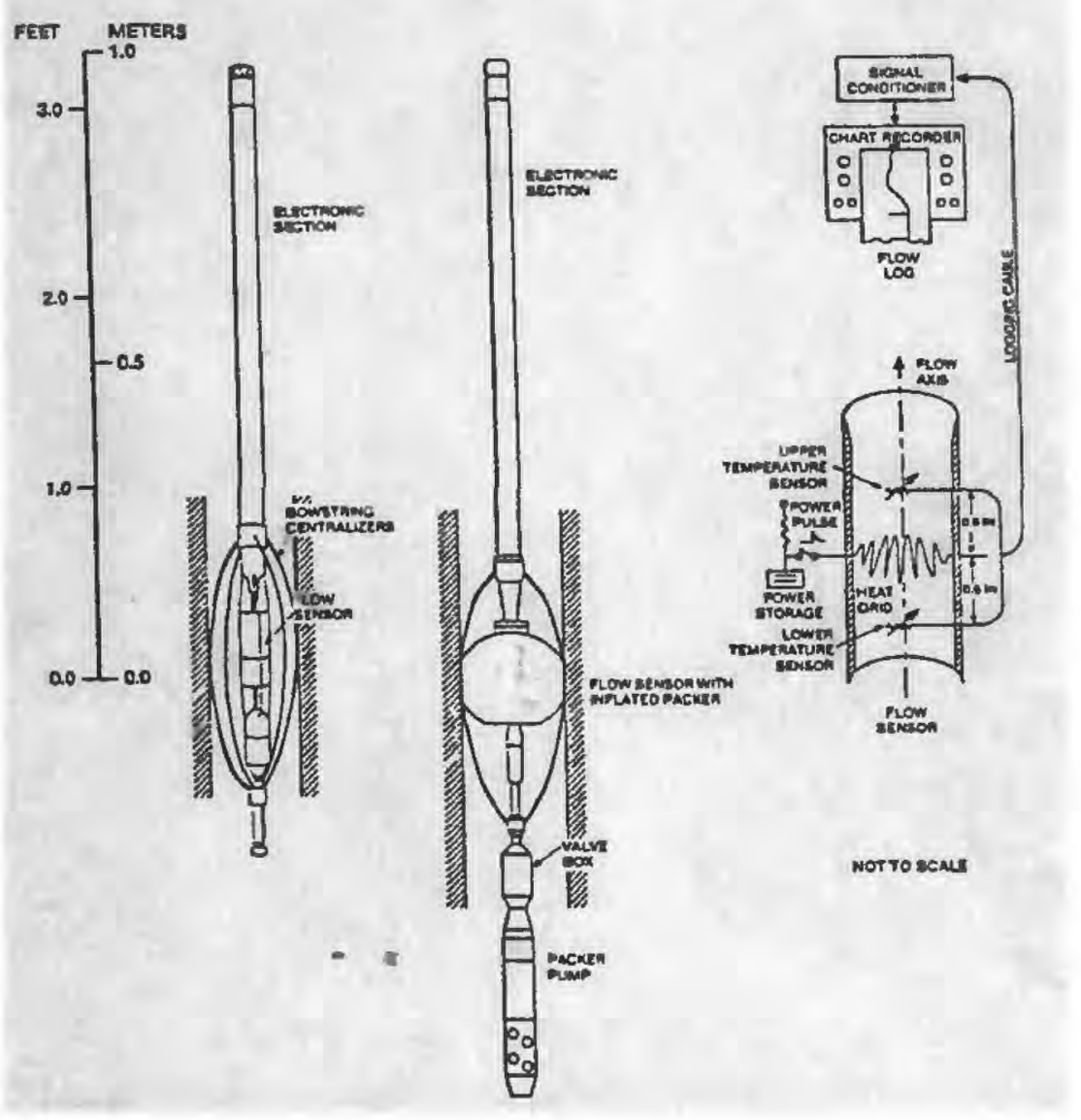

Figure - Borehole heat-pulse flowmeter Measures vertical flow.

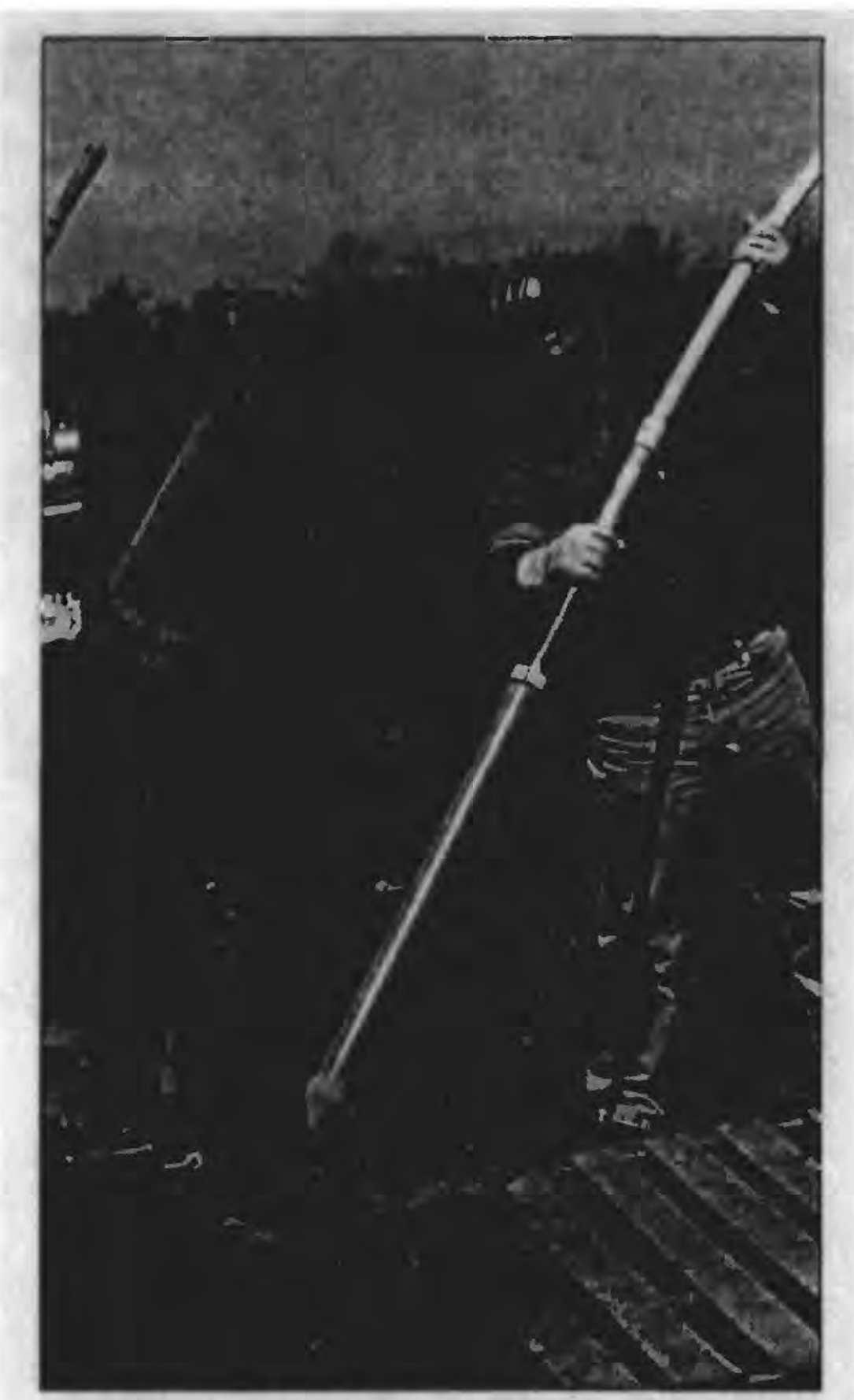

Figure - In-situ ground-water flowvelocity tool. Measures 3-dimensional flow field

\section{TRACER TESTS}

Tracer tests involve emplacing a tracer (conservative substance that mixes with the ground water) in a monitoring well and documenting the movement of the tracer in the aquifer around the injection well, or between two or more wells, over a period of time. Tracer tests can be used to document flow paths, determine ground-water-flow velocities and provide contaminant-transport parameters.

Any hazardous-waste site that involves ground-water contamination can be considered a tracer test. Generally, however, we have no control over the rate of injection.

Unlike most other ground-water characterization techniques, the tracer test usually provides direct information on the ground-water flow paths and velocities. However, the tests are seldom used because of the costs involved, the general reluctance to inject additional constituents into ground-water contamination sites, and the difficulty in completing the tests. 


\section{TYPES OF TRACER TESTS}

- Single Well

- Injection/Withdrawal

- Borehole Dilution

- Dual or Multiple Well

- Uniform (Natural Gradient)

- Radial flow
Measure aquifer characteristics near the borehole, but very little beyond a few feet. These tests are generally easier to Implement than multiple-well tests.

Measure aquifer characteristics in the area between the well tests. Usually the further Away the wells, the more tracer is lost to the system, and the harder the interpretation.

\section{TYPES OF TRACERS}

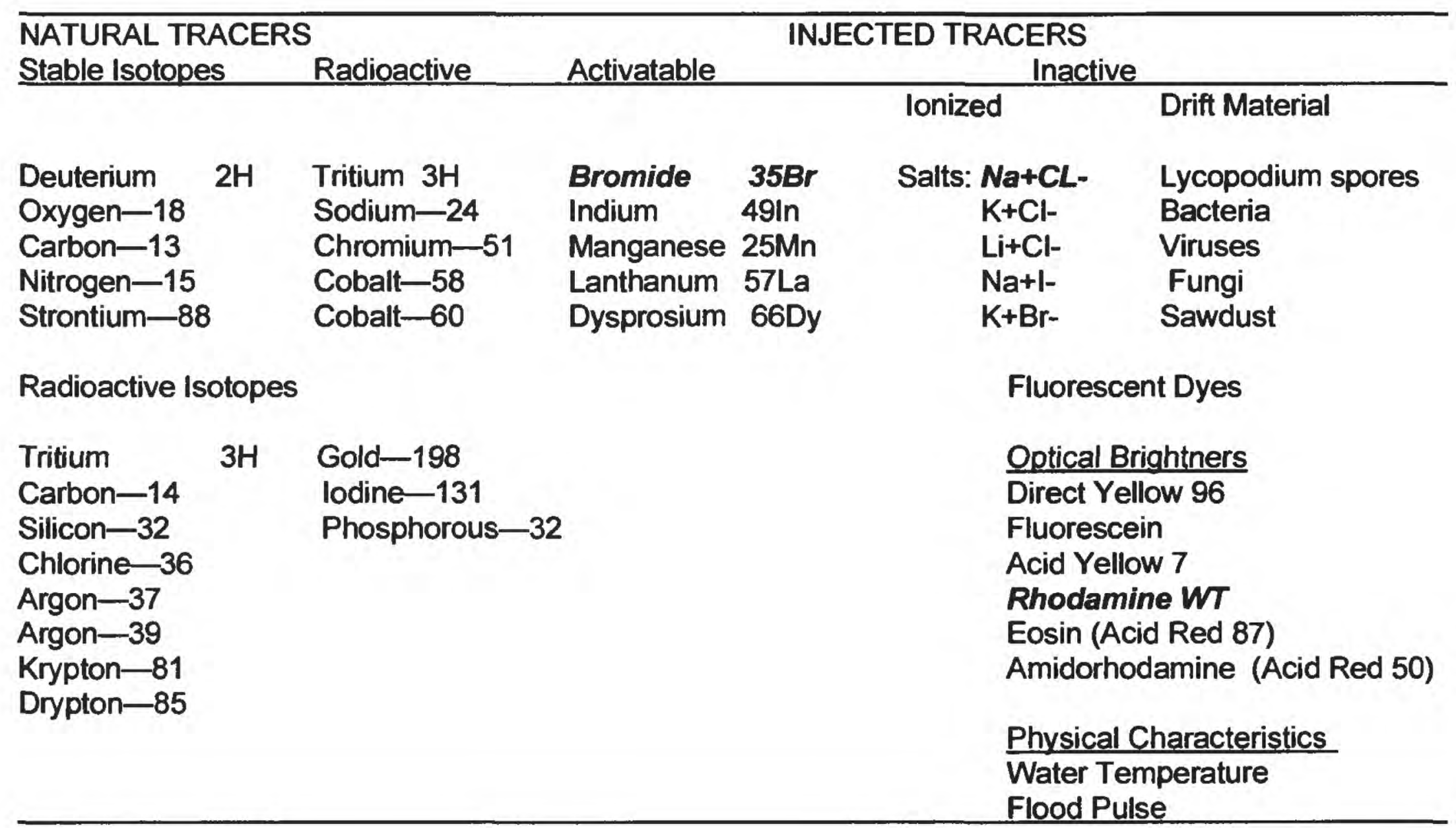




\section{Conceptual Diagram of a Two-Well Tracer Test}
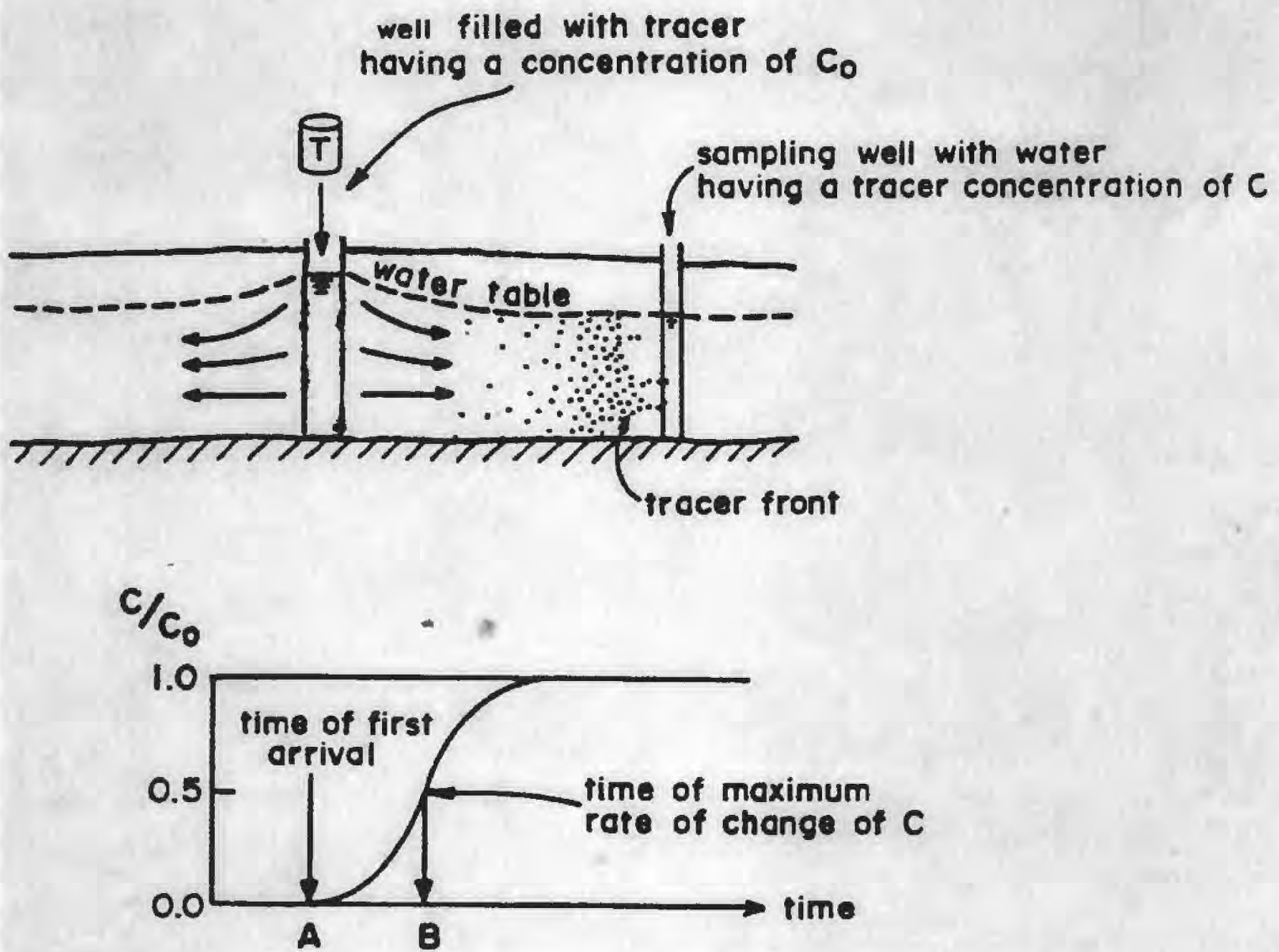

\section{BREAKTHROUGH CURVES FOR DIFFERENT \\ TYPES OF TRACERS}

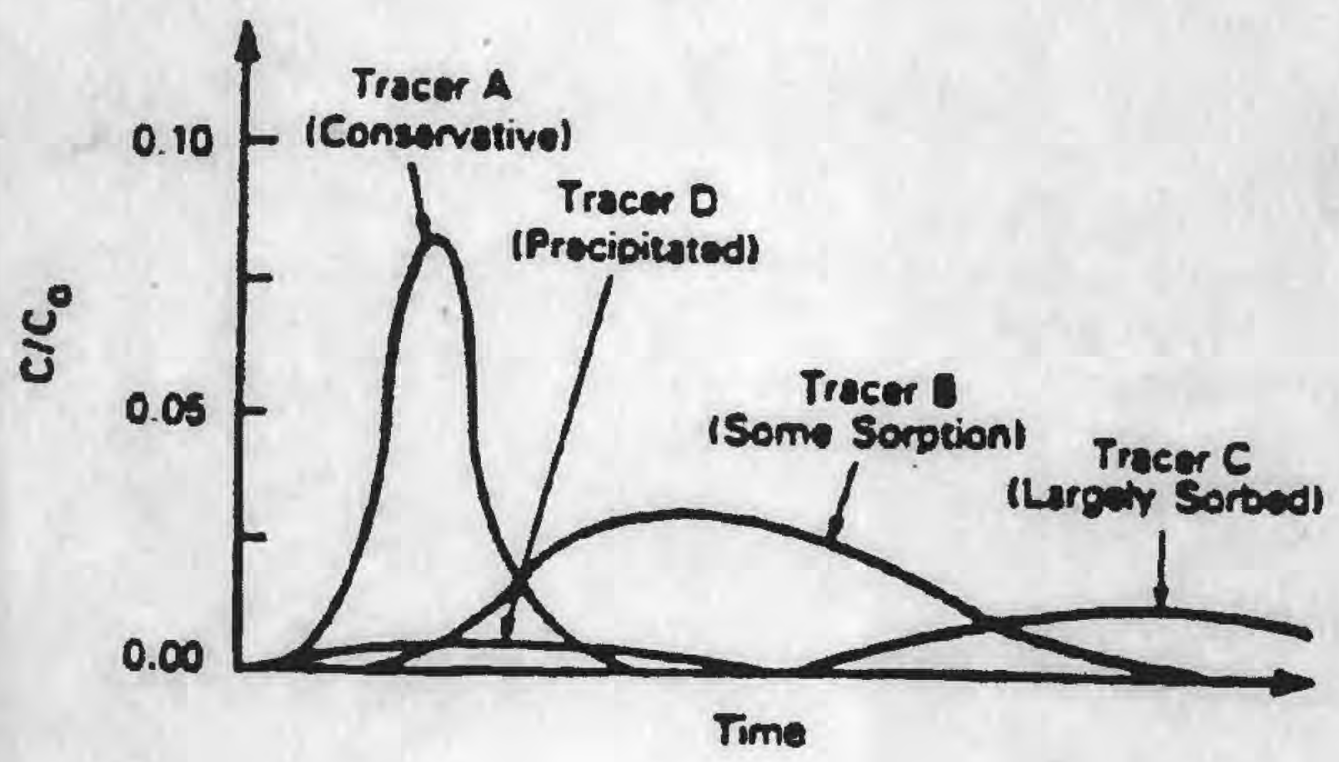




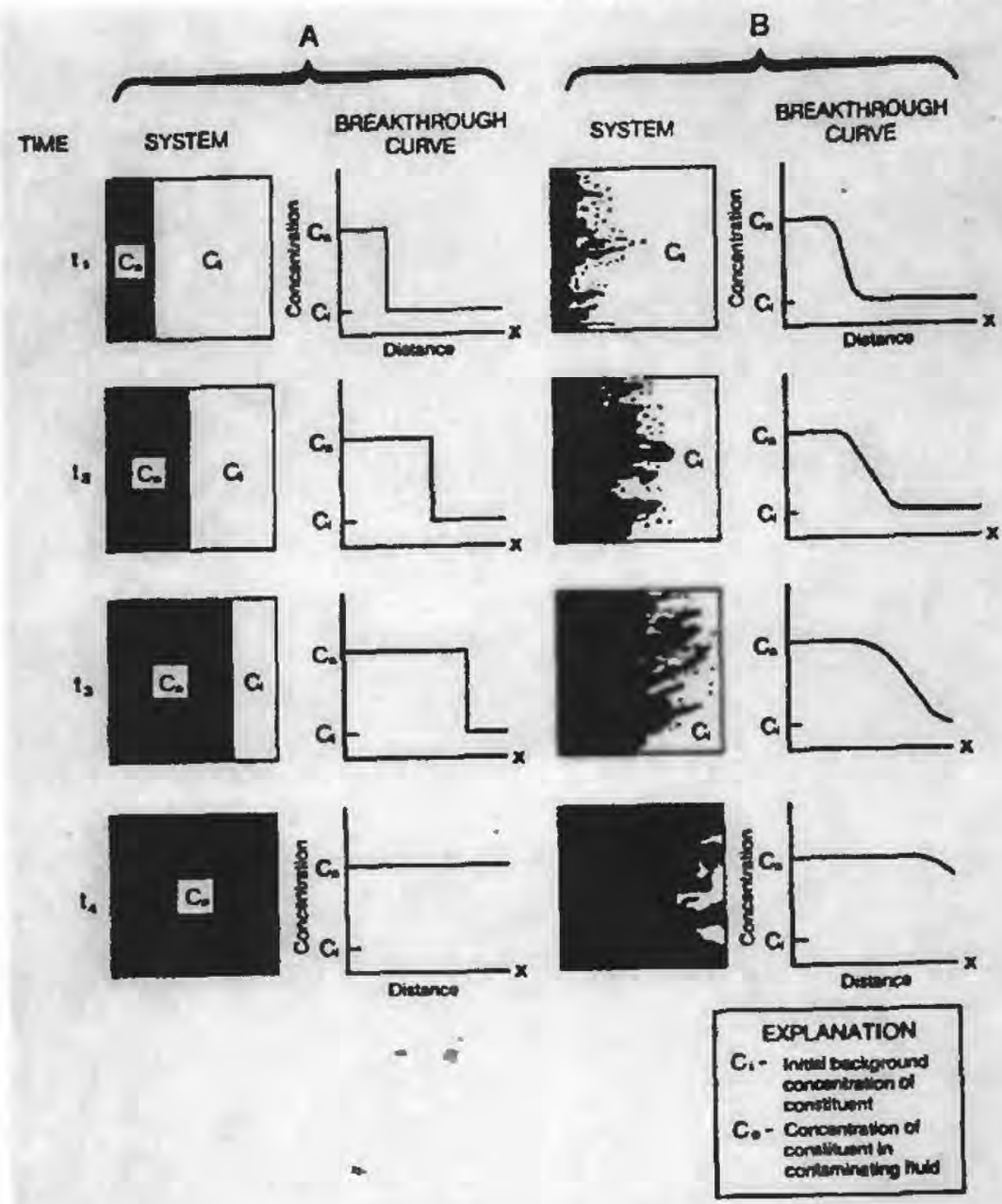

Figure 9. Advances of a recer for. (A) a eharp tront and (B) an irreguler advance.

Figure - Typical irregular breakthough curve.

\section{Bromide Concentration vs. Time}

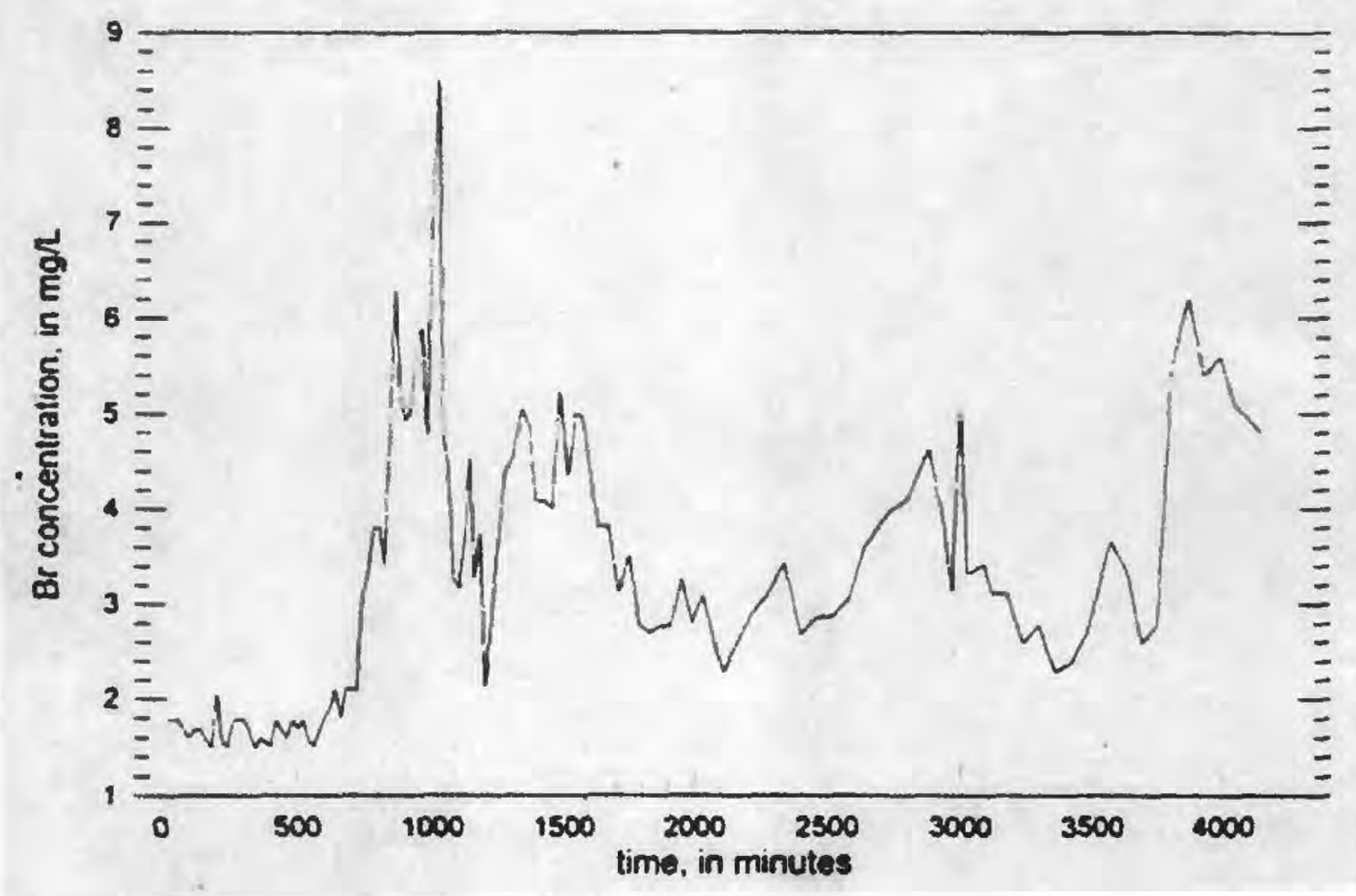

Figure - Actual test. Unfortunately most tracer tests don't perform as intended (note multiple breakthroughs). 


\section{MEASURING AND MAPPING GROUND-WATER LEVELS IN WELLS}

\section{REASONS FOR TAKING WATER LEVELS}

- Determine flow directions

- Identify changes in gradients and (or) flow directions (temporal variance)

- Measurements for aquifer testing

- Measurements related to ground-water sampling

METHODS FOR MEASURING THE DEPTH TO WATER LEVEL IN WELLS

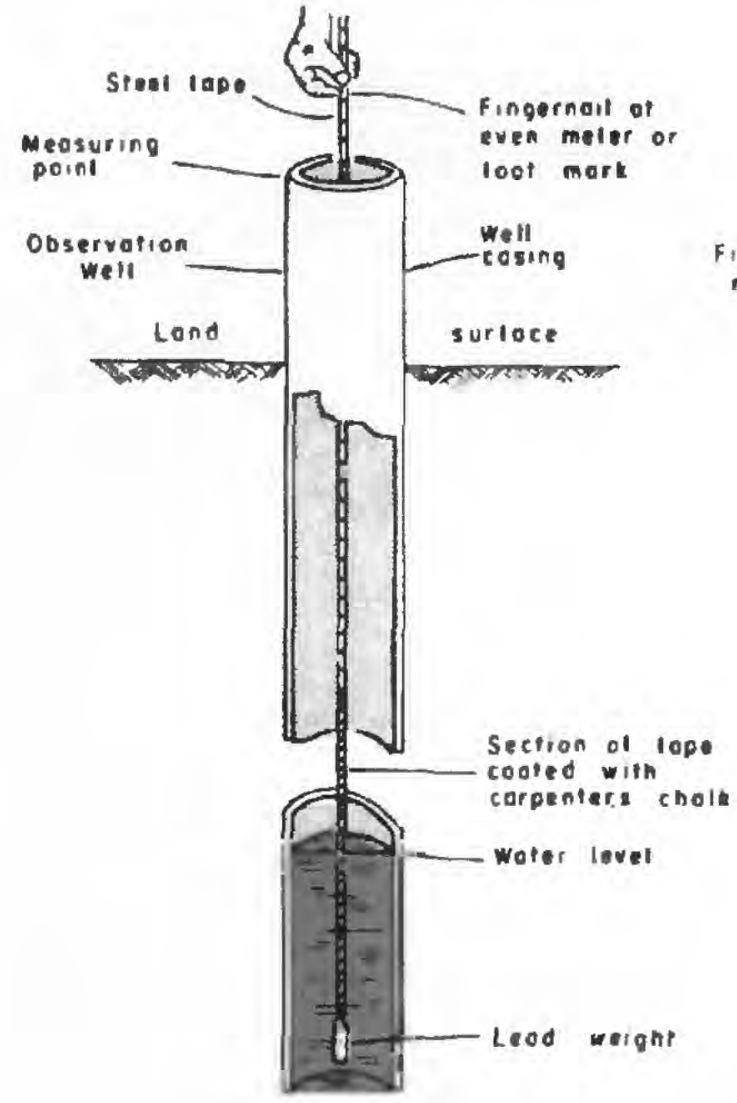

(1)

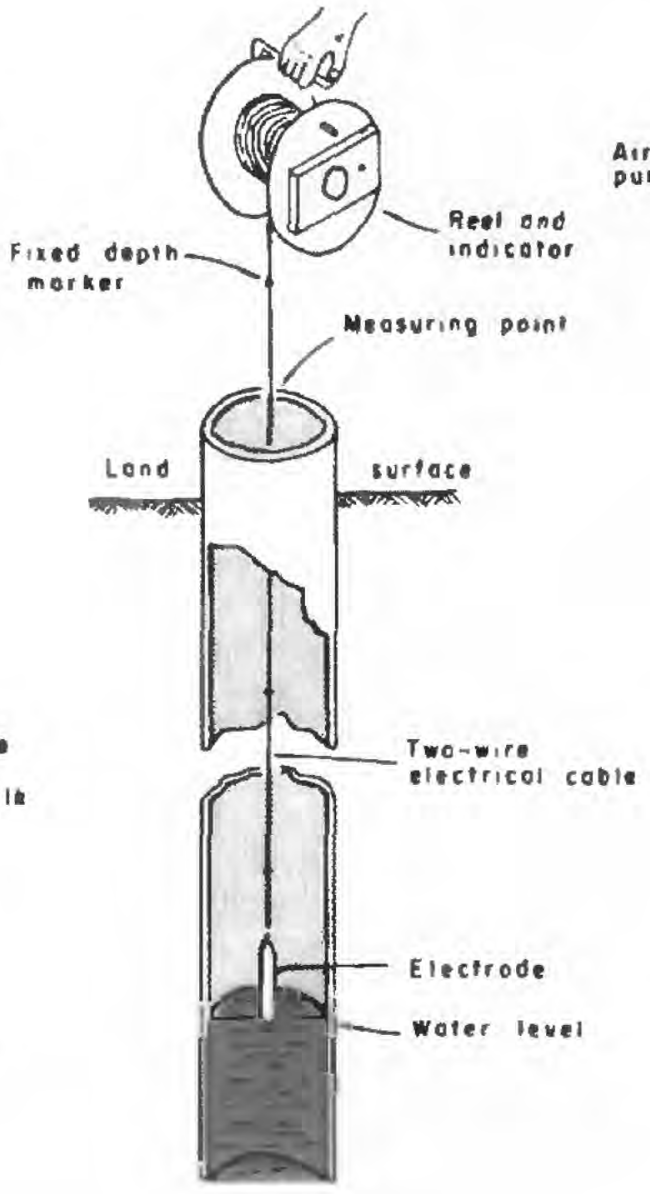

(2)

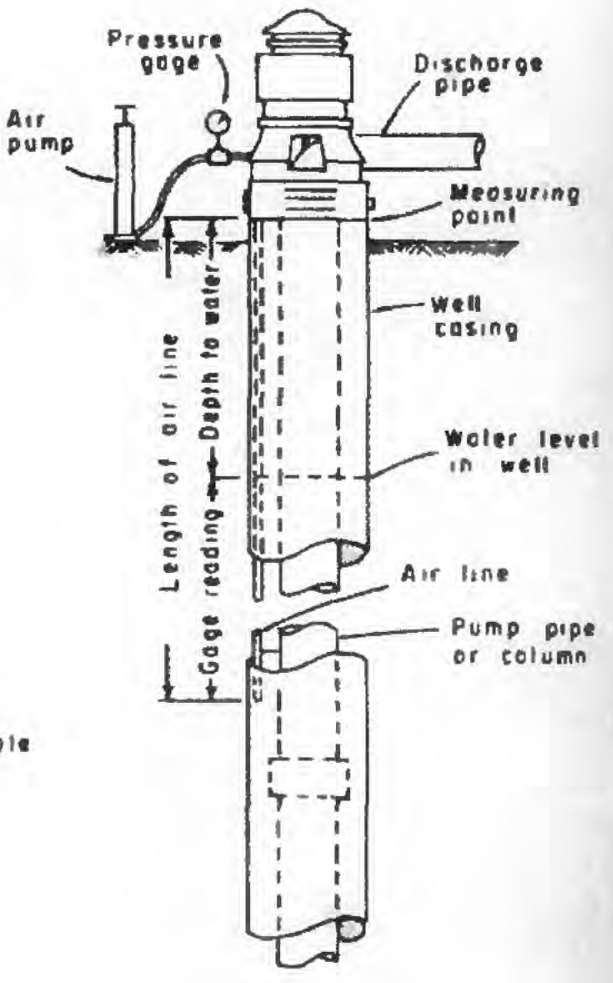

(3)

Figure --. Equipment and methods of manually measuring ground-water levels.
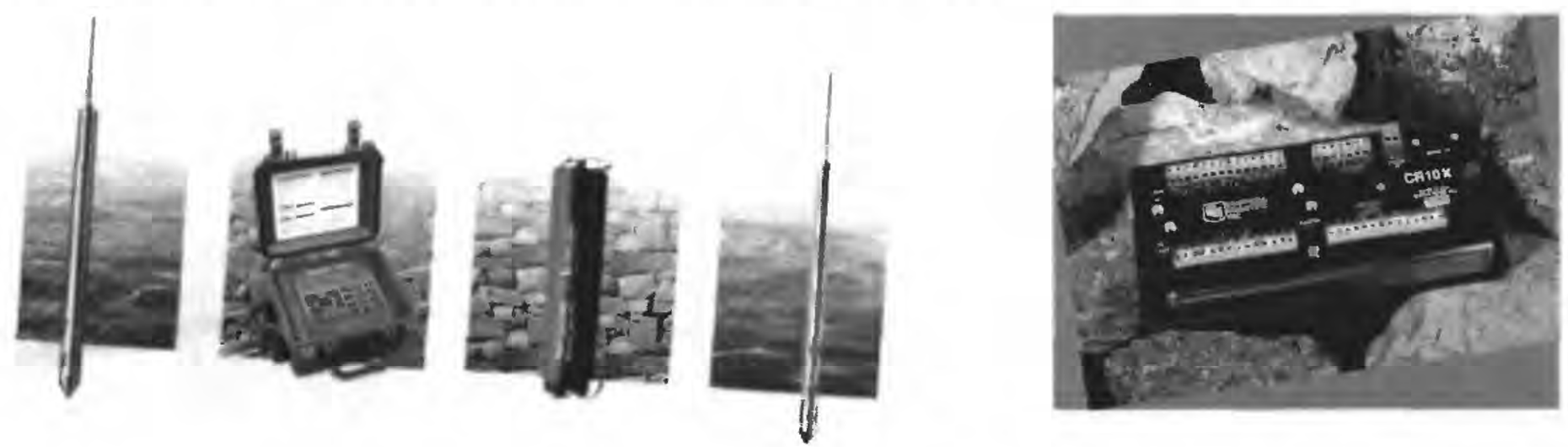

Figure --. Pressure transducers and data loggers for automatically measuring water levels. 
A basic measurement in ground-water studies is that of water levels in wells. Measurements may be made with several types of equipment. The choice of equipment depends on several factors including the accuracy or ease of measurement required, waterquality concerns, type of well (monitoring or water supply), and pumping activity of well and (or) nearby wells.

For all measurements, a fixed reference point must be established at the well head. This point usually is the top of the casing or the access port in water-supply wells. The reference point typically is surveyed to establish its position above sea level, to an accuracy of $0.01 \mathrm{ft}$. To ensure the same reference points are used for all measurement, a notch or marking is made on the casing and the location of the point well documented in the site file. If the well cap is not vented, remove several minutes before measurement to allow water levels to equilibrate to atmospheric pressure.

The most accurate measurement (+- 0.01 feet $(\mathrm{ft}))$ is obtained with a chalked steel tape. This method utilizes a graduated tape with a weight attached to its end. A quality steel tape has limited elasticity and with sufficient weight hangs vertically in the well. Older tapes may use a lead weight, but present concerns about water quality require that the weight be brass or stainless steel.

The lower 3-4 $\mathrm{ft}$ of the tape is coated with carpenter's chalk, and the tape is lowered into the water until the lower part of the tape (about $2 \mathrm{ft}$ ) is submerged. By lowering the tape at intervals of about 2-3 ft the contact of the weight with the water's surface can be heard. For wells with deep water levels, it may be necessary to approximately know the depth to water or to make several measurement attempts to ensure that the tape is not submerged below its chalked length. The tape is held at the reference point and the tape position recorded. The depth to the water level below the reference point is determined by subtracting the length of wet tape (indicated by wet chalk) from the total length of tape lowered into the well. To lessen the possibility of computation errors, the "hold" position should be either on even foot or --.99 ft. The measurement should be repeated to ensure its accuracy (two measurements of within 0.01 $\mathrm{ft}$ ) and that the measured water level is static.

Steel tape measurements usually are required in studies where horizontal gradients are very low and, thus, are not accurately determined with less accurate measuring devices. For water-supply wells, particularly small-diameter ( $<6$ inches) domestic wells with pitless adapters, the tapes may be used without the weight to ensure against entanglement with the wiring and damage to the contained pump.

Electric measuring tapes typically consist of a pair of insulated wires whose exposed ends are separated by an air gap in an electrode and containing, in the circuit, a source of power such as flashlight batteries. When the electrode contacts the water surface, a current flows through the tape circuit and is indicated by an ammeter-needle deflection, light, and (or) audible signal. The "hold" depth against the reference point on the well is read directly from the tape as depth to water. Recent electric tapes are marked at $0.01 \mathrm{ft}$. Some tapes are marked at to 0.05 to $5 \mathrm{ft}$ intervals, particularly tapes that are used in deep wells (> about $500 \mathrm{ft}$ ). For these tapes the unmarked interval must be estimated or measured with another device. Because the tape medium may be easily bent and the weight is often less than that used on steel tapes, the accuracy of electric tapes is considered to be +-0.02 , but may be as great as $0.1 \mathrm{ft}$. The tape can be calibrated against a steel tape and if several electric tapes are used in a study, they should all be calibrated against a reference steel tape. Calibration is especially important when electric tapes are used in studies of where horizontal gradients are small. If water levels are affected by nearby ground-water pumping or previous use of the well (not static), the measurement is more easily and accurately made with an electric tape. 
Special sensing probes with an optical liquid sensor along and conducting electrodes is used to simultaneously measure the thickness of hydrocarbon layers floating on ground water and the depth to water.

Water levels in water-supply wells may not be measurable by steel or electric tapes if an access port is not present or the well cap is not easily removed. Such wells, particularly highcapacity industrial and municipal well use an air line for measurement. This method involves the installation of a small-diameter pipe or tube (the air line) from the top of the well to a point about $10 \mathrm{ft}$ below the lowest anticipated water level and a pressure gage. The water level in this pipe is the same as that in the well. To determine the depth to water, an air pump with a sufficient pressure rating $(1 \mathrm{PSI}=2.31 \mathrm{ft} \mathrm{H} 20$ ) are attached to the top of the air line (at a noted reference point and gage location). Air is pumped into the line until all the water is displaced. This occurs when the pressure indicated on the gage stabilizes. The gage reading indicates the length of submerged air line. The result of subtracting the submerged length of the air line from the total length of the air line is the depth to water below the measuring point. Air lines generally are accurate to about $+-1 \mathrm{ft}$.

Measurement of water levels often is intended to represent "static" levels. For watersupply wells, the well should generally not be used for a minimum of 30 minutes before measurements are made. Longer time periods generally are required for high-capacity wells.

Long term or near-continuous measurement of ground-water levels is generally done with the use of pressure transducers and automatic digital data loggers. Pressure transducers use silicon-based strain gages that generate an electric current. The current is calibrated to pressure (pounds per square inch) which can be related to water levels by the equation: 1 psi = $2.31 \mathrm{ft}$ of water. Pressure transducers generally used vented cables to eliminate response to atmospheric pressure changes (thus measured changes do not include aquifer response to barometric pressure fluctuations). Pressure transducers are selected on the basis of expected water-level change. For example, 0-10 psi (up to $23 \mathrm{ft}$ change in level); 0-30 psi. The smallest acceptable range provides the greatest measurement resolution. Accuracy generally is 0.01 $0.1 \%$ of the full scale range. For example, for a $0-10$ psi transducer with an accuracy of $0.01 \%$, measurements will be to the nearest $0.02 \mathrm{ft}$. Data loggers are use to store measurements. Logger software allows measurement at various linear and logarithmic intervals, setting of sensitivity limits for data storage, and field calibration of the transducers.

Pressure transducers are temperature sensitive and cables are subject to stretching with time. Thus, the transducers must be both factory and field calibrated. To measure water levels, select appropriate psi-range transducer. Submerge to transducer to about mid-monitoring range (about $12 \mathrm{ft}$ for 0-10 psi). Allow it to acclimate to ground-water temperature for about 20 minutes. Set factory-prescribed range, linearity, and offset for proper quadratic conversion of electric signal to psi/feet of water. Wrap a small piece of electrical tape on the transducer cable at the top of the well casing. Using a measuring tape position vertically on top of the well casing, raise the cable and transducer $1.00 \mathrm{ft}$; check water level change using the data logger. Raise cable another $1.00 \mathrm{ft}$. Check water level change again. Lower the cable $1.00 \mathrm{ft}$, check change and repeat. Each measurement should be within about 0.02 $\mathrm{ft}$ of the $1.00 \mathrm{ft}$ raising increments. Secure the cable to the well head, so it will not slip and the reference tape can be used to monitor possible slippage. Measure the depth to water with a steel or electric tape and set reference depth in data logger $(0.00$ to record relative change or depth to water or water-level altitude. Periodically check the transducer reading with tape measurement to monitor electronic drift or slippage of the cable. If drift or slippage reset position and datum and adjust record accordingly (prorating change in position/depth reading?). 
Major manufactures of pressure transducers include Druck and In-Situ, Inc. Major manufactures of data loggers include In-Situ, Inc. and Campbell Scientific, Inc. In-Situ's Hermit loggers are preprogrammed and easy to use. Campbell Scientific loggers are programmable and therefore very flexible in their application, but may be difficult to use because of the required programming language.

\section{POTENTIAL INACCURACIES IN WATER-LEVEL MEASUREMENT AND MAPPING}

- Faulty procedures and (or) equipment

- Incorrect measurement point used

- Long well screens intercept more than one aquifer unit

- Water levels not "static"

- Hydrocarbons (LNAPL's) in water (require special sensors, measured thickness in Well may be greater than mobile component in ground water)

Table -- Water-level measuring devices (Nielson, 1991)

\begin{tabular}{lll}
$\begin{array}{l}\text { Measurement } \\
\text { method }\end{array}$ & $\begin{array}{l}\text { Accuracy, } \\
\text { in feet }\end{array}$ & $\begin{array}{l}\text { Major interference } \\
\text { or disadvantage }\end{array}$ \\
\hline
\end{tabular}

Non-flowing wells

Steel tape and chalk

Electric tape

Pressure transducers

Acoustic probe

Ultrasonics

Floats

Poppers

Air Lines

Flowing wells

Transducers

Casing extensions

Manometerl

pressure gage
0.01

$0.02-0.1$

$0.01-0.1$

0.02

$0.02-0.01$

$0.02-0.05$

0.1

$0.25-1.0$
Cascading water

Cable wear; hydrocarbons on water Temp. change; elect. drift; blocked capillary Cascading water; hydrocarbons on water Temperature change; well materials Float or cable drag; float size or lag Well noise; well equipment; well depth Air line or fitting leaks; gage inaccuracies
0.02

0.1

$0.1-0.5$
Temperature changes; electronic drift Limited range; awkward Gage inaccuracies; calibration required 

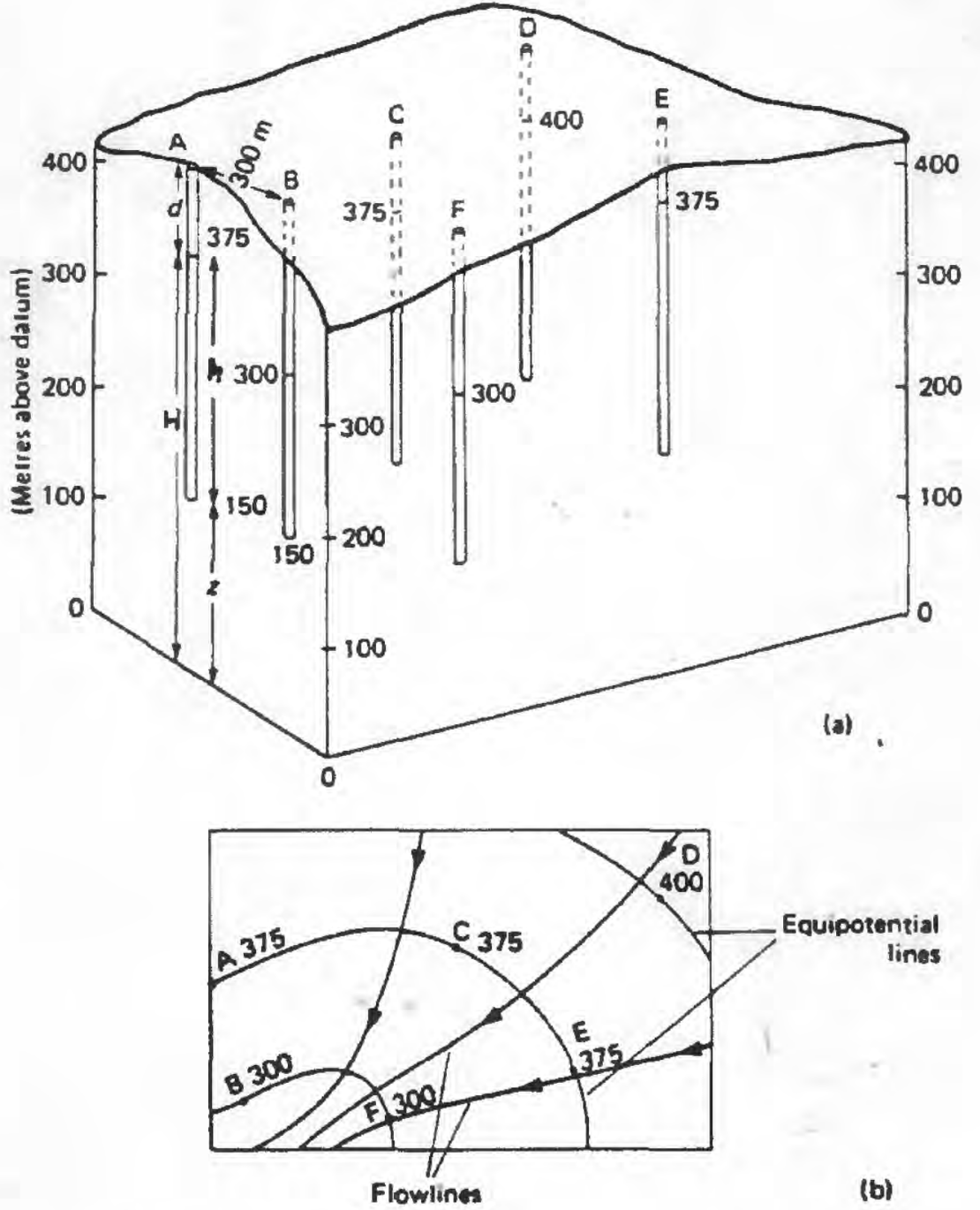

(a) A 'field' of piezometers. (b) Plan view (x-y plane).

Figure - Mapping of potentiometric surface from measured ground-water levels

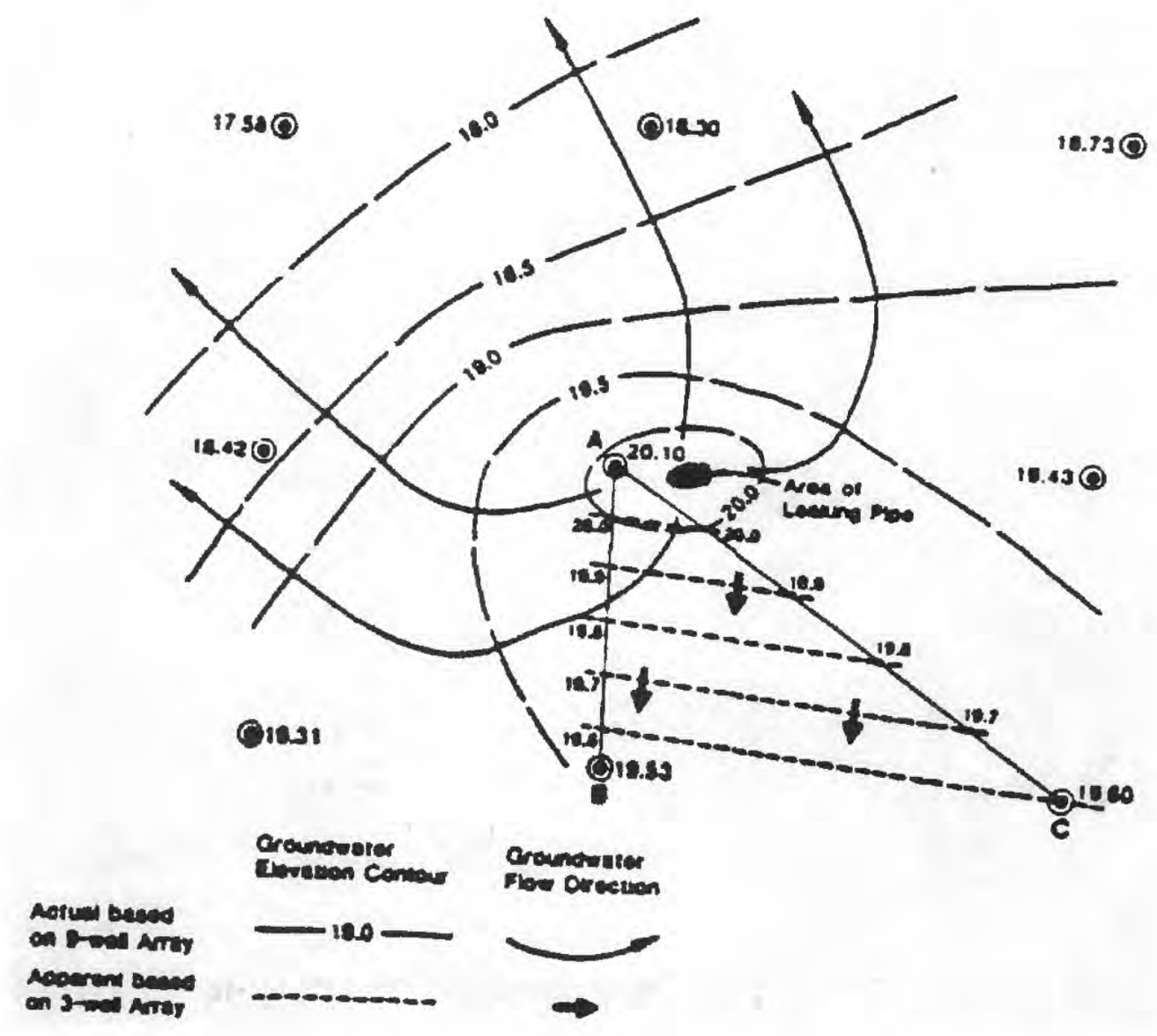

Figure .- Estimation of ground-water flow directions with 3- and 9-well array. 


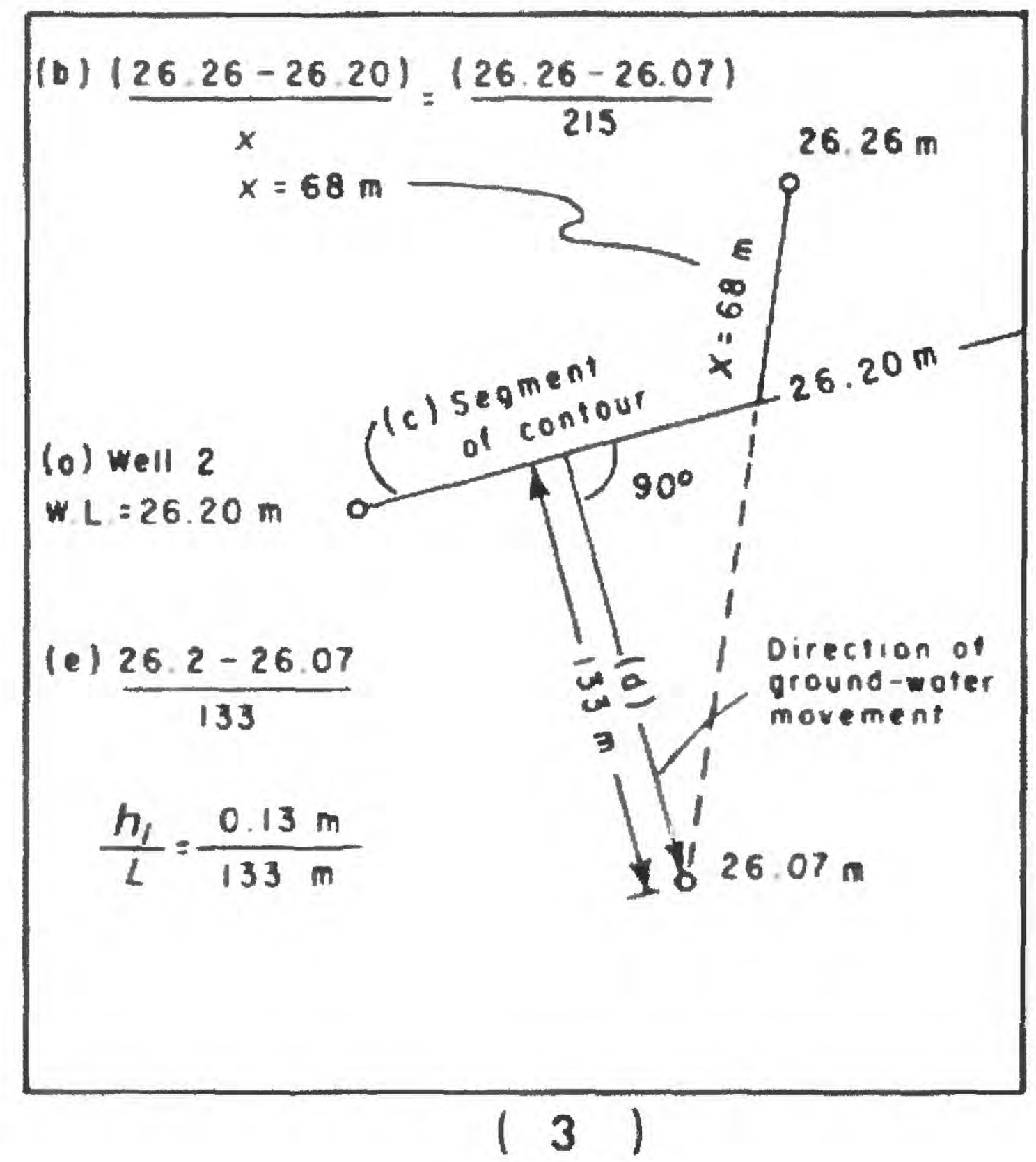

Figure - Method for determining direction of flow and hydraulic gradient from 3-well array . (Heath, 1983, p.11)

\section{REFERENCE:}

Garber, M.S. and Koopman, F.C., 1978, Methods of measuring water levels in deep wells: U.S. Geological Survey Techniques of Water-Resources Investigations of the United States Geological Survey, Book 8, Chapter A1, 23 p. 


\section{COLLECTING WATER-QUALITY AND QUALITY-CONTROL SAMPLES}

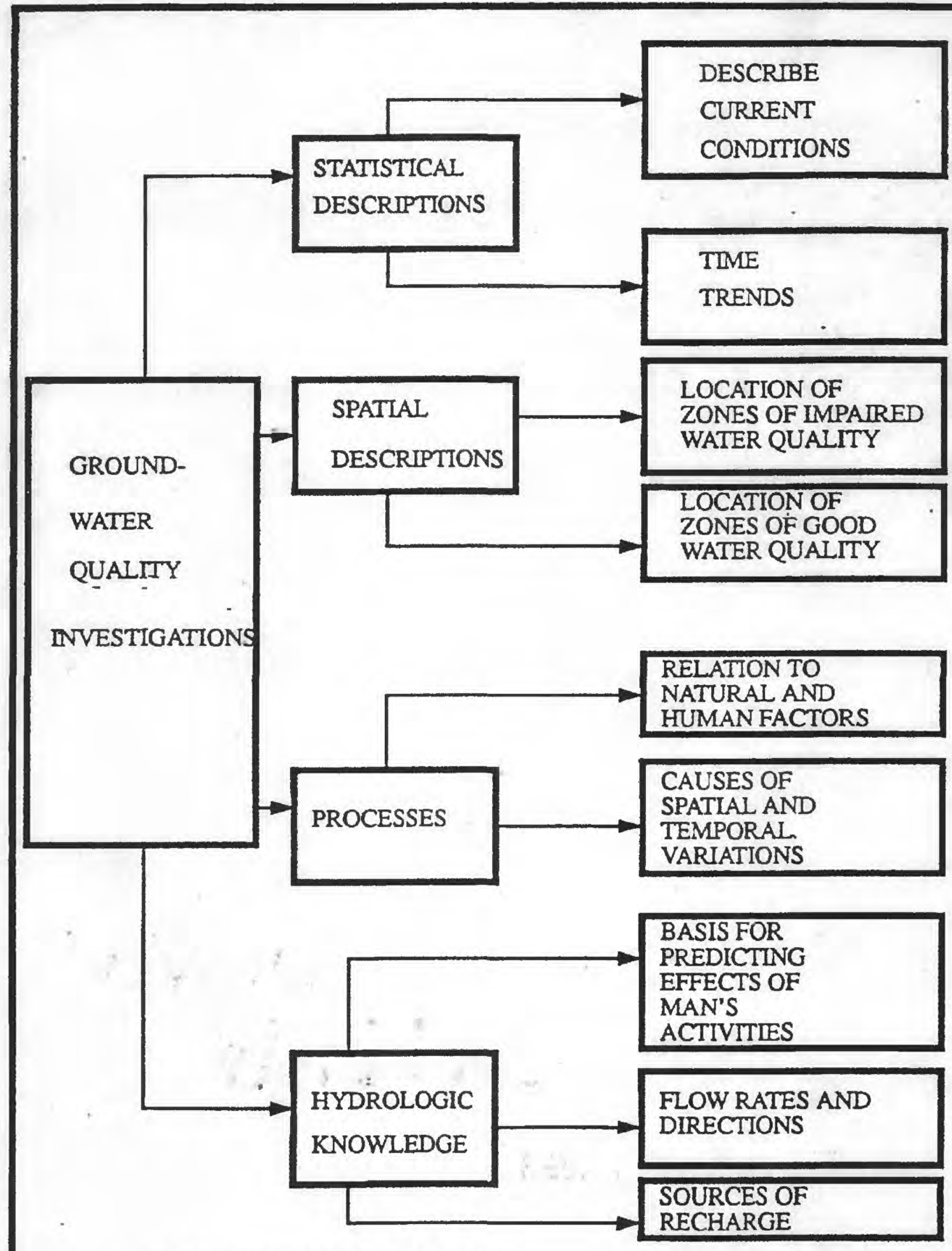

MODIFIED AFTER ALLEY, 1993

Table - Purposes of ground-water-quality investigations 


\section{RELATE SAMPLING TO STUDY GOALS}

- What is the problem to be solved

- What are the goals to be achieved

- What are the limits of sampling

- Available sampling points

- Time

- Budget

\section{OPTIMIZE FOLLOWING RESTRAINTS}

- Greatest understanding of system

- Best address of study goals

- Collect representative samples

- Select meaningful parameters

- Integrate study-specific QA/QC

- Select relevant and applicable sampling and analytical methods

\section{SAMPLING STRATEGY}

- What type of study?

- Site Specific

- Regional

- When are samples collected?

- Synoptic

- Temporal trends
Where are samples collected?

Vertical

Horizontal

Upgradient/background Down/cross-gradient (consider DNAPL's)

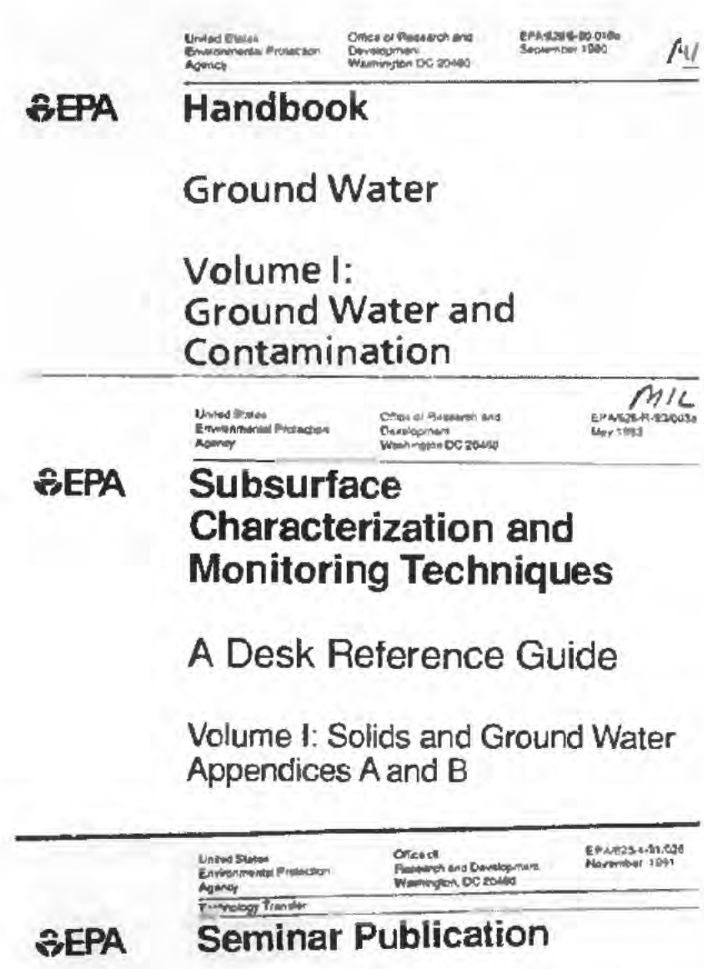

Site Characterization for Subsurface Remediation

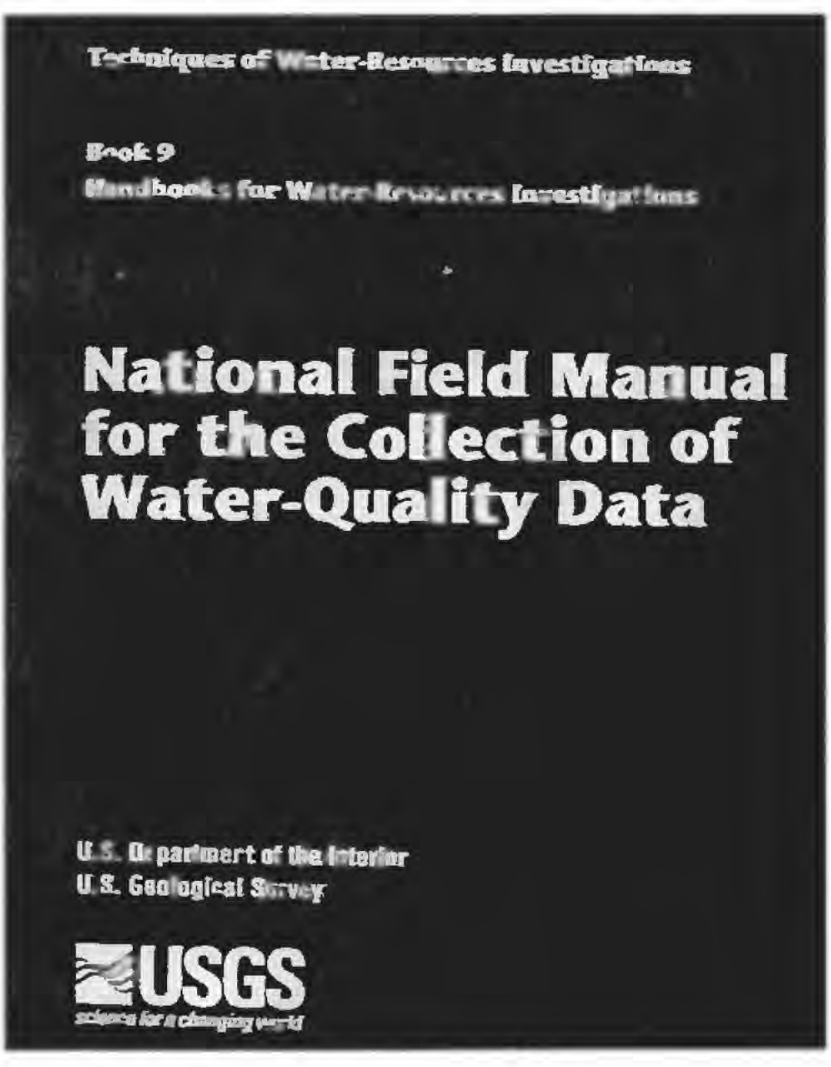

Figure--Examples of ground-water-quality sampling methodology manuals 


\section{KEY CONCEPTS}

- Representative sample: reproducible and unbiased sample within defined limits of variability

- Every step requires thinking: data collection is never "canned"

\section{OUR ENEMIES}

- TIME - Reactions can be rapid-temperature can affect reaction rate

- PRESSURE DECREASE - Pressures can be much greater than atmospheric in ground water (organics may volatilize with change in pressure due to atmospheric affects and sampling procedure; loss of inorganic gases)

- EXPOSURE TO ATMOSPHERE - Introduction of atmospheric gases and dust; Evaporation (introduced oxygen may result in oxidation and precipitation of Fe and Mg, co-precipitation of As, Cu, Mo, U, etc.; VOC's may be introduced by storage of chemicals in pump house or field vehicle, exhaust fumes)

- MIXING WITH NON-AQUIFER LIQUIDS - Due to well construction and development (multi-well systems; water-treatment systems)

- LEACHING AND ABSORPTION - From equipment, well materials, storage/ pressure tanks

\section{DESIGN ACTIVITIES TO MINIMIZE THE EFFECTS OF "ENEMIES"}

- RULES FOR GOOD FIELD PRACTICE

- Know the "enemies"

- Wear gloves and other protective equipment

- Use cleaned equipment

- Minimize sample-handling steps

- Collect field blanks

- Plan sight visits so that you sample from lowest to highest concentrations of target constituents

- Upgradient to downgradient

- Lowest ionic strength to highest strength

- Pristine to contaminated 


\section{ADDITIONAL GFP'S FOR COMBATTING "ENEMIES"}

- TIME - Minimize temperature increases and time for reactions (minimize sample handling time)

- LOSS OF PRESSURE - Use equipment that minimizes pressure decreases (use inline filtration, positive displacement pumps)

- EXPOSURE TO ATMOSPHERE - Use enclosed systems (use flow-through cells; in-line filtration; collection and preservation chambers; flush filters; bottom fill bottles)

- MIXING WITH NON-AQUIFER LIQUIDS - Isolate the sample aquifer (flush sampling equipment; develop well)

- LEACHING AND ADSORPTION - Select correct materials; minimize flow rate; Minimize surface contact

\section{USE A PREFIELD ACTIVITIES CHECKLIST}

Table. - Prefield activities checklist

Order and make a checklist of supplies and equipment

Clear site access (permits, owner notification, etc)

Create and maintain a site file for each well (for field as well as office reference)

Create schedules of planned field activities, including laboratory schedules of analytes

Prepare field sheets: complete site-descriptive informacion on field forms and National Water Quality Laboratory analycical services reques forms (except for date, time, sample data)

Ascerain proper storage of supplies and equipment (to avoid equipment contamination and : preserve chemical integrity of reagents)

Prepare supply of District-deionized water (routinely analyzed for cargeted analytes)

Routine equipment maintenance and operation checks

Charge batteries

Preclean new/used equipment

Collest préfield equipment blanks

Wash, cap, label, and bag sample botcles

Arrange proper storage and disposal of hazardous materials

Updare compurer files; run quality-assurance cheoks on data 


\section{Table - Information to obtain when sampling water-quality data-collection activities}

1. Type of Well Hookup for Sampling: Determine if a hookup to a garden-hose-threaded flow valve (common for water-supply wells) or to a portable, submersible pump (common for monitoring wells) is needed for sample collection.

2. Depth Measurements: Measure the depth of the well and depth to the water level in the well to check well-construction integrity and to determine pump lift, height of water column, volume of standing water held in the well, and purge volume.'

3. Site Conditions and Restrictions: Note road or access conditions to the well, areas of low clearance, limits on arrival and departure times, or presence of roaming animals (for example, livestock or pets) that could create problems for a field team.

4. Contact Person: Obtain land- or well-owner name and telephone numbers (business and home) and contact owner before or upon arrival, and perhaps upon departure.

5. Local Maps and Photographs: Locate well on maps, site sketches, or photographs, and indicate the measuring point for well-depth measurements, as well as areas for equipment
setup and waste discharge.

6. Travel Maps and Travel Times: Identify route and travel times from District of fice or previous site, and possible tunnel or bridge restrictions on the transport of gasoline, bottled gas, or methanol (or other organic cleaning agent).

${ }^{1}$ Measurements are made in accordance with National Water-Quality Assessment Program and U.S. Gcolngical Survey protocois (Laphan and others, in press). Purge volume is defined as three limes the volume of standing water in the well casing or, in absence of a casing. the borehole.

Figure. - Example of U.S. Geological Survey field record
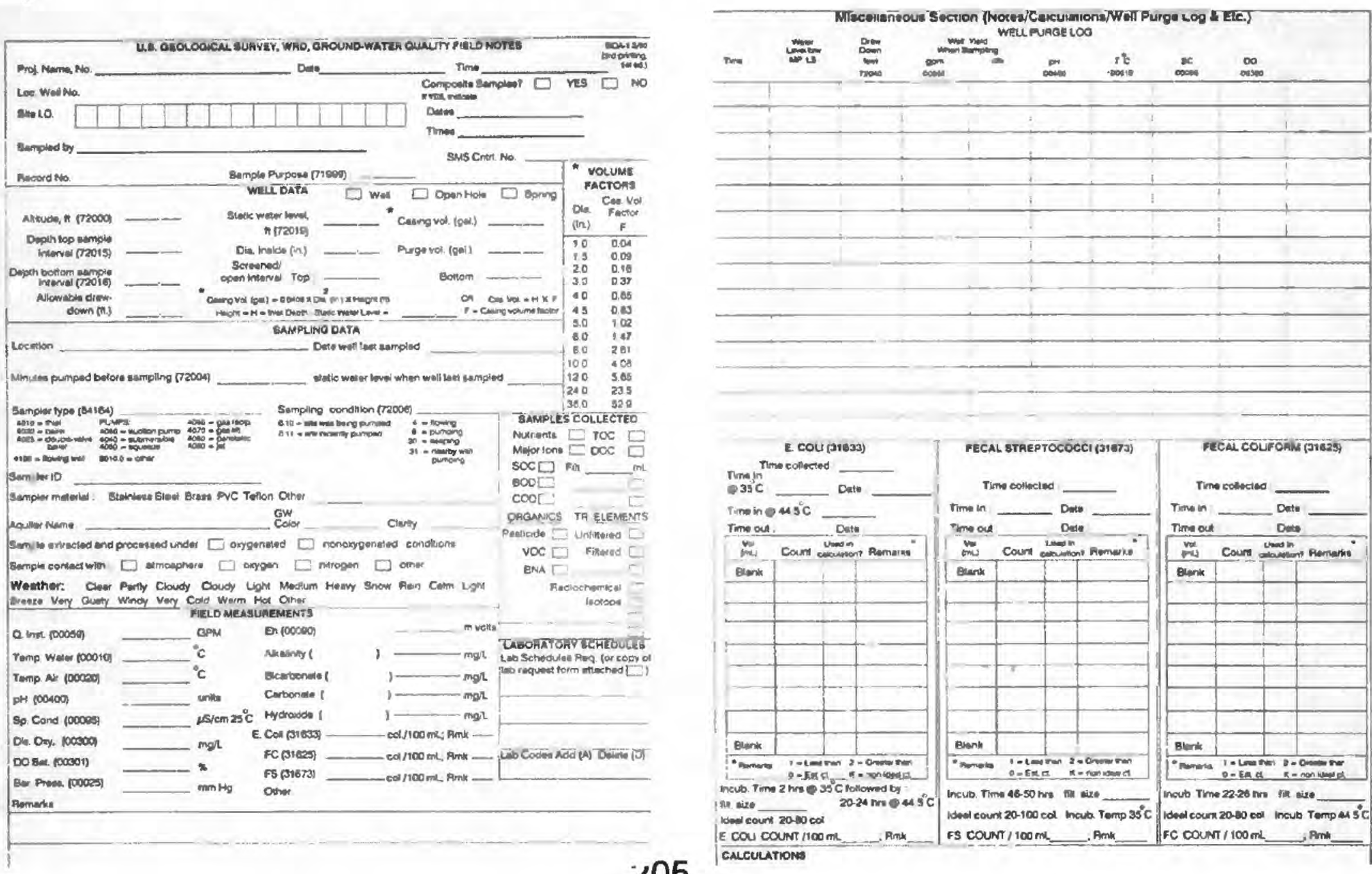


\section{FIELD SEQUENCE GROUND-WATER SAMPLING}

\section{Decontaminate equipment used in well sampling}

2. Determine purge volumes from measured water level in well

3. Purge well (Volume and Stability of Field Water-Quality Characteristics)

4. Collect field measurements of water quality - Use a flow-through cell

5. Collect sample

6. Preserve samples

7. Decontaminate equipment used in well sampling

Prior to sampling a well, the sampling equipment must be precleaned (decontaminated) and standing water in the well casing or well bore must be removed to ensure the sample is representative of aquifer water quality.

\section{DECONTAMINATION}

- PURPOSE

- Reduces contamination of the subsurface from equipment used in the well

- Reduces possible cross contamination between wells

- Ensures the sample chemistry represents the aquifer chemistry at the sampled location

\section{WHAT SHOULD BE CLEANED}

- Measuring tapes, pumps/other sampling equipment, bottles; mobile lab

- Similar considerations for other aspects of ground-water study (drilling, and lithologic Sampling equipment; well completion, construction and well-development equipment) (generally will include heated-water high-pressure wash)

\section{HOW SHOULD EQUIPMENT BE CLEANED}

- Procedure depends on degree and type of contamination, project objectives, and data quality objectives

- At a minimum:

- Scrub/wash/circulate with non-phosphate detergent solution

- Liquinox) (0.5-2\%)

- Trisodium phosphate (2-4 lbs/gallon)

- Others for compound specific cleaning

- Bleach (2 Tsp/gallon) for disinfecting measuring tapes use in supply wells

- Rinse with clean tap water

- Flush with deionized or distilled water

- Clean before equipment dries

- Where feasible wrap clean equipment for transport/storage

- Method will vary with inorganic/organic analytes 
- Inorganic- - After rinse detergent, wash with $5 \% \mathrm{HCL}$ solution, rinse with DI water, methanol

\section{PRE-SAMPLING WELL PURGING}

- Measurement of well-water volume

- Selection of purge method and pump placement

- Removal of predetermined number of well-water volumes

$\bullet$

\section{PURGE VOLUME CALCULATION}

1. Measure depth to water from reference point

2. Measure or provide well depth (from measuring point) from well log

3. Calculate length of water column (Depth to water - well depth)

4. Calculate casing volume, in gallons (Length of water column $\mathrm{x}$ well diameter)

5. Calculate purge volume (casing volume $\times 3-5$ )

1. Depth to water $=10 \mathrm{ft}$

2. Well depth $=20 \mathrm{ft}$

3. Water column $=10 \mathrm{ft}$

4. Casing volume $=10 \mathrm{ft} x, 163$ gallons/ft (for 2 -inch diameter well) $=1.63$ gallons

5. Purge volume $=1,63$ gal $\times 3=4.9$ gallons

\section{PURGE METHODS AND STANDARD PROTOCOLS}

- Lowering pump - continuous or two step

- Fixed position just above open interval

- Micro-purge

- Dedicated pump - water withdrawn just above or within sample interval

- Use on of these withdrawal methods in conjunction with well-water volume and field characteristic stability criteria 


\section{Standard protocols and recommended procedures for conducting and assessing well purging (adapted from Lapham and others, 1995)}

1. Purge minimum volume of water equal to 3 times the casing (or wellbore) volume (flow rate $2-3 \mathrm{gal} / \mathrm{min}$ or less)

2. Reduce flow rate to $0.1-0.5 \mathrm{gal} / \mathrm{min}$ during later part of purge period (5-25 minutes). Lower flow rate will approximate sample collection rate.

3. During purging, monitor $\mathrm{pH}$, temperature, specific conductance, dissolved oxygen (DO), Eh, particularly during final 15-25 minutes. Monitor turbidity (TU) near the end of purging, particularly if sampling for trace elements. Note and record water clarity,

4. The well is considered purged after at least 3 casing volumes have been removed and values of the monitored field parameters between 3-5 successive measurements separated by about 3-5 minute intervals or 3 successive _ well volumes are within the allowable differences specified below:

\section{Parameter}

$\mathrm{Ph}$

Temperature

Specific conductance

DO

Eh

TU

\section{Allowable difference or value}

+-0.1 units (+-0.05 units if instrument capable of display

$+-0.2^{\circ} \mathrm{C}$

$+-5 \%$, for $\mathrm{SC}<-100 \mathrm{us} / \mathrm{cm}$

$+-3 \%$, for $\mathrm{SC}>100 \mathrm{us} / \mathrm{cm}$

$+-0.3 \mathrm{mg} / \mathrm{L}$

$+-5 \%$

$+-10 \%$ for TU < 100 NTU; ambient TU

Is $<5$ NTU for most ground-water

Systems; visible TU > 5 NTU

(or check visually for water clarity)

- If measurements appear stable, either the last or median value of the last 5 measurements for each parameter (except pH, use last) is recorded; proceed with sampling

- If criteria for stability is not achieved, purging is continued until either measurements stabilize or equivalent of 5 or more wellbore volumes have been removed; note unstable parameters in field notes

- If measurements remain unstable, determine study objectives/sampling priority. If sample, note parameters that are not stable 


\section{OTHER PURGE CONSIDERATIONS}

- Lack of stability may indicate problems with well design or purge set-up and method

- Generally, Eh will stabilize last, followed by DO.

- If feasible water level in well SHOULD NOT be drawn down below top of open interval. Water levels can be monitored by e-tape or transducer and data used with flow rate to compute specific discharge

- Flow rate should be measured: use a gallon jug, 5-gallon pickle bucket, etc.

- Micro (low-flow) -purging at flow rates that approximate $0.1 \mathrm{gal} / \mathrm{min}$ theoretically withdraw water along a single flow line and do not induce negligible drawdown in the well. Purge volumes are measured in tubing volumes and pumps are located in the open interval of the well.

- For continuously pumped wells flush lines and pressure tank (if present); record field measurements 5 times at regular intervals prior to sampling; 3-5 casing volumes not required

- For low-yielding wells empty the well once and wait for $90 \%$ recovery

\section{WATER-QUALITY SAMPLING PROTOCOL}

- Monitoring wells

- Use a submersible sampling pump (portable or dedicated) or a bailer appropriate for environmental sampling. If possible avoid the use of bailers; if necessary use with bottom-emptying device.

- Collect sample at a flow rate of about 0.1 to $0.5 \mathrm{gal} / \mathrm{min}$. For volatile organic compounds (VOC's a rate $<0.5$ is recommended. A flow rate of $0.1 \mathrm{gal} / \mathrm{min}$ is not feasible for many pumps. Use a flow rate of about $0.1 \mathrm{gal} / \mathrm{min}$ for lowflow sampling. Constant rate, non-turbulent flow for all samples.

- Store bottles at the ambient temperature or less of ground water (about $55^{\circ} \mathrm{F}$ )

- Use laboratory, quality-assured and cleaned bottles that are securely capped

- Select proper bottle type for sample (polyethylene, baked glass, amber glass, etc.). Sample bottles for inorganic compounds are rinsed with sample water (unfiltered or filtered, as required) immediately before sample collection; Do not rinse glass bottles for organics.

- If concerned with atmosphere, bottle can be filled to overflowing from bottom, otherwise fill to shoulder. Fill at non

- Samples for volatile organics should contain NO AIR. Check for air. If present discard or empty bottle and recollect sample. 
- If necessary, filter sample with in-line filter. Invert and pre-flush filter with sample water; rinse with DI water. Generally use 0.45 um filter. Project objectives dictate pore size and type of filter. Report as FILTERED, not DISSOLVED.

- Filtering may be done to: provide comparability with historical record; compatibility with other sources of data; removal of well-installation and samples withdrawal artifacts (increases reproducibility); remove source of bias (suspended carbonate may interfere with alkalinity measurements); project objectives (geochemical modeling). Often samples collected by regulatory agencies are NOT FILTERED in order to provide an indication of the drinking-water quality at point of distribution.

- Collect the filtered anion and alkalinity sample sequentially

- Preserve samples, as necessary (acidification, chilling to $<4^{\circ} \mathrm{C}$ ). Different protocols require acidification before or after sample collection.

- Preservatives maintain the integrity of the sample (retard biologic degradation of VOC's; keep metals in solution)

- After decontamination of sampling equipment, periodically (about 1 per 20 samples, including before the start of sampling, following sampling of a highly contaminated well, and from each type of pump used). Use the standard decontamination procedure to collect the field blank.

- Water-supply wells

- Reduce flow rate to $0.5 \mathrm{gal} / \mathrm{min}$ or less. Select a sample location before water treatment equipment and pressure tanks. Avoid use of threaded and dirty/rusty taps. Pre-clean tap with non-phosphate detergent and rinse before sampling, if necessary.

\section{SAMPLING EQUIPMENT}

Ground-water-sampling pumps used in water-quality studies require several essential characteristics:

- Submersible, positive displacement: gear or worm drive

- Constructed of inert materials: stainless steel and Teflon

- Low flow rate (<1 gal/min), preferably variable between 0.1 and about $2 \mathrm{gal} / \mathrm{min}$

Other sampling devices may include bailers (Teflon) and peristaltic pumps, which. If possible avoid use of these devices, particularly when sampling VOC's. Bailers agitate samples and expose them excessively to the atmosphere. Peristaltic pumps rely on suction (negative pressure) to extract water samples. In some cases, these devices must be used - bailers where water levels in wells are too low to withdraw sample with a submersible pump, water in well is very turbid or highly contaminated, particularly with hydrocarbons that may foul pump; peristaltic pumps where well diameter is too small for 
Chapter 4

Ground-Water-Data Collection

submersible pump (although pump is limited sampling where depths to water are less than about $29 \mathrm{ft}$.). 


\section{SAMPLER PERFORMANCE - ORGANIC SAMPLES \\ EFFECIENCY OF SAMPLERS TO PROVIDE RECOVERY OF COMPOUNDS AT 20, $100 \mathrm{UG} / \mathrm{L}$}

- RECOVERY $>95 \%$

Grunfos Redi-Flo2

Fultz SP-300

Bladder pumps

Bennett Pump

Keck SP-81

- RECOVERY $<95 \%$

Teflon bailer (top emptying as low as $85 \%$ )

\section{SAMPLER PERFORMANCE - INORGANIC SAMPLES \\ SAMPLERS PROCESS DI WATER WITHOUT CONTRIBUTING INORGANIC CONSTITUENTS AT CONCENTRATIONS OF $1.0 \mathrm{UG} / \mathrm{L}$}

\section{RECOVERY $>95 \%$}

Grunfos Redi-Flo2

Fultz SP-300

Bladder pumps

Bennett Pump

Teflon bailers

- RECOVERY $<95 \%$

Teflon bailer (top emptying as low as $85 \%$ )

- Various types of pumps are used in large diameter water-supply wells ( $>4$ inch diameter). In most cases, turbine pumps will be found in high-capacity industrial and public-supply wells and submersible positive displacement pumps will be found in low-capacity (about 5-30 gal/min) domestic wells. If possible, avoid wells with jet pump when selecting wells for sampling.

- Submersible pump

- Piston pump

- Centrifugal pump

- Jet pump

\section{PUMP SELECTION CRITERIA}

- Materials -- Consider "Enemies" (select pump with inert materials: SS, Teflon)

- Water withdrawal mechanism - Consider "Enemies" (select positive displacement)

- Flow rate - Consider "Enemies" (low flow: $0.1-2 \mathrm{gal} / \mathrm{min}$ ); variable rate best

- Cost - $\$ 2500-\$ 5000$ (bailers about $\$ 200$ )

- Portability

- Power source (portable battery pack, 12V car battery, 115-VAC, 220-VAC compressed air) Variable source preferred 


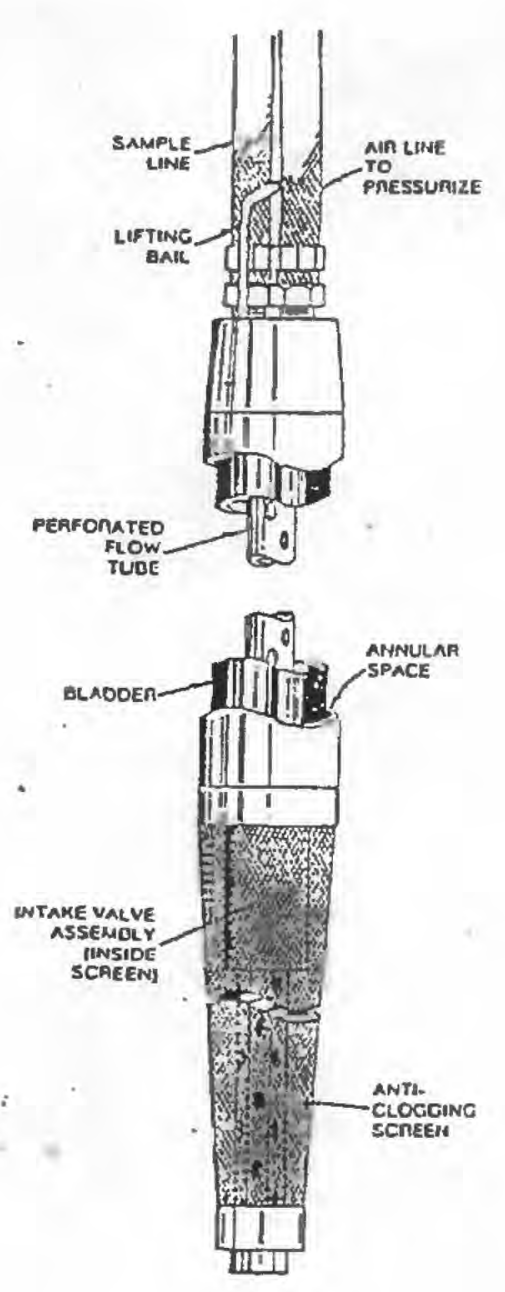

Figure.-Schematic of bladder pump (typically dedicated to well)

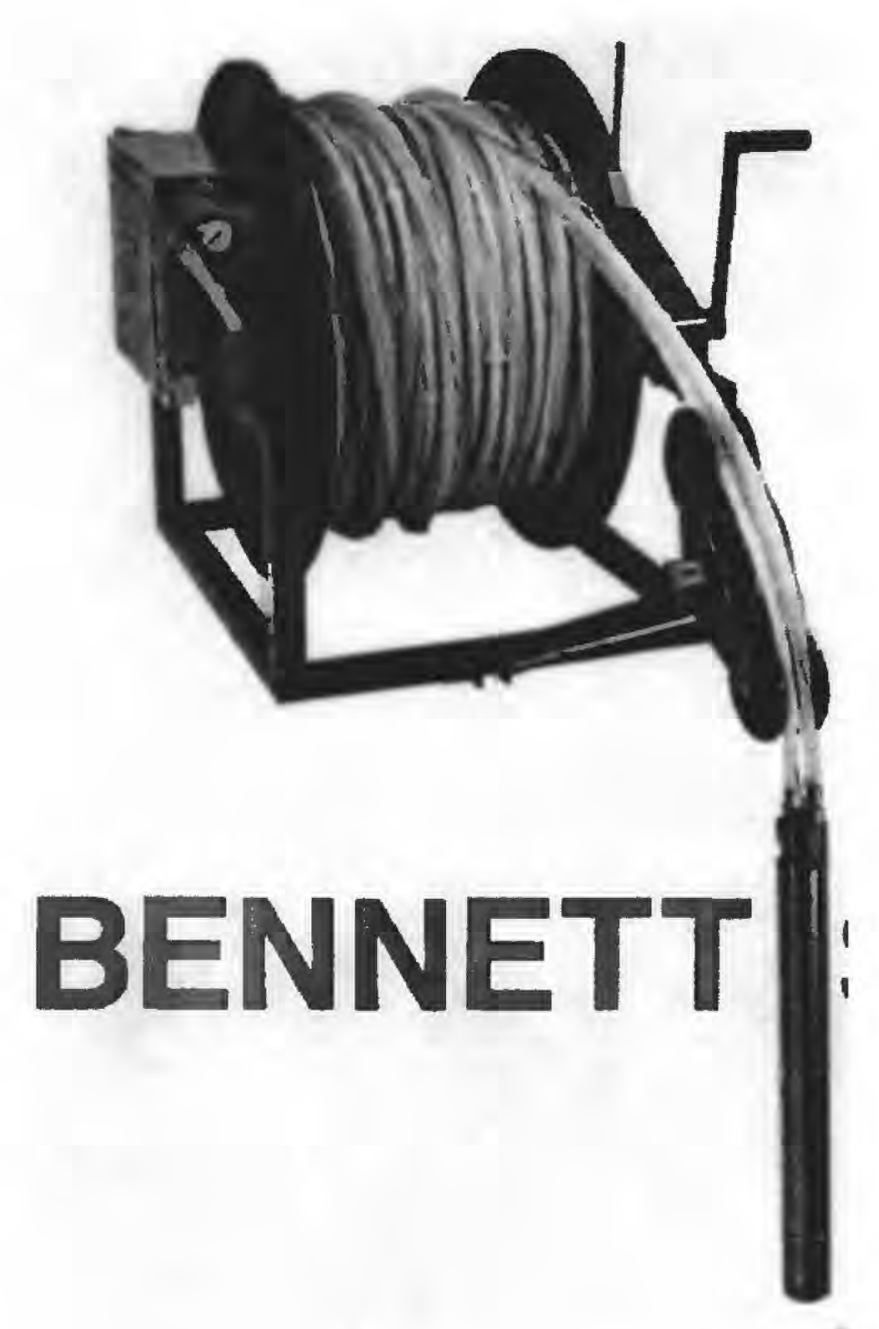

Figure. - Submersible piston pump

\section{SAFETY CONSIDERATIONS}

- Wear protective clothing (PPE) if sampling potentially hazardous ground water

- Level A-D

- Select proper glove for contaminant sampled for (natural rubber, neoprene, PVC, nitrile)

- Monitor air quality at well head with organic vapor or gas-specific analyzer, if sampling in potentially hazardous setting (photoionization/flame ionization, cyanide detectors)

- Consider medical monitoring, immunizations, if appropriate

- Prepare site-hazards analyses/safety plan with information of nearest hospital 


\section{QUALITY-ASSURANCE/QUALITY-CONTROL ISSUES}

\section{QUALITY CONTROL ALONG WITH QUALITY ASSURANCE AND DATA VALIDATION ARE PARTS OF A FORMALLY ESTABLISHED PROCESS INTENDED TO ENSURE DATA COLLECTED FOR PROJECTS ARE:}

1) Of such a quality that they are useful to address project goals

2) All information regarding data quality are documented and defensible

- Data "quality" refers to the magnitude of error associated with a data set and uncertainty relative to end-use requirements and is expressed in terms of precision, accuracy, and representativeness

- Quality assurance involves a management QA plan and auditing results as the project evolves

\section{QUALITY ASSURANCE BEGINS AT THE START OF THE PROJECT!}

\section{BASIC QUALITY ASSURANCE PRINCIPLES}

- All activities are controlled by project objectives (USGS SOP's provide methods for meeting most project objectives)

- Field protocols are designed to ensure that project objectives are met

- Quality assurance allows us to document that we have met project objectives PROJECT OBJECTIVES CONTROL:

- Strategy for Quality Control - types, distribution, and frequency of QC samples and analytical methods

- Field Strategy - where, when, and what to sample

- Methods and Equipment - wells, pumps, filtration, measurements, preservation

- Documentation - have we met project objectives

\section{COMPLETING SUPPORTING DOCUMENTATION}

Ground-water studies require careful and complete documentation of site information and criteria and methods used for the selection and installation of wells, and collection of geologic, geophysical, hydraulic, and water-quality data and samples. Such documentation is integrated throughout each process. 
Systematic documentation is:

- a basic component of quality assurance-provides the basis for evaluating the utility of data for a specific objective

- aids in interpretation of data

- provides a historical reference for future use of the data or sampling location (well)

For example, documentation of a well site involves the establishment of a file that includes paper and electronic records that describes the field verified location with map and photographs of site; available construction information (commercial driller's permit on file w/ State or contracted driller's log. Commercial log may contain information on the geologic units and thicknesses, water level, well materials and position, specificdischarge tests, installed pumps), geophysical logs; water-level and water-quality data; land-use information; and permission agreements

USGS establishes an electronic well record in the National Water Information System (NWIS) data base. Other government agencies (ISGS, IEPA) maintain their own data bases.

\section{USEFUL REFERENCES:}

Wood, W.W., 1981, Guidelines for collection and field analysis of ground-water samples for selected unstable constituents: U.S. Geological Survey Techniques of WaterResources Investigations of the United States Geological Survey, Book 1, Chapter D2, 24 p. 


\section{AQUIFER TESTING}

Introductory text (Introduction, Design, Field Observation) for this section on aquifer testing is from the University of Arkansas Field Hydrogeology course notes prepared by Van Brahana, U.S. Geological Survey)

\section{References:}

Driscoll, F.G., 1987, Groundwater and wells: Johnson Division, St. Paul, Mn. chapters 9 and 15

Stallman, R.W., 1968, Aquifer-test design, observation and data analysis:

U.S. Geological Survey Techniques of Water-Resources Investigation of the United States Geological Survey, book 3, chapter B1, 26 p.

Kruseman, G.P. and de Ridder, N.A., 1991, Analysis and evaluation of pumping test data: International Institute for Land Reclamation and Improvement, Wageningen, The Netherlands, pub. 47, $377 \mathrm{p}$

Fetter. C.W.,1988, Applied hydrogeology, Merrill Publishing Co.: Columbus, Ohio, $592 \mathrm{p}$.

Bouwer, H. and Rice, R.C., 1976, A slug test for determining hydraulic conductivity of unconfined aquifers with completely or partially penetrating wells: Water Resources Research, v. 12, no. 4, p. 423-428.

\section{INTRODUCTION}

Aquifer tests are controlled experiments in which the rock hydraulic properties are determined in the field. Numerous tests have been developed for different hydrogeologic conditions. Regardless of the particular formula used, there is a basic rationale that is common to all aquifer tests, and each test has a specific set of conditions that describe its proper use. Recognition of this common rationale greatly reduces the complexity of data handling and processing.

Aquifer tests typically may be considered as having three main components, 1) design, 2) field observations, and 3) data analysis. Each is important to the ultimate objectives of quantifying the hydraulic properties, boundary determination, indication of the general type of aquifer, and hypothesis testing. Successful aquifer tests typically have the following attributes:

1. The geology of the site is known (driller's logs, geophysical logs, mapping)

2. The construction of the wells is known (width, depth, materials used, development)

3. Test design is consistent with measuring important aquifer properties

4. All measuring devices (time, discharge, and water level) are calibrated and verified

5. Discharge is accurately monitored

6. Prepumping variations in water levels are defined and explained, as are atmospheric and climatic effects on water levels during the time of the test

7. Data are plotted during the test 
8. Testing rationale is flexible to accommodate changing conditions or anomalous responses

9. Data from the recovery portion of the test are compared to the pumping portion 10. Data are analyzed completely

11. All implied aquifer properties are reasonable, and the conceptual model is valid

\section{DESIGN}

The purpose of design is to improve the chance that a test will yield acceptably accurate values of the hydraulic coefficients (Stallman, 1968). Tests can be expensive (from several thousand dollars to greater than $\$ 1,000,000$ ), and use of existing wells as data-observation sites is frequently done to keep costs to a minimum. Site evaluation, including inventory of wells and springs in an area is typically the first step in test design. Verify that potential data-collection sites are usable. Many existing wells have poor or no access to measure water levels because of pump wires, plumbing, small casing diameter, and other practical problems that prevent access to measure water levels. If wells other than the pumping well (control well) are inadvertently stressed during the test period, the resulting water levels will reflect a total response, and the calculated hydraulic properties of the aquifer will not be accurate.

Commonly used aquifer test and analysis methods are:

- Theis method

- Jacob Straight-line method

- Step-drawdown method

- Recovery method

- Slug test

Because of time and other limitations of this course, we will focus on single-well slug tests.

\section{FIELD OBSERVATION}

An aquifer test is an in situ field experiment in which the field hydrogeologist measures numerous aquifer responses to a known stress. The responses are water levels, and the stresses are either injection or withdrawal of known quantities of water or other material volumes from the aquifer. Mud, rain, bitter cold, insects, faulty equipment, and other environmental distractions may compete for the hydrogeologists' attention during the test. As much as possible, prepare fully prior to the test. Record data carefully, and graph and evaluate data during the test, for it's much easier to locate problems and explain anomalous hydraulic response at the time than at some later time in the office. 
Data required to analyze an aquifer test are shown in the following table. Acceptable levels of tolerance for each measurement are shown in brackets.

1. Discharge from the pumped well [+- 10\%]

2. Depth to water in pumped and observation wells referenced to measuring point [+-.01 ft]

3. Radial distance from pumped well to each observation well [+-0.5\%]

4. Description and sketches of each measuring point $\{+-0.01 \%]$

5. Elevations of measuring points [variable, depending on if the measuring point is surveyed, or if it is calculated using estimated topo elevations]

6. Total depths of all wells [1\%]

7. Completion data for all wells (casing, screen, and other dimensions of length and width and materials [+-1\%]

8. Location of all wells in plan [variable, but generally $+-1 \%$ ]

Data types 2 through 8 are collected prior to the test; data types 1 and 2 are monitored throughout the test, along with the time of measurement of each. Numerous test forms have been developed that simplify water-level data, time, and discharge collection.

\section{MULTIPLE-WELL AQUIFER TESTS}

- Consist of measurement of a water-level response over time and (or) space (in one or more observation wells) to a known stress (pumping). The observed response is matched to a computed (ideal) response ad the corresponding hydraulic properties are determined. These properties are not measured directly.

- Can be used to determine horizontal hydraulic conductivity and storage of unconfined or confined aquifers with fully or partially penetrating wells. Used for wide range of aquifer permeabilities. Test wells can be used for simultaneous sampling. Tests a relatively large volume of the aquifer; more definitive of the bulk hydraulic properties of an aquifer (within the affected volume of the aquifer)

- Drawbacks include time and expense of the tests and disposal of water pumped during test (a particular concern for tests at hazardous-waste sites-safety, regulatory, cost issues) 


\section{BEFORE TEST BEGINS}

- Objectives of test should be clearly defined

EX: Is the test to define aquifer hydraulic parameters, be used for designing extractionsystem operation, define aquifer interconnection, etc.

- Conceptual model of system should be defined (OTHERWISE, DOOMED FOR FAILURE) EX: Insufficient wells to define aquifer interconnection if that is objective of test (no wells in multiple aquifers or confining unit). If test is to define anisotropy of system, then number of wells insufficient if well network is for an isotropic system.

- Determine optimal number of wells and define background information needed before test begins This is related to defining the objectives of the test. Additional information that should be Defined are things such as nearby pumping centers, controlled surface water projects (such as locks and (or) dams), etc.

- The system of wells used in the test should be monitored before test begins.

This is needed to determine background trends which are necessary to define true effects of the aquifer test versus other outside influences.

- Optimal pumping rates are determined prior to the test.

This is usually done by a step-drawdown test in order to determine the pumping rates which stress the aquifer sufficiently to meet the objectives, without pumping the well dry.

\section{COMPLETION OF TEST}

- Water level data is collected very frequently at the beginning of the test (commonly every 30 seconds) and decreases as the test goes on (to about every 30 minutes after 24 hours).

- Other data collected to support the test, such as discharge measurements of the pump, barometric pressure, etc.

- The tests usually consist of measurements of pumping and then recovery (once the pump is turned off)

- As a general rule of thumb, unconfined aquifers are pumped 3 days (and then recover for 3 days) and confined aquifers are pumped for 24 hours (and recover 24 hours). The periods of testing may be increased or decreased (not usually recommended) depending on the objectives of the test.

- Plot the data out in the field. This means some additional work, but can save re-doing the tests when problems are encountered. 


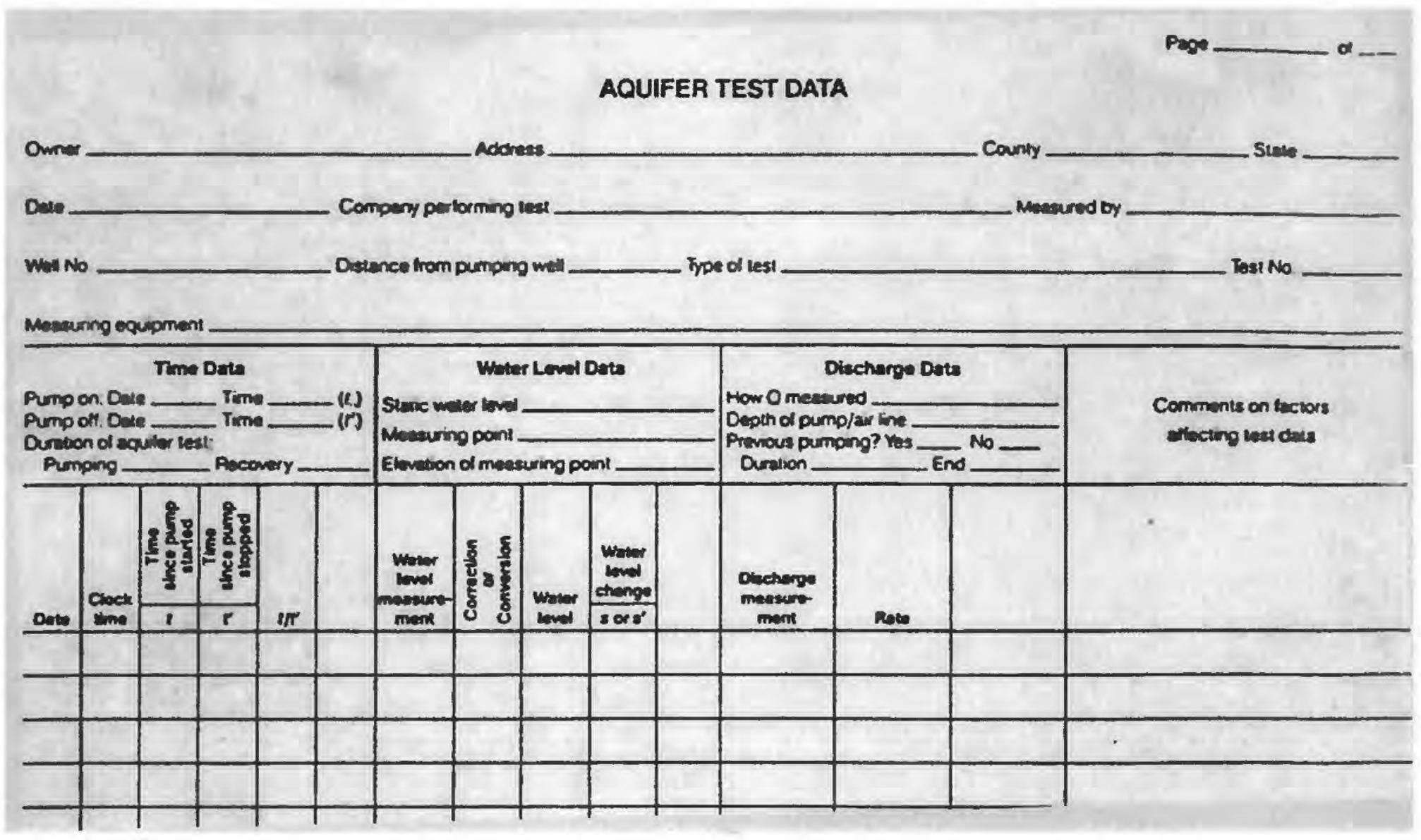

Figure - Example of aquifer-test data sheet

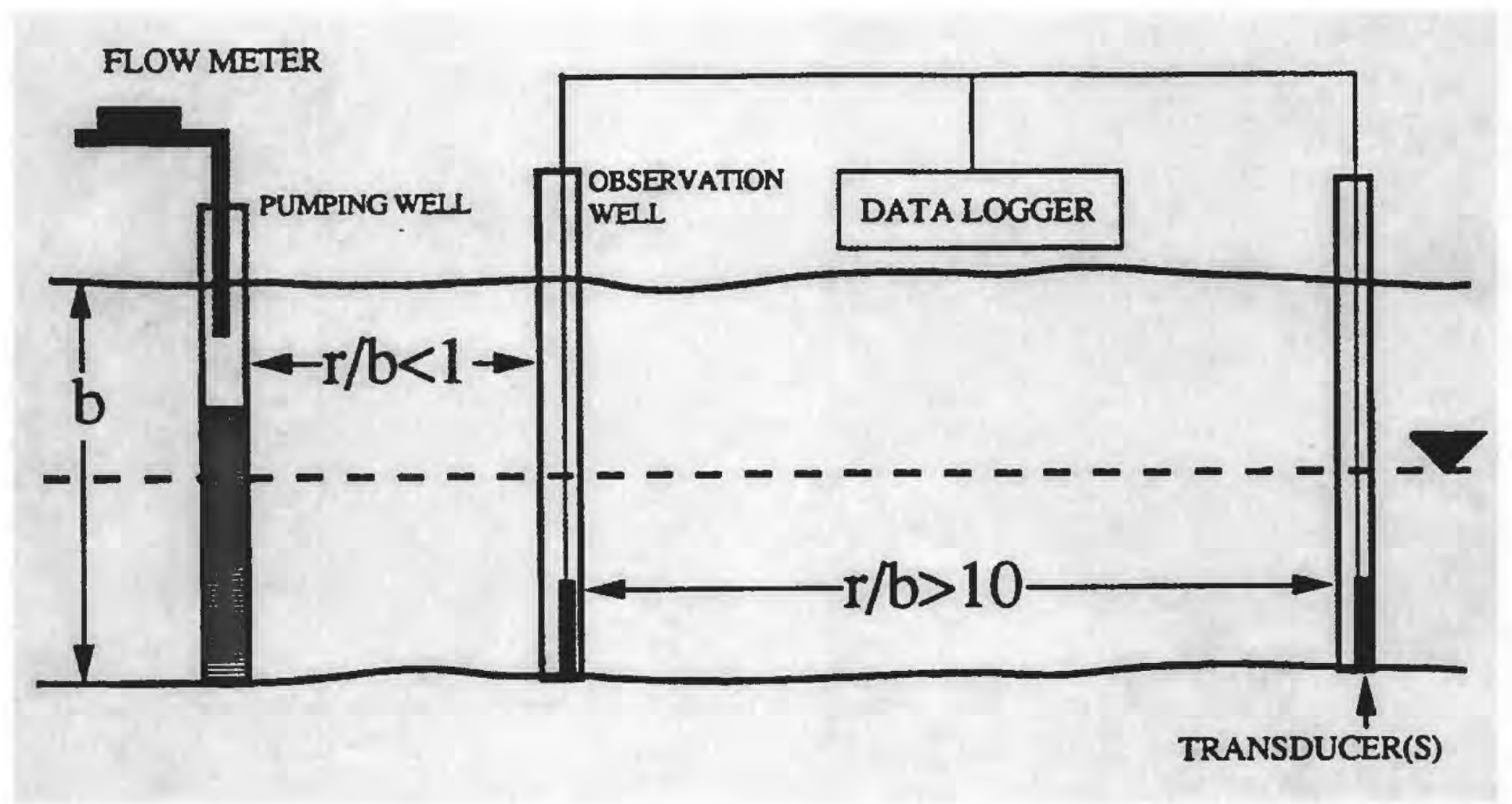

Figure - Suggested minimal arrangement for multiple-well aquifer tests in unconfined aquifers. 


\section{EQUIPMENT FOR AQUIFER TESTING}

\section{- WATER LEVELS}

- Electric and (or) steel tapes

- Pressure transducers and data logger

\section{- WEATHER INSTRUMENTS}

- Rain gage - Measure recharge events. Especially important unconfined aquifers, those with shallow water tables

- Barometers-Measure barometric pressure changes. Especially important for confined aquifers and tests in low permeability environments

- Evaporation pans-Measures evaporation rates. May be important for dry, hot weather with shallow water tables and long-term aquifer tests.

- Temperature-Measures air temperatures. May be important in determining when recharge events occur in freeze/thaw cycles.

- Solar radiation-Measures solar output. May be important in determining when recharge events occur in freeze/thaw cycles and evaporation effects may occur in shallow, unconfined aquifer tests.

\section{- PUMP-DISCHARGE MEASUREMENT DEVICES}

BUCKET AND BTOPWATCH The discharge is measured volumetrically and an estimate is made of unmeasured leakage. The accuracy of this method is dependent on the care with which the measurements are made. Under most circumstances, a measurement within 10 t can be obtained and it is possible to get within 5 under good conditions.

IN-LINE FLOMHETERs The discharge is usually measured by an inline paddlewheel arrangement that activates a counter. Most flowmeters, if properly installed and calibrated, will read between 2 and 8 percent of proper flow rates, although errors as high as 50 percent have been noted. Placement of meters, depth of flow in the discharge line, presence of air in the water, turbulence, and sediment can all play a factor in the accuracy of the flowmeter.

DOPPLER EFFECT FLOWHETER The doppler meter is an electronicacoustic device that uses the same principle that is used in police radar systems. The meter measuree the velocity of particles (e.g. sediment or air bubbles) in the water by measuring the doppler shift in ultrasonic waves bouncing off the particles. This meter is easy to use and can give accurate measurements under the correct conditions. Certain precautions need to be observed to minimize error, including locating the measuring site away from noises and vibrations of the pump, end away from pipe bends and constrictions. The site should be clean of paint, dirt and grease.

TRAJECTORY METHOD This method operates on the principle that the discharge from an end of the pipe will travel a distance horizontally before falling e certain vertical distance (usually 12 inches) proportional to the discharge rate.

FREE DIBCEARGE PIPE ORITICE AISO kNOWn As a CIRCULAR ORIFICE WEIR. Discussed in detail in GROUND WATER MANUAL, U.S. Dept. Of the Interior, Weter and Power Resources Service provided. A piezometer (manometer) tube is attached to the discharge pipe from the pump. The tube is used to measure the water head (pressure) in the discharge pipe which is then used to calculate the pumping rate. This device is generally not used to measure pulsating flow from pumps such as a piston pump.

WEIRB/FLUKEs The idea of a weir (as well as a flume) is to measure llow from a pump by constricting flow and measuring either a head (a weir) or a change in head (a flume). A good source of discussion of weirs and flumes is in Driscoll, 1986, GROUNDWATER AND WELLS, Published by Johnson Division. Accuracies are expected to plus or minus $10 z$ or better. 
- OTHER POSSBLE EQUIPMENT

- Tracers-Usually injected into the aquifer to determine transport rate of contaminants And ground water. May also be used to determine zones of interconnection in complicated aquifer frameworks.

- Downhole flowmeters-Used to measure flow directions in situ in wells. May be used to pinpoint transmissive zones and identify zones with aquifer interconnection.

- In-line water-quality meters-Used to provide qualitative indicators of changes in water Quality during aquifer testing. May be used to provide indications of capturing contaminant plumes, localized changes of water quality, and provide different zones of water quality.

DUPLICATE ALL EQUIPMENT AND DOUBLE CHECK ALL MEASUREMENTS

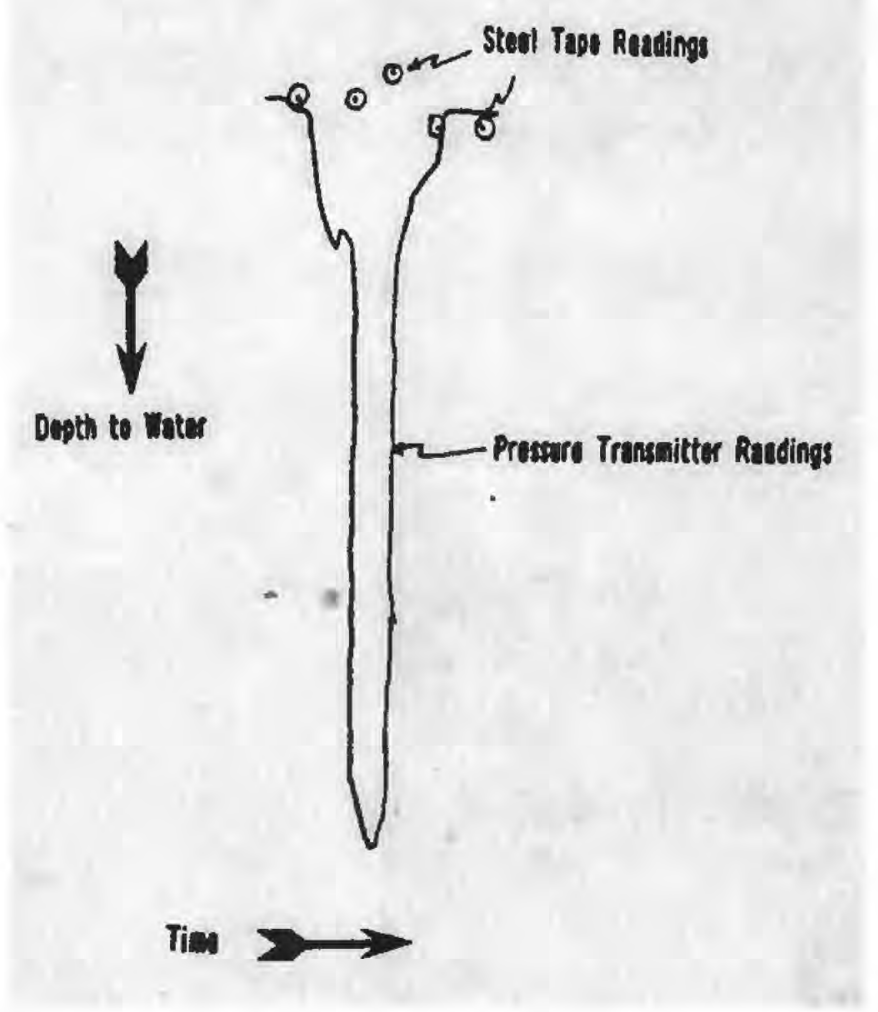

Figure - Illustration of need for double checking measurements.

\section{WATER-LEVEL RESPONSE}

\section{CONE OF DEPRESSION}

As the aquifer test proceeds, a cone of depression is created as the water is pulled from aquifer. The shape of the cone changes with different aquifer characteristics.

General Rule of Thumb: The more permeable the aquifer, the shallower, but more extensive the cone of depression. The less permeable the aquifer, the steeper, less extensive the cone of depression

To determine the aquifer anisotropy, wells that are screened across the same zone are contoured. 


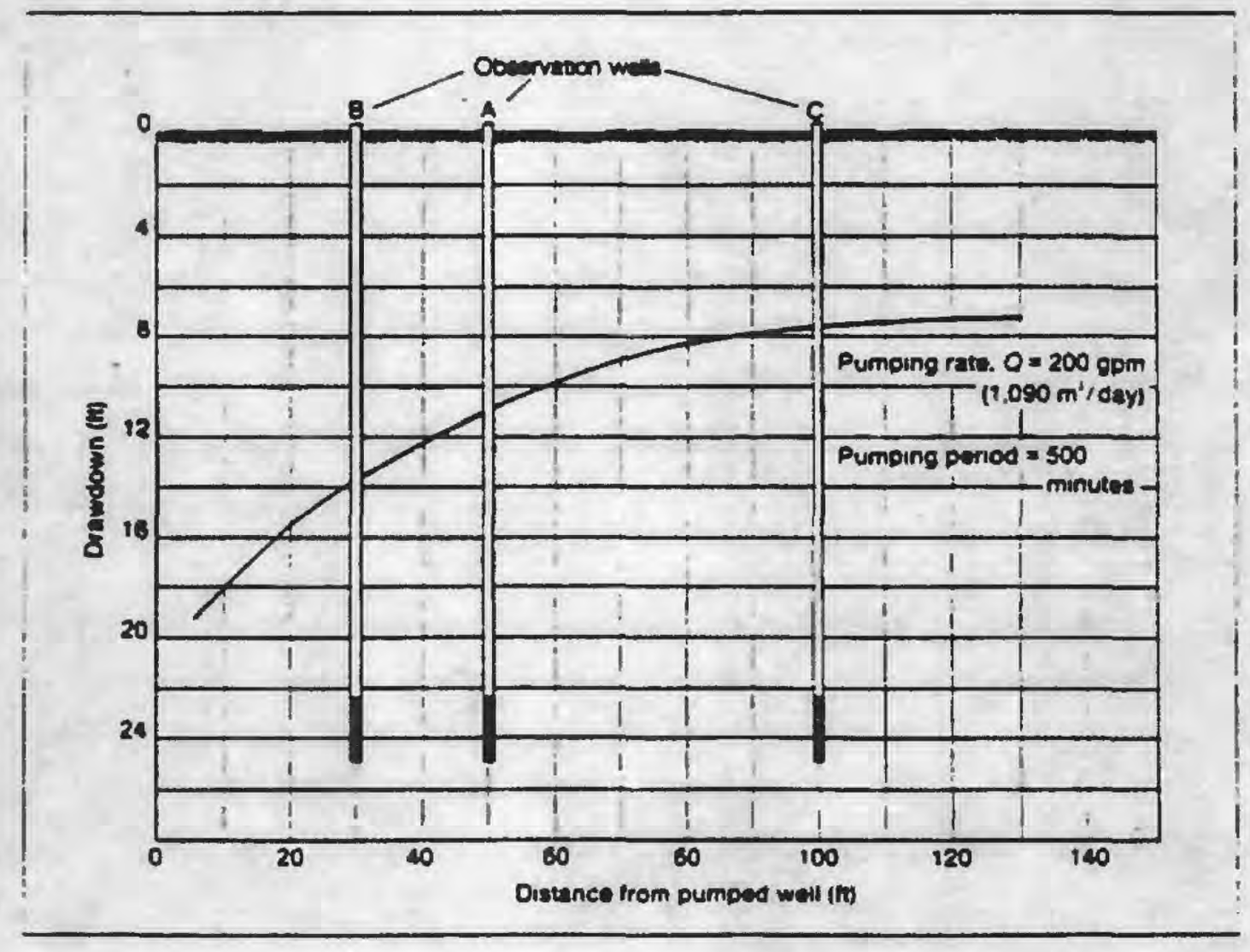

Figure - Cross section of a cone of depression.

Isotropic Aquifer
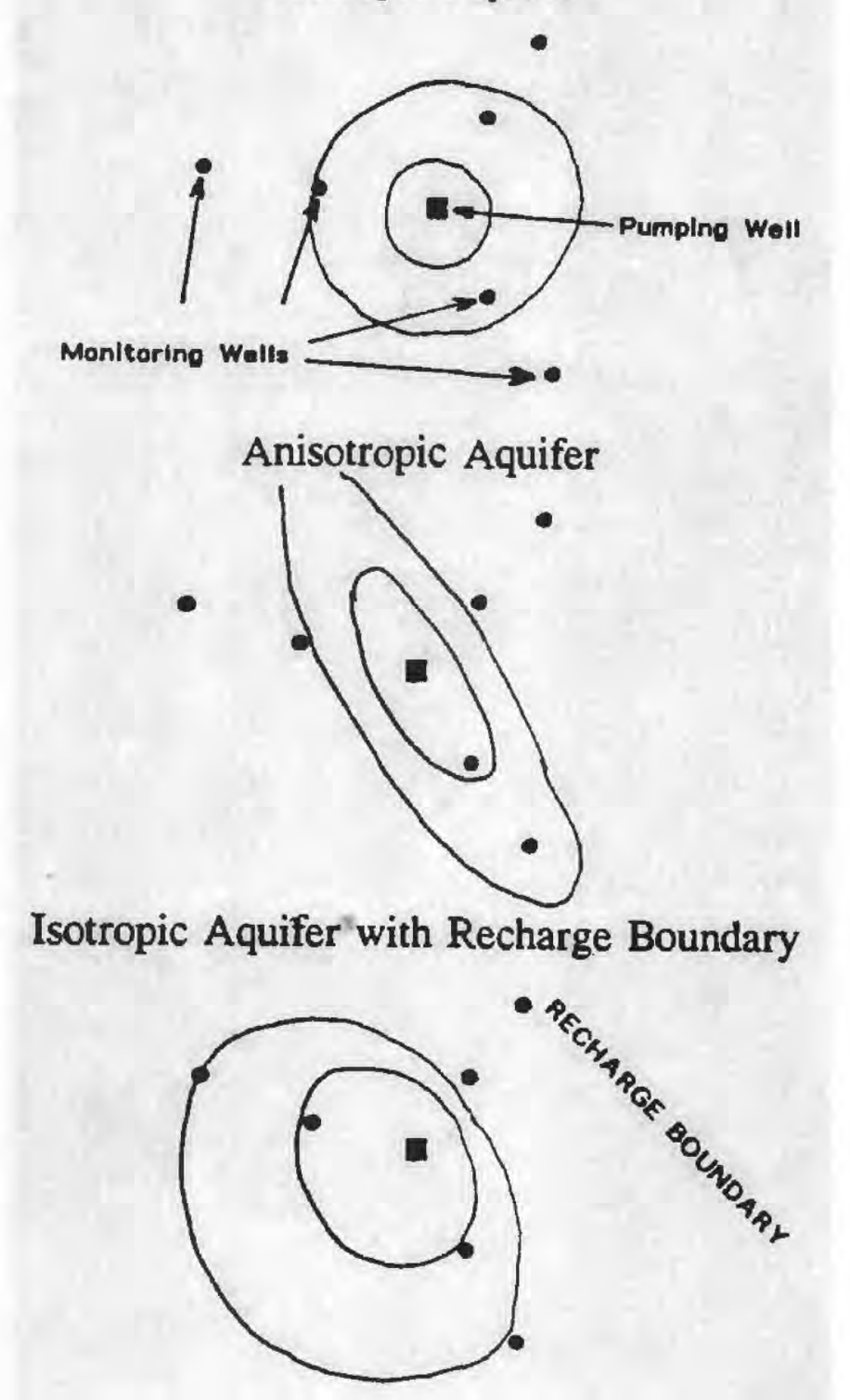

Figure - Conceptual drawings of cones of depression found during multiple-well aquifer tests. 


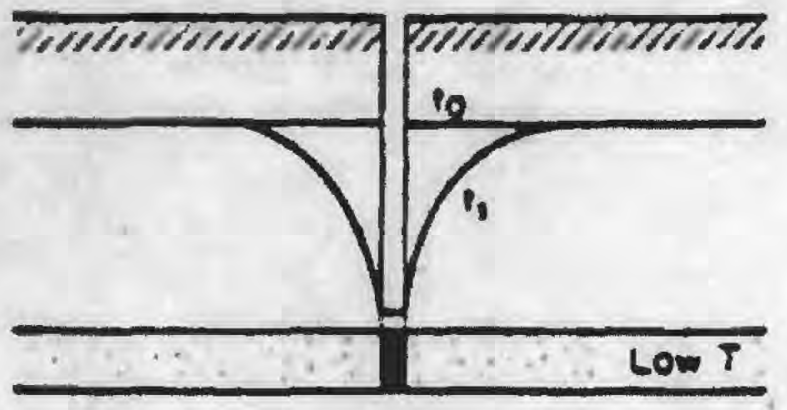

(a)

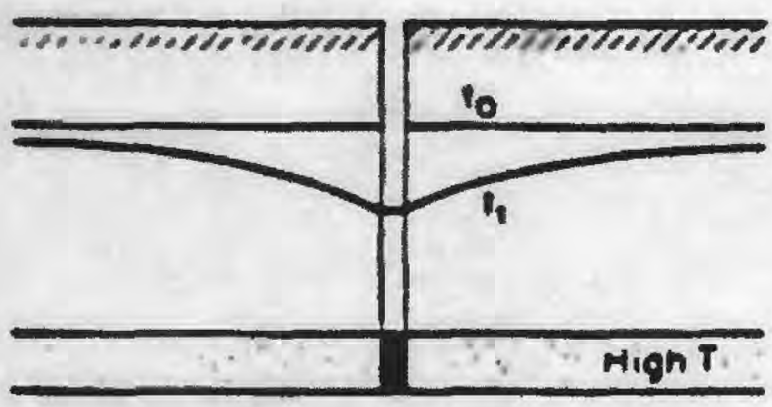

(b)

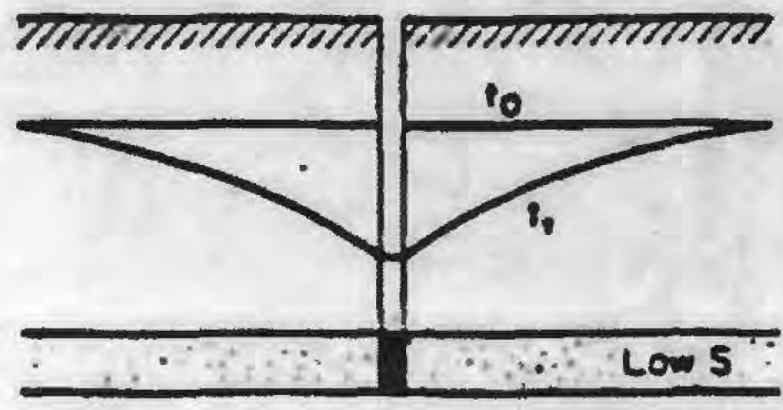

(e)

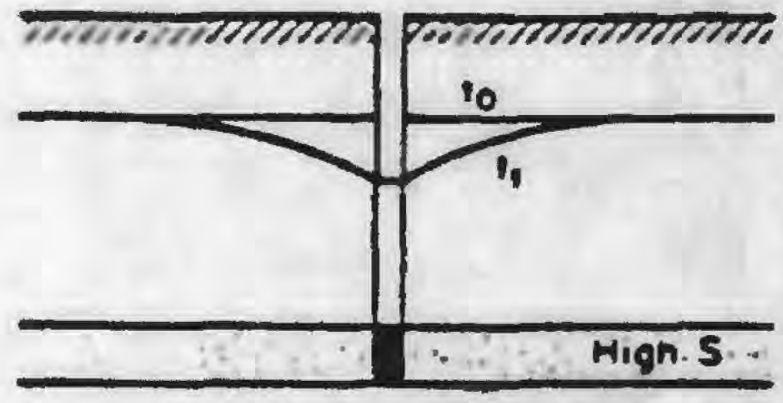

(d)

Figure - Comparison of drawdown at given time for aquifers of: (a) low transmissivity,

(b) high transmissivity, (c) low storage, (d) high storage.

(0)
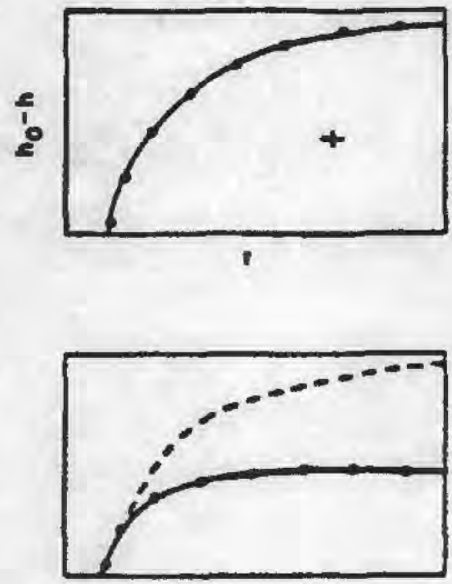

(c)
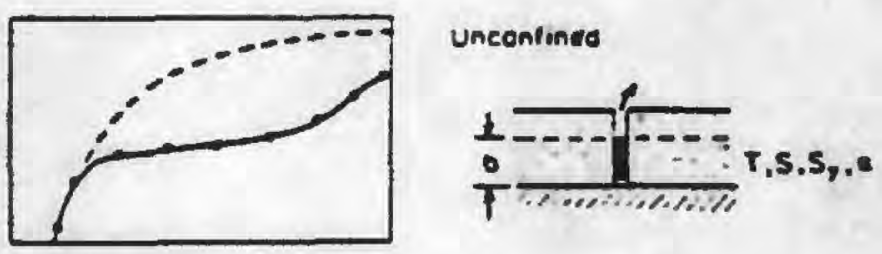

(d)

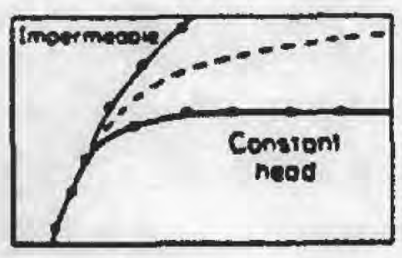

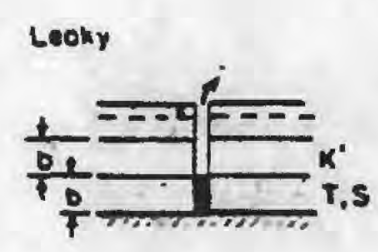

Unconfined

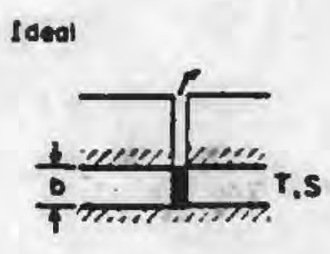

Dounced

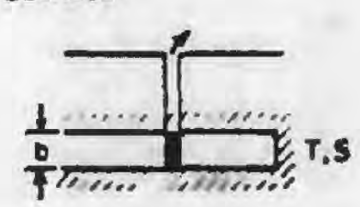

Figure - Comparison of log-log plots of drawdown versus time for (a) confined (ideal),

(b) confined (leaky), (c) unconfined, and (d) bounded aquifers. 


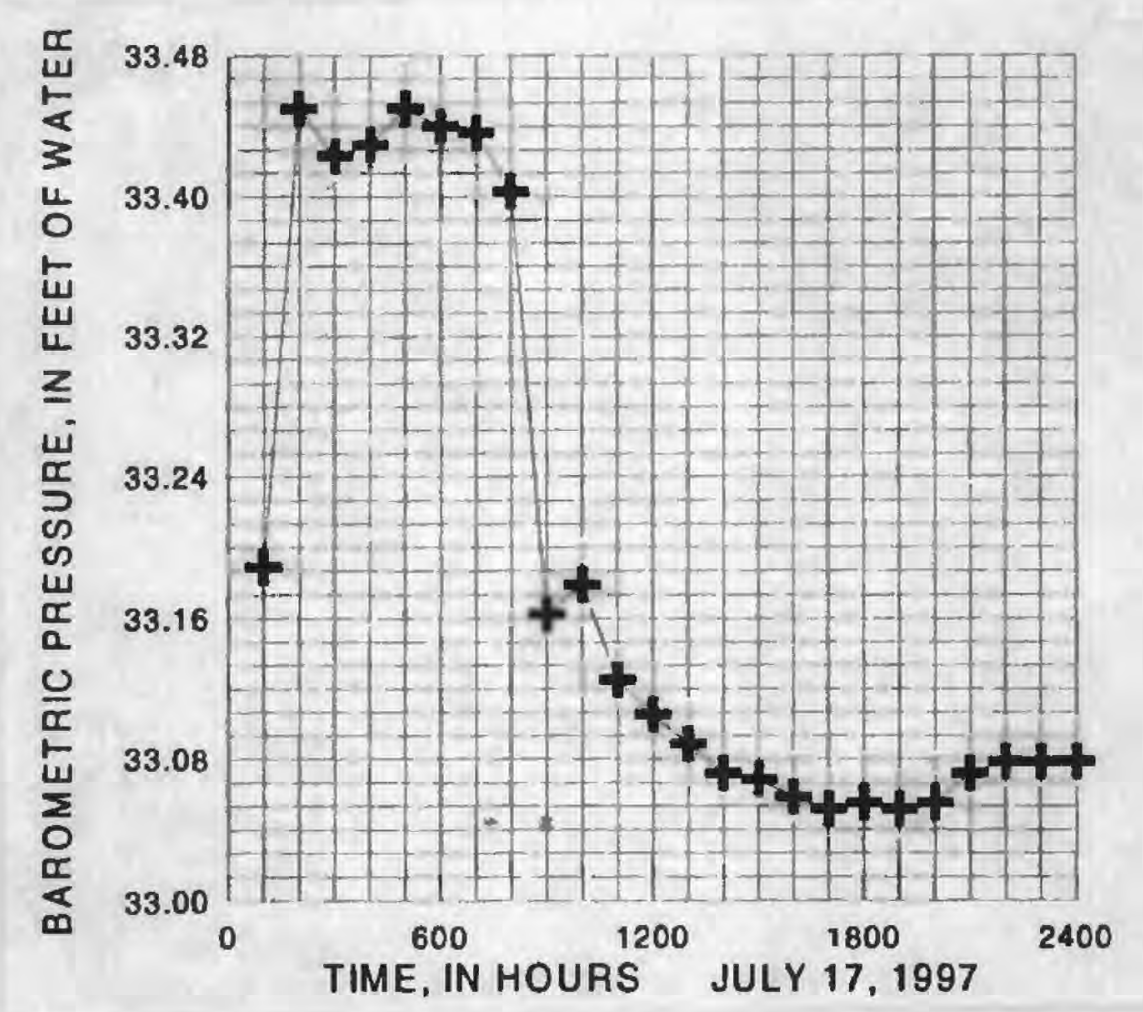

Figure - Example of change in barometric pressure during an aquifer test

Step 1: Plot data on log-log paper at same cycles as type curves

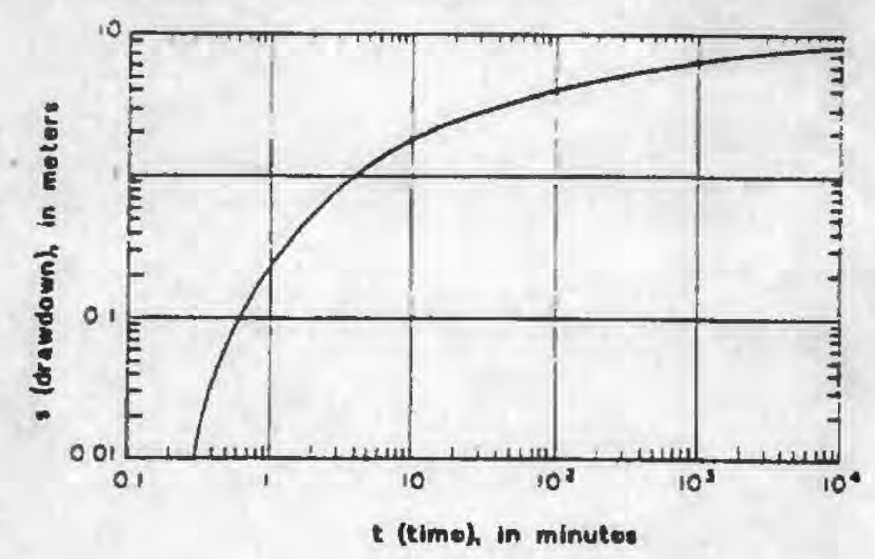

Step 2: Match type curves, determine match points and determine aquifer parameters

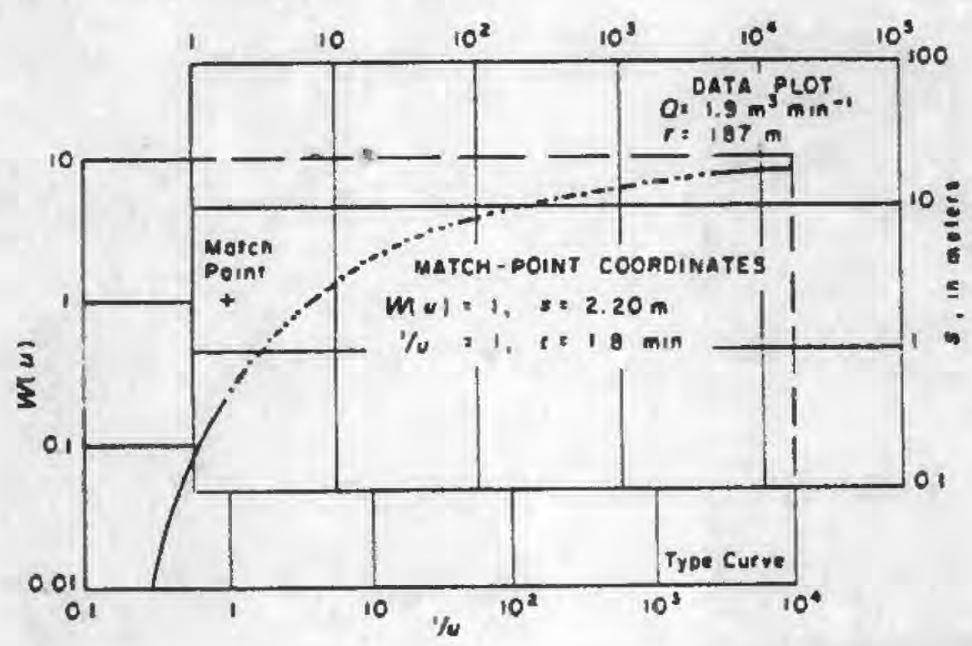

Figure - Plotting of field data and comparing to type curves to determine aquifer hydraulic properties. 


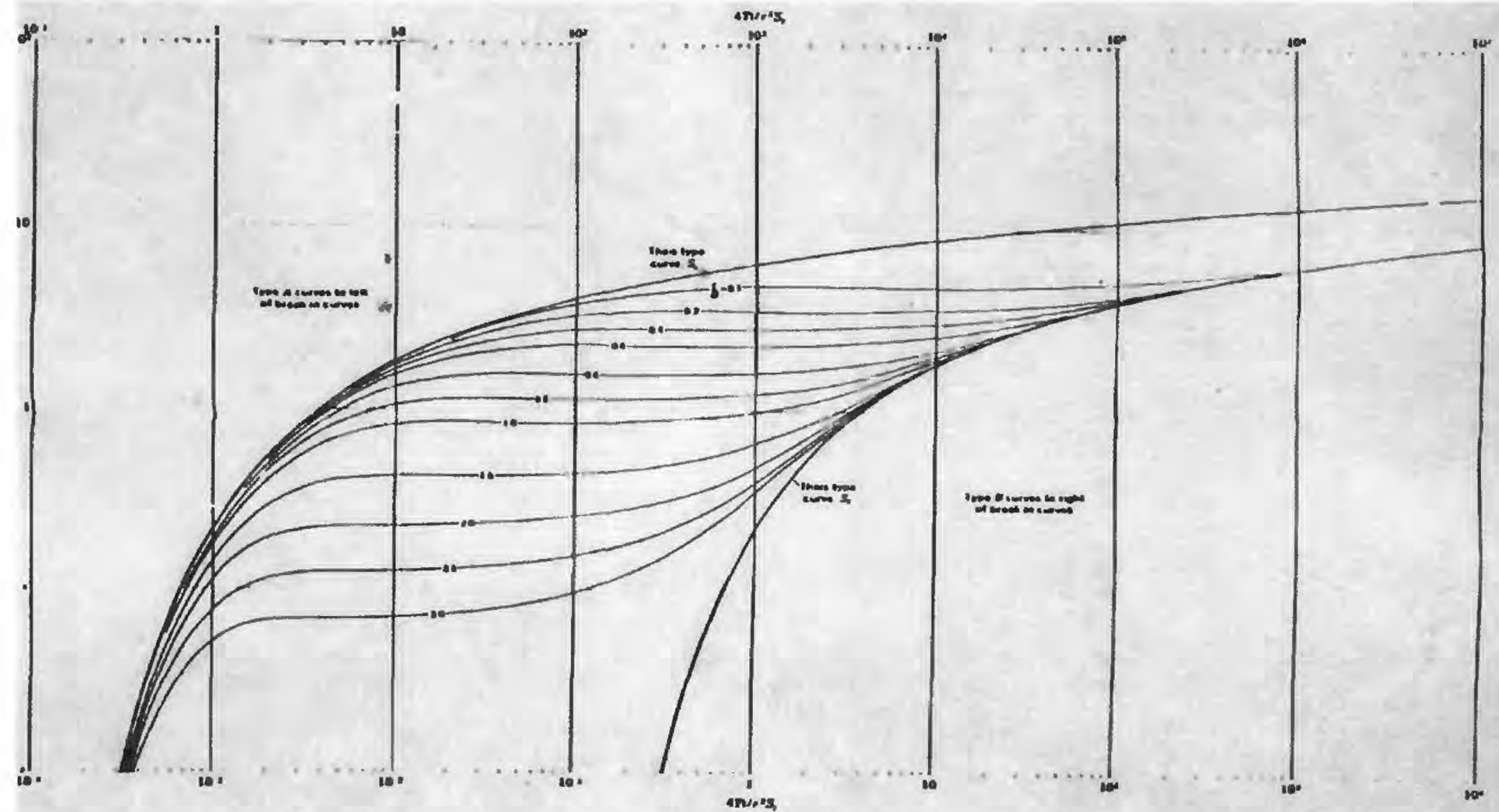

DEI.AYBI)-YIKI.D TYPE (UUVBS

cenconosion on of

Figure - Example of type curves (for delayed-yield system)

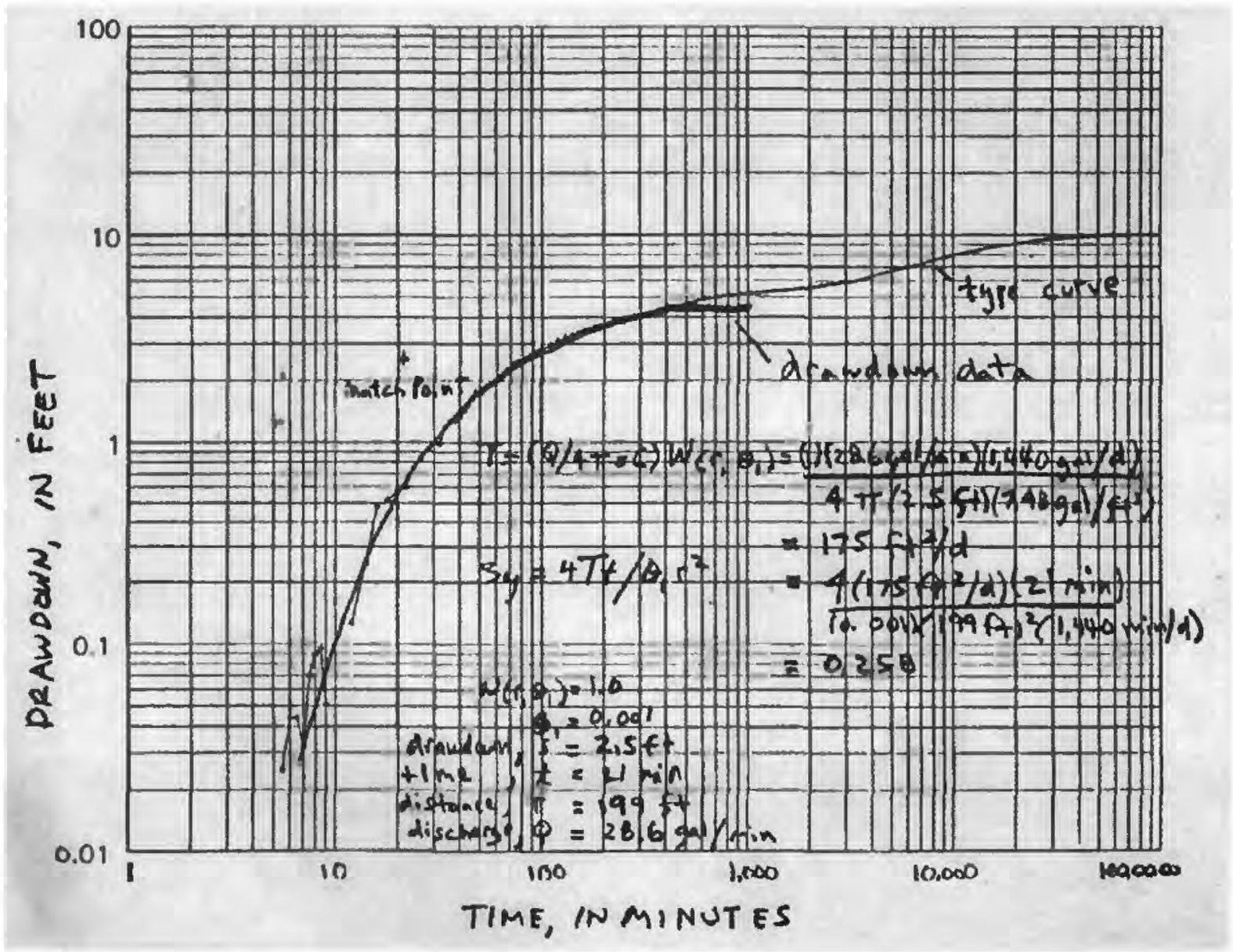

Figure - Example of field data plotted against a type curve (dual-porosity system) 


\section{SLUG TESTS}

Slug tests are conducted in partially to fully penetrating wells to determine horizontal hydraulic conductivity or transmissivity of unconfined or confined aquifers. The tests are highly affected by well construction and borehole conditions and only stress a small volume of the aquifer (generally few feet around the well). Tests assume the aquifer is homogeneous and isotropic (generally assumed true for small volume of aquifer tested).

\section{REFERENCES AND TYPES OF ANALYSES:}

Bouwer and Rice (1976)

Cooper and others (1967)

Hvorslev (1951)

van der Kamp (1976)
For a fully or partially penetrating well in either a confined or unconfined aquifer For a fully penetrating well in a confined aquifer

For a well with various geometries

For highly permeable aquifers that result in oscillatory water-level response

Slug tests involve removing, adding, or displacing a quantity of water or other known volume in a well or peizometer and monitoring the change in water level over time.

\section{TWO PHASES OF A SLUG TEST}

- Falling Head: Produce a rise in the water level and monitor the water-level decline.

- Rising Head Produce a drop in the water level and monitor the water-level rise.

\section{TYPICAL METHODS OF PRODUCING CHANGE IN WATER LEVEL} DURING A SLUG TEST

- Insertion/removal of a solid cylinder of known volume into/from the water column (most common - use a solid PVC cylinder)

- Addition of a known volume of water to the well (seldom used)

- Use of compressed gas to induce a water-level decline, then release the gas pressure while monitoring the water-level rise (used with moderate frequency; good for highly permeable aquifers, but not good for low permeability aquifers or for water-table wells) 


\section{SLUG-TEST ADVANTAGES OVER MULTIPLE-WELL TESTS}

- Less expensive to conduct

- Less equipment needed

- Take less time to set up and obtain data

- Data interpretation and reporting time is shorter

- Tests can be done in small diameter wells

- There is no water to dispose of

\section{SLUG-TEST DISADVANTAGES}

- $T$ and $\mathrm{K}$ estimates are less certain

- Test only a small volume of the aquifer

- May be applicable only to lower yielding aquifers

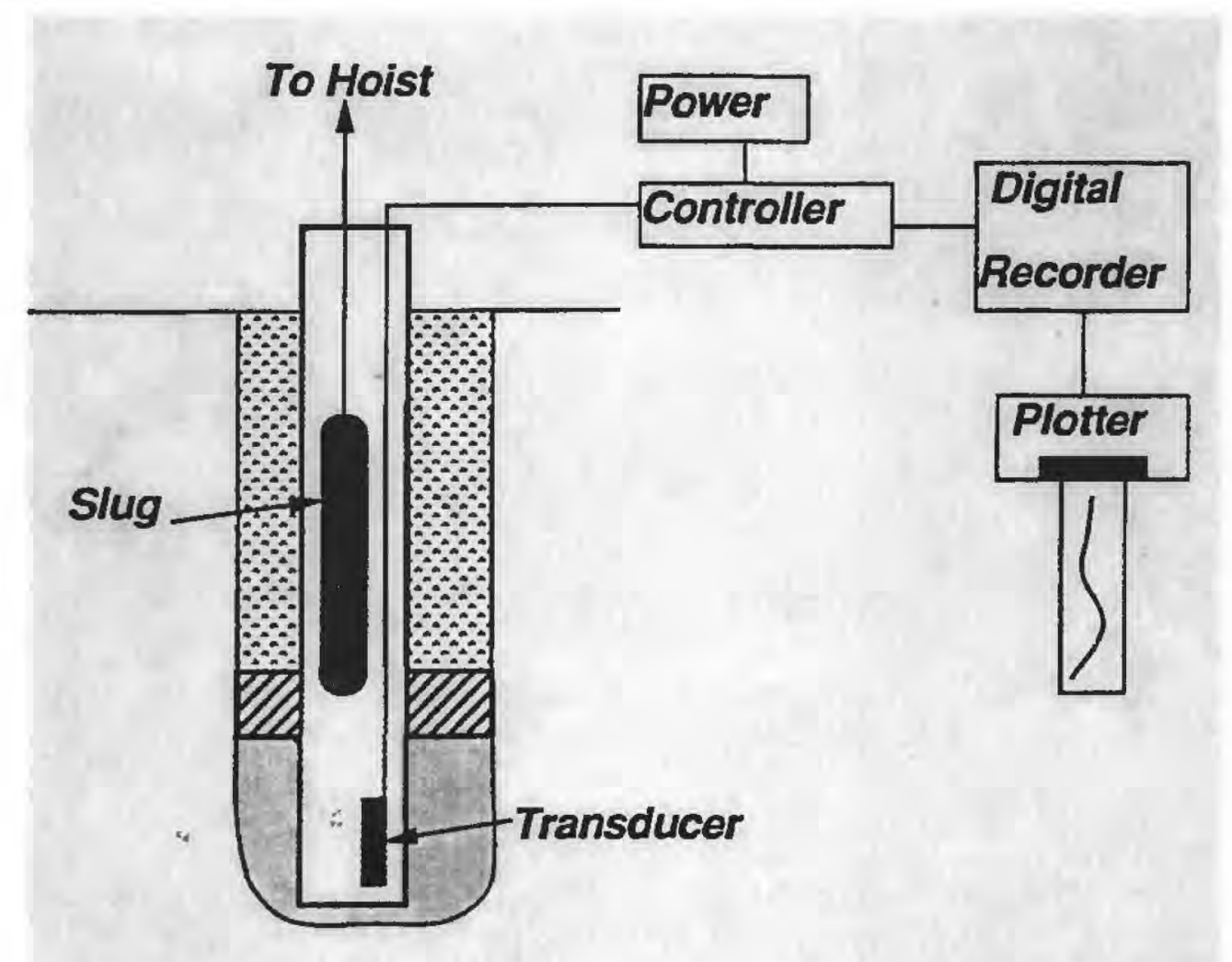

Figure - Suggested arrangement for conducting a slug test. 


\section{STEPS FOR CONDUCTING A SLUG TEST WITH A PVC CYLINDER}

1. Obtain a clean length of poly rope and tie securely to decontaminated PVC slug (make sure rope length is at least $10 \mathrm{ft}$ longer than depth of water from top of well casing).

2. Calculate the expected change in water level for the selected slug. Select an appropriately ranged pressure transducer (generally a 5-ft x 1.5-in PVC slug will displace about $2.5 \mathrm{ft}$ of water; a 0-10 psi transducer allows the transducer to be placed sufficiently deep to avoid interference with the sinking slug and provide good resolution of water-level change).

3. Place the decontaminated transducer in the well below the expected level that the slug will sink and within its measurement range (a 0-10 psi transducer will be out of range if the head above it is greater than $23 \mathrm{ft}$ ). Account for expected rise in water level. Allow the transducer at least 10 minutes to equilibrate to water temperature. If the well is deep, allow at least 20 minutes to account for flex of the hanging cable.

4. Program the data logger for the transducer characteristics and the test. Set the test for a logarithmic time interval (10 minutes max interval generally appropriate)

5. Field calibrate the transducer by wrapping the cable with a piece of electrical tape, placing a folding ruler vertically on top of the well casing, moving the transducer up and down the well at 1-ft intervals and comparing with change indicated by logger (a few hundredths of a foot error over several feet of change is generally acceptable).

6. Lower the transducer to a set position in the well. The tape on the cable should be Even with the top of the well casing to identify if the transducer position has changed during the test. Secure the cable to the casing.

7. Lower the slug slower in short 2-3 $\mathrm{ft}$ increments, so that it can be determined when it strikes the water surface. Raise the slug to just above the water surface and periodically check the water level on the data logger to determine when the level is static.

8. Zero the reference level on the data logger. Start logging the test (on data logger) a few seconds before the slug is dropped into the water (to ensure the first few seconds of the tests are not logged).

9. Periodically monitor the water level to determine when it has returned to a static level.

10. Set up another test. Re-zero the reference level.

11. Start logging the test a few seconds before pulling the slug completely out of water in a smooth continuous action. 


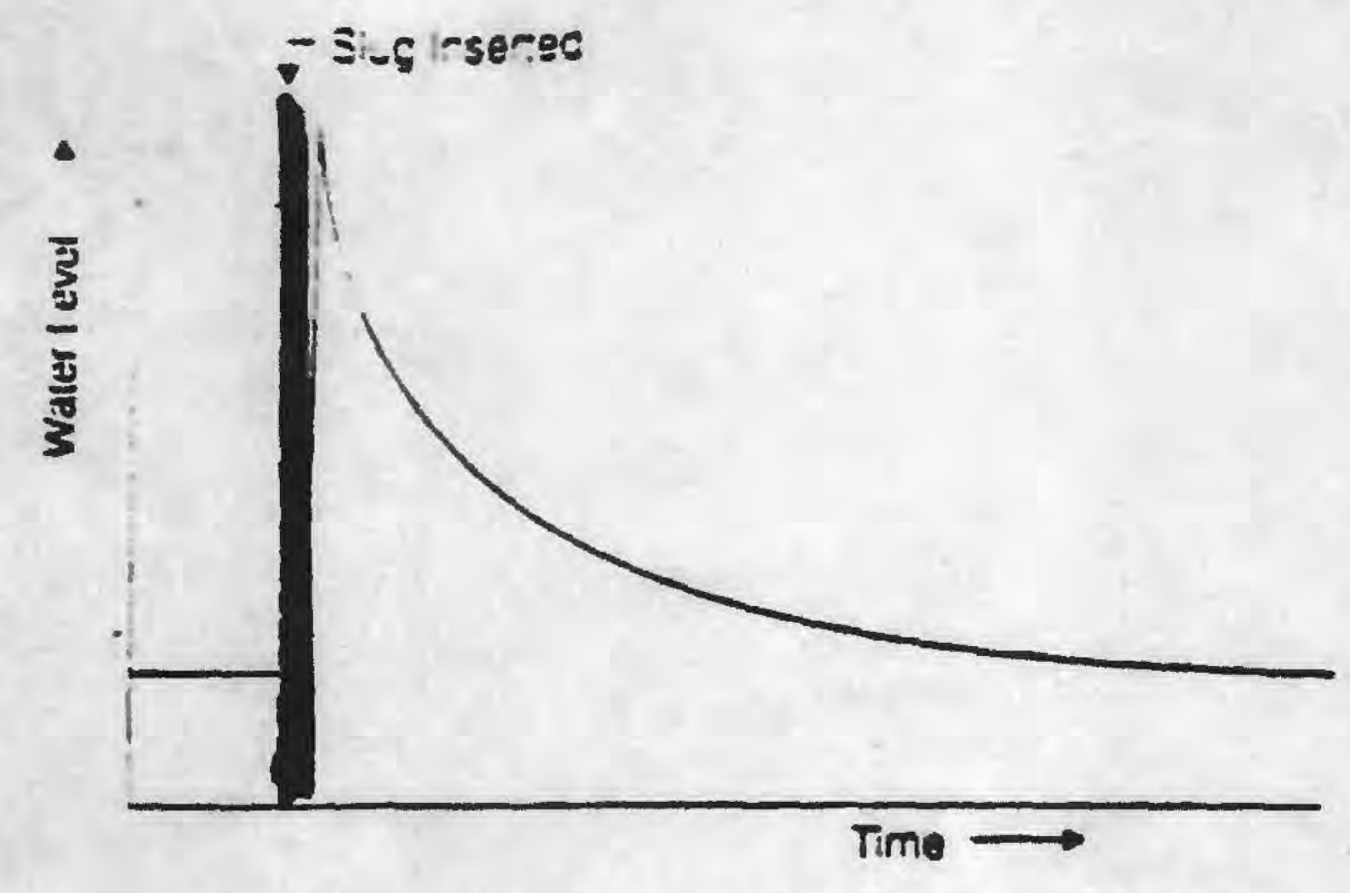

a) Example of an Exponental Aesponse

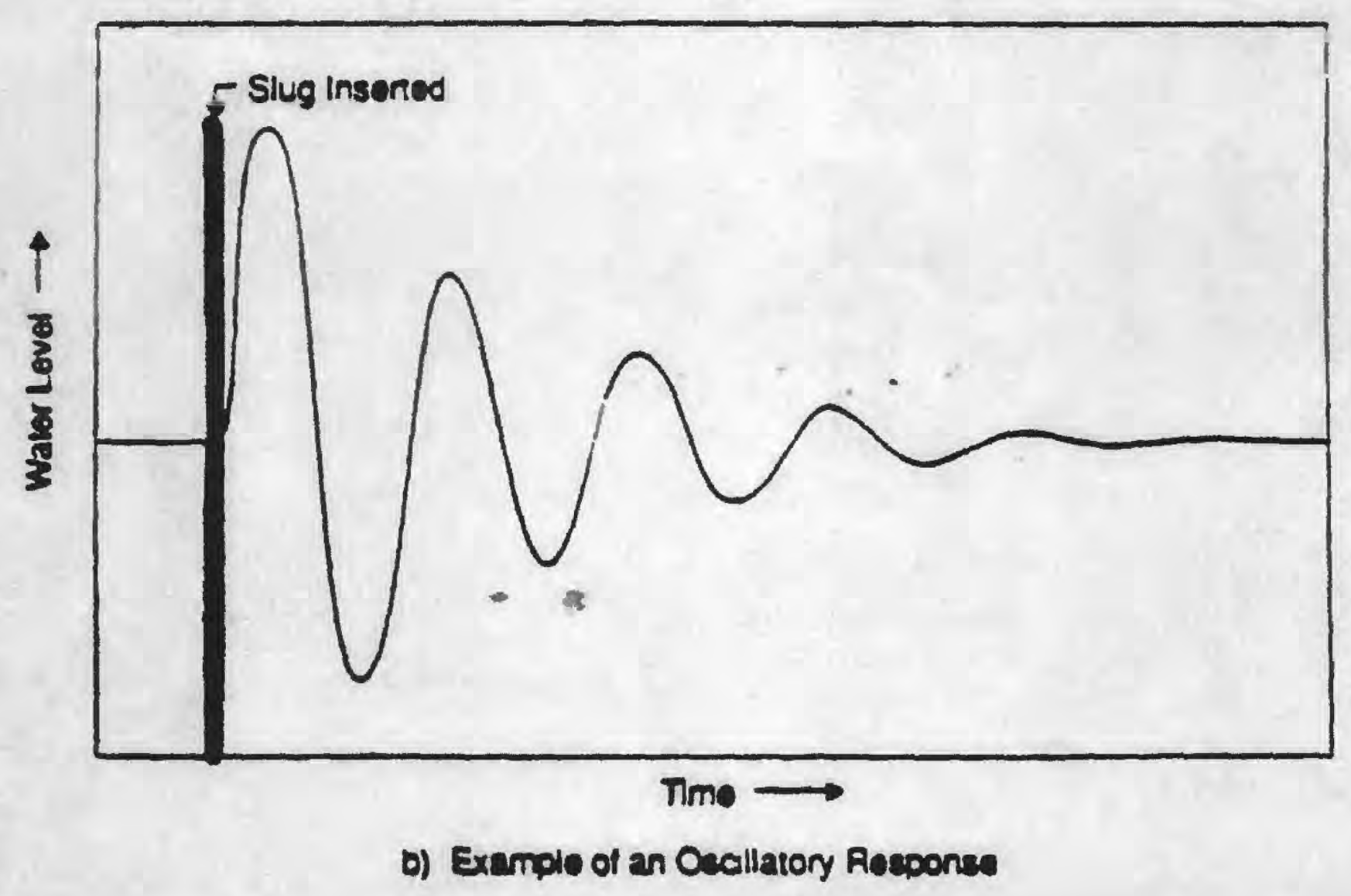

Figures - Examples of (a) exponential water-level response in aquifer with low to moderate hydraulic conductivity, and (b) oscillatory water-level response in aquifer with high hydraulic conductivity. 


\section{ANALYSIS OF SLUG TEST BY THE BOUWER AND RICE (1976) METHOD}

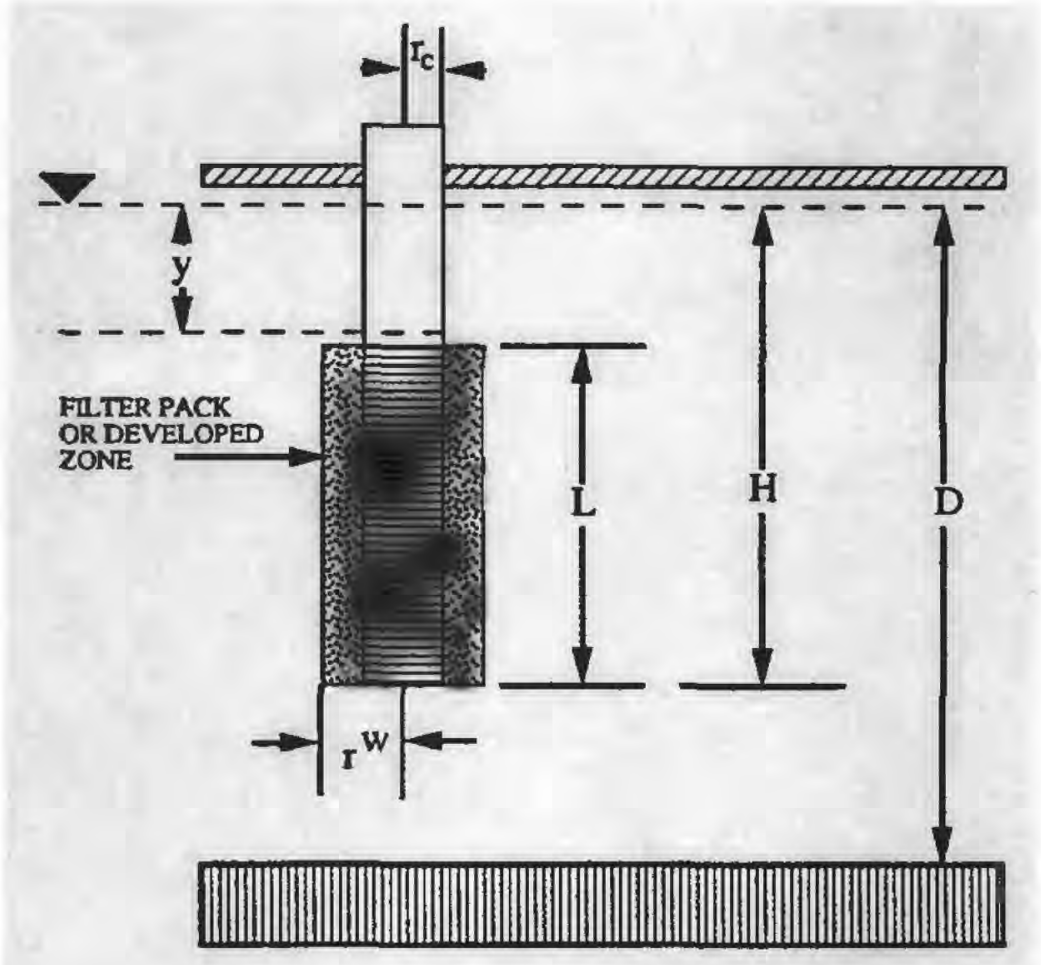

Figure - Geometry for typical well-aquifer arrangement in slug test and analysis by the Bouwer and Rice (1976) method.

$r_{c} \quad=$ Radius of the well casing

$r_{w} \quad=$ Radius of the filter pack or developed zone

$y \quad=$ Change from initial water level

D = Distance between initial water level and base of aquifer

$\mathrm{H} \quad$ = Distance between base of well and initial water level

$\mathrm{L} \quad \quad=$ Length of well screen

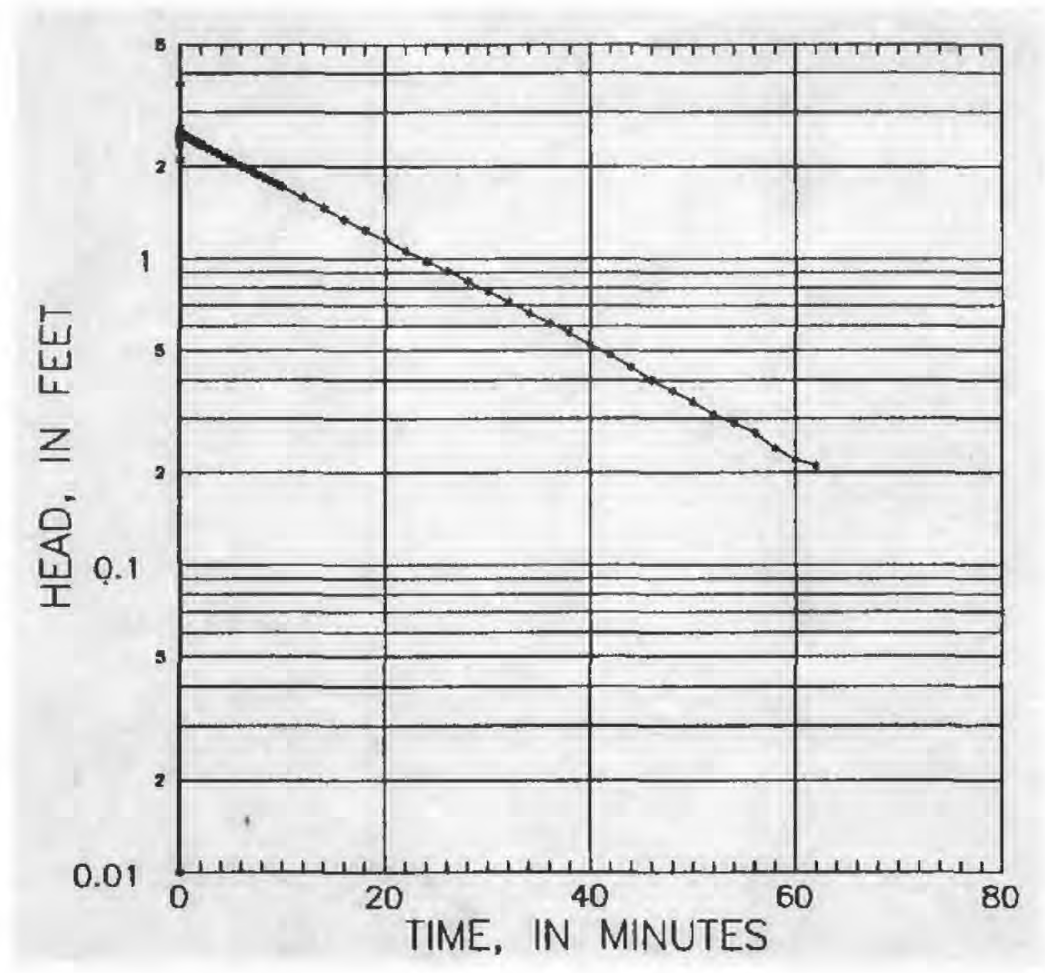

Figure - Typical plot of water level as a function of time, as used for estimating Horizontal hydraulic conductivity by the Bouwer and Rice method (1976) 


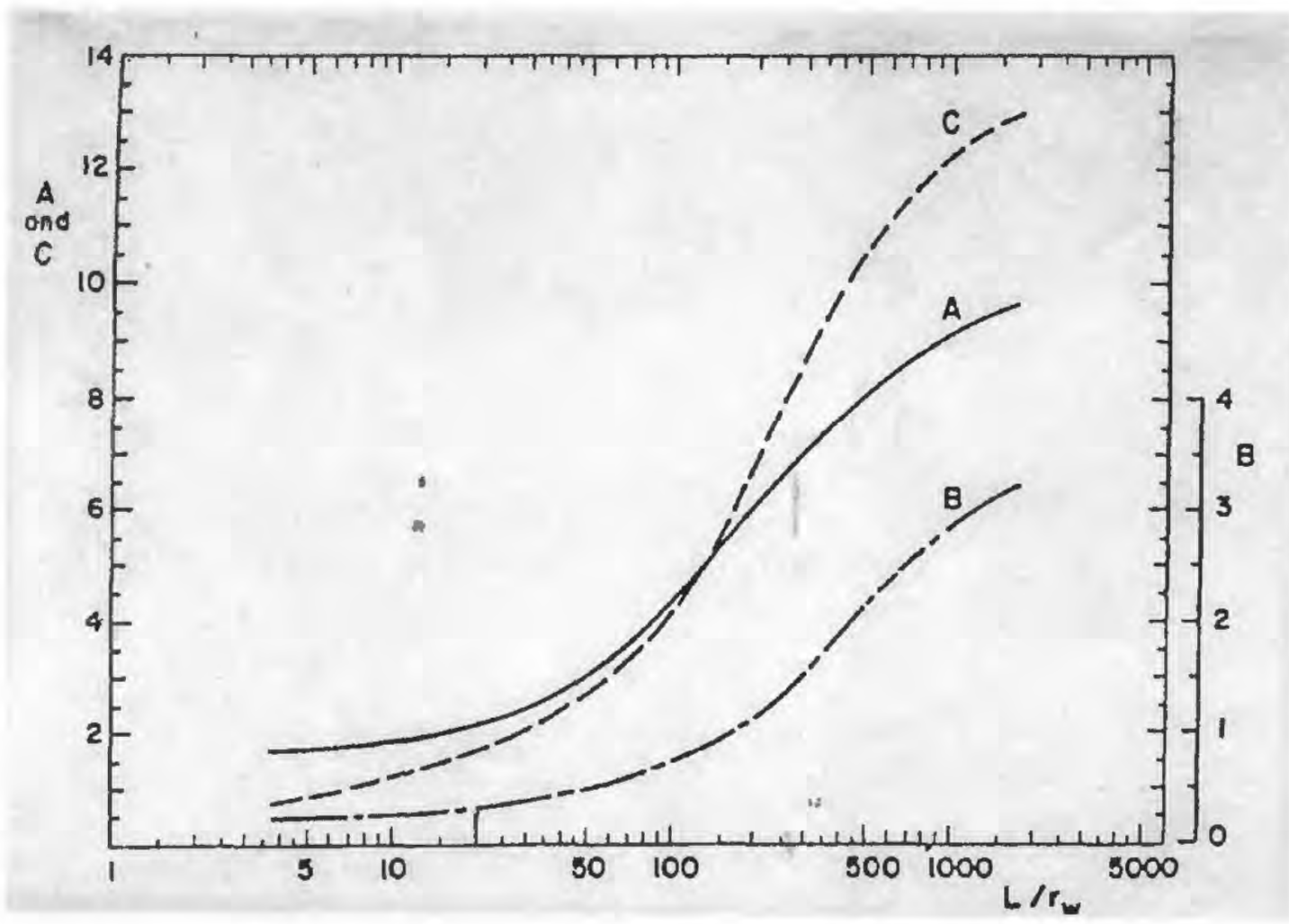

Figure - Curves relating coefficients $A, B$, and $C$ to $L / r_{w}$ for analysis of slug tests by Bouwer and Rice (1976) method.

Data for Bouwer and Rice (1976) method obtained from semi-log plot of waterlevel change as a function of time:

$1 / \mathrm{t} \ln$ yo/yt $=$

$$
\begin{aligned}
& t=t_{t}-t_{o} \\
& y=\text { head at time } t_{t} t_{o}
\end{aligned}
$$

$\ln \left[(D-H] / r_{w}=\right.$

$\begin{array}{ll}\text { case } 1 & D=H, \text { use curve } C \\ \text { case } 2 & =>0,<6, \text { use calculated value } \\ \text { case } 3 & >6, \text { use } 6\end{array}$

In $\mathrm{Re} / \mathrm{r}_{\mathrm{w}}=$ 


\section{REFERENCES:}

Bouwer, H. and Rice, R.C., 1976, A slug test for determining hydraulic conductivity of unconfined aquifers with completely or partially penetrating wells: Water Resources Research, v. 12, no. 4, p. 423-428.

Cooper, H.H., Jr., Bredehoeft, J.D., and Papadopulos, I.S., 1967, Response of a finitediameter well to an instantaneous charge of water: Water Resources Research, v. 3, p.263-269.

Hvorslev, M.J., 1951, Time lag and soil permeability in ground-water observations: U.S. Waterways Experimental Station, U.S. Army Corps of Engineers, Vicksburg, Ms., 49 p.

van der Kamp, G., 1976, Determining aquifer transmissivity by means of well response tests: Water Resources Research, v. 12, no. 1, p. 71-77. 


\section{PACKER TESTS}

Packer tests consist of isolating specific sections (usually $10 \mathrm{ft}$ ) of a bedrock borehole with inflatable packers (bladders) so that water-quality samples can be collected and aquifer tests can be conducted. A series of such tests allows definition of the vertical distribution of water quality (usually contaminants) and hydraulic conductivity (pathways for water and contaminant movement) in an aquifer. Monitoring water levels in nearby wells while pumping packed intervals can identify permeable intervals within the aquifer. Information from the packer tests can be used to properly site the future location of monitoring wells.

Smaller packers designed to fit a submersible sampling pump can be used isolate the lower part of a monitoring well. Isolation by the packer allows reduced water volumes to be purged prior to sampling. This reduction can be beneficial because it can reduce purge times and may limit the handling and disposal of contaminated water.

Why Do Packer Tests?

- Give vertical distribution of hydraulic properties and water quality in the aquifer

- Usually cheaper than a nest of wells and gives more continuous record

Cautions:

- Water-quality data should be considered reconnaissance data. (Packers may leak, well may not be full developed, with removal of all contaminants and water introduced during and after drilling)

- May provide open conduit for contaminant movement to depth within an aquifer if left open after drilling without a temporary packer

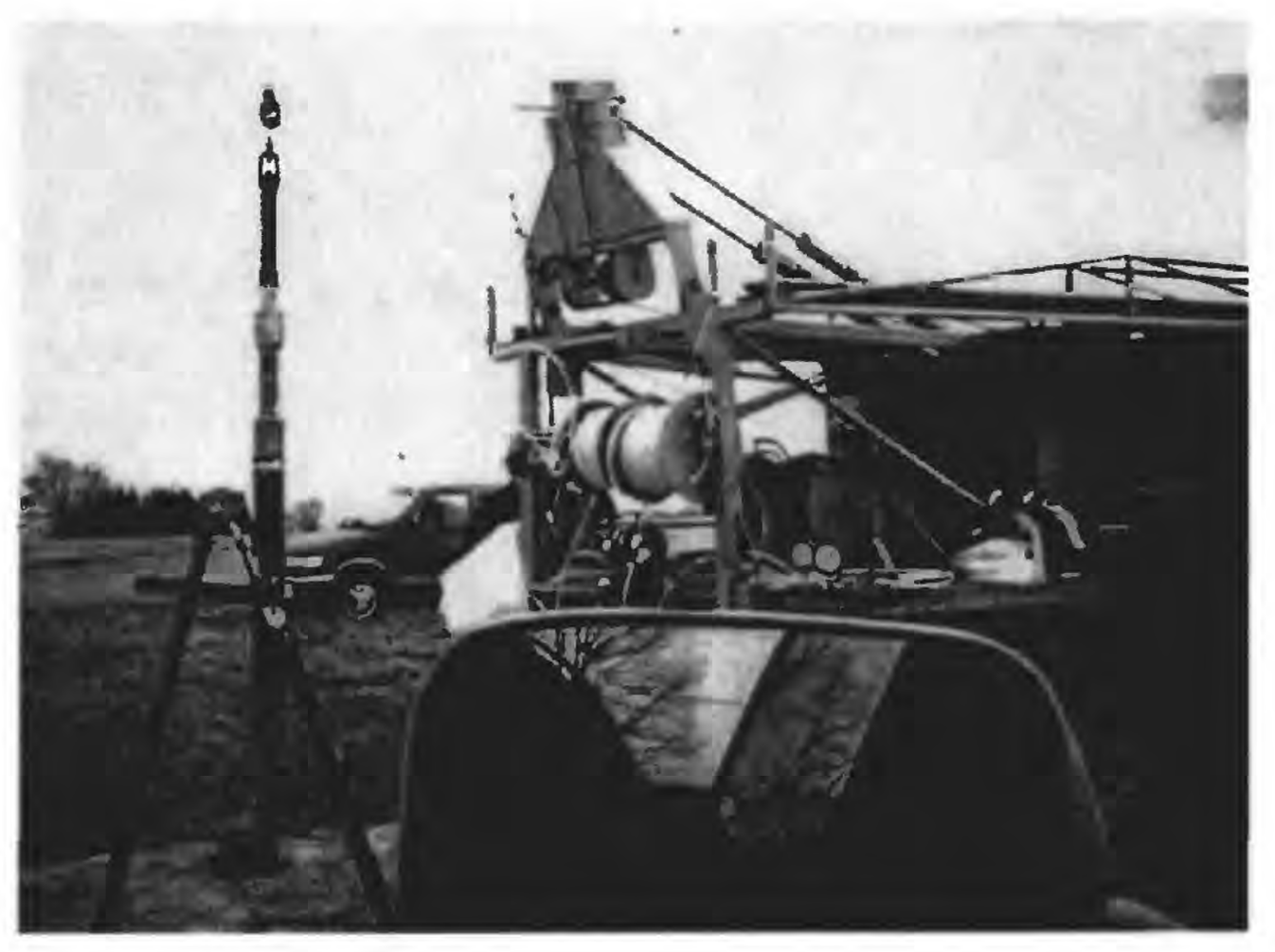

Figure - Packer-hoisting rig and straddle-packer system (upper blabber and 


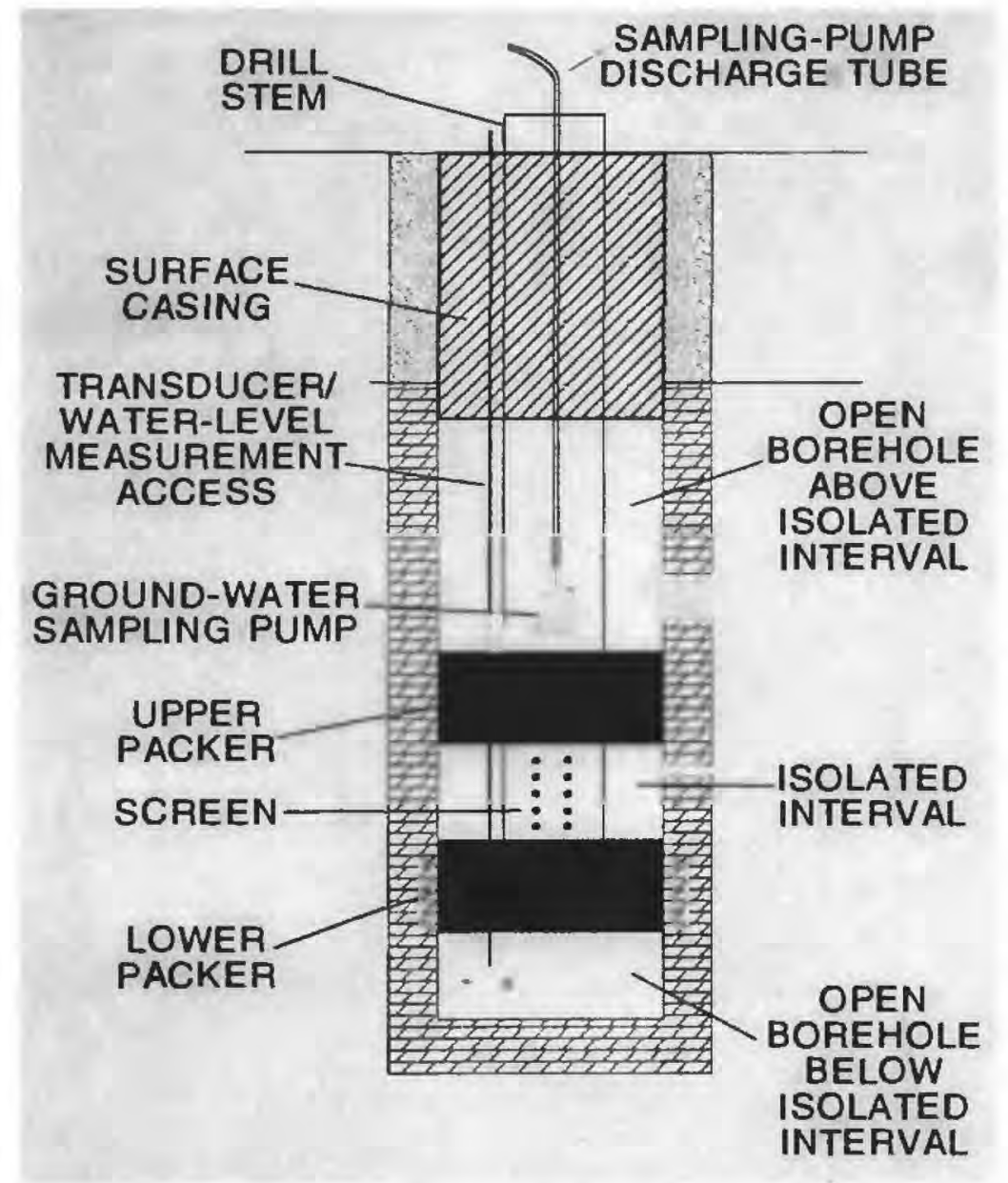

screen shown lowered in borehole)

Figure - Schematic of straddle-packer system in A borehole

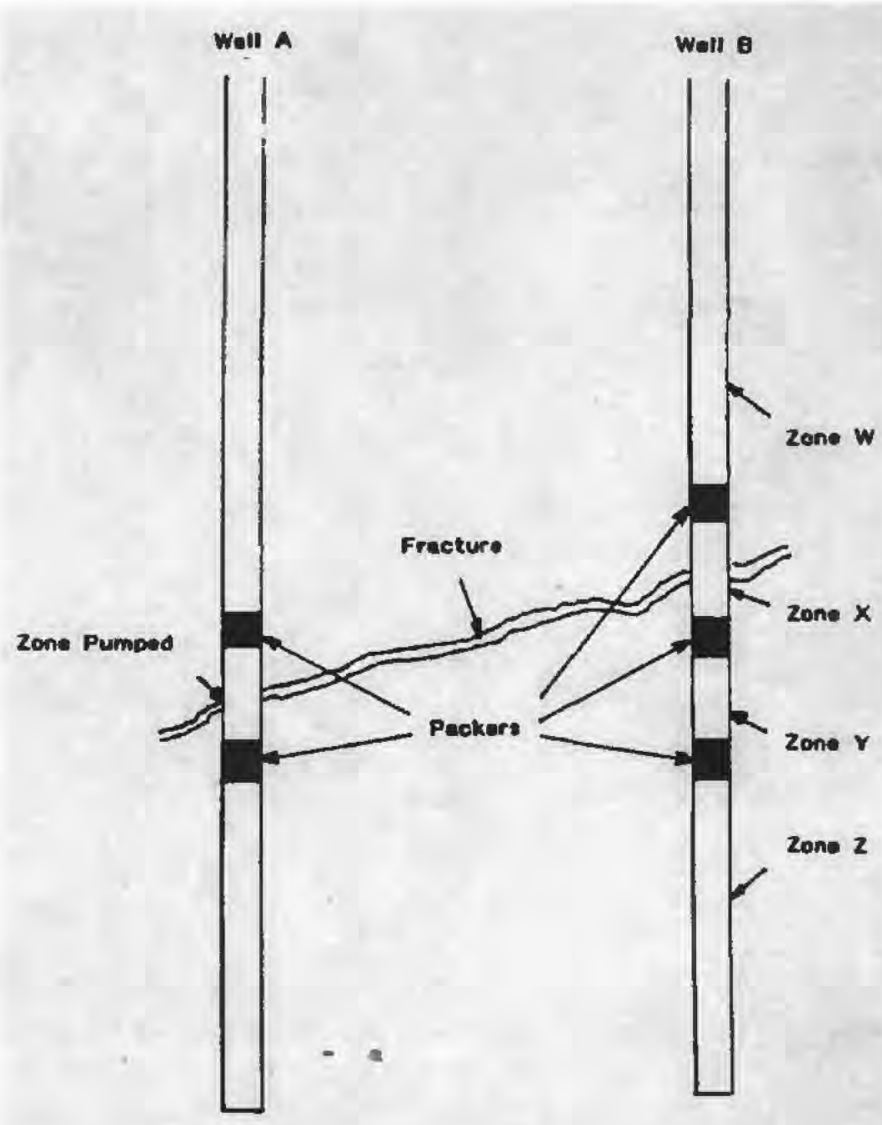

Conceptual Picture of Cross-Hole Packer Testing

\section{METHODOLOGY}

- Develop entire length of borehole to ensure test intervals don't contain water and fines from drilling

- Decontaminate packer equipment before use

- Lower to test zone and inflate packer(s)

- Monitor pressures and water levels to ensure equilibration of pressures in test intervals and leakage between intervals

[((DTP-DTW) * FT H20 To PSI Conversion Factor) + Packer Inflation at Atmospheric Pressure] * Fudge 1.3

- Purge at 1-2 gal/min; Remove 3 well volumes and monitor field parameter stability

- Pump at $0.25-0.5 \mathrm{gal} / \mathrm{min}$ to limit uptake of fine sediment, aeration, volatilization

- Place pump intake above the level that would allow dewatering of the test interval

- Monitor pump rate and water level

Water level very important. May affect analyte chemistry and packer position 
if drawdown is too great during purging and sampling 


\section{USEFUL RESOURCES: (Bolded ones stress or discuss field techniques)}

- Heath, R.C., 1984, Basic Ground-Water Hydrology, U.S. Geology WaterSupply Paper 2220, 84 p.

- Bear, Jacob, 1979, Hydraulics of groundwater: McGraw-Hill, New York, $569 \mathrm{p}$.

- Davis, S.N. and DeWeist,R.J.M., 1966, Hydrogeology: John Wiley \& Sons, New York, $461 \mathrm{p}$.

- Driscoll, F.G., 1987, Groundwater and wells: Johnson Division, St. Paul, Minnesota, $1089 \mathrm{p}$.

- Fetter. C.W.,1988, Applied hydrogeology, Merrill Publishing Co.: Columbus, Ohio, 592 p.

- Freeze, R.A. and Cherry, J.A., 1979, Groundwater: Prentice-Hall, Inc., Englewood Cliffs, N.J., 604 p.

- Kruseman, G.P. and de Ridder, N.A., 1991, Analysis and evaluation of pumping test data: International Institute for Land Reclamation and Improvement, Wageningen, The Netherlands, pub. 47, 377 p.

- Lapham, W.W., Wilde, F.D., and Koterba, M.T., 1997, Guidelines and standard procedures for studies of ground-water quality: Selection and installation of wells, and supporting documentation: U.S. Geological Survey Water-Resources Investigations Report 96-4233, $110 \mathrm{p}$.

- Nielson, D.M. (ed.), 1991, Practical handbook of ground-water monitoring: Lewis Publishers, Inc., Chelsea, Mi., 717 p.

- Todd, D.K., 1980, Groundwater hydrology: John Wiley \& Sons, New York, $535 \mathrm{p}$.

- U.S. Geological Survey Technical Water-Resources Investigations Reports

- American Society for Testing and Materials guidelines

Photographs of data-collection equipment from promotional materials prepared by:

Bennett Sample Pumps, Inc., Campbell Scientific, Inc., In-Situ, Inc., HydroTechnics, Inc.,

\section{References cited or used in compilation of course notes:}

Alley, W.M., ed., 1993, Regional ground-water quality: New York, Van Nostrand Reinhold, $634 \mathrm{p}$.

Brehana, J.V., 1998, Field hydrology-theory, techniques, and applications, unpublished summer field course workbook: U.S. Geological Survey and University of Arkansas, [variously paged]

Bouwer, H. and Rice, R.C., 1976, A slug test for determining hydraulic conductivity of unconfined aquifers with completely or partially penetrating wells: Water Resources Research, v. 12, no. 4, p. 423-428. 
Driscoll, F.G., 1987, Groundwater and wells: St. Paul, Min., Johnson Division, 1089 p.

Fetter, C.W.,1993, Contaminant hydrogeology: New York, Mcmillan, 458 p.

Heath, R.C., 1983, Basic ground-water hydrology: U.S. Geological Survey Water-Supply Paper 2220, 84 p.

Keys, W. S. and MacCary, L.M., 1990, Application of borehole geophysics to waterresources investigations: U.S. Geological Survey Techniques of Water-Resources Investigations of the U.S. Geological Survey, book 2, chapter E1, 126 p.

Koterba, M.T., Wilde, F.D., and Lapham, W.W., 1995, ground-water datacollection protocols and procedures for the national water-quality assessment program: collection and documentation of water-quality samples and related data: U.S. Geological Survey Open-File Report 95-399, 113 p.

Lapham, W.W., Wilde, F.D., and Koterba, M.T., 1997, Guidelines and standard procedures for studies of ground-water quality: selection and installation of wells, and supporting documentation: U.S. Geological Survey Water-Resources Investigations Report 96-4233, $110 \mathrm{p}$.

Lohman, S.W., 1979, Ground-water hydraulics: U.S. Geological Survey Professional Paper 708, $70 \mathrm{p}$.

Mills, P.C., Yeskis, D.J., and Straub, T.D., 1998, Geologic, hydrologic, and water-quality data from selected boreholes and wells in and near Belvidere, Illinois, 1989-1996: U.S. Geological Survey Open-File Report 97-242, 151 p. 
Nielson, D. M., ed., 1991, Practical handbook of ground-water monitoring: Chelsea, Mi., Lewis, $717 \mathrm{p}$.

Paillet, F.L. and Williams, J.H., eds., 1994, Proceedings of the U.S. Geological Survey workshop on the applications of borehole geophysics to ground-water investigations, Albany, New York, June 2-4, 1992: U.S. Geological Survey Water-Resources Investigations Report 94-4103, $79 \mathrm{p}$.

Reilly, T.E., Franke, O.L., Buxton, H.T., Bennett, G.D., 1987, A conceptual framework for ground-water solute-transport studies with emphasis on physical mechanisms of solute transport: U.S. Geological Survey Water-Resources Investigation Report $87-4191,44 p$.

Reynolds, S.D., 1991, Selection and analysis of shallow aquifer tests, notebook for short course no. $1,34^{\text {th }}$ annual meeting, September 29-October 5, 1991, Chicago, III.: Association of Engineering Geologists, [variously paged]

Stallman, R.W., 1968, Aquifer-test design, observation, and data analysis:

U.S. Geological Survey Techniques of Water-Resources Investigations of the U.S. Geological Survey, book 3, chapter B1, 26 p.

U.S. Department of Energy, 1997, In situ permeable flow sensor: U.S. Department of Energy Innovative Technology Summary Report, April 1997, 16 p.

U.S. Environmental Protection Agency, 1990, Ground water, volume 1: ground water and contamination: U.S. Environmental Protection Agency Handbook, EPA/625/R-93/003a, [variously paged]

U.S. Environmental Protection Agency, 1991, Site characterization for subsurface remediation: U.S. Environmental Protection Agency Seminar Publication EPA/625/4-91/026, $259 \mathrm{p}$.

U.S. Environmental Protection Agency, 1992, Aquifer-test and interpretation workshop, unpublished notes for workshop presented June 15-19, 1992, Willowbrook, III., [variously paged]

U.S. Environmental Protection Agency, 1993, Subsurface characterization and monitoring techniques, a desk reference guide, volume 1: solids and ground water, appendixes A and B: U.S. Environmental Protection Agency Technology Transfer EPA/625/6-90/016a, 144 p.

U.S. Geological Survey, 1998, Introduction to borehole geophysics: accessed March 4, 1998 at URL http://wwwdnyalb.er.usgs.gov/projects/bgag/intro.text.html 
U.S. Geological Survey, 1999, National field manual for the collection of water-quality data: U.S. Geological Survey Techniques of Water-Resources Investigations, book 9 , [variously paged]

Welch, A.H., 1995, Field water-quality methods for ground water and surface water, unpublished notes for a training class presented October 16-27, 1995, Lakewood, Col.: U.S. Geological Survey, [variously paged]

Yeskis, D., Chiu, K., Meyers, S., Weiss, J., and Bloom, T., 1988, A field study of various sampling devices and their effects on volatile organic contaminants, in Proceedings of the Second National Outdoor Action Conference on Aquifer Restoration, Ground Water Monitoring, and Geophysical Methods, Las Vegas, 1988: Dublin, Ohio, National Water Well Association, p. 471-479.

Yeskis, D.J., ed., 1995, Waste site characterization, unpublished notes for workshop presented November 6-9, 1995, Siauliai, Lithuania: U.S. Environmental Protection Agency, Chicago, III., [variously paged]

Zohdy, A. A. R., Eaton, G.P., and Mabey, D.R., 1990, Application of surface geophysics to ground-water investigations: U.S. Geological Survey Techniques of WaterResources Investigations of the U.S. Geological Survey, book 2, chapter D1, 116 p. 